University of Louisville

ThinkIR: The University of Louisville's Institutional Repository

Electronic Theses and Dissertations

8-2014

\title{
Mechanistic insights and functionalization of alkynes in homogeneous gold catalysis.
}

\author{
Manish Kumar \\ University of Louisville
}

Follow this and additional works at: https://ir.library.louisville.edu/etd

Part of the Chemistry Commons

\section{Recommended Citation}

Kumar, Manish, "Mechanistic insights and functionalization of alkynes in homogeneous gold catalysis." (2014). Electronic Theses and Dissertations. Paper 781.

https://doi.org/10.18297/etd/781

This Doctoral Dissertation is brought to you for free and open access by ThinkIR: The University of Louisville's Institutional Repository. It has been accepted for inclusion in Electronic Theses and Dissertations by an authorized administrator of ThinkIR: The University of Louisville's Institutional Repository. This title appears here courtesy of the author, who has retained all other copyrights. For more information, please contact thinkir@louisville.edu. 


\title{
MECHANISTIC INSIGHTS AND FUNCTIONALIZATION OF ALKYNES IN HOMOGENEOUS GOLD CATALYSIS
}

\author{
By \\ Manish Kumar \\ B.S., Himachal Pradesh University, Shimla, India, 2005 \\ M.S., Panjab University, Chandigarh, India, 2007
}

\begin{abstract}
A Dissertation
Submitted to the Faculty of the

College of Arts and Sciences of the University of Louisville in Partial Fulfillment of the Requirements

for the Degree of

Doctor of Philosophy

Department of Chemistry

University of Louisville

Louisville, Kentucky
\end{abstract}

August, 2014 



\title{
MECHANISTIC INSIGHTS AND FUNCTIONALIZATION OF ALKYNES IN HOMOGENEOUS GOLD CATALYSIS
}

\author{
By \\ Manish Kumar \\ A Dissertation Approved on \\ $2^{\text {nd }}$ June, 2014 \\ by the following Dissertation Committee:
}

Dr. Gerald B. Hammond

Dissertation Director

Dr. Christopher T. Burns

Dr. Richard P. Baldwin

Dr. Francis P. Zamborini

Dr. Humberto R. Gutierrez 


\section{DEDICATION}

This dissertation is dedicated to my respected \& beloved guru 'Saint Shri Asharam

Ji Bapu', beautiful \& great country 'Mother India', and my family members especially Grandparents, Parents, \& brave Sister. 


\section{ACKNOWLEDGEMENTS}

Let me convey my 'vote of thanks' to all those who helped me to materialize this dissertation. I am extremely obliged to my research advisor, Dr. Gerald B. Hammond, for being an excellent and supportive mentor during my Ph.D. studies. I would like to thank him for his motivation and encouragement on science and lessons on life, which I will remember forever. I have hugely benefited from the 'freedom of thought' and independence that he conveys to his co-workers. I also want to express my deep gratitude towards the incredibly humble and intelligent Dr. Bo Xu, for guiding me throughout my doctoral work.

I would also like to thank the faculty members at the University of Louisville, Dr. Francis P. Zamborini, Dr. Christopher T. Burns, and Dr. Richard P. Baldwin of the Department of Chemistry, and Dr. Humberto R. Gutierrez of the Physics Department for their precious input, and for serving in my Ph.D. thesis defense committee. I am also thankful to Dr. Michael H. Nantz, Dr. Craig A. Grapperhaus, and Dr. Mark E. Noble for their valuable suggestions and serving in my ORP and research committee. I would also like to acknowledge Dr. Craig A. Grapperhaus to help and allow me to do voltammetry studies in his lab. Also, I am thankful to Dr. Neal Stolowich who has been tremendously helpful in running NMR experiments. I would like to acknowledge the XPS studies support provided by Dr. Jacek Jasinski (Conn Centre, University of Louisville), and the important input provided 
by Dr. Martin Scobie (Karolinska Institutet, Swedon), described at length in Chapter 2 and 5 of this thesis, respectively. Also, I am grateful to Dr. Mark S. Mashuta for crystallographic support and Dr. William N. Richmond for technical help. I am also very thankful to Tracy's and Steve's help for their stockroom chemical supplies and other many technical problems.

I am thankful to various funding agencies; the National Science Foundation, the National Institute of Health, the University of Louisville for teaching support, and the Institute of Molecular Diversity and Drug Design of the University of Louisville (IMD-3) for a travel award.

During the course of my doctoral work, I was fortunate to be part of a dedicated research group: Dr. Bo Xu, Dr. LePing Liu, Dr. Weibo Wang, Dr. Zhuang Jin, Dr. Jose C. Aponte, Dr. Junbin Han, Dr. Deepika Malhotra, Shengzong Liang, Elisa Otome, Zhichao Lu, Mallory Durham, Ebule Rene and Andrew Flach. I believe our bond of friendship will always remain intact even after I leave the lab. Last but not the least, I would like to thank the office staff in the Chemistry Department; Dr. Wittebort, Sherry Nalley, Syble Bullock, Aaron Howell, and Sabrina Haug, for being so supportive and helpful. I am thankful to all my friends at the University of Louisville: Manoj, Neeraj, Deepika, Davinder, Gori, Rahul, and Rajat. It is a true blessing to have you all in my life.

I have a deep appreciation and sincere regards for my motivating grandparents (Sh. Goverdhan Singh, Smt. Shalo Devi), and parents (Sh. Kuldip Singh, Smt. Surendra Devi), without their prayers and blessing I would not have made it this far. I am also highly obliged to my brave young sister, Mamta, for her unconditional love 
and being so supportive throughout, even to the point of sacrificing her education to take care of our family.

I would like to acknowledge my beloved Guru ji, Saint Shri Asharam ji Bapu (Diamond of my life) for his blessing and motivation on how to live a real life with happiness and pride. Finally, thanks to my great country, Mother India (country of spirtuality), who inspired me to pursue my higher degree education from another great country, the United States of America (country of opportunity). 


\title{
ABSTRACT
}

\section{MECHANISTIC INSIGHTS AND FUNCTIONALIZATION OF ALKYNES IN HOMOGENEOUS GOLD CATALYSIS}

\author{
Manish Kumar \\ $2^{\text {nd }}$ June, 2014
}

The focus of my dissertation work was to study the basic mechanistic insights of gold-catalyzed reactions. Although the various mechanistic pathways of gold catalysis are better understood nowadays, numerous questions still remain unanswered concerning the nature of deactivation of the catalyst's active species, high resistance towards protodeauration, and how we can solve these problems to improve the efficiency of gold catalysis. To address these challenges in gold catalysis we conducted first a detailed experimental study to understand the mechanism of deactivation of gold active species. Based on the combination of experimental data, we proposed that gold disproportionation is preferred as compared to reduction of the active gold catalyst. To address the high resistance toward protodeauration, we explored a new strategy to enhance the efficacy of gold-catalyzed reactions through hydrogen-bonding assisted protodeauration using additives chosen for their $\mathrm{p} K_{\mathrm{BHX}}$ (hydrogen-bond basicity). To address the threshold phenomenon, we observed that high gold affinity impurities (halides, 
bases) in solvents, starting materials, filtration or drying agents could affect the reactivity of the gold catalyst adversely, which, in turn, may significantly reduce the TON of cationic gold. Use of a suitable acid activator (e.g. HOTf, In(OTf) 3 ) reactivates the gold catalyst and makes the reaction proceed smoothly at low gold catalyst loading. To explore the reactivity of Au catalysts towards oxygen-atom transfer reactions, we investigated the gold-catalyzed addition of $O$-nucleophiles to alkynes and found that this reaction can produce synthetically important vinyl ether products in excellent yields and regioselectivities at room temperature. At higher temperature, 3,3-sigmatropic rearrangement of vinyl ether products gives access to highly functionalized benzotriazoles. 


\section{TABLE OF CONTENTS}

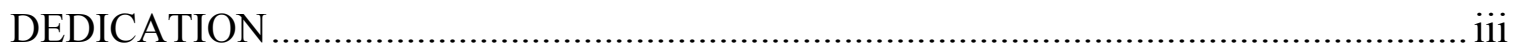

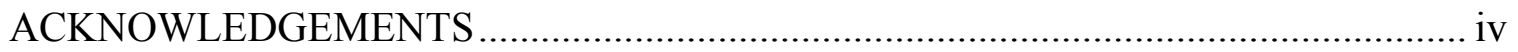

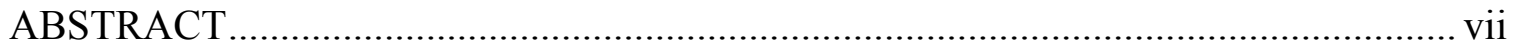

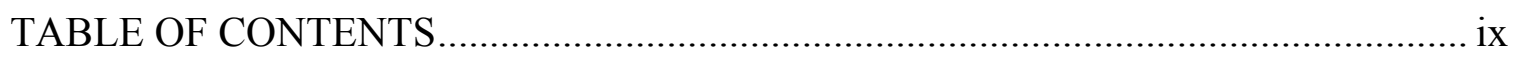

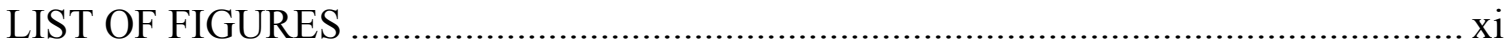

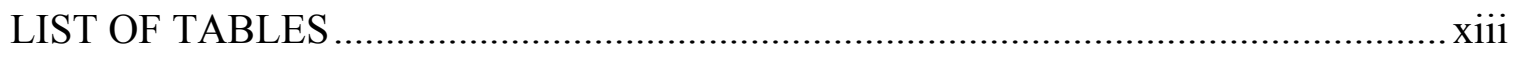

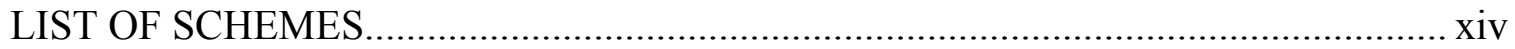

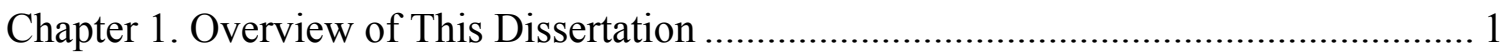

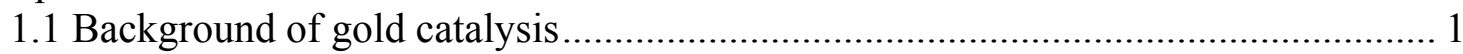

1.2 Mechanistic insights in cationic gold catalysis ...................................................... 3

1.3 Functionalization of alkynes through addition of $N$-hydroxy heterocycles.............. 7

Chapter 2. Alkyne/Alkene/Allene Induced Disproportionation of Cationic Gold(I)

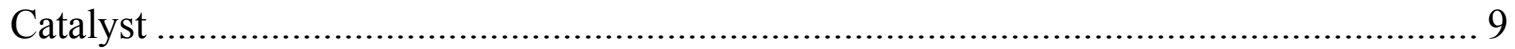

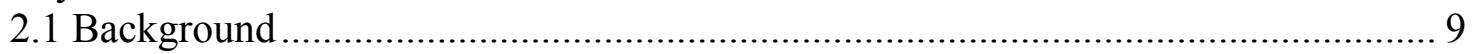

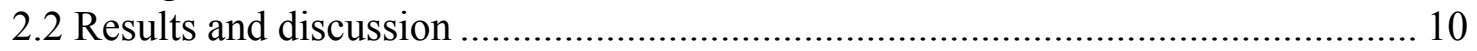

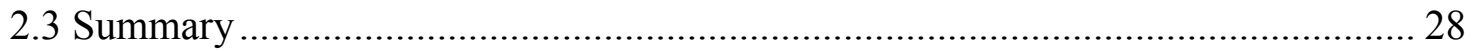

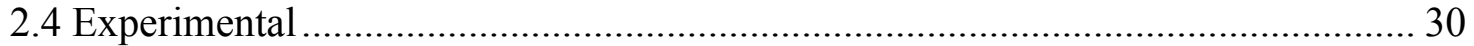

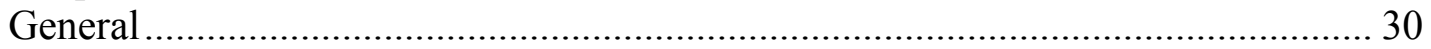

Monitoring the reaction using in situ NMR spectroscopy ...................................... 30

General procedure for preparation of $\mathrm{Ph}_{3} \mathrm{PAuCl}$ and $\mathrm{Ph}_{3} \mathrm{PAu}^{+} \mathrm{X}^{-}\left(\mathrm{X}=\mathrm{OTf}^{-}, \mathrm{NTf}_{2}^{-}\right.$,

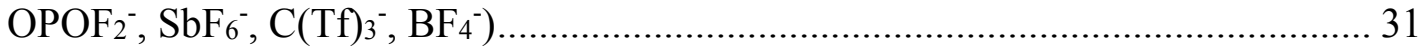

X-Ray photoelectron spectroscopy (XPS) studies .................................................. 32

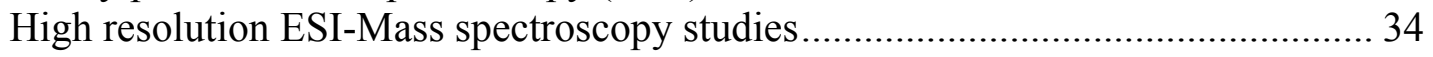

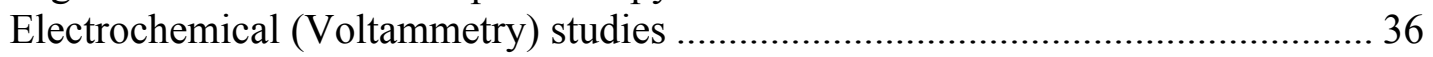

Chapter 3. Enhanced Reactivity in Homogeneous Gold Catalysis through Hydrogen

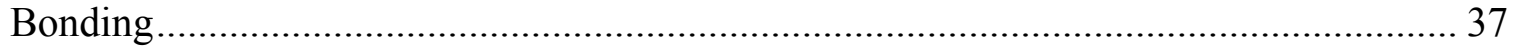

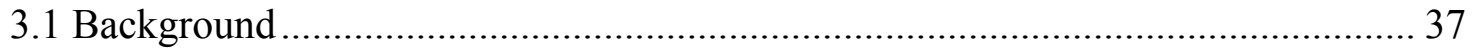

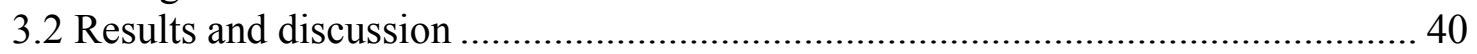

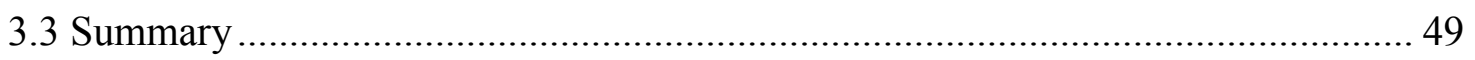

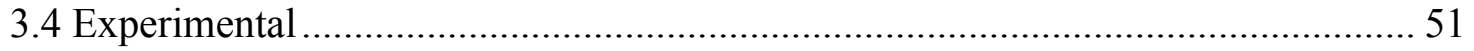

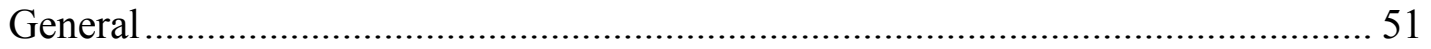

General procedure for kinetic experiments using in situ NMR spectroscopy .......... 52 
General synthesis of starting materials.

Determination of the initial reaction rate for the cyclization of propargyl amide 3-1.

Chapter 4. Cationic Gold Catalyst Poisoning and Re-activation ................................. 56

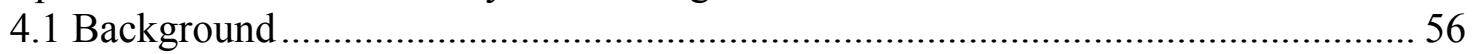

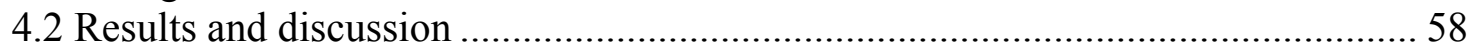

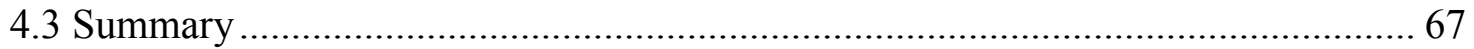

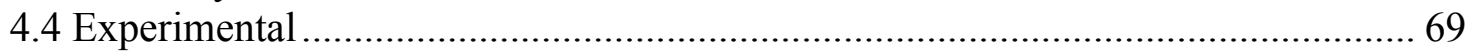

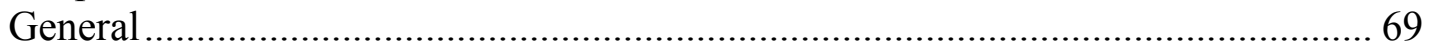

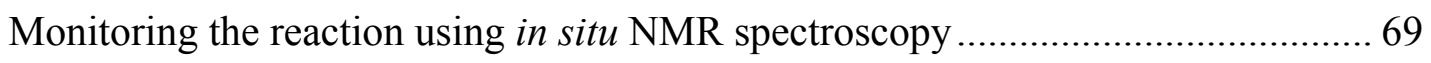

General procedure for preparation of starting materials .................................. 70

Kinetic study for cyclization of 4-1 using initial rate method ............................. 72

General procedure for the hydroarylation of alkyne (4-3) ................................... 72

General procedure for the hydration of propargyl alkyne (4-5) ........................... 74

General procedure for the cycloisomerization of 1,6-enyne (4-7) ........................ 75

General procedure for the cyclization of hexynoic acid (4-9) .............................. 75

General procedure for the cycloisomerization of allenone (4-11) ........................ 76

Chapter 5. Gold-Catalyzed Addition of N-hydroxy Heterocycles to Alkynes and

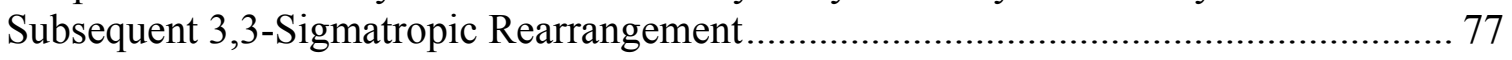

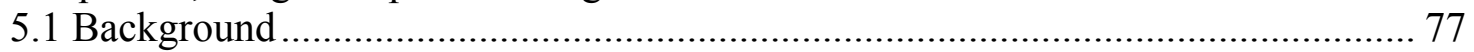

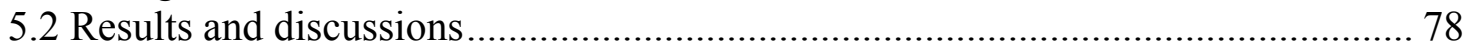

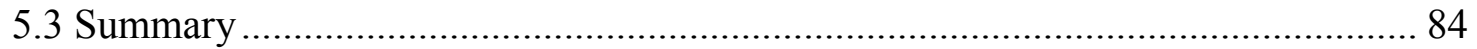

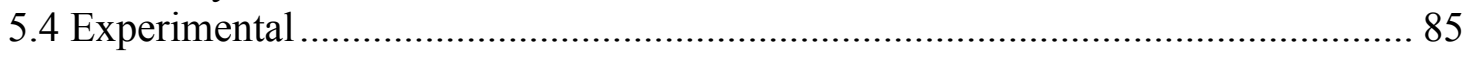

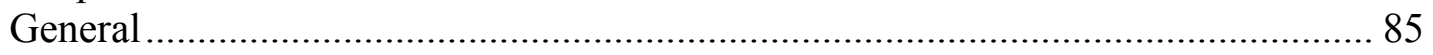

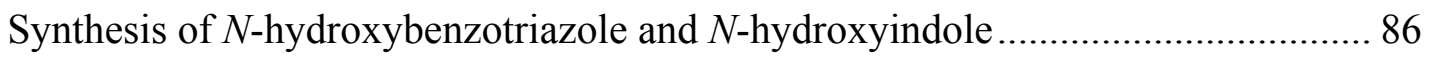

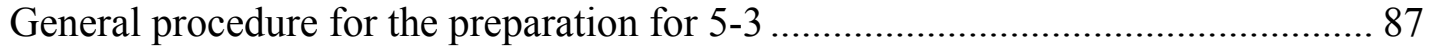

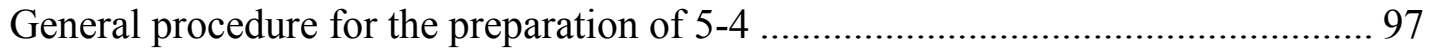

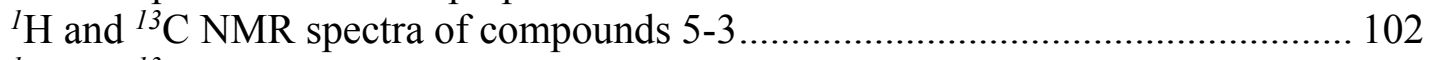

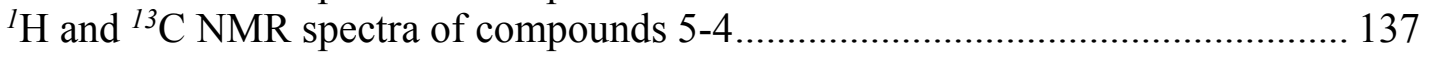

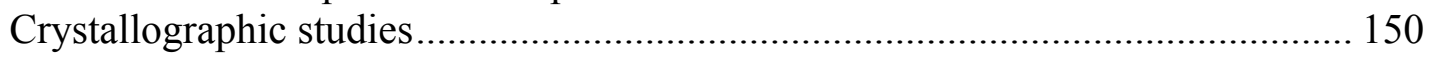

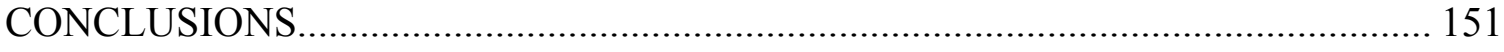

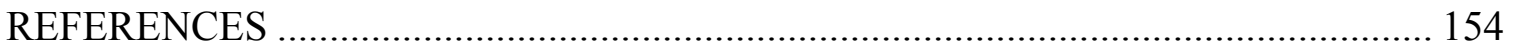

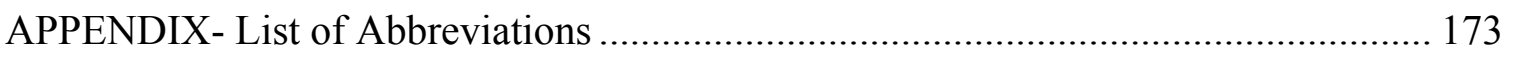

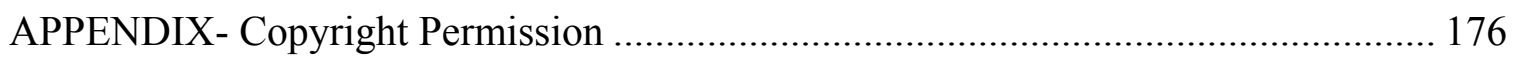

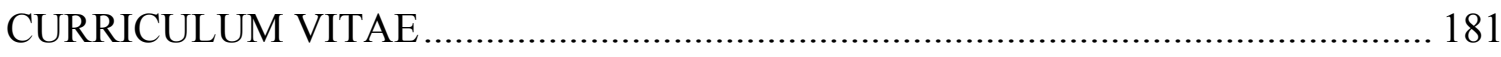




\section{LIST OF FIGURES}

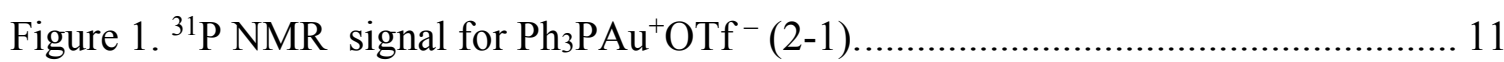

Figure 2. Decay of 2-1 in the presence of cyclohexene monitored by ${ }^{31} \mathrm{P}$ NMR

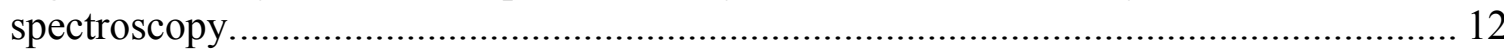

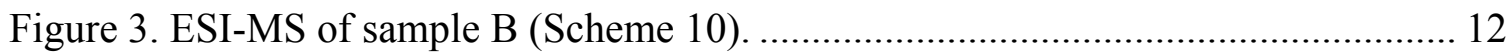

Figure 4. a) Decay of $\left[\mathrm{Ph}_{3} \mathrm{PAu}^{+} \mathrm{OTf}^{-}\right](2-1)$ in the presence of cyclohexene; b) decay of 2-1 in the presence of alkene/alkyne/allene; c) decay of 2-1 in various solvents in the presence of cyclohexene; d) decay of $\left[\mathrm{Ph}_{3} \mathrm{PAu}^{+} \mathrm{X}^{-}\right]$in the presence of cyclohexene; e) decay of 2-1 in the presence of cyclohexene and additives; and f) water effect on decay of

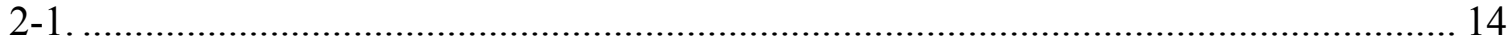

Figure 5. Cyclic voltammogram (red line) of 2-1 (2 mM in $\mathrm{CH}_{2} \mathrm{Cl}_{2}$ with $0.1 \mathrm{M}$ tetrabutylammonium hexafluorophosphate (TBAHFP)). Blue line is background $\mathrm{CV}$ of

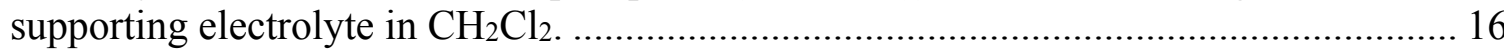

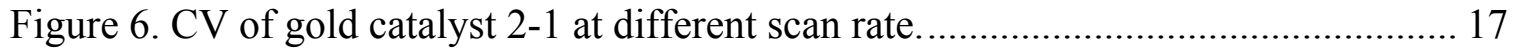

Figure 7. XPS spectra of standard samples $\left(\mathrm{Al}_{\mathrm{K} \alpha}=1486.6 \mathrm{eV}\right)$ corresponding to the $\mathrm{Au}$ $4 \mathrm{f}_{7 / 2}$ photoelectron peaks 18

Figure 8. XPS spectra $\left(\mathrm{Al}_{\mathrm{K} \alpha}=1486.6 \mathrm{eV}\right)$ corresponding to the $\mathrm{Au} 4 \mathrm{f}_{7 / 2}$ photoelectron peaks.

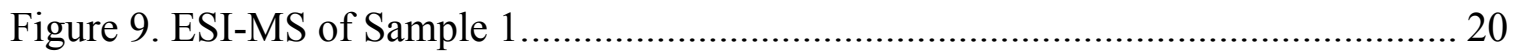

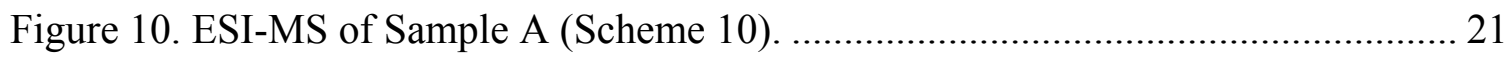

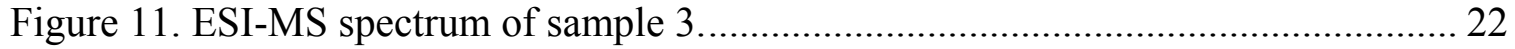

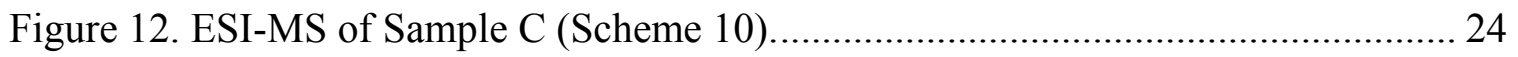

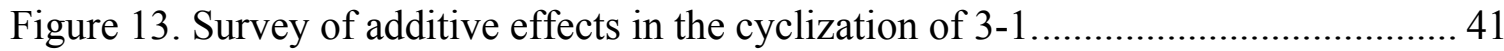

Figure 14. ${ }^{31} \mathrm{P}$ NMR study of protodeauration: a) $\mathrm{Ph}_{3} \mathrm{PAu}^{+} \mathrm{OTf}{ }^{-}$in $\mathrm{CDCl}_{3}$; b) 5 min after mixing of $\mathrm{Ph}_{3} \mathrm{PAu}^{+} \mathrm{OTf}^{-}$(2 equiv) with $3-1$; c) 5 min after mixing of $\mathrm{Ph}_{3} \mathrm{PAu}^{+} \mathrm{OTf}^{-}(0.05$ equiv) with 3-1; d) 30 min after addition of benzotriazole (2 equiv towards gold) to b; e) 30 min after addition of benzotriazole ( 2 equiv towards gold) to c............................. 42

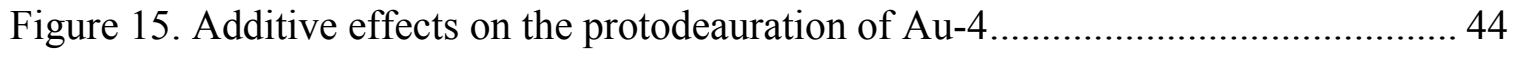

Figure 16. The activity of additives [measured by $\left.\ln \left(\mathrm{v} / \mathrm{v}_{0}\right)\right]$ vs. their basicity $\left(p \mathrm{~K}_{\mathrm{aH}}\right) \ldots . . .46$ 
Figure 17. The activity of additives [measured by $\ln (\mathrm{v} / \mathrm{v} 0)]$ vs. their hydrogen-bond basicity (measured by $\left.p \mathrm{~K}_{\mathrm{BHX}}\right)^{140}$

Figure 18. Determination of the initial reaction rate for the cyclization of propargyl amide $3-1$ 54

Figure 19. Correlation between rate and catalyst concentration..................................... 57

Figure 20. Influence of acid activators in alkyne hydroarylation reaction. ...................... 60

Figure 21. Influence of acid activators in hydration reaction of 4-5 .................................. 61

Figure 22. Influence of acid activators in cycloisomerization reaction............................ 62

Figure 23. Influence of acid activators in cyclization of 4-9 ........................................... 63

Figure 24. Influence of acid activators in cycloisomerization of 4-11 ........................... 64

Figure 25. NMR array of hydroarylation 4-3 in the absence of acid activator................. 73

Figure 26. NMR array of hydroarylation of 4-3 in the presence of acid activators.......... 74

Figure 27. ORTEP-3 diagram of 5-3od showing 50\% ellipsoids. Selected bond lengths (A) O1-N1, 1.3697(18); O1-C6, 1.418(2); C6-C7, 1.313(3); N1-N2, 1.345(2); N2-N3, $1.309(2)$.

Figure 28. ORTEP-3 diagram of 5-4e illustrating two unique conformers present in the asymmetric unit shown at 50\% ellipsoids. A third molecule identical to the top conformer in the asymmetric unit has been omitted for clarity. Additionally, only $\mathrm{H}$ atoms attached to $\mathrm{N}$ atoms are shown. Selected bond lengths $(\AA)$ : O1-C8, 1.2238(19); C6-C7, 1.504(2); C7-C8, 1.516(2); N1-N2, 1.3497(17); N2-N3, 1.3130(19). 


\section{LIST OF TABLES}

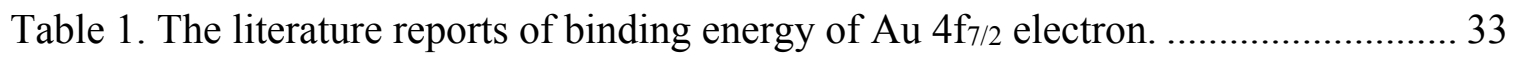

Table 2. Relative surface distribution of gold valence change based in XPS studies. ..... 34

Table 3. Initial reaction rate for the cyclization of propargyl amide 3-1 in the presence of

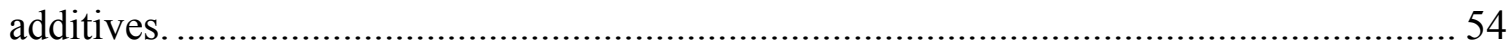

Table 4. Influence of molecular sieves and filtration agent...................................... 65

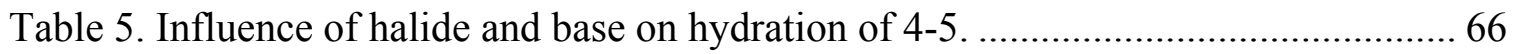

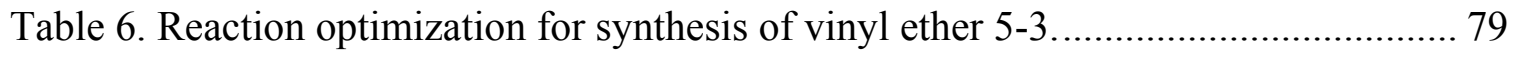

Table 7. Synthesis of vinyl ether intermediates.................................................. 81 


\section{LIST OF SCHEMES}

Scheme 1. Catalytic cycle of a typical gold-catalyzed reaction....................................... 2

Scheme 2. Outline of deactivation mechanism of active gold catalyst........................... 4

Scheme 3. Outline of enhanced reactivity in gold catalysis through hydrogen bonding.... 5

Scheme 4. Outline of cationic gold catalyst poisoning and re-activation......................... 6

Scheme 5. Outline of fuctionalization of alkynes through nucleophilic addition.............. 8

Scheme 6. Simplified representation of the gold catalytic cycle .................................. 10

Scheme 7. Proposed mechanism for substrate-induced cationic gold decay................... 24

Scheme 8. Catalyst decay in different gold catalyzed reactions.................................. 27

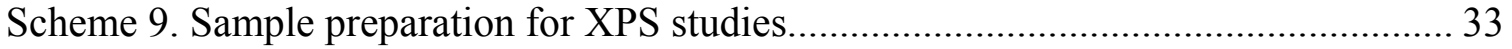

Scheme 10. Sample preparations for ESI-MS ...................................................... 35

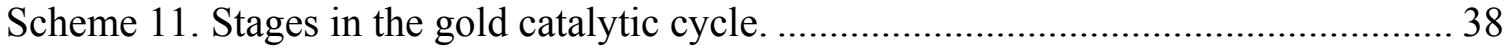

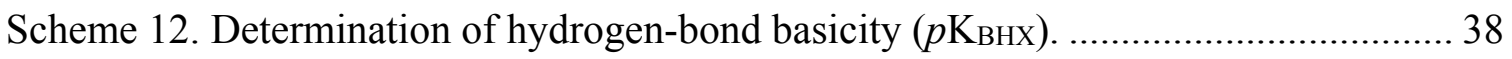

Scheme 13. Hydrogen-bonding in our reaction system (cyclization of propargyl amide).

Scheme 14. Additive effects on various gold catalyzed reactions $(\mathrm{S}=$ hydrogen bond

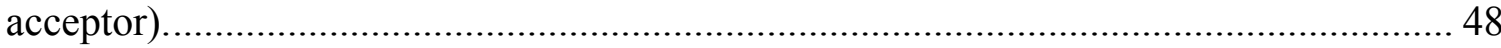

Scheme 15. Poisoning and re-activation of cationic gold catalyst............................... 58

Scheme 16. Gold-catalyzed oxygen transfer reactions. ............................................ 78

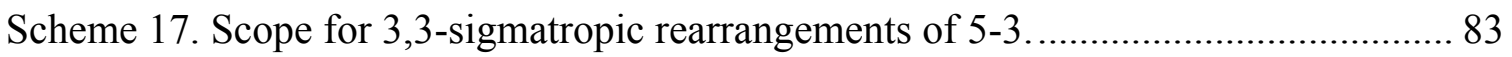




\section{CHAPTER 1. OVERVIEW OF THIS DISSERTATION}

\subsection{Background of gold catalysis}

Gold catalysis is considered one of the most important breakthroughs in organic synthesis for the synthesis of common core structures of various natural products, synthetic intermediates, and pharmaceuticals during the last decade. ${ }^{1-8}$ The first breakthrough in gold catalysis occurred in 2000, when Hashmi and coworkers developed a new gold-catalyzed methodology for $\mathrm{C}-\mathrm{C}$ bond formation. ${ }^{9}$ Then onwards, cationic gold species were regarded as the most powerful catalysts for the electrophilic activation of alkynes/allenes/alkenes towards a variety of nucleophiles due to the relativistic effect of gold. ${ }^{10-13}$ Gold catalysis is widely used in reactions like hydroamination, hydration, hydroalkoxylation of alkynes, cycloisomerization of enynes and isomerization of allenyl esters. ${ }^{14-19}$ Unlike many transition metal catalyzed reactions, gold catalysis does not require anhydrous and air free conditions.

In the literature, it has been proposed that gold(I)-catalyzed nucleophilic addition reactions proceed through innersphere and outersphere mechanisms. ${ }^{20-22}$ The most accepted catalytic cycle is shown in Scheme 1 (outersphere mechanism). First, a cationic gold complex (Au) acts as Lewis acid to activate C-C multiple bonds and form a $\eta^{2}$ complex Au-S (stage 1). At the same time, Au will also complex with 
other components I (solvent, nucleophiles, products, additives) in the reaction system. Hoffmann and coworkers postulated that a symmetrical metal-olefin $\eta^{2}$ complex like Au-S does not have the right LUMO to interact with an incoming nucleophile. ${ }^{23}$ Therefore, the transition state corresponding to the nucleophilic attack cannot resemble the equilibrium $\eta^{2}$-complex Au-S. But slippage of the metal creates a LUMO, which can interact with the HOMO of a nucleophile. ${ }^{5}$ Thus, the slippage of Au-S will form a very reactive intermediate $\mathbf{B}$, which is eventually attacked by the nucleophile to form $\mathbf{C}$. Finally, $\mathbf{C}$ undergoes protodeauration (protodeauration means addition of proton to the place from where the removal of gold catalyst takes place to regenerate cationic gold) to give the final product. In this mechanism, a monomeric cationic gold(I) is proposed to be the catalytically active species.

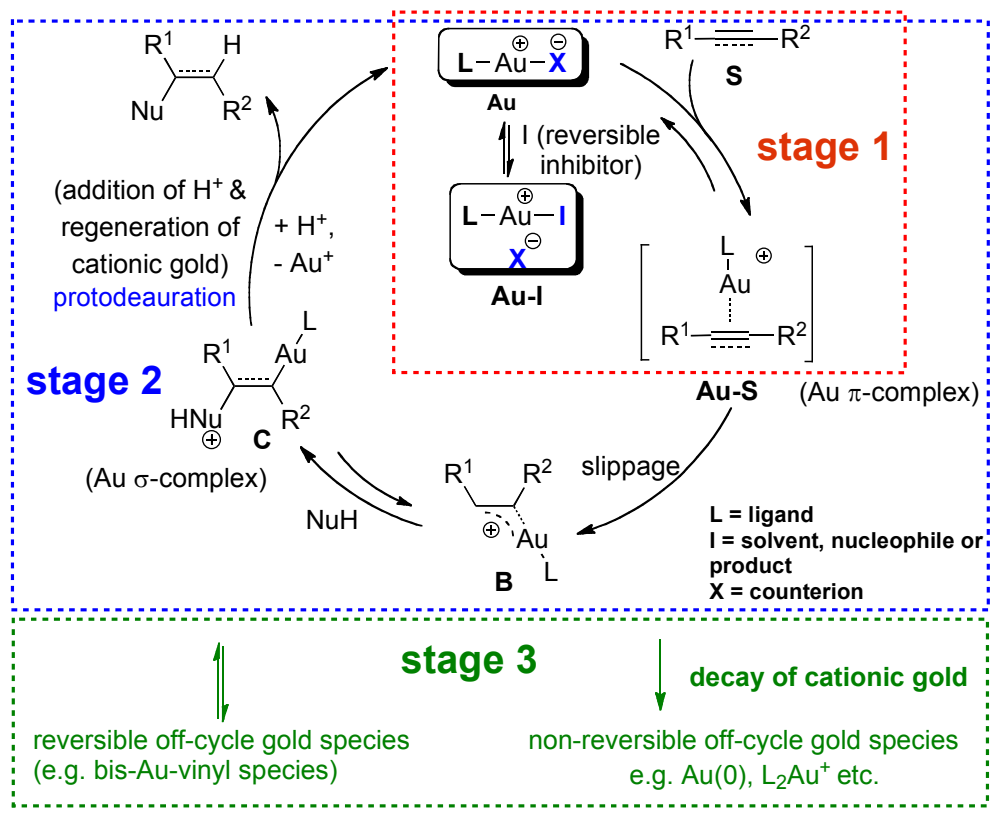

Scheme 1. Catalytic cycle of a typical gold-catalyzed reaction. 
A parallel reaction--the decay of cationic gold(I) complexes--also takes place, leading to the formation of inactive species like $\mathrm{Au}(0)$, and $\mathrm{L}_{2} \mathrm{Au}^{+}$(stage 3). Recently Widenhoefer and coworkers reported the formation of reversible offcycle gold species (e.g. bis-Au-vinyl species, stage 3). ${ }^{24}$

\subsection{Mechanistic insights in cationic gold catalysis}

Although in general cationic gold species are regarded as the most powerful catalysts for the electrophilic activation of alkynes toward a variety of nucleophiles. ${ }^{1-8,25}$, the following fundamental challenge has to be addressed before a wider adoption of gold catalysis in medicinal chemistry and material synthesis can take place, namely, catalyst loading (or turnover number) has to be improved. It is common to use $5 \%$ catalyst loading in gold catalysis; considering that gold is a precious metal and that it is difficult to recycle after each reaction, a 5\% loading is often not practical in large-scale synthesis. Conversely, on many palladiumcatalyzed coupling reactions (e.g., Suzuki reaction), the loading can be reduced to ppm levels. ${ }^{26}$ To begin narrowing the gap with palladium, turnover numbers in gold catalysis have to be improved significantly. Despite their remarkable reactivity toward the electrophilic activation of alkynes, the challenge of cationic $\mathrm{Au}(\mathrm{I})$ complexes, such as the popular standard gold catalyst $\left(\mathrm{Ph}_{3} \mathrm{PAu}^{+} \mathrm{OTf}{ }^{-}\right)$, is how to overcome their poor stability (which has led to the formation of a gold mirror and gold nanoparticles). ${ }^{27}$ Although the basic mechanistic pathways are better understood nowadays, numerous questions still remain unanswered concerning the nature of deactivation of catalyst's active species, and how we can prevent the deactivation to improve the efficiency of gold catalysis. 
In this regard, we conducted the first detailed experimental study of the deactivation of cationic gold, and examined the influence of each component in the reaction system (e.g. substrate, counterion, solvent) on the decay process (Scheme 2). We found that a substrate (alkyne/allene/alkene) that induced disproportionation of gold(I) might play a key role in the decay process. Our mechanism was supported by kinetic, XPS, voltammetry studies and highresolution ESI-MS data. The detailed description of deactivation of the gold catalyst will be described in Chapter 2.

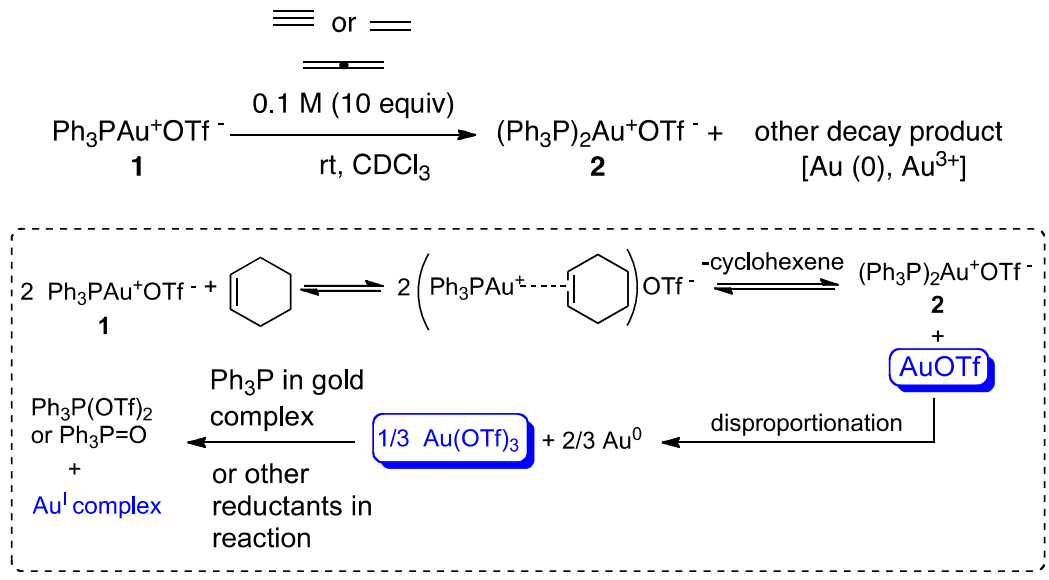

Deactivation mechanism of active gold catalyst in gold catalysis:

Kumar, M.; Jasinski, J.; Hammond, G. B.; Xu, B. Chem. Eur. J. 2014, 20, 3113-3139.

\section{Scheme 2. Outline of deactivation mechanism of active gold catalyst.}

It is well established that most gold-catalyzed reactions go through two major stages (Scheme 1). ${ }^{28}$ In stage 1 (from $\mathrm{L}-\mathrm{Au}^{+}$to $\mathbf{C}$ ) a nucleophile attacks a gold activated alkyne/alkene $\eta^{2}$-complex to generate a charged trans-vinyl gold complex intermediate $\mathbf{C}$ (or an alkyl gold complex in the case of alkenes). In stage $2, \mathbf{C}$ is converted to product with concomitant regeneration of the cationic gold species via protodeauration. The turnover limiting stage for a large percentage of 
gold catalyzed reactions actually occurs in the protodeauration stage. ${ }^{29}$ This circumstance is not surprising because a protonated vinyl gold intermediate $\mathbf{C}$ is reluctant to undergo protodeauration easily due to the fact that its positive charge will hinder interaction with another proton-containing molecule (acid). Keeping this fact in mind, we observed in our investigations that additives that are good hydrogen-bond acceptors increase the efficiency of gold-catalyzed reactions in those instances where protodeauration is the rate-determining step (Scheme 3). The efficiency of additives capable of hydrogen bonding-assisted protodeauration correlated with their standing in a scale of hydrogen bonding basicity (measured by $\left.p \mathrm{~K}_{\mathrm{BHX}}\right)$. All additives used in our study were commercially available. The detailed description of additive effects through hydrogen bonding will be described in Chapter 3.

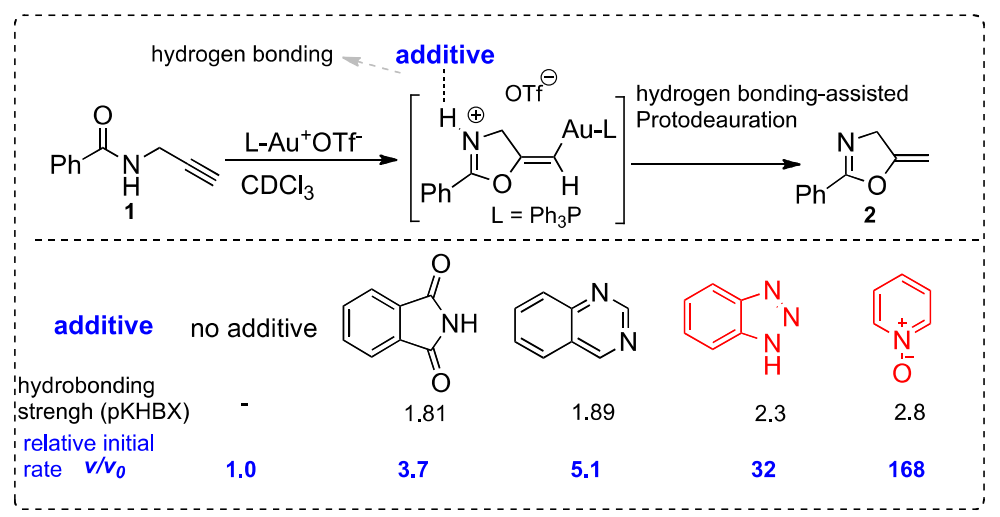

Enhanced reactivity in gold catalysis through hydrogen bonding:

Wang, W.; Kumar, M.; Hammond, G. B.; Xu. B. Org. Lett. 2014, 16, 636-639.

Scheme 3. Outline of enhanced reactivity in gold catalysis through hydrogen bonding.

In kinetic studies of catalyzed reactions it is customary to study the relationship between the rate of the reaction and the concentration of the catalyst to learn more about the mechanism of the reaction. Although a linear correlation between the 
concentration of the catalyst and the initial rate data often exists when the rate is plotted against concentration, numerous studies have shown that the regression line does not intersect with the origin (eq $1, \mathrm{~A} \neq 0$ ). If there is no background reaction, the rate should be zero when the catalyst concentration is zero, so A (intercept) should also be zero, but this is not the case in many reactions (A is usually less than zero), ${ }^{30-32}$ indicating that a threshold catalyst concentration is required. Beyond vaguely implying some sort of catalyst poisoning, literature reports have not addressed the causes of this type of threshold. Although this phenomenon is ubiquitous in catalysis, relatively little effort has been spent on the investigation of this anomaly and the possible implications of this threshold phenomenon in catalysis. ${ }^{30-32}$ During our research to improve the efficiency of gold catalysis, ${ }^{29,33-36}$ we found that this threshold phenomenon is common in gold-catalyzed reactions.

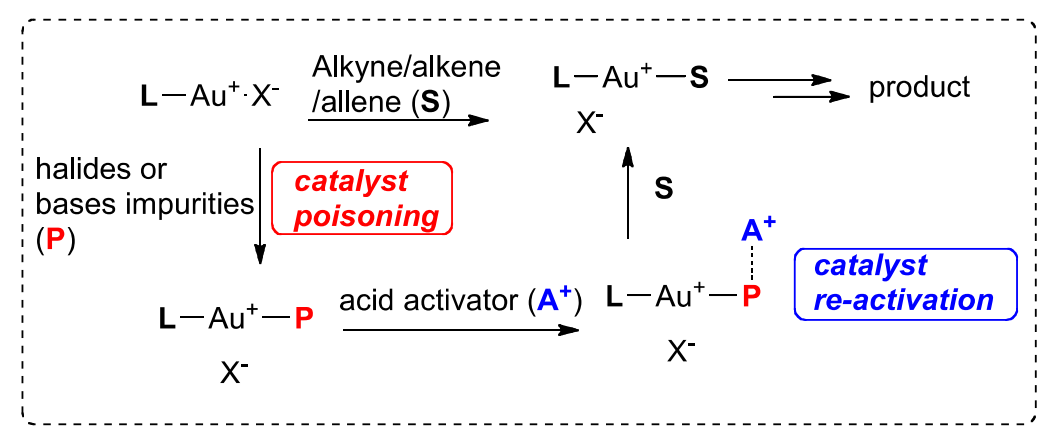

Cationic gold catalyst poisoning and re-activation

Kumar, M.; Hammond, G. B.; Xu. B. Org. Lett. 2014, (DOI: 10.1021/ol501663f).

\section{Scheme 4. Outline of cationic gold catalyst poisoning and re-activation.}

We observed during our investigations that high gold affinity impurities (halides, bases) in solvents, starting materials, filtration or drying agents could affect the reactivity of the gold catalyst adversely (Scheme 4), which may significantly reduce the TON of cationic gold catalyzed reactions. Use of a suitable acid 
activator (e.g. HOTf, $\left.\operatorname{In}(\mathrm{OTf})_{3}\right)$ re-activates the gold catalyst and makes the reaction proceed smoothly at low gold catalyst loading. The detailed description of the threshold phenomenon will be described in Chapter 4 .

\subsection{Functionalization of alkynes through addition of $N$ - hydroxy heterocycles}

$N$-heterocycles such as benzotriazoles and indoles are among the most important structural classes in medicinal chemistry. ${ }^{37-47}$ For example, 4-functionalized benzotriazoles are important precursors for the synthesis of pyrimidine- or pyridine-based compounds used in the treatment of GSK3 mediated disorders because they inhibit glycogen synthase kinase (GSK3). ${ }^{48}$ Many functionalized benzotriazoles and indoles are also important synthetic intermediates. ${ }^{49,50}$ Gold complexes are well known for their ability to catalyze a wide variety of synthetically interesting reactions of alkynes/allenes/alkenes. ${ }^{4,728,51-58}$ In particular, the gold-catalyzed oxygen transfer of a nucleophilic oxygen atom to an alkyne group is synthetically useful. ${ }^{59-65}$

To further explore the reactivity of Au catalysts towards oxygen-atom transfer reactions, we investigated the gold-catalyzed addition of $O$-nucleophiles to alkynes to produce synthetically important vinyl ether products in excellent yields and regioselectivities at room temperature. Although these vinyl ethers are generally not stable enough to be isolated with standard silica gel chromatography, they were stable in our hands. At higher temperatures, the subsequent 3,3-sigmatropic rearrangement of vinyl ether products gave access to the pharmaceutically important functionalized $N$-heterocycles. 
This two-step sequence represents an efficient oxygen transfer protocol of a nucleophilic oxygen atom to an alkyne group (Scheme 5). Furthermore, the reaction of a vinyl ether with electrophiles, such as the electrophilic fluorinating

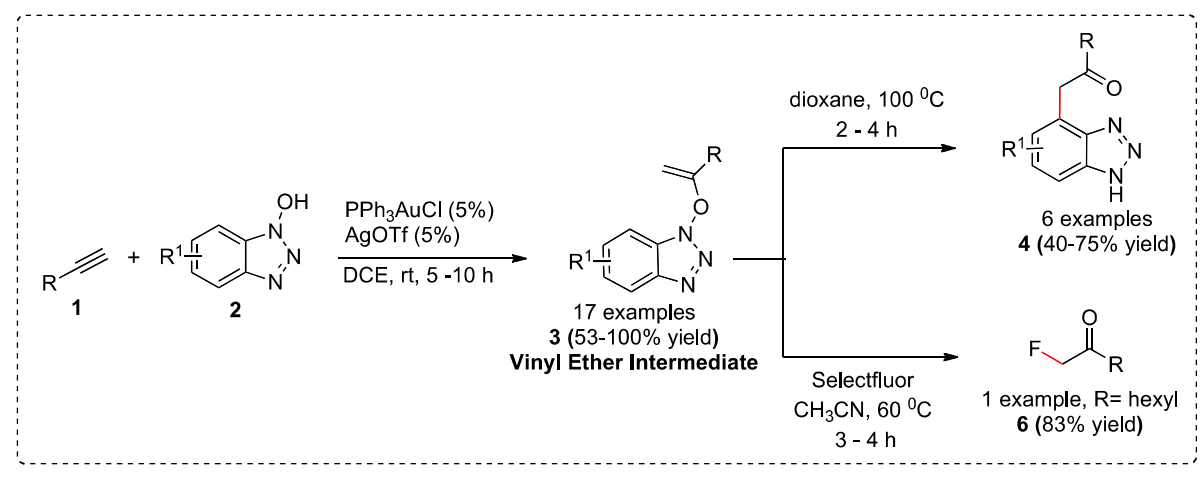

Gold-catalyzed addition of $\boldsymbol{N}$-hydroxy heterocycles to alkynes

Kumar, M.; Scobie, M.; Mashuta, M. S.; Hammond, G. B.; Xu, B. Org. Lett. 2013, 15, 724-727.

Scheme 5. Outline of fuctionalization of alkynes through nucleophilic addition.

reagent Selectfluor, gives a fluorinated ketone in good yield and exclusive regioselectivity. The detailed syntheses will be described in Chapter 5. 


\section{CHAPTER 2. ALKYNE/ALKENE/ALLENE INDUCED DISPROPORTIONATION OF CATIONIC GOLD(I) CATALYST}

\subsection{Background}

During the last six years both our group and others have been working rigorously for the development of new gold methodologies for the synthesis of interesting compounds. However gold catalysis, a landmark addition to the field of organic synthesis, ${ }^{1,3,4,6,66,67}$ is not without shortcomings, the main one being the relatively low turnover numbers observed in the majority of gold-catalyzed reactions. Indeed, high turnover numbers (or low catalyst loadings) $\left(10^{6} \mathrm{TON}\right)$ are observed only for a few types of gold catalyzed reactions (e.g., hydration of alkynes). ${ }^{68-74}$ In most gold catalyzed reactions, catalyst loadings in the $1-5 \%$ range are the norm. ${ }^{14-18}$ One reason for the low turnover numbers (TON) is the relatively fast decay of cationic gold and its conversion into non-reactive species (e.g., $\mathrm{Au}^{0}$ - gold mirror and/or gold particles and $\left[\mathrm{L}_{2} \mathrm{Au}^{\mathrm{I}}\right]^{+}{ }^{75-79}$ Despite this drawback, there has been no comprehensive systematic investigations on the decay of homogeneous gold catalysis, a stark contrast with the extensive work reported on catalyst deactivation in heterogeneous catalysis. ${ }^{80}$ In this chapter, we answer some fundamental and intriguing questions on gold(I) decay, such as the effects of starting material, 
nucleophile, solvent, counterion and additives, and we offer a probable pathway for gold(I) decay.

\subsection{Results and discussion}

A simplified gold catalytic cycle is shown in Scheme 6. The cationic gold complex $\left(\mathbf{L}-\mathbf{A u}^{+}\right)$acts as carbophilic Lewis acid, ${ }^{81}$ activating an unsaturated $\mathrm{C}-\mathrm{C}$ bond to form a $\pi$-complex $\left[\mathbf{L}-\mathbf{A} \mathbf{u}^{+}-\mathbf{S}\right]$. The interaction of $\left[\mathbf{L}-\mathbf{A} \mathbf{u}^{+}-\mathbf{S}\right]$ with a nucleophile (Nu) yields a gold $\sigma$-complex ([L-Au-S-Nu $]$ ) that eventually undergoes protodeauration and the regeneration of cationic gold.

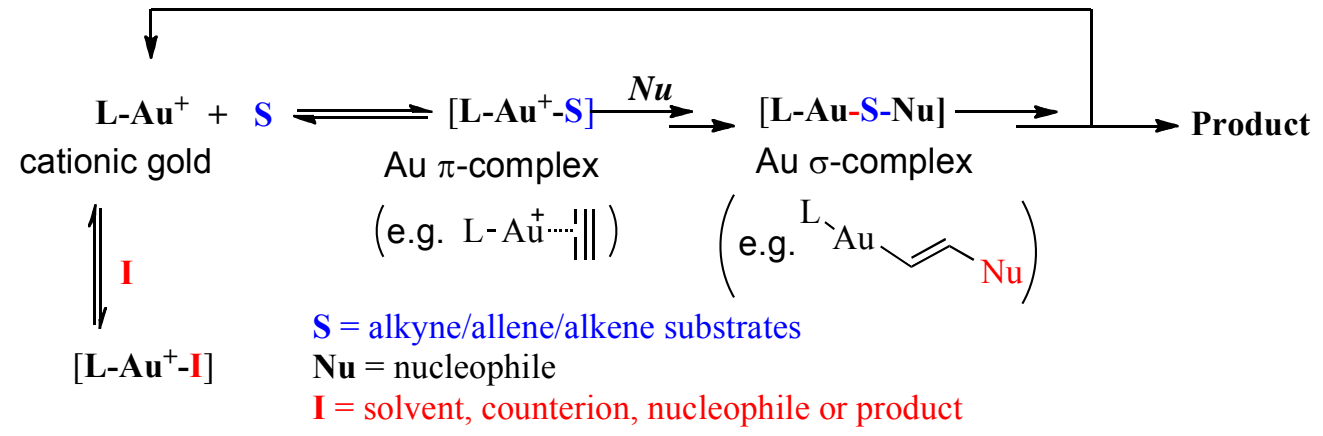

\section{Scheme 6. Simplified representation of the gold catalytic cycle.}

The complex $\left[\mathrm{L}-\mathrm{Au}^{\mathrm{I}}\right]^{+} \mathrm{X}^{-}\left(\mathrm{X}=\right.$ weakly coordinating counterion such as $\left.\mathrm{OTf}^{-}\right)$is relatively stable by itself, but in many reactions it decays at a fast rate (from a few minutes to a few hours). This behavior suggests that a cationic gold catalyst may decay rather rapidly in the presence of certain components in a reaction system. Because $\mathrm{Ph}_{3} \mathrm{PAu}^{+} \mathrm{OTf}{ }^{-}(\mathbf{2 - 1})$ is one of the most commonly used cationic gold catalysts, ${ }^{15,16,18}$ we chose it as our model catalyst to study the deactivation process. 2-1 in $\mathrm{CDCl}_{3}$ is relatively stable $\left({ }^{31} \mathrm{P}\right.$ NMR peak at $27.4 \mathrm{ppm}$ is the only peak ${ }^{82}$ and also catalytically active for $24 \mathrm{~h}$ at room temperature (Figure 1). 


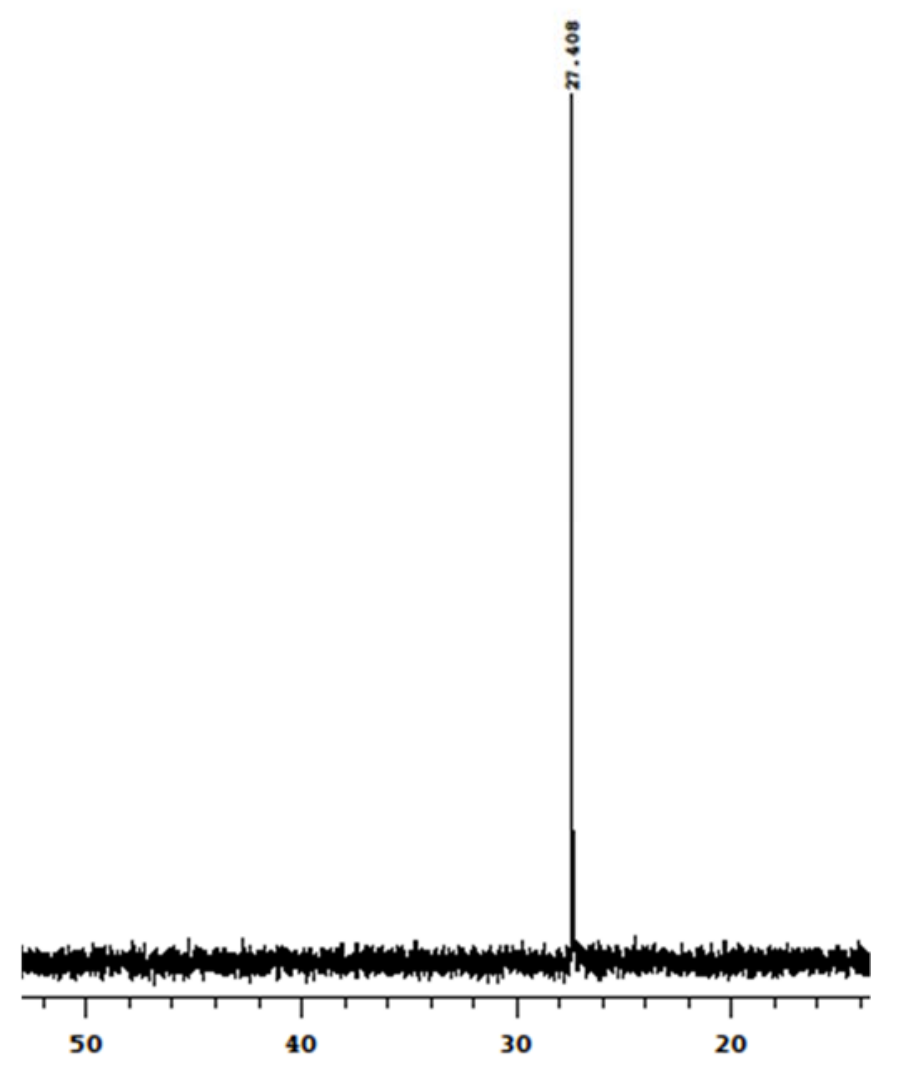

Figure 1. ${ }^{31} \mathrm{P}$ NMR signal for $\mathrm{Ph}_{3} \mathrm{PAu}^{+} \mathrm{OTf}^{-}$(2-1).

First, we investigated the kinetic stability of $\left[\mathrm{L}-\mathrm{Au}^{+}-\mathrm{S}\right]$ (Scheme $4, \mathrm{~S}=$ alkyne/allene/alkene). After adding cyclohexene (10 equiv vs. 2-1) at room temperature, we noticed significant amounts of gold mirror/black particles $\left(\mathrm{Au}^{0}\right)$ in the NMR tube, a telltale indication that 2-1 $\left(0.01 \mathrm{M}\right.$ in $\left.\mathrm{CDCl}_{3}\right)$ had undergone significant decay. In the beginning, only a single ${ }^{31} \mathrm{P}$ NMR peak at $29.5 \mathrm{ppm}$ was recorded, consistent with a gold-alkene $\pi$-complex or a fast equilibrium between free $\mathrm{Ph}_{3} \mathrm{PAu}^{+} \mathrm{OTf}^{-}$and $\left[\mathrm{Ph}_{3} \mathrm{PAu}-\text { alkene }\right]^{+} \mathrm{OTf}^{-}$(Figure 2). The signal at $29.5 \mathrm{ppm}$ [gold(I)-alkene complex] decreased over time, and a new signal at $45.0 \mathrm{ppm}$ increased over the same time period. We assigned this new signal the structure $\left(\mathrm{Ph}_{3} \mathrm{P}\right)_{2} \mathrm{Au}^{+} \mathrm{OTf}^{-}(\mathbf{2 - 2})$. This assignment is in agreement with the ${ }^{31} \mathrm{P}$ NMR shift 


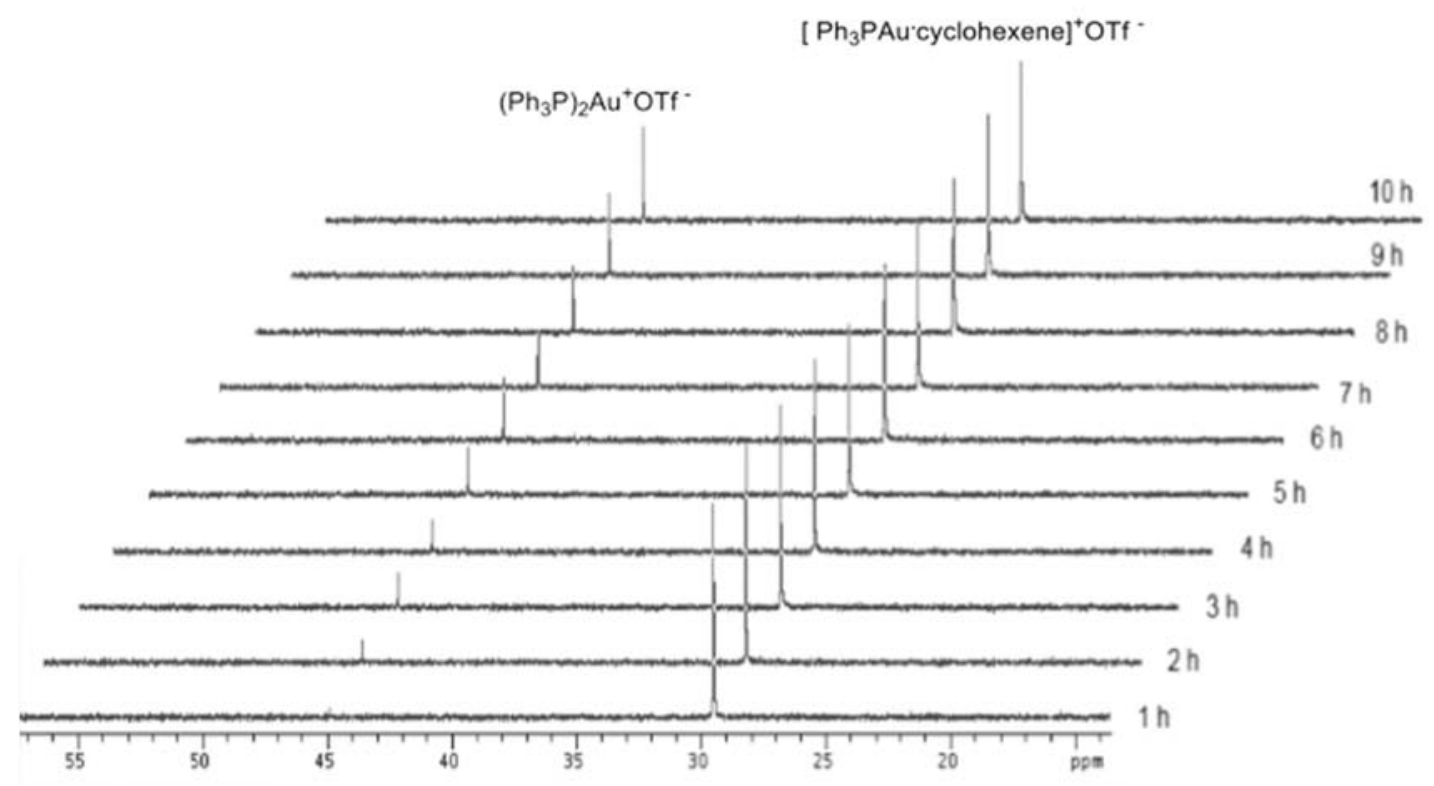

Figure 2. Decay of 2-1 in the presence of cyclohexene monitored by ${ }^{31} \mathrm{P}$ NMR spectroscopy. value of 2-2 reported in the literature ${ }^{83-86}$ and also with the chemical shift recorded for our independently synthesized 2-2 (Figure 3).
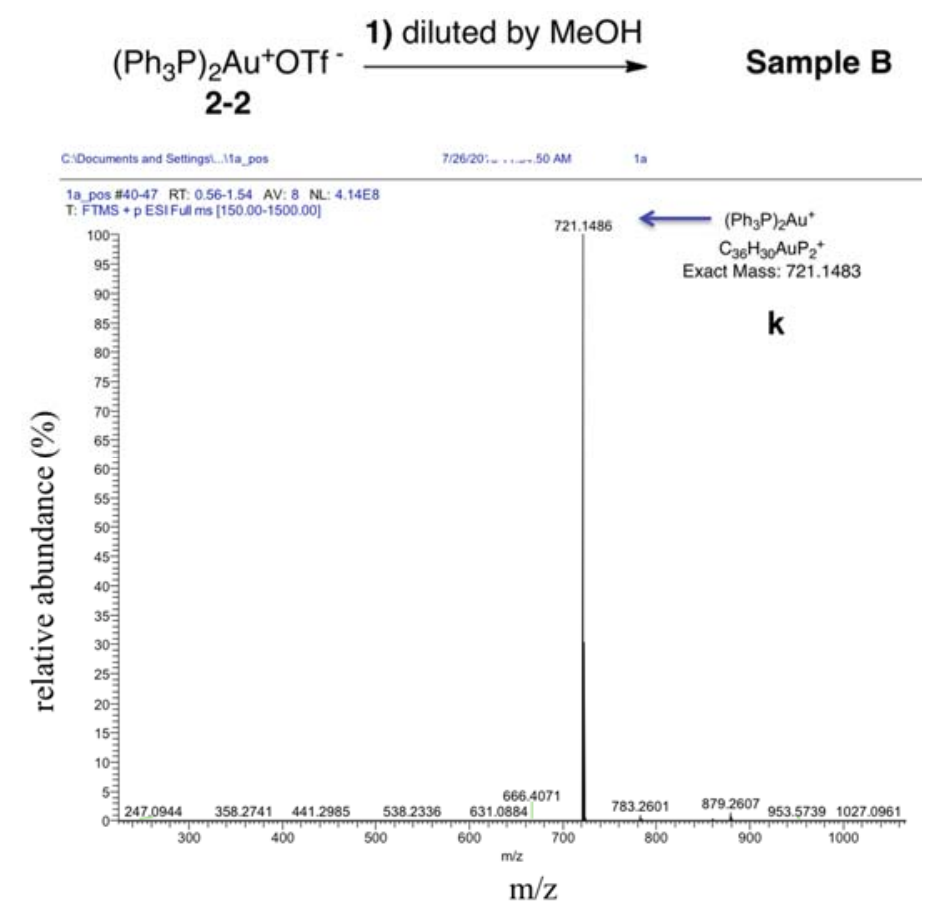

Figure 3. ESI-MS of sample B (Scheme 10). 
This assignment was further confirmed by high resolution ESI mass spectroscopy $\left([\mathrm{M}-\mathrm{OTf}]^{+}\right.$at $\mathrm{m} / \mathrm{z}=721.1483$ ) (Figure 3). We also recorded the ${ }^{1} \mathrm{H}$ NMR of the reaction mixture, and found that cyclohexene itself had remained unchanged during the decay process. Moreover, we also observed cationic gold deactivation with different concentrations of cyclohexene, in which we found that increase in concentration of cyclohexene sped up the decay (Figure 4a). Furthermore, We also conducted NMR experiments to compare gold decay with diferrent unsaturated compounds like alkene/alkyne/allene (10 equiv vs. 2-1). We observed that significant deactivation of the cationic gold catalyst 2-1 took place in all cases (Figure 4b).

Next, we investigated the influence of other common components (e.g. solvent, counterion, and additives) on the kinetics of gold catalyst decay. We found that solvent also affects the stability of the gold catalyst 1 . Gold catalyst (2-1) was stable against deactivation for $24 \mathrm{~h}$ at room temperature in the solvents that we tested. However when cyclohexene (10 equiv vs. gold) was added, the decay process began in earnest. Highly coordinating solvents $\left(\mathrm{CH}_{3} \mathrm{CN}\right.$, dioxane) have shown good aptitude in preventing the deactivation of the gold catalyst due to their high binding affinity with the gold catalyst, even higer than alkyne/alkene/allene (Figure 4c).

As mentioned above, $\mathrm{Ph}_{3} \mathrm{PAu}^{+} \mathrm{X}^{-}$alone is relatively stable, but when cyclohexene was added, different degrees of decay were observed in all cases (Figure 4d). Moreover, compared to the commonly used OTf ${ }^{-}$counterion, $\mathrm{NTf}_{2}^{-}$has great ability to stabilize the cationic gold catalyst. As described (Figure 4d), a more 
coordinating counterion $\left(\mathrm{NTf}_{2}^{-}, \mathrm{OPOF}_{2}^{-}\right)$made a significant increase in the stability of our model gold catalyst $\mathbf{2 - 1}$, rather than a non-coordinating counter ion $\left(\mathrm{BF}_{4}{ }^{-}\right) .{ }^{87}$ Just as it was the case with solvents and counterions, most of the additives we screened did not induce the decay of cationic gold, but when we tested how they influenced the decay kinetics in the presence of cyclohexene, we found that the decay of cationic gold slowed down differently depending on the type of additives used (Figure 4e). Many $N$-heterocycles and HMPA stabilized the gold catalyst significantly; similarly, other additives ( $\operatorname{LiNTf}_{2}$, pyridine $N$-oxide, sodium sufinimide, $\mathrm{KCTf}_{3}$, DMPU) slowed down the decay of gold catalyst $\mathbf{2 - 1}$ to different extents.
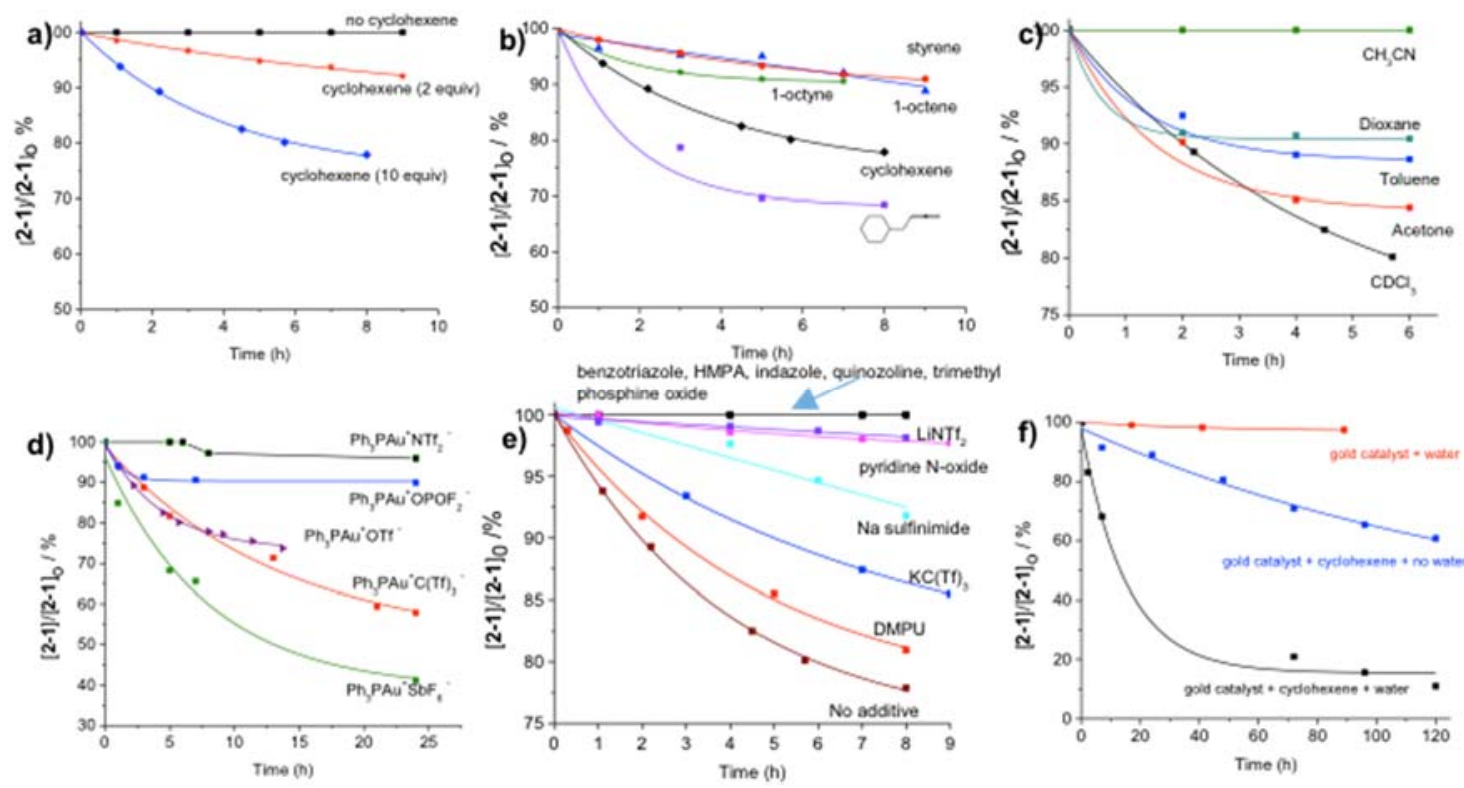

Figure 4. a) Decay of $\left[\mathrm{Ph}_{3} \mathrm{PAu}^{+} \mathrm{OTf}{ }^{-}\right](2-1)$ in the presence of cyclohexene; b) decay of 2-1 in the presence of alkene/alkyne/allene; c) decay of 2-1 in various solvents in the presence of cyclohexene; d) decay of $\left[\mathrm{Ph}_{3} \mathrm{PAu}^{+} \mathrm{X}^{-}\right]$in the presence of cyclohexene; e) decay of 2-1 in the presence of cyclohexene and additives; and f) water effect on decay of 2-1.

Because trace water is ubiquitous in the reaction system, we investigated the effect of water on catalyst deactivation. We found that water alone has little effect on the 
decay (Scheme 4f). Nevertheless, we observed a significantly faster deactivation of gold catalyst 2-1, when 2-1 (0.01 M) was mixed with both cyclohexene (10 equiv) and water (1 equiv) at room temperature.

We postulated two possible pathways to explain the decay behavior (generation of $\mathrm{Au}^{0}$ from $\left.\mathrm{Au}^{\mathrm{I}}\right)$. One pathway is disproportionation, and the other is reduction of gold(I) by certain reductants in the reaction system. Ceroni and coworkers ${ }^{88}$ reported that gold nanoparticles $\left(\mathrm{Au}^{0}\right)$ can be produced by disproportionation of $\mathrm{Au}^{+}$ions. Some research groups have also speculated that the deactivation of the gold catalyst is due to disproportionation. ${ }^{76,77}$ However, no direct experimental evidence has been reported to support these statements. We decided to investigate the actual gold valence change in the decay process experimentally. The redox potential of cationic gold should provide us with quantitative information to determine the ease of reduction of $\mathrm{Au}^{\mathrm{I}}$ in a reaction system. Laguna and coworkers have studied the redox chemistry of $\mathrm{Au}^{\mathrm{I}}$ and $\mathrm{Au}^{\mathrm{III}}$ complexes using cyclic voltammetry in $\mathrm{CH}_{2} \mathrm{Cl}_{2}$ and also in acetonitrile. ${ }^{89}$ In this work, they observed reduction of $\mathrm{Au}(\mathrm{III})$ to $\mathrm{Au}(\mathrm{I})$ for $\mathrm{Au}(\mathrm{III})$ complexes (eg., PPN[AuCl 4$]$ ) and reduction of $\mathrm{Au}(\mathrm{I})$ to $\mathrm{Au}(0)$ for most of the $\mathrm{Au}(\mathrm{I})$ complexes (eg., $\mathrm{Ph} 3 \mathrm{PAuCl}$ ). They observed that peak potentials of -0.1 and $-0.7 \mathrm{~V}$ vs. SCE for the successive reduction of $\mathrm{PPN}\left[\mathrm{AuCl}_{4}\right][\mathrm{Au}(\mathrm{III})$ complexes] in contrast to the reduction peaks at $-2 \mathrm{~V}$ vs. SCE for $\mathrm{Ph}_{3} \mathrm{PAuCl}[\mathrm{Au}(\mathrm{I})$ complexes].

Initially we thought that cationic gold 2-1 $\left(\mathrm{Ph}_{3} \mathrm{PAu}^{+} \mathrm{OTf}{ }^{-}\right.$, active gold species in catalysis) would have a different half potential as compared to covalent complex $\mathrm{Ph}_{3} \mathrm{PAuCl}$, inactive gold species in catalysis (-2 V vs. SCE). But we also observed 
the same behaviour for a single irreversible redox event at very high negative half potential for our cationic gold 2-1 species as discussed next.

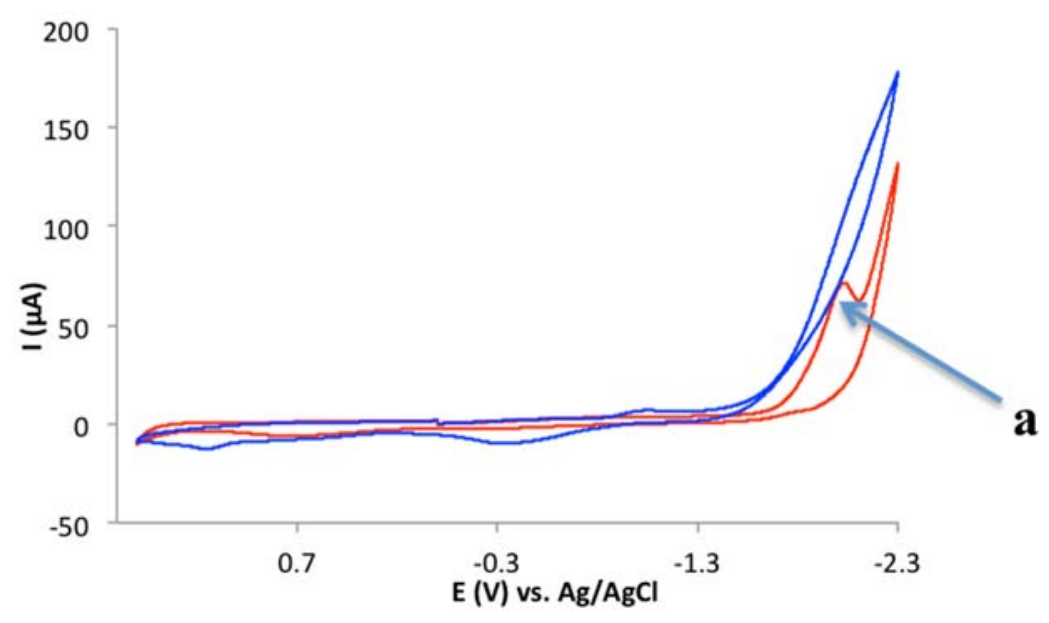

Figure 5. Cyclic voltammogram (red line) of 2-1 $\left(2 \mathrm{mM}\right.$ in $\mathrm{CH}_{2} \mathrm{Cl}_{2}$ with $0.1 \mathrm{M}$ tetrabutylammonium hexafluorophosphate (TBAHFP)). Blue line is background CV of supporting electrolyte in $\mathrm{CH}_{2} \mathrm{Cl}_{2}$.

We also chose $\mathrm{CH}_{2} \mathrm{Cl}_{2}$ as solvent to have a frame of reference to measure the reduction potential of cationic $\mathrm{Au}^{\mathrm{I}}$. The cyclic voltammogram of 2-1 revealed a single irreversible redox event (Figure 5) at a very negative formal potential (-2.5 V vs. ferrocenium/ferrocene). Data were collected at 100, 200, 400, 600, 800, and $1000 \mathrm{mV} / \mathrm{s}$ (Figure 6). Compared with the formal potential of $\mathrm{Au}^{+}\left(\mathrm{AuCl}_{2}-\mathrm{Au}\right.$ pair) in aqueous media $\left(+1.11 \mathrm{~V}\right.$ vs. SHE),${ }^{90,91}$ the highly negative potential of $\mathbf{2 - 1}$ in $\mathrm{CH}_{2} \mathrm{Cl}_{2}$ denotes that a direct reduction of catalyst 2-1 could be very difficult. This observation was further confirmed by adding a strong reductant to $\mathbf{2 - 1}$. When [CoCp* ${ }_{2}$ (reduction potential in $\mathrm{CH}_{2} \mathrm{Cl}_{2}$ is $-1.94 \mathrm{~V}$ vs. ferrocenium/ferrocene) ${ }^{90}$ was added to a solution of $\mathbf{2 - 1}$, no reduction took place. [CoCp*2] is already a very strong reductant, and most compounds in the reaction system are far less reducing. 
Also, in our decay kinetic studies, we did not observe any change in the ${ }^{1} \mathrm{H}$ NMR of cyclohexene in the solution.

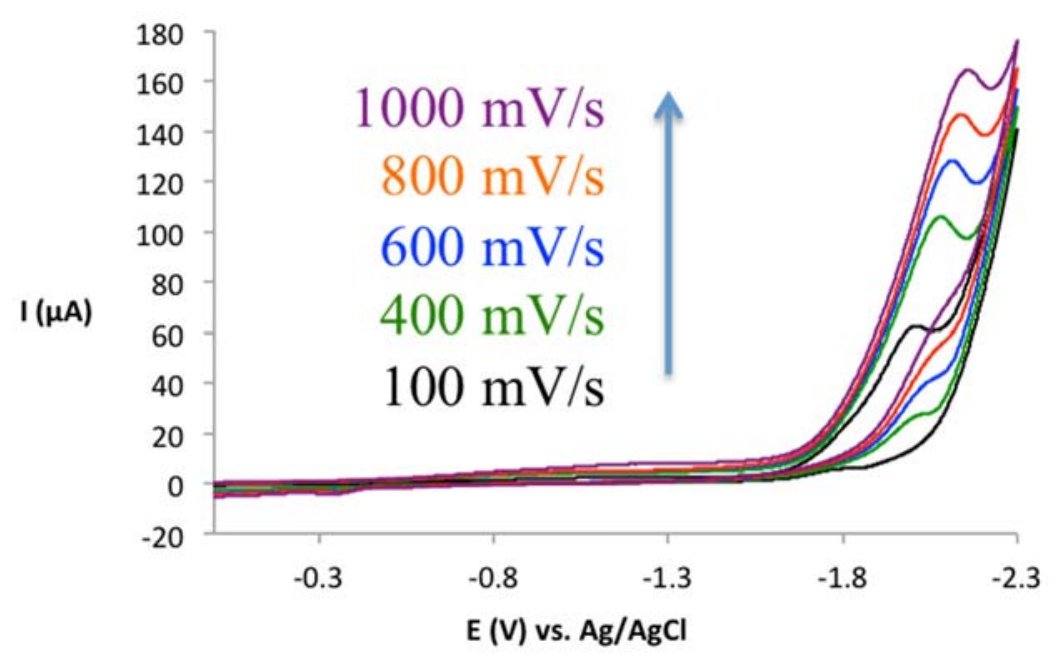

Figure 6. CV of gold catalyst 2-1 at different scan rate.

Because ${ }^{31} \mathrm{P}$ NMR, ${ }^{1} \mathrm{H}$ NMR or voltammetry do not reflect the change in the chemical state of gold itself, we used other more direct techniques to investigate the change in the chemical state of gold. XPS (X-ray photoelectron spectroscopy) is a quantitative spectroscopic technique that measures the elemental composition, chemical state, and electronic state of the elements that exist within a material. ${ }^{92}$ $\mathrm{We}^{93}$ and others ${ }^{94,95}$ have used XPS in the determination of the chemical state of gold catalysts. The $A u 4 f_{7 / 2}$ peaks can be resolved into a doublet (spin-orbit splitting) and the binding energy of $\mathrm{Au} 4 \mathrm{f}_{7 / 2}$ electrons in each gold oxidation state are usually sufficiently wide apart to be differentiated using this technology.

First, we tested our gold standard samples $\left(\mathrm{ClAu}^{\mathrm{I}} \mathrm{PPh}_{3}\right.$ and $\left.\mathrm{NaAu}^{\mathrm{III}} \mathrm{Cl}_{4}\right)$ and found that the $\mathrm{Au} 4 \mathrm{f}_{7 / 2}$ photoelectron peak was located at a $\mathrm{BE}$ value at 85.7 and $87.5 \mathrm{eV}$ respectively, which is quite consistent with literature reports (Figure 7). 


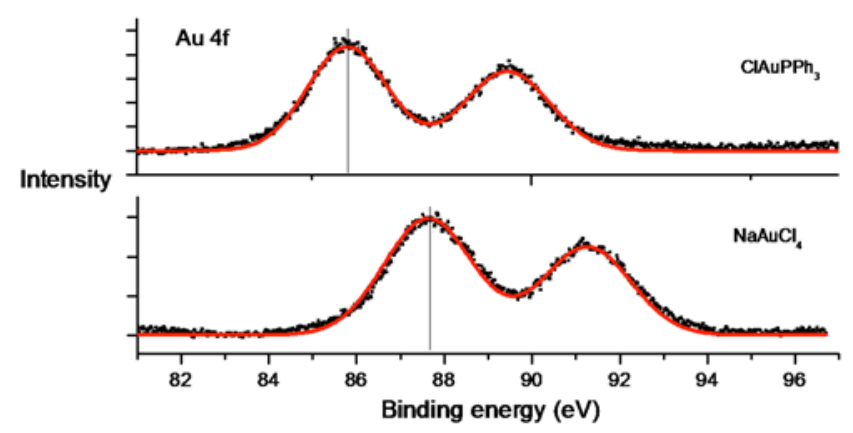

Figure 7. XPS spectra of standard samples $\left(A l_{K a}=1486.6 \mathrm{eV}\right)$ corresponding to the $\mathrm{Au} 4 \mathrm{ff}_{7 / 2}$ photoelectron peaks.

Then, we tested our cationic gold catalyst with various counterions. We prepared these cationic gold samples in chloroform; $24 \mathrm{~h}$ later these solutions were dried in high vacuum and were subjected to XPS analysis (Figure 8, a-c). As expected, the gold valence in these three samples is still $\mathrm{Au}(\mathrm{I})$. We treated $\mathbf{2 - 1}(0.01 \mathrm{M}$ in $\mathrm{CDCl}_{3}$ ) with cyclohexene (10 equiv), after $48 \mathrm{~h}$ we filtered the mixture and collected the liquid portion (sample 1, Figure 8d) and solid precipitate (sample-2, Figure 8e). We conducted XPS analyses of both samples.

The majority of the solid sample (sample 2) was $\mathrm{Au}^{0}$ (Figure 8e), and the liquid fraction was $\mathrm{Au}^{\mathrm{I}}$ (Figure 8d). Because we detected none or very little of an $\mathrm{Au}^{\mathrm{III}}$ component, it is highly possible that a reductive agent like the phosphine ligand reduced $\mathrm{Au}^{\mathrm{III}}$ (because of the high oxidation power of cationic $\mathrm{Au}^{\mathrm{III}}$ itself). Next, we investigated the disproportionation of gold(I) in the absence of a phosphine ligand. First, we tested a commercial $\mathrm{Au}^{\mathrm{I}} \mathrm{Cl}$ sample; although the majority of it corresponded to $\mathrm{Au}^{\mathrm{I}}$, there was also a small amount of $\mathrm{Au}^{\mathrm{III}}$ present (Figure 8f). We wanted to investigate the behavior of cationic gold(I) ( $\mathrm{Au}$ IOTf) under these conditions. $\mathrm{Au}{ }^{\mathrm{I}} \mathrm{Cl}$ and $\mathrm{Ag}^{\mathrm{I}} \mathrm{OTf}$ ( 1 equiv) were mixed (to prepare $\mathrm{Au}^{1} \mathrm{OTf}$ ) in dry dichloromethane with, and without, cyclohexene; after stirring for 30 min under 
dark and anhydrous conditions, we observed the formation of black particles. We collected the black particles (sample-3) and conducted a XPS analysis of sample 3 (Figure 8g), which denoted the presence of $\mathrm{Au}^{0}, \mathrm{Au}^{\mathrm{I}}$ and $\mathrm{Au}^{\mathrm{III}}$. We conducted the same experiment but in the company of cyclohexene, and observed a similar result.

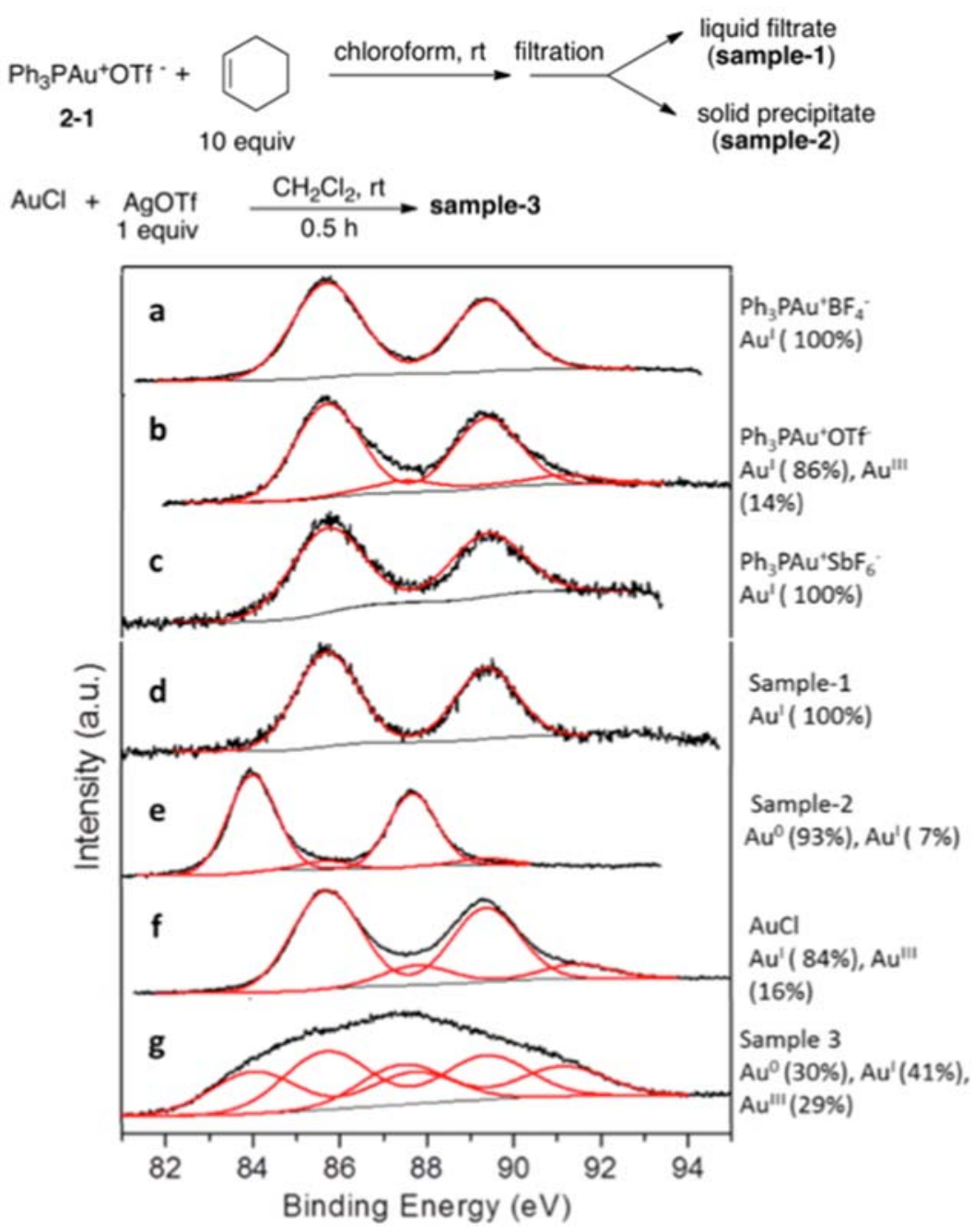

Figure 8. XPS spectra $\left(A l_{K a}=1486.6 \mathrm{eV}\right)$ corresponding to the $A u 4 f_{7 / 2}$ photoelectron peaks.

${ }^{1} \mathrm{H}$ NMR analysis indicated no change in the structure of cyclohexene in the decay solution. This result suggested that cyclohexene did not play a role as reductant. All together, the experimental data supported the disproportionation of cationic gold(I) in the absence of a phosphine ligand. 
Because XPS is conducted under high vacuum and the samples are tested in the solid state there was some concern that the gold catalyst might have changed under these conditions. We wanted to further confirm the existence of gold(III) by investigating the gold species directly in solution phase. Electrospray ionization mass spectroscopy (ESI-MS) is a soft ionization technique $e^{96,97}$ and is an especially suitable technique because cationic gold intermediates are charged species. In a previous work we succeeded in detecting the existence of gold(III) species using high resolution-ESI-MS. ${ }^{98}$ In this work first, we checked the high-resolution ESIMS spectra of sample 1 (Figure 9). We only detected the presence of various $\mathrm{Au}^{\mathrm{I}}$ species (e.g. $\left[\left(\mathrm{Ph}_{3} \mathrm{P}\right) \mathrm{Au}^{\mathrm{I}}\right]^{+}\left(\mathrm{m} / \mathrm{z}\right.$ 459.0571), $\left[\left(\mathrm{Ph}_{3} \mathrm{P}\right) \mathrm{Au}^{\mathrm{I}} \cdot \mathrm{H}_{2} \mathrm{O}\right]^{+}(\mathrm{m} / \mathrm{z}$ 477.0677), $\left[\left(\mathrm{Ph}_{3} \mathrm{P}\right)_{2} \mathrm{Au}^{\mathrm{I}}\right]^{+}(\mathrm{m} / \mathrm{z}$ 721.1483)). This observation is consistent with our previous XPS analysis (Figure 8d).

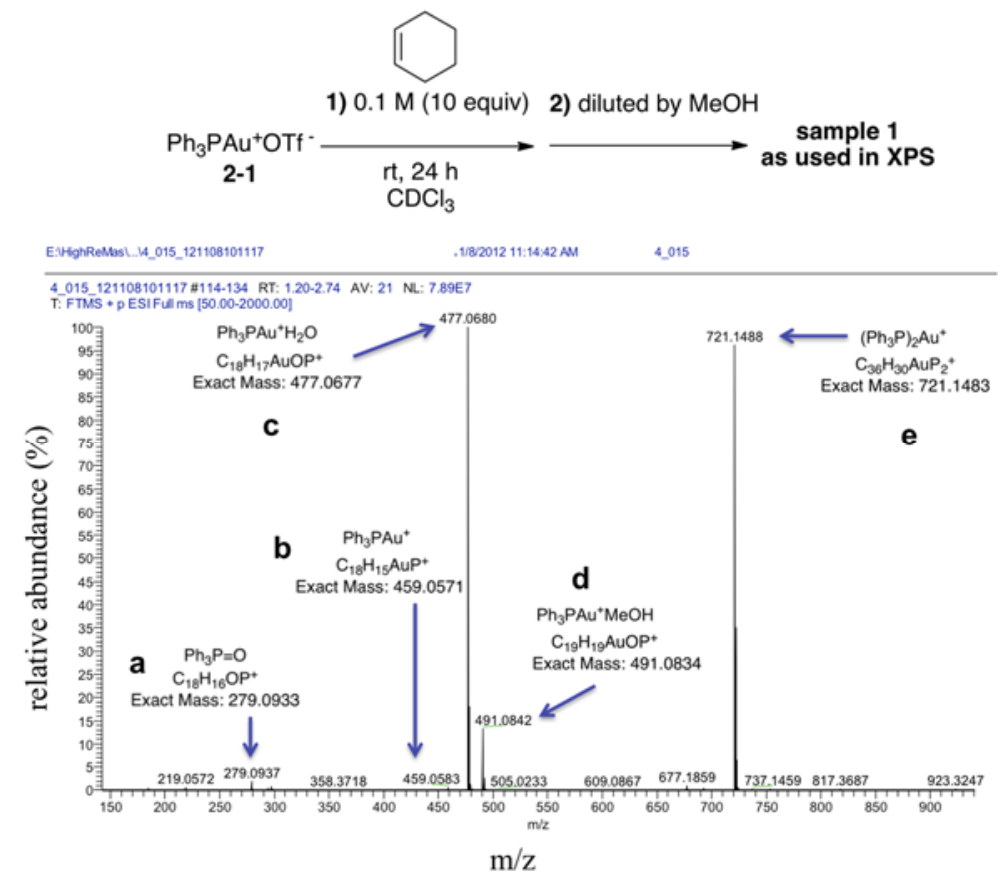

Figure 9. ESI-MS of Sample 1. 
According to our previous studies of gold valence using ESI-MS, ${ }^{93} \mathrm{Au}^{\mathrm{III}}$ species are difficult to detect under standard condition, but we have been able to detect $\mathrm{Au}^{\mathrm{III}}$ species by adding a bidentate ligand and a halide (bipyridine and chloride). ${ }^{93}$ Because $\mathrm{Au}^{\mathrm{III}}$ complexes have square-planar geometry, a bidentate ligand should greatly stabilize the $\mathrm{Au}^{\mathrm{III}}$ cation during the ionization process and chloride will

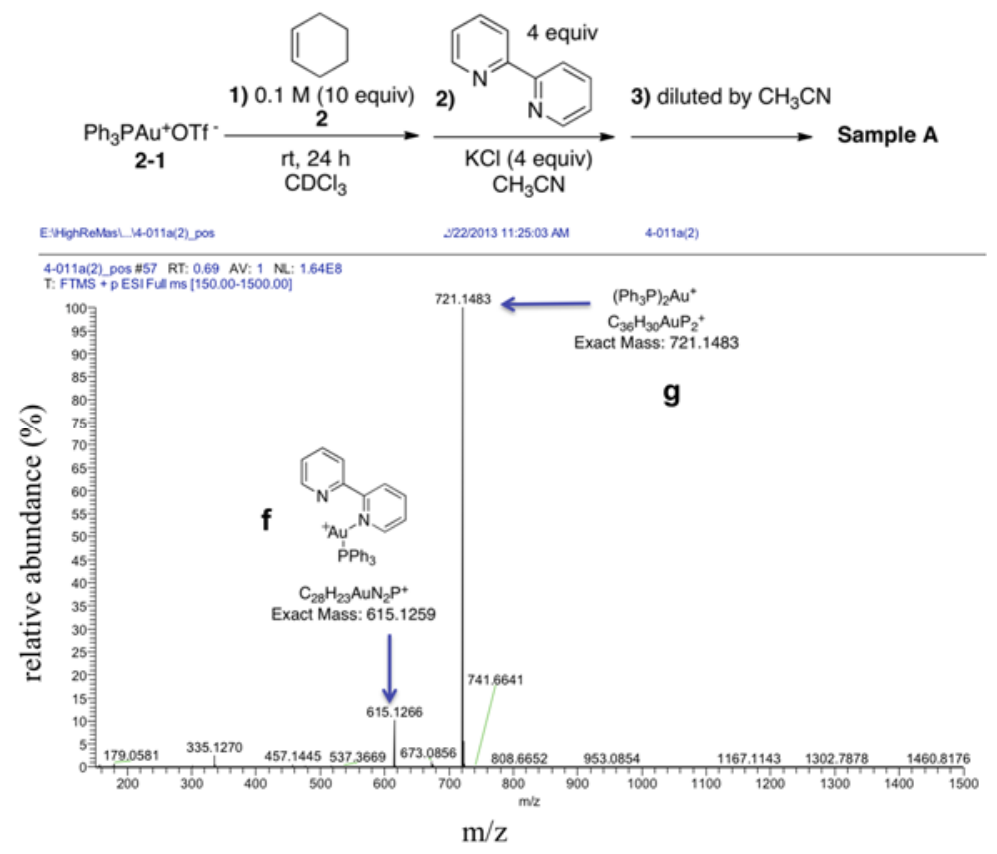

Figure 10. ESI-MS of Sample A (Scheme 10).

further stabilize cationic $\mathrm{Au}^{\mathrm{III}} .{ }^{93}$ Therefore, we added bipyridine and chloride in sample 1. Again, only $\mathrm{Au}^{\mathrm{I}}$ species (e.g. [(Ph 33$) A u^{\mathrm{I}}$.bypridine ${ }^{+}(\mathrm{m} / \mathrm{z}$ 615.1266), $\left[\left(\mathrm{Ph}_{3} \mathrm{P}\right)_{2} \mathrm{Au}^{\mathrm{I}}\right]^{+}(\mathrm{m} / \mathrm{z}$ 721.1483)) were detected (Figure 10). This result indicates there is no $\mathrm{Au}^{\mathrm{III}}$ in the presence of a phosphine ligand $\left(\mathrm{PPh}_{3}\right)$. We used the same method to investigate the ESI-MS of sample 3. Various $\mathrm{Au}^{\mathrm{III}}$ species were detected (Figure 11). Our high resolution-ESI-MS studies are consistent with our previous XPS studies, that is, there was no $\mathrm{Au}^{\mathrm{III}}$ species (only $\mathrm{Au}^{\mathrm{I}}$ species) in sample-1, but various $\mathrm{Au}^{\mathrm{III}}$ species were detected in sample-3. 


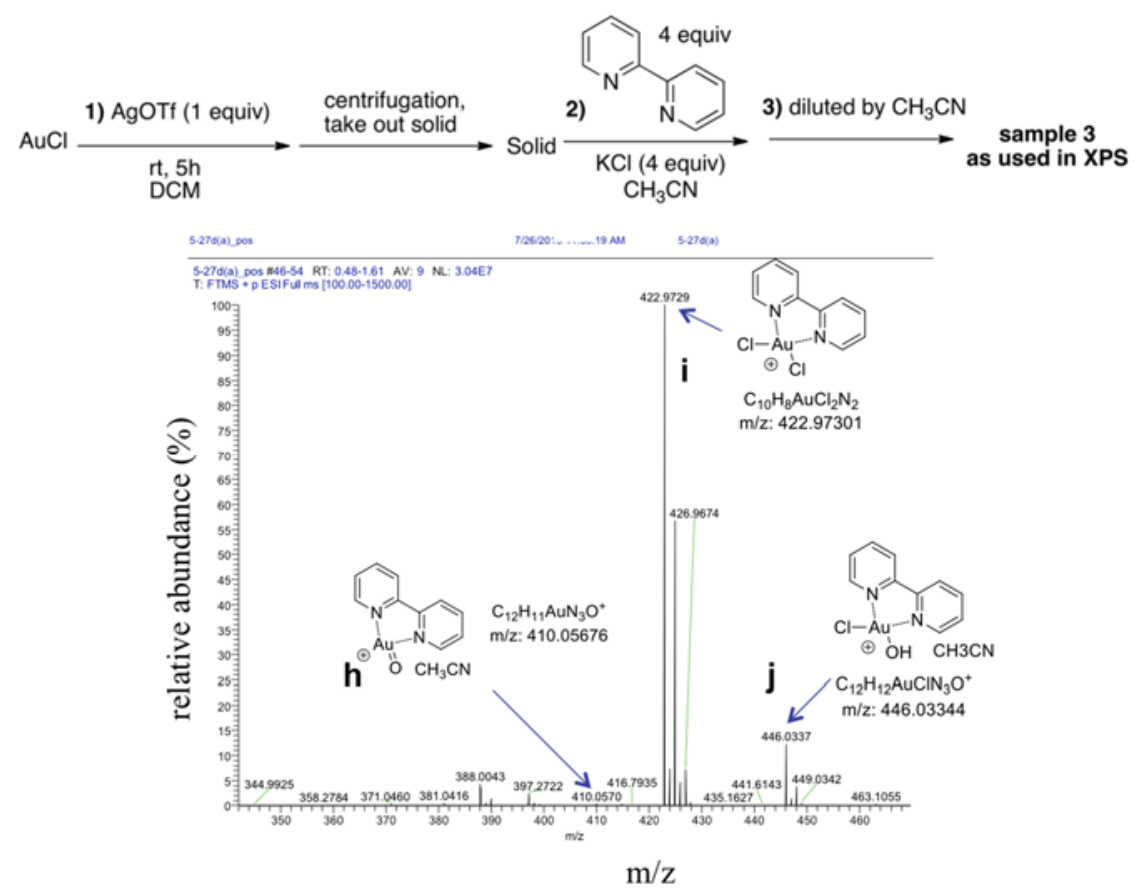

Figure 11. ESI-MS spectrum of sample 3.

Based on the combination of all the above experimental data, we are now in a good position to understand the decay mechanism, which can be summed up as follows:

1) Cationic $\mathrm{Au}^{\mathrm{I}}$ without a suitable ligand (e.g. $\mathrm{Au}^{\mathrm{I}} \mathrm{OTf}$ ) disproportionates readily compared to the non-cationic form (e.g. $\mathrm{Au}{ }^{\mathrm{I}} \mathrm{Cl}$ ) (see Figure 8, sample 3).

2) In the presence of a suitable ligand, cationic gold(I) decays (or disproportionates) at a much slower pace. $\mathrm{Ph}_{3} \mathrm{PAu}^{+} \mathrm{OTf}^{-}$is stable for at least $24 \mathrm{~h}$ (Figure 8b) and Au ${ }^{\mathrm{I} O T f}$ disproportionates in less than $0.5 \mathrm{~h}$ (Figure 8g). This conclusion serves to explain why ligands are so ubiquitous in gold catalysis.

3) Cationic $\mathrm{Au}^{\mathrm{I}} \square \pi$-complexes with $\pi$-donors (C-C unsaturated compounds like alkyne/allene/alkene) undergo relative fast decay, whereas cationic $\mathrm{Au}^{\mathrm{I}} \square$ complexes with most $\sigma$-donors ( $N$-heterocycles, acetonitrile etc) are very stable. 
The detailed role of substrates (alkyne/allene/alkene) in substrate-induced cationic gold decay is not very clear yet. Considering the great stabilization effect of the phosphine ligand (or NHC ligand) against disproportionation, our hypothesis is that an alkyne/allene/alkene may help to temporarily displace the phosphine ligand from the gold(I) center via a trans-effect. The trans-effect is the labilization (destabilization) of ligands that are trans to certain other ligands in a metal complex. Although most examples of trans-effect are observed in square planar complexes (e.g. Pd, Pt), we propose that it may also operate in linear metal complexes like gold(I) complexes. ${ }^{99}$ And alkenes/alkynes are indeed the ligands that have shown the strongest trans-effect. Odell and coworkers demonstrated that alkenes and alkynes showed the highest trans effect of any other compounds in platinum complexes (trans effect: $\mathrm{C}_{2} \mathrm{H}_{4} \sim{ }^{i} \mathrm{PrCH}=\mathrm{CHMe} \sim \mathrm{Me}_{2} \mathrm{C}(\mathrm{OH}) \mathrm{C} \equiv \mathrm{C}-$ $\left.\mathrm{C}(\mathrm{OH}) \mathrm{Me}_{2}>>\mathrm{Et}_{3} \mathrm{Sb}>\mathrm{Ph}_{3} \mathrm{Sb}>\mathrm{Me}_{3} \mathrm{P}>\mathrm{Et}_{3} \mathrm{P}>\mathrm{Ph}_{3} \mathrm{P}\right) .{ }^{100}$

Our proposed decay mechanism is shown in Scheme 7. First, cyclohexene will complex with cationic gold to form a gold-alkene $\pi$-complex, then, because of the trans-effect of the alkene, the phosphine ligand will be temporarily replaced to form complex 2-2 and free $\mathrm{Au}^{\mathrm{I} O T f}$. The disproportionation of $\mathrm{Au}^{\mathrm{I}} \mathrm{OTf}$ generates $\mathrm{Au}^{0}$ and $\mathrm{Au}^{\mathrm{III}}(\mathrm{OTf})_{3}$. This disproportionation may be enhanced by the presence of trace water in the system. This statement is supported by a literature report that stated that a $\mathrm{Au}^{\mathrm{I}}$ complex undergoes disproportionation in aqueous solution, while $\mathrm{Au}^{\mathrm{I}}$ is stable in organic solvents. ${ }^{101}$ 


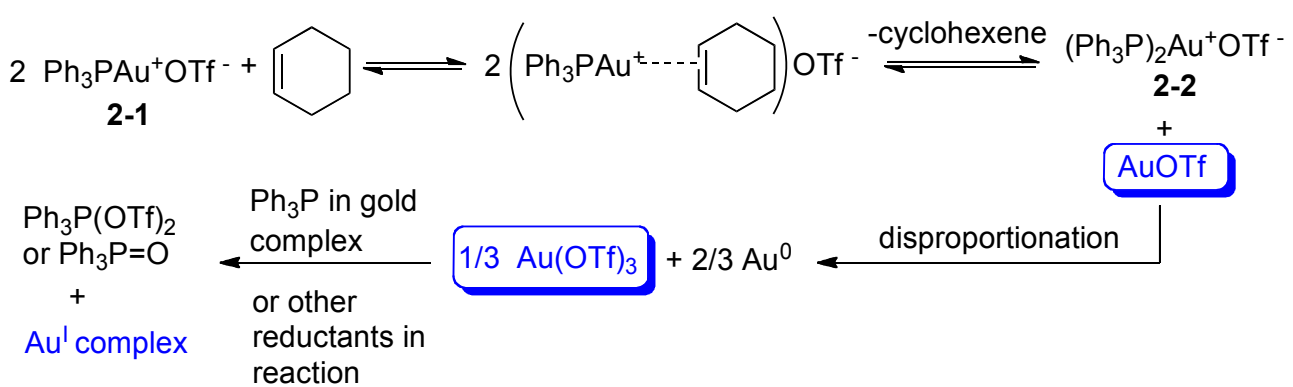

\section{Scheme 7. Proposed mechanism for substrate-induced cationic gold decay.}

The disproportionation of $\mathrm{Au}^{\mathrm{I}} \mathrm{OTf}$ or its alkene/alkyne complex can be a relatively fast process (see Figure 8g, sample 3). This statement also has literature support: Dias and coworkers ${ }^{102-105}$ reported that $\mathrm{Au}^{\mathrm{I}}$ alkene or alkyne complexes without ligands are only stable at very low temperature, turning into black particles at room temperature. It is well known that $\mathrm{Au}^{\mathrm{III}}$ will oxidize the phosphine ligand, ${ }^{106}$ and it will be reduced to $\mathrm{Au}^{\mathrm{I}}$ again.

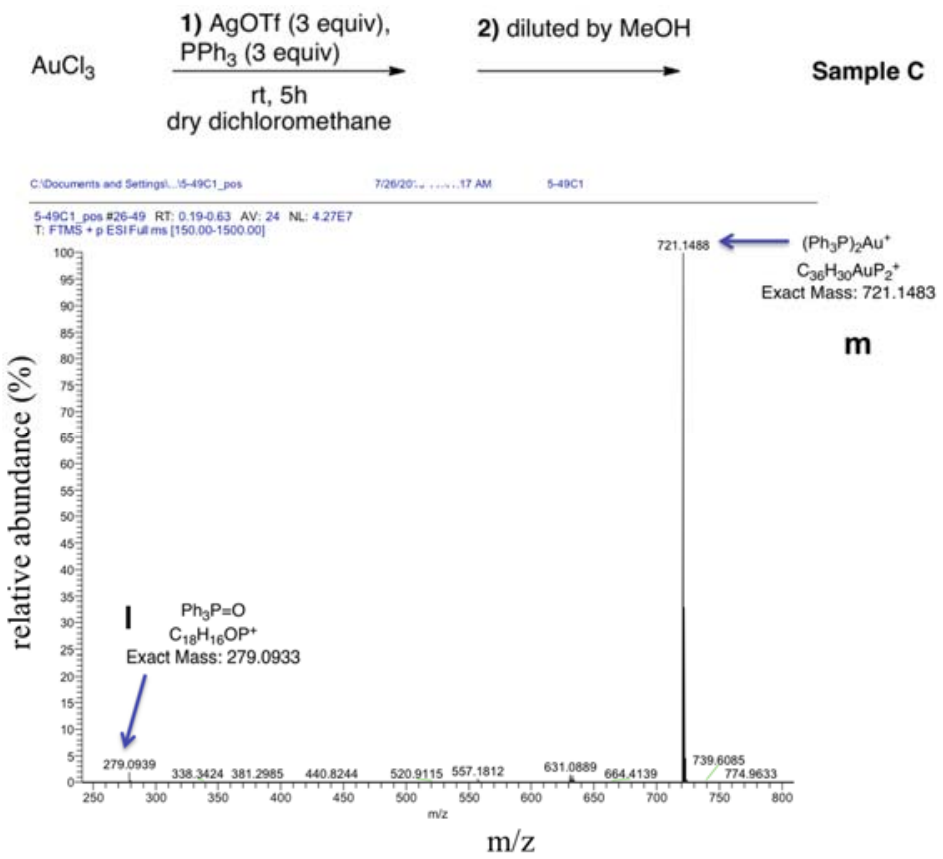

Figure 12. ESI-MS of Sample C (Scheme 10). 
We propose that $\mathrm{Ph}_{3} \mathrm{P}$ is oxidized to $\mathrm{Ph}_{3} \mathrm{P}(\mathrm{OTf})_{2},{ }^{107}$ which could then be hydrolyzed to give $\mathrm{Ph}_{3} \mathrm{P}=\mathrm{O}$ in the presence of water. The presence of $\mathrm{Ph}_{3} \mathrm{P}=\mathrm{O}$ has been confirmed by ESI-MS and TLC (by comparison with an authentic sample).

Furthermore, when we mixed $\mathrm{Au}(\mathrm{OTf})_{3}$ (generated from $\mathrm{AuCl}_{3} / \mathrm{Ag}^{\mathrm{I}} \mathrm{OTf}$ ) with $\mathrm{PPh}_{3}$ (sample C), we did obtain $\left(\mathrm{Ph}_{3} \mathrm{P}\right)_{2} \mathrm{Au}^{+} \mathrm{OTf}{ }^{-}(\mathbf{2 - 2})$ and $\mathrm{Ph}_{3} \mathrm{P}=\mathrm{O}$ (Figure 12). This behavior could explain why we were not able to detect $\mathrm{Au}^{\mathrm{III}}$ in gold solutions using XPS and ESI-MS (sample 1).

We now can apply our decay mechanistic study to explain some unanswered questions:

i) What causes the decay of cationic gold? Induced cationic gold decay by unsaturated compounds (alkyne/allene/alkene) is the major reason for cationic gold decay. It should be noted that the starting material is not the only source of $\mathrm{C}-\mathrm{C}$ unsaturated compounds; the products often contain $\mathrm{C}-\mathrm{C}$ unsaturated compounds as well.

ii) Why is it that a high turnover can be achieved in some reactions but not in others? The decay process is highly dependent on the resting state of the gold catalyst. Based on our most recent study, ${ }^{29}$ we have classified gold catalyzed reactions according to their turnover limiting stage: in type $\mathrm{I}$, the formation of gold- $\sigma$-complex ([L-Au-S-Nu] in Scheme 6) is the turnover limiting stage; in type II, the regeneration of cationic gold catalyst (e.g. protodeauration) from [L-Au-S$\mathbf{N u}]$ is the turnover limiting stage. For type I reactions, the resting state is often [L$\left.\mathbf{A u}^{+}-\mathbf{S}\right]$ (Scheme 6), thus, a relatively fast decay is to be expected, and so, turnover 
numbers will be low in general. On the other hand, in type II reactions, the resting state is usually not $\left[\mathbf{L}-\mathbf{A u} \mathbf{u}^{+}-\mathbf{S}\right]$, so the decay is relatively slow and high TON are to be expected.

According to our recent study, ${ }^{29}$ the hydroamination of an allene is a type I reaction (Scheme $8 \mathrm{a}$ ). Toste and coworkers ${ }^{32}$ have found that the gold resting state is the gold-allene complex $\mathbf{2 - 3 A}$ in this reaction (Scheme 8a). Intermolecular hydroamination of an alkene ${ }^{16}$ is a similar example (Scheme 8b). In these reactions, high loadings of gold catalyst (5\% or higher) are typically used. And in these reactions, we did observe the formation of decay gold products $\mathbf{2 - 2}$ and $\mathrm{Au}^{0}$ in the reaction mixture, especially when triflate was used as counterion.

A typical example of Type II reactions is the cyclization of propargyl amide (2-7) (Scheme 8c); its catalyst resting state is a [L-Au-S-Nu] type intermediate 27A. ${ }^{29,108}$ Thus, the decay of the active catalyst is expected to be slow. Indeed, low catalyst loadings $(0.1 \%)$ have been achieved for this reaction. ${ }^{109}$ Similarly, the alkyne hydration (Scheme $8 \mathrm{~d}$ ) reported by Nolan and coworkers, ${ }^{70}$ and the intramolecular addition of a diol to an alkyne reported by Hashmi and coworkers $^{71,110,111}$ have been achieved with very high turnover numbers. In these reactions, the turnover limit determining stage is most likely the protodeauration of [L-Au-S-Nu] type complex (Scheme 6). ${ }^{29}$

We chose those reactions because acyclic and heterocyclic nitrogen-containing derivatives are common components of naturally occurring compounds agrochemicals, cosmetics, and pharmaceuticals; they are also useful intermediates in a number of industrial processes. 

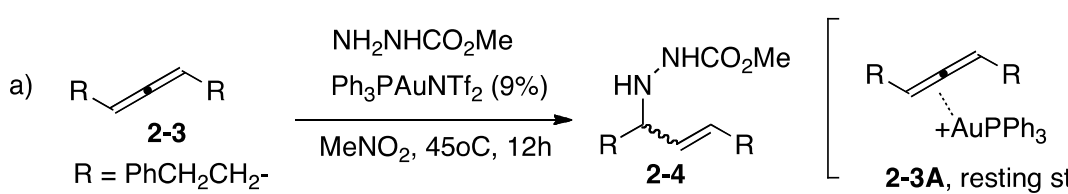

2-3A, resting state

b)

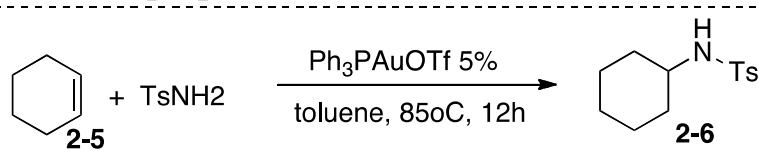

c)
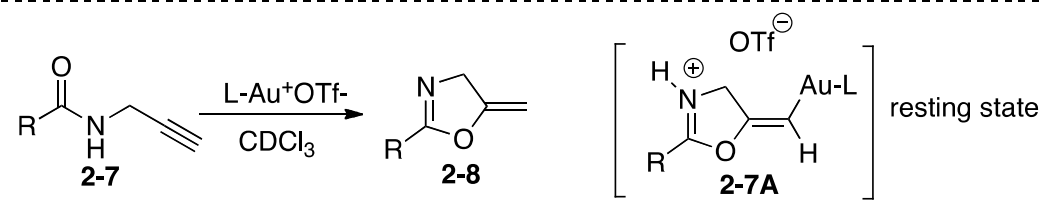

d)

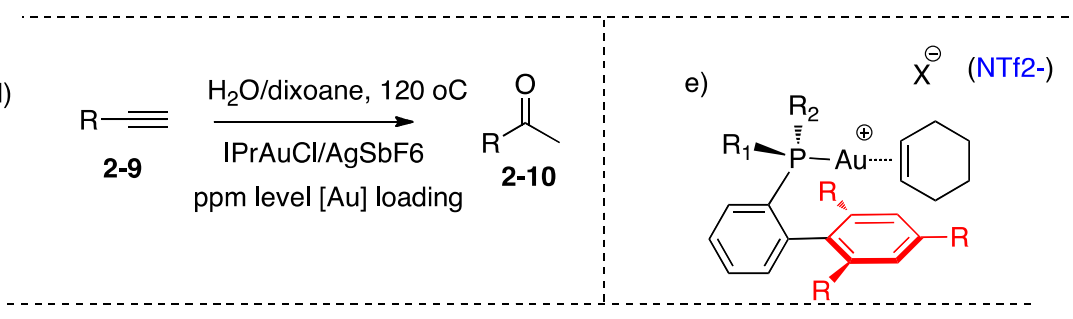

\section{Scheme 8. Catalyst decay in different gold catalyzed reactions.}

iii) What can we do to reduce the decay of an active gold catalyst? Our studies indicate that the use of $\sigma$-donors like $N$-heterocycles and $\mathrm{CH}_{3} \mathrm{CN}$ will enhance the stability of the cationic gold, ${ }^{9,112}$ but $\sigma$-donors also have significant detrimental effects on reactivity, so their use is usually not a good option. But it is still possible to disrupt the gold-alkyne/alkene interaction and therefore reduce the decay by using suitable ligands and counterions. We have reported recently that the use of a ligand containing a $o$-biphenyl steric handle can reduce the decay of cationic gold. ${ }^{29,113}$ As shown in 8e, a $o$-biphenyl motif will clearly interrupt the bonding of the gold center with an alkene/alkyne, which may be the reason it slowed down its decay. A steric handle like o-biphenyl will not reduce the reactivity though; actually for many types of gold catalyzed reactions, ligands with biphenyl motif often give faster reactions. ${ }^{4,114}$ In Figure $4 \mathrm{~d}$, we demonstrated that some counterions are more capable of stabilizing the cationic gold. $\mathrm{NTf}_{2}{ }^{-}$is a notable 
example. The use of $\mathrm{NTf}_{2}^{-}$won't reduce reactivity; in many reactions, $\mathrm{NTf}_{2}^{-}$ actually enables faster reactions compared with a commonly used counterion such as OTf $^{-} \cdot 87$

It should be noted that the alkyne/alkene/allene induced disproportionation of cationic gold(I) species may generate small gold clusters or gold nanoparticles under suitable conditions, which can exhibit high reactivity in certain gold catalyzed reactions. ${ }^{72,115}$ Therefore, disproportionation may not be the end of the story for gold catalysts. We believe that if relatively large gold particles or a gold mirror are generated through disproportionation, the reactivity of the gold catalyst will be lost, but if we can control this disproportionation process so as to generate small gold clusters or gold nanoparticles, we may then be able to obtain new reactivity.

\subsection{Summary}

In summary, we have conducted the first detailed experimental studies to describe the possible mechanism of gold decay. There have been no reports with direct experimental details about the deactivation mechanism. In most gold-catalyzed reactions, catalyst loadings in the $1-5 \%$ range are the norm. One reason for the low turnover numbers (TON) is the relatively fast decay of cationic gold and its conversion into non-reactive species. We proposed two mechanisms i.e., reduction, and disproportionation. Our experimential studies support that disproportionation was the most preferable as compared to reduction, based on our individual studies of each step, and we proposed a mechanism. All our results, based on ${ }^{1} \mathrm{H} \&{ }^{31} \mathrm{P}$ 
NMR, Cyclic Voltammetry, XPS, and High-Resolution ESI-MS spectroscopy, favor the disproportination mechanism rather than reduction of gold catalyst. Our experimental studies support the substrate (alkyne/allene/alkene)-induced cationic gold decay (disproportionation) as the main reason behind cationic gold deactivation, but it should be noted that there could be other decay pathways. We also observed that decay depends on the resting state of the gold catalyst. We also found out that additive effects (neutral organic compound, counterion, solvent) could be useful to prevent the deactivation of the common gold catalyst. Our studies indicated that the use of $\sigma$-donors like $\mathrm{N}$-heterocycles and $\mathrm{CH}_{3} \mathrm{CN}$ enhance the stability of the cationic gold, but $\sigma$-donors also have a significant detrimental effect on reactivity, so their use is usually not a good option. But it is still possible to disrupt the gold-alkyne/alkene interaction and therefore reduce the decay by using suitable ligands and counterions that could be useful to lower gold catalyst loading, and could be useful to increase the turnover number in gold catalysis. In a future roadmap, and as a corollary of our finding that additives play a very important role in catalysis, we would like to expand the use of additives such as LiNTf $_{2}$ not only in other types of gold catalysis but also apply them to other metal catalyzed reactions. The work described in this chapter was published in Chem. Eur. J. 2014, 20, 3113-3119. 


\subsection{Experimental}

\section{General}

${ }^{1} \mathrm{H},{ }^{13} \mathrm{C}$, and ${ }^{31} \mathrm{P}$ NMR spectra were recorded with Varian spectrometers at 400 , $100,160 \mathrm{MHz}$ respectively, using $\mathrm{CDCl}_{3}$, dacetone as a solvent. The chemical shifts are reported in $\delta(\mathrm{ppm})$ values relative to $\mathrm{CDCl}_{3}\left(\delta 7.26 \mathrm{ppm}\right.$ for ${ }^{1} \mathrm{H}$ NMR and $(\delta$ $77.0 \mathrm{ppm}$ for ${ }^{13} \mathrm{C}$ NMR), relative to ${ }^{\mathrm{d}}$ acetone ( $\delta 2.05$ for ${ }^{1} \mathrm{H}$ NMR), multiplicities are indicated by s (singlet), $\mathrm{d}$ (doublet), $\mathrm{t}$ (triplet), q (quartet), $\mathrm{m}$ (multiplet), and br (broad). Coupling constants $(J)$ are reported in Hertz. All deuterated solvents used in the reactions were used as received. All simple solvents (e.g. dichloromethane) were chemically dried using a commercial solvent purification system. All other reagents and solvents were employed without further purification. TLC was developed on Merck silica gel 60 F254 aluminum sheets. All the commercial reagents, and solvents were purchased from Aldrich or Strem or Fisher, and used without purification except cyclohexene (cyclohexene was redistilled). FT-ICRMS - Fourier Transform-Ion Cyclotron Resonance-Mass Spectrometer was used for high resolution ESI-MS spectroscopy. Electrochemistry (Voltammetry) was performed with Potentiostat/Galvanostat Model 273.

\section{Monitoring the reaction using in situ NMR spectroscopy}

The model reaction was conducted in a NMR tube equipped with a screw cap and septa. All reactions were monitored using a Varian $400 \mathrm{Mz}$ NMR Spectrometer with the capacity to adjust the probe temperature with robotic sample changer at 
room temperature. When ${ }^{31} \mathrm{P}$ NMR was used to monitor the progress of reaction, $85 \% \mathrm{H}_{3} \mathrm{PO}_{4}$ (sealed in a capillary tube) was used as external standard for NMR integration. When ${ }^{1} \mathrm{H}$ NMR was used to monitor the progress of reaction, a solution of tetramethylsilane in $\mathrm{CDCl}_{3}$ (sealed in a capillary tube) was used as external standard for NMR integration.

\section{General procedure for preparation of $\mathrm{Ph}_{3} \mathrm{PAuCl}$ and $\mathrm{Ph}_{3} \mathrm{PAu}^{+} \mathrm{X}^{-}(\mathrm{X}=$ $\mathrm{OTf}^{-}, \mathrm{NTf}_{2}^{-}, \mathrm{OPOF}_{2}^{-}, \mathrm{SbF}_{6}^{-}, \mathrm{C}\left(\mathrm{Tf}_{3}{ }_{3}^{-}, \mathrm{BF}_{4}^{-}\right)$}

\section{Synthesis of gold complexes ( $\mathrm{L}-\mathrm{AuCl})$.}

Gold complexes ( $\mathrm{L}-\mathrm{AuCl})$ were synthesized using a slightly modified version of a literature method. ${ }^{116}$ These complexes were prepared via the following general procedure:

Sodium tetrachloroaurate(III) dihydrate $(1 \mathrm{mmol})$ was dissolved in water, and the orange solution was cooled in ice. To this solution, 2,2'-thiodiethanol (3 mmol) was slowly added (ca. $30 \mathrm{~min}$ ) with stirring. A solution of the phosphine ligand (1 mmol) in $\mathrm{EtOH}$ (if the ligand could not be dissolved, more EtOH was used) was added dropwise to yield a white solid. The solid was filtered, washed with water and then $\mathrm{EtOH}$, and dried in vacuum.

\section{Preparation of cationic gold $\left(\mathrm{L}-\mathrm{Au}^{+} \mathrm{OTf}^{-}\right)$stock solution.}

$$
\begin{gathered}
\mathrm{Ph}_{3} \mathrm{PAuCl}+\mathrm{AgX} \longrightarrow \mathrm{Ph}_{3} \mathrm{PAuX}+\mathrm{AgCl} \\
\mathrm{X}=\mathrm{OTf}^{-}, \mathrm{NTf}_{2}^{-}, \mathrm{OPOF}_{2}^{-}, \mathrm{SbF}_{6}^{-}, \mathrm{C}\left(\mathrm{Tf}_{3}\right)_{3}^{-}, \mathrm{BF}_{4}^{-}
\end{gathered}
$$

Standard stock solutions of cationic gold catalyst were made by weighing the L$\mathrm{Au}(\mathrm{I}) \mathrm{Cl}(0.1 \mathrm{mmol})$ complex into a vial and adding corresponding deuterated 
solvent, then 1.2 equiv of $\mathrm{Ag}^{\mathrm{I} O T f}(0.12 \mathrm{mmol})$ was added, the vial was sonicated for 3-5 min at room temperature, then the vial was centrifuged and the clear solutions was transferred to a clean glass vial. The solution was kept in freezer ($20^{\circ} \mathrm{C}$ ) until it was used.

\section{Preparation of $\left(\left(\mathrm{Ph}_{3} \mathrm{P}\right)_{2} \mathrm{Au}^{+} \mathrm{OTf}^{-}\right)$2-2.}

Cationic gold catalyst 2-1 was made by weighing the $\mathrm{Ph}{ }_{3} \mathrm{PAu}(\mathrm{I}) \mathrm{Cl}(0.1 \mathrm{mmol})$ complex into a vial and adding corresponding dichloromethane solvent $(2 \mathrm{~mL})$, then 1.2 equiv of $\operatorname{Ag}^{\mathrm{I}} \mathrm{OTf}(0.12 \mathrm{mmol})$ was added, the vial was stirred for $2-3 \mathrm{~h}$ at room temperature, then the vial was centrifuged and the clear solution was transferred to a clean glass vial and the solvent was removed at high vacuum to leave a white solid $\mathrm{Ph}_{3} \mathrm{PAu}^{+} \mathrm{OTf}^{-}(\mathbf{2 - 1}) . \mathrm{Ph}_{3} \mathrm{P}(0.1 \mathrm{mmol})$ was added in a vial having 2-1 with dichloromethane $(1 \mathrm{~mL})$ and the solution was stirred at room temperature for 2-3 h. Solvent was removed at high vacuum to leave a white solid $\left(\mathrm{Ph}_{3} \mathrm{P}\right)_{2} \mathrm{Au}^{+} \mathrm{OTf}^{-}$(2-2). 2-2 was characterized by ${ }^{31} \mathrm{P}$ NMR (45.0 ppm) and ESI-MS (Figure 3).

\section{X-Ray photoelectron spectroscopy (XPS) studies}

XPS is a quantitative spectroscopic technique that measures the elemental composition, chemical state and electronic state of the elements that exist within a material. ${ }^{117}$ For example, it has been used in determination of chemical state of supported gold catalysts. ${ }^{94}$ The binding energy of $\mathrm{Au} 4 \mathrm{f}_{7 / 2}$ electron of each gold oxidation state is usually wide enough apart to be differentiated by this technology (Table 1). 
Table 1. The literature reports of binding energy of $A u \mathbf{4 f}_{7 / 2}$ electron.

\begin{tabular}{|c|c|c|c|c|}
\hline Sample & $\mathrm{Au}^{0}$ & $\mathrm{ClAu}^{\prime} \mathrm{PPh}_{3}$ & $\mathrm{ClAu}\left(\mathrm{PPh}_{3}\right)_{2}$ & $\mathrm{Cl}_{3} \mathrm{Au}^{\mathrm{III}} \mathrm{PPh}_{3}$ \\
\hline $\mathrm{Au} 4 \mathrm{f}_{7 / 2} \mathrm{BE}(\mathrm{eV})$ & $84.0 \pm 0.1$ & 85.4 & 85.4 & 87.3 \\
\hline
\end{tabular}

X-ray photoelectron spectroscopy (XPS) spectra were collected by a Thermo Fisher Scientific XPS spectrometer, equipped with standard Al Ka excitation source $(1486.6 \mathrm{eV})$. Gold complex standards $\left(\mathrm{ClAu}^{\mathrm{I}} \mathrm{PPh}_{3}, \mathrm{NaAu}^{\mathrm{III}} \mathrm{Cl}_{4}\right)$ were sampled as powders and pressed on a double-sided adhesive carbon tape. Gold catalyst aliquots were sampled as solution and solid (Scheme 9), dried in normal atmosphere on a double-sided adhesive carbon tape.
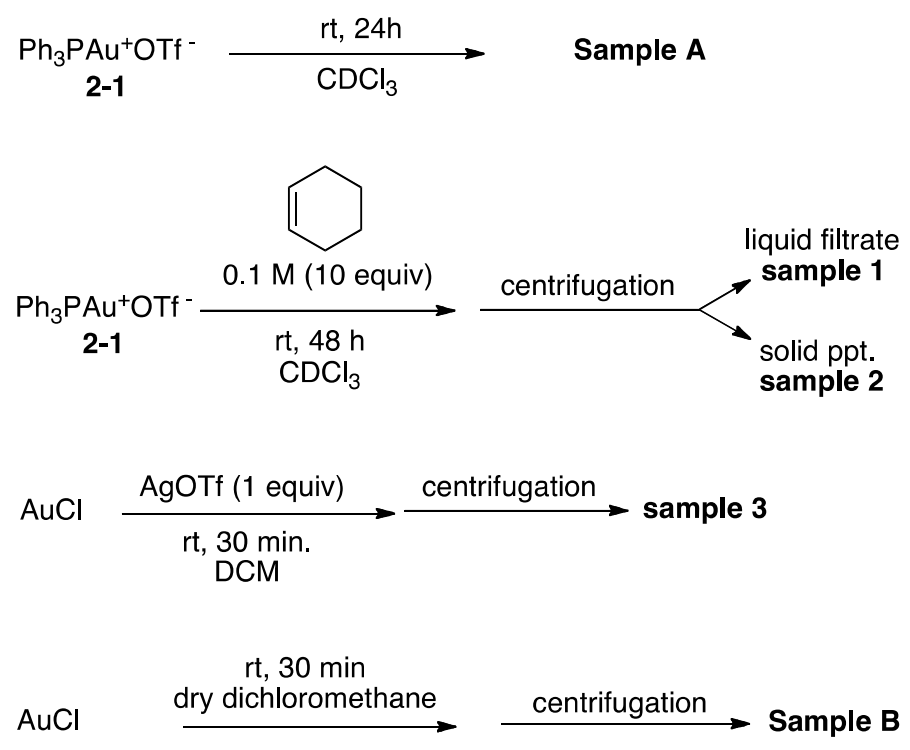

Scheme 9. Sample preparation for XPS studies.

The binding energy scale was calibrated by measuring C 1s peak (BE $284.6 \mathrm{eV}$ ) from the surface contamination and the accuracy of the measurement was $0.1-0.2$ eV. A non-linear least square peak fitting routine was used for the analysis of XPS spectra, separating elemental species in different oxidation states. The curve fitting of the $4 \mathrm{f}$ core level spectrum was performed using two spin split $\mathrm{Au} 4 \mathrm{f}_{7 / 2}$ and $\mathrm{Au}$ 
4f $\mathrm{f}_{5 / 2}$ components, separated by $3.67 \mathrm{eV}$, in a fixed intensity ratio (1.33). We tested our gold standard samples (ClAu${ }^{\mathrm{I}} \mathrm{PPh}_{3}$ and $\left.\mathrm{NaAu}^{\mathrm{III}} \mathrm{Cl}_{4}\right)$, (Table 2, entries 1-2); the $\mathrm{Au} 4 \mathrm{f}_{7 / 2}$ photoelectron peak is located at a $\mathrm{BE}$ value at 85.7 and $87.5 \mathrm{eV}$ respectively, which is quite consistent with literature reports (Table 1).

Table 2. Relative surface distribution of gold valence change based in XPS studies.

\begin{tabular}{|c|c|c|c|}
\hline entry & Sample & Au $4 f_{7 / 2} B E(e V)$ & Surface Au Species \\
\hline 1 & $\mathrm{ClAuPPh}_{3}$ & 85.7 & $\mathrm{Au}(\mathrm{l}) 100 \%$ \\
\hline 2 & $\mathrm{NaAuCl}_{4}$ & 87.6 & $\mathrm{Au}(\mathrm{III}) 100 \%$ \\
\hline 3 & Sample A & $\begin{array}{l}85.6 \\
87.4\end{array}$ & $\begin{array}{l}\mathrm{Au}(\mathrm{I}) \mathbf{8 5 . 4 \%} \\
\mathrm{Au}(\mathrm{III}) 14.6 \%\end{array}$ \\
\hline 4 & sample 1 & 85.6 & $\mathrm{Au}(\mathrm{I}) 100 \%$ \\
\hline 5 & sample 2 & $\begin{array}{l}84.2 \\
85.7\end{array}$ & $\begin{array}{l}\mathrm{Au}(0) 92.3 \% \\
\mathrm{Au}(\mathrm{l}) 7.7 \%\end{array}$ \\
\hline 6 & Sample B & $\begin{array}{l}85.6 \\
87.8\end{array}$ & $\begin{array}{l}\mathrm{Au}(\mathrm{l}) 93.6 \% \\
\operatorname{Au}(I I I)) 16.4 \%\end{array}$ \\
\hline 7 & sample 3 & $\begin{array}{l}84.4 \\
85.6 \\
87.4\end{array}$ & $\begin{array}{l}\mathrm{Au}(0) 30.1 \% \\
\mathrm{Au}(\mathrm{I}) 41.5 \% \\
\mathrm{Au}(\mathrm{III}) 28.4 \%\end{array}$ \\
\hline
\end{tabular}

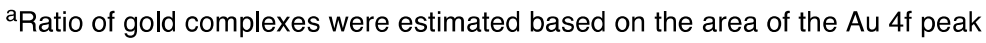

\section{High resolution ESI-Mass spectroscopy studies}

FT-ICR-MS analyses were done in a hybrid linear ion trap (LIT) FT-ICR mass spectrometer (LTQ-FT, Thermo Electron, Bremen, Germany) equipped with a TriVersa NanoMate ion source (Advion BioSciences, Ithaca, NY) with an "A" electrospray chip (nozzle inner diameter $5.5 \mu \mathrm{m}$ ) was used for mass spectral analysis. Applying $1.70 \mathrm{kV}$ with 0.1 psi head pressure operated the TriVersa NanoMate in positive ion mode. MS runs were recorded over an $\mathrm{m} / \mathrm{z}$ range from 50 to $1,000 \mathrm{Da}$ using optimized ion abundance targets enabled for the selected mass range. Initially, low-resolution LIT-MS scans were acquired for 0.50 min to track the stability of the ion spray, after which high mass 
accuracy data were collected using the FTICR- MS analyzer where MS scans were acquired for $3 \mathrm{~min}$ at a target resolving power of $\mathrm{m} / \Delta \mathrm{m}=200,000$ at $\mathrm{m} / \mathrm{z}=400(10 \%$ valley).

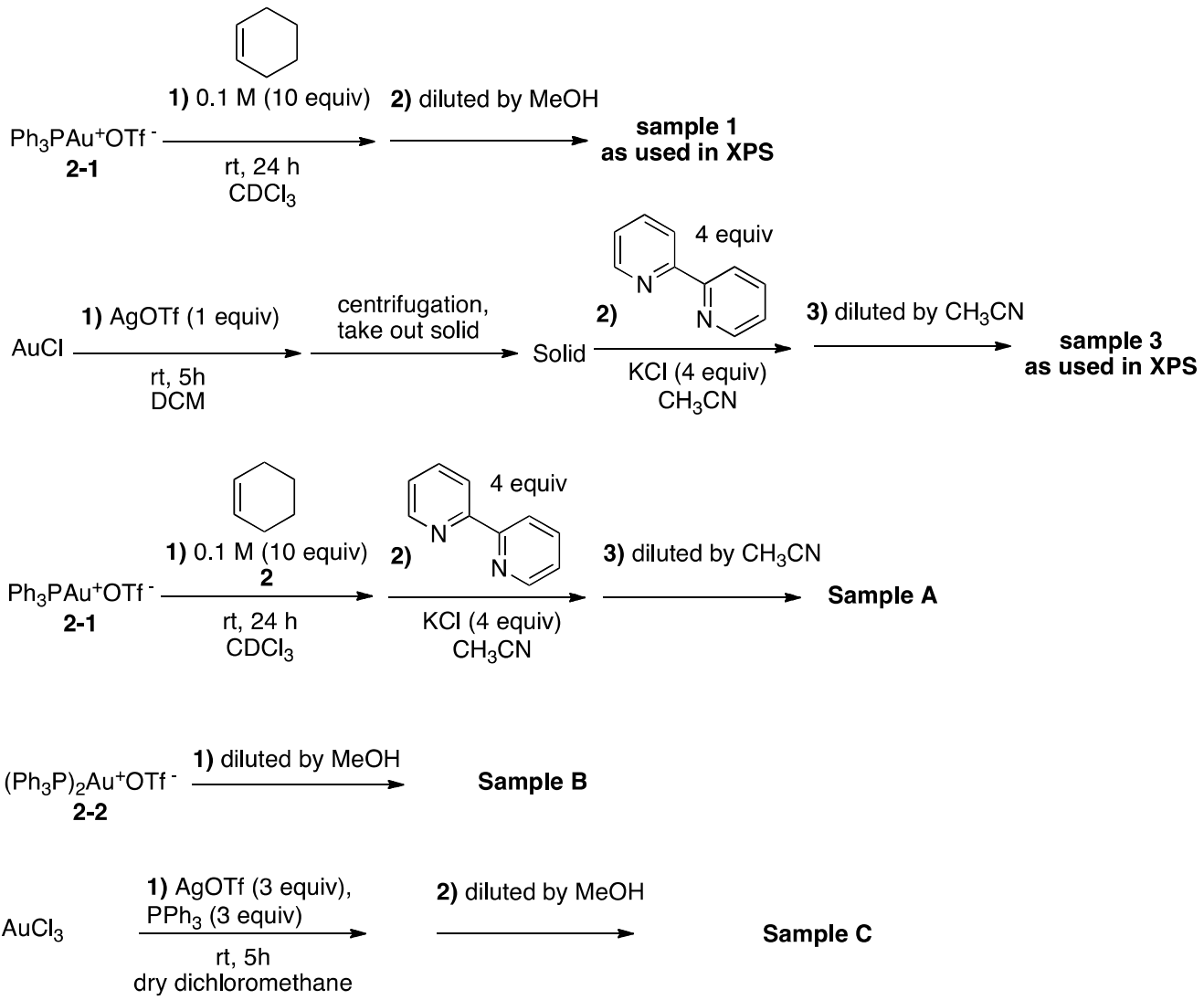

\section{Scheme 10. Sample preparations for ESI-MS.}

Five "microscans" (ICR-MS transients) were accumulated before Fourier transformation to produce each saved spectrum; thus the cycle time for each transformed, saved spectrum was about $5 \mathrm{~s}$. The LTQ-FT was tuned and calibrated according to the manufacturer's default standard recommendations, which typically achieved better than $0.5 \mathrm{ppm}$ mass accuracy at a resolving power of 200,000 at $\mathrm{m} / \mathrm{z}=400$. FT-ICR-MS mass spectra were centroided by Xcalibur and exported as exact mass lists into an Excel file using QualBrowser 2.0 SR2 (all software from Thermo Electron,"Bremen" version for 
the LTQ-FT).

The mildness of ESI-MS allows direct sampling from the reaction mixture. Because cationic gold intermediates are charged species, they are especially suited for ESI-MS analysis. The samples were prepared (Scheme 10) for ESI-MS analysis.

\section{Electrochemical (Voltammetry) studies}

Electrochemical measurements were carried out in a $10 \mathrm{~mL}$ custom designed cell that was designed by E. Bothe of the Max-Planck Institute für Bioanorganische Chemie, Mülheim, Germany. ${ }^{118}$ The cell is equipped with quartz windows with a $0.5 \mathrm{~cm}$ path length. The sample holder and cell were connected in a series to a circulating bath. To prevent condensation of the quartz cell during low-temperature measurements, the cell holder and the cell were placed in custom-built Plexiglas box fitted with Dynasil 4000 quartz windows (Pacific Quartz), through which nitrogen gas was purged. All measurements were recorded in dry, freshly distilled dichloromethane containing $0.1 \mathrm{M}$ tetrabutylammonium hexafluorophosphate (TBAHFP) as a supporting electrolyte. A platinum electrode-working electrode $\left(\right.$ area $=0.071 \mathrm{~cm}^{2}$ ) was used for cyclic voltammetry methods. In all cases, a Pt counterelectrode and an $\mathrm{Ag} / \mathrm{AgCl}$ reference electrode was used. All data is scaled to ferrocenium/ferrocene. Cyclic voltammetry (CV) experiments were conducted on samples at room temperature with an analyte concentration of $2 \mathrm{mM}$. For each scan rate, a background voltammogram was collected on the solvent and supporting electrolyte prior to sample addition. 


\section{CHAPTER 3. ENHANCED REACTIVITY IN HOMOGENEOUS GOLD CATALYSIS THROUGH HYDROGEN BONDING}

\subsection{Background}

It is well established that most gold-catalyzed reactions go through two major stages (Scheme 11). ${ }^{28}$ In stage 1 (from $\mathrm{L}-\mathrm{Au}^{+}$to $\mathbf{C}$ ) a nucleophile attacks a gold alkyne/alkene $\eta^{2}$-complex $\mathbf{B}$ to generate a charged gold intermediate $\mathbf{C}$. In stage 2, C is converted to product with concomitant regeneration of the cationic gold species via protodeauration (protodeauration means addition of proton to the place

from where the removal of gold catalyst take place to regenerate cationic gold). ${ }^{119}$ If $\mathbf{C}$ contains a relatively basic heteroatom (e.g. nitrogen) it may be reluctant to relinquish its proton.

A positively charged intermediate $\mathbf{C}$ is aversed to undergo protodeauration because its positive charge is a deterrent for an incoming proton. Indeed, many charged vinyl gold species have been isolated (e.g. Au-2) because they have shown high resistance towards protodeauration. ${ }^{120-122}$ The turnover limiting stage for many gold catalyzed reactions actually occurs in the protodeauration stage (stage 2). ${ }^{29}$ In this chapter, we investigated a new strategy to enhance the efficacy of gold catalyzed reactions through hydrogen-bonding assisted protodeauration, using 
additives chosen by their $p \mathrm{~K}_{\mathrm{BHX}}$ (hydrogen-bond basicity) ${ }^{123}$ rather than by their $p \mathrm{~K}_{\mathrm{a}}$

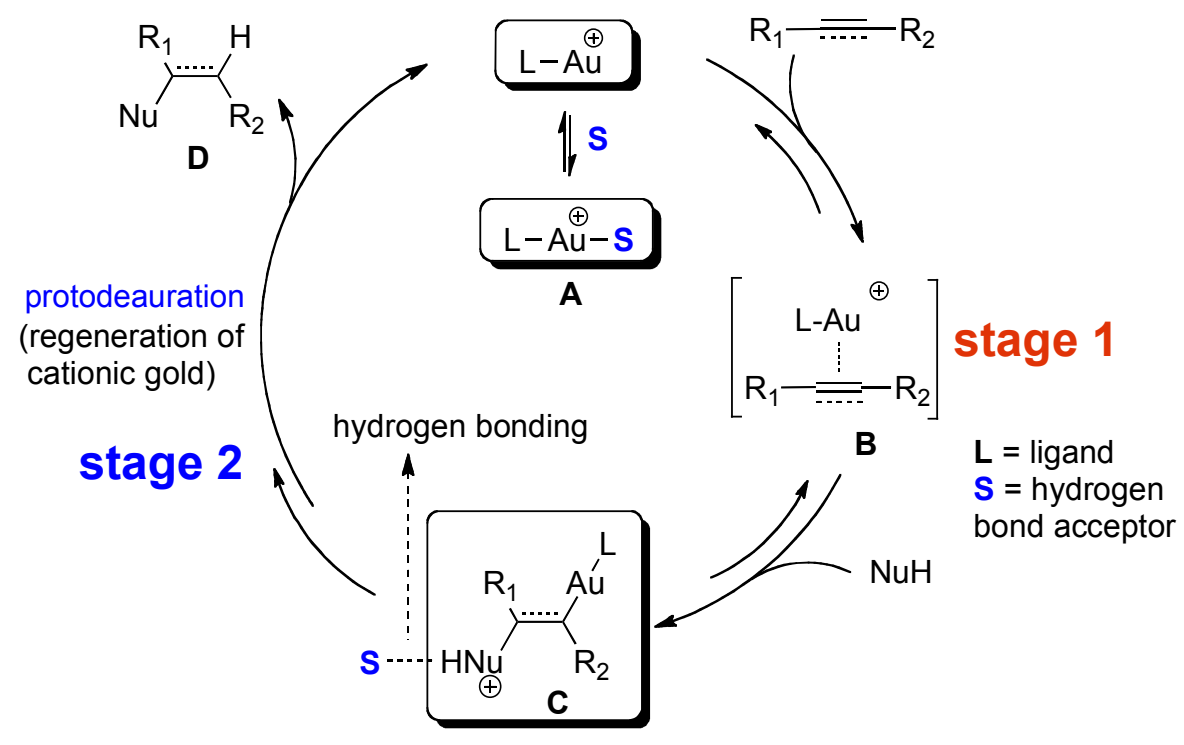

Scheme 11. Stages in the gold catalytic cycle.

The hydrogen bond is one of the fundamental noncovalent interactions between a drug molecule and its local environment in biological system. Despite its importance, scientists in the medicinal chemistry community have a poor understanding of the relative basicity (i.e., strength) of hydrogen-bond acceptors. In 2009, Laurence and co-workers reported a comprehensive database of hydrogen-bond basicity (measured by $\left.p \mathrm{~K}_{\mathrm{BHX}}\right) .{ }^{123}$

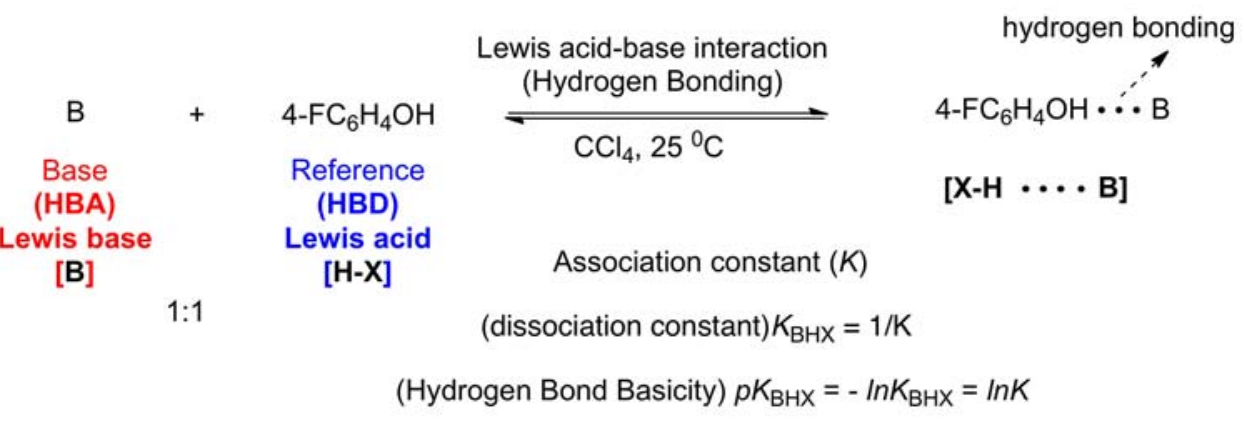

Scheme 12. Determination of hydrogen-bond basicity ( $\left.p K_{\mathrm{BHx}}\right)$. 
The hydrogen bond is an attractive interaction between a hydrogen-bond donor (HBD; Lewis acid) $\mathrm{XH}$ and a hydrogen-bond acceptor (HBA; Lewis base). Comparative measures of $p \mathrm{~K}_{\mathrm{BHX}}$ are provided by the equilibrium constants $\mathrm{K}$ for [1:1 hydrogen-bonded complex] formation for a series of (HBAs) with a common reference (HBD). Laurence chose 4-fluorophenol as a common reference (HBA; Lewis acid) to obtain $p \mathrm{~K}_{\mathrm{BHX}}$ of different compounds. Thus, the hydrogen-bond basicity of a series of bases B is measured by the 1:1 complexation constant $\mathrm{K}$ of the equilibrium given in Scheme 12. The normal range of $p \mathrm{~K}_{\mathrm{BHX}}$ is from $1-5$, a larger value indicates higher hydrogen-bond strength.

Addition of a relatively strong base has a deleterious effect in the protodeauration of $\mathbf{C}$ (Scheme 11). Although a base will remove the proton in $\mathbf{C}$, it will also quench any acid in the system and by doing so it will inhibit protodeauration.

We asked ourselves if a hydrogen bond acceptor with low basicity could be a better alternative ( $\mathbf{S}$ in Scheme 11). The nonbonding orbital of $\mathbf{S}$ will partially transfer its charge to the antibonding $\sigma^{*}$ orbital of $\mathbf{C} .{ }^{124,125}$ This effect will reduce the positive charge on $\mathbf{C}$ and cause the hydrogen bond acceptor to function as a proton shuttle, thus facilitating protodeauration. This concept is similar to general base catalysis, ${ }^{126,127}$ with $\mathbf{S}$ acting as a general base. General base catalysis is a common occurrence in biological systems where strong bases are not tolerated and where deprotonation or proton transfer is mediated by weak bases through hydrogen-bonding interaction. ${ }^{128-130}$

In gold catalysis, the role of a hydrogen bond acceptor ( $\mathbf{S}$ in Scheme 11) is more complex than that of a general base. Because $\mathbf{S}$ is aurophilic to some extent, it 
competes with an alkyne/alkene starting material in their complexation with cationic gold (Scheme 11). Hence, with regards to stage 1, $\mathbf{S}$ could be considered a reversible inhibitor. Only if the acceleration effect of $\mathbf{S}$ outweighs its inhibitory effect, the effect of $\mathbf{S}$ in the overall reaction will be positive. Thus, $\mathbf{S}$ will be useful in gold catalysis only when protodeauration is the rate-determining step.

\subsection{Results and discussion}

To implement our proposed tactic we screened a diverse group of additives using a well-studied gold catalyzed reaction in which stage 2 (protodeauration) is known to be the slow step. ${ }^{29}$ The reaction we chose was the gold-catalyzed cyclization of propargyl amide 3-1 to oxazole $\mathbf{3 - 2}^{108,109,131,132}$ because its key vinyl gold intermediate (Au-1, L = IPr) had been identified by the Hashmi group in the case of $\operatorname{gold}(\mathrm{I}),{ }^{132,133}$ and by $\mathrm{Ahn}^{120}$ in the case of $\operatorname{gold}(\mathrm{III})$ (Au-2) (Figure 13). Based on those studies, we proposed that intermediate $\mathbf{A u - 3}$ is equivalent to $\mathbf{C}$ in Scheme 11. We measured the initial reaction rate in the absence of an additive (vo), and the initial reaction rate (v) in the presence of various additives, and then calculated the ratio $\mathrm{v} / \mathrm{v} 0$ for each additive. The data shown in Figure 13 indicated that basic additives completely inhibited the reaction [e.g. $\mathbf{A 1}\left(\mathrm{Et}_{3} \mathrm{~N}, p \mathrm{~K}_{a H}=9.0\right), \mathbf{A 2}$ (imidazole, $p \mathrm{~K}_{a H}=7.1$ )]. These results are not surprising because stronger bases ought to inhibit the protodeauration step (stage 2 in Figure 13). Additives that were less basic than collidine (A3) did not inhibit the reaction, but most of them (e.g. A4-A8: alkene, phenol, sulfide, indole and acetyl imidazole) had no effect on the kinetics of the reaction $\left(\mathrm{v} / \mathrm{v}_{0}=1\right)$. We were pleased though when $N$-heterocycles, 
such as benzotriazole $\left(\mathbf{A 1 6}, \mathrm{v} / \mathrm{v}_{0}=32\right)$, indazole $\left(\mathbf{A 1 1}, \mathrm{v} / \mathrm{v}_{0}=10.3\right)$, and quinazoline $\left(\mathbf{A} 14, \mathrm{v}^{\prime} \mathrm{v}_{0}=5.1\right)$ showed dramatic acceleration effects and were astounded when pyridine $N$-oxide (A18) increased the reaction rate 168 times.

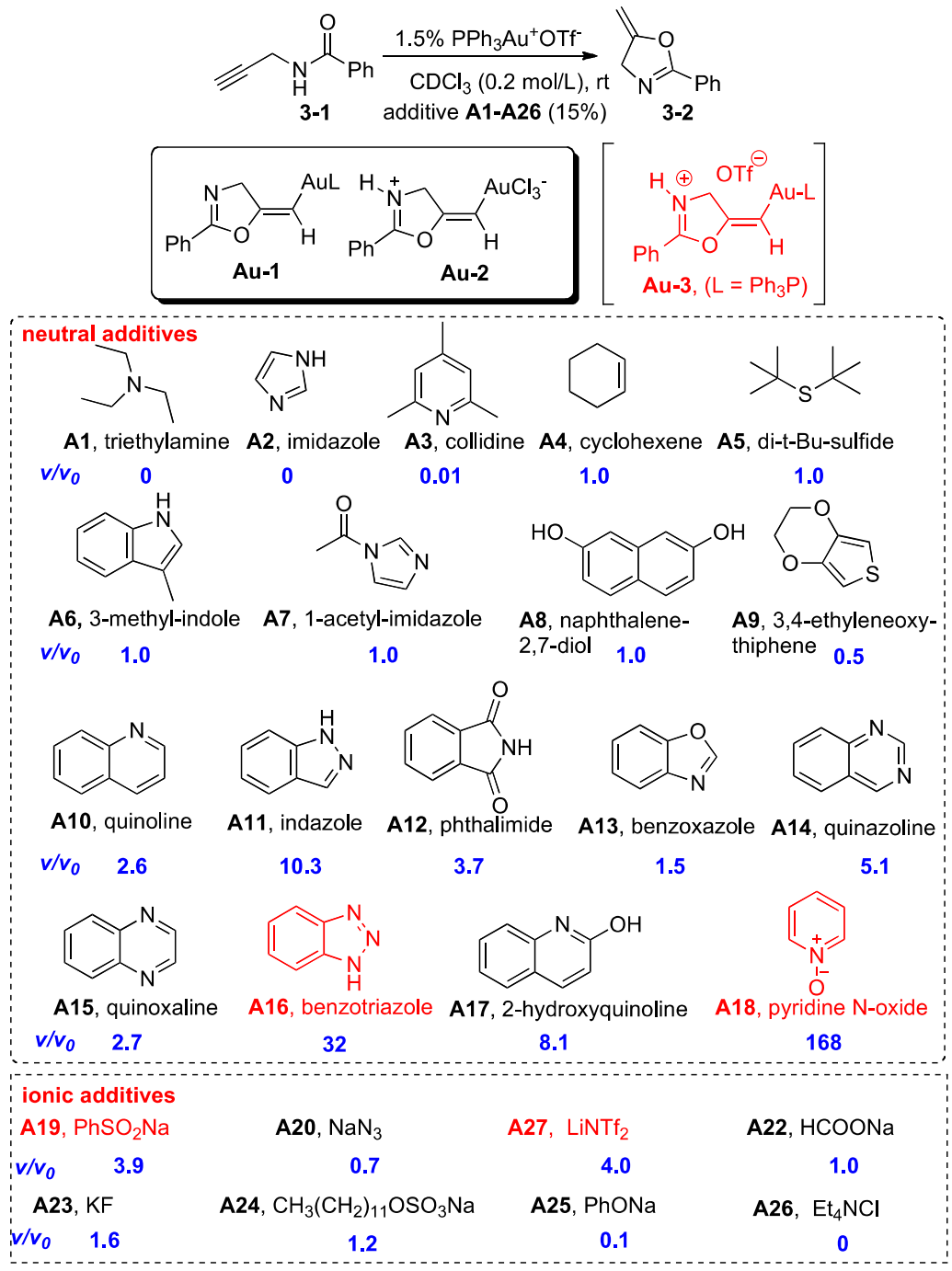

Figure 13. Survey of additive effects in the cyclization of 3-1.

The only way that benzotriazole (A16), a good hydrogen bond acceptor, could have accelerated the protodeauration of $\mathbf{A u - 3}$ is through hydrogen bonding.

We tried to verify our hypothesis in Scheme 11 more directly (Figure 14). To be confident that we had generated the protonated vinyl gold complex Au-3, we 
employed two different experimental conditions (Figure 14). In the first one, we mixed propargyl amide 3-1 with excess amounts of $\mathrm{Ph}_{3} \mathrm{PAu}^{+} \mathrm{OTf}^{-}$; the purpose of the later was to consume all the starting material 3-1, so there could be no proton acceptor left in the system (Figure 14b). For the second condition, we mixed propargyl amide 3-1 with catalytic amounts of $\mathrm{Ph}_{3} \mathrm{PAu}^{+} \mathrm{OTf}{ }^{-}$and a strong acid, $\mathrm{TfOH}$; the purpose of the strong acid was to make sure that the all the vinyl gold complex was protonated (Figure $14 \mathrm{c}$ ). When monitored by ${ }^{31} \mathrm{P}$ NMR, both conditions ended up generating a single new peak at around $45 \mathrm{ppm}$ (Figure 14b and Figure 14c).

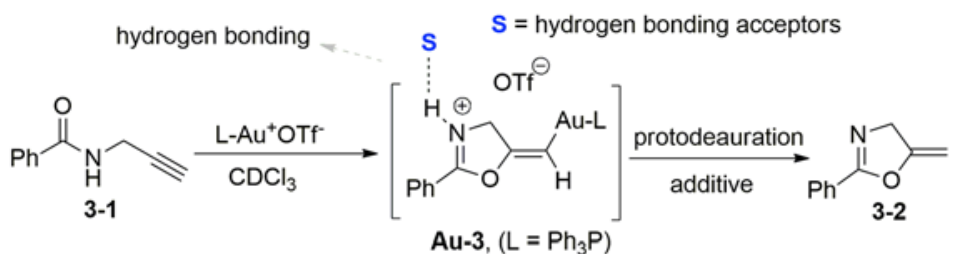

(a)

$\mathrm{Ph}_{3} \mathrm{PAu}^{+} \mathrm{OTf}$
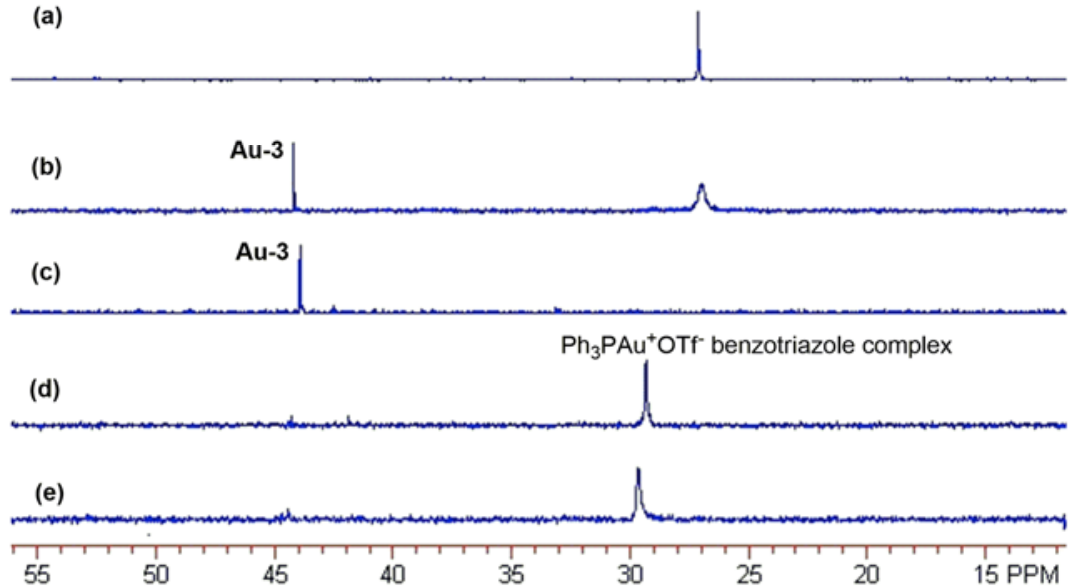

Figure 14. ${ }^{31} \mathrm{P}$ NMR study of protodeauration: a) $\mathrm{Ph}_{3} \mathrm{PAu}^{+} \mathrm{OTf}^{-}$in $\mathrm{CDCl}_{3}$; b) 5 min after mixing of $\mathrm{Ph}_{3} \mathrm{PAu}^{+} \mathrm{OTf}^{-}\left(2\right.$ equiv) with $3-1$; c) 5 min after mixing of $\mathrm{Ph}_{3} \mathrm{PAu}^{+} \mathrm{OTf}^{-}(0.05$ equiv) with $3-1$; d) 30 min after addition of benzotriazole ( 2 equiv towards gold) to b; e) 30 min after addition of benzotriazole ( 2 equiv towards gold) to c.

Because Hashmi and coworkers had isolated and identified the vinyl gold complex Au-1 $(\mathrm{L}=\mathrm{IPr})$ in the presence of base $\left(\mathrm{Et}_{3} \mathrm{~N}\right)^{132}$ and Ahn had identified the 
corresponding vinyl gold (III) complex Au-2, ${ }^{120}$ we thought reasonable to assign the new peak the structure $\mathbf{A u - 3}\left(\mathrm{L}=\mathrm{Ph}_{3} \mathrm{P}\right)$. Its characteristic vinyl proton at 5.2 ppm in ${ }^{1} \mathrm{H}-\mathrm{NMR}$ confirmed this assignment. ${ }^{134} \mathbf{A u - 3}$ is relatively stable in the two systems; both signal intensities didn't show significant change after $30 \mathrm{~min}$. This behavior indicated that their protodeauration was a relatively slow process and allowed us the possibility of testing the effect of an additive on the protodeauration of Au-3. Thus, we added 2 equiv (vs. gold) of the additive benzotriazole to both systems, and after $30 \mathrm{~min}$, the signals corresponding to Au-3 had disappeared and were replaced by a new one that corresponded to a cationic gold benzotriazole complex (Figure 14d and Figure 14e). ${ }^{135}$ In both cases, the starting material 3-1 converted to the expected product 3-2 after the additive was added, as indicated by its ${ }^{1} \mathrm{H}-\mathrm{NMR}$ spectrum (quantitative yield). These experiments clearly indicated that the additive (benzotriazole) indeed accelerated the protodeauration of protonated vinyl gold complex Au-3. The $p \mathrm{~K}_{\mathrm{aH}}$ of a protonated vinyl gold intermediate (Au-3) should be around 4.4 (based on the $p \mathrm{~K}_{\mathrm{aH}}$ of 2-phenyl-oxazoline), but our most effective additives, pyridine N-oxide $\left(p \mathrm{~K}_{\mathrm{aH}}=0.8\right)$ and benzotriazole $\left(p \mathrm{~K}_{\mathrm{aH}}<0\right)$, both have much lower $p \mathrm{~K}_{\mathrm{aH}}$. In other words, they are not basic enough to abstract the proton from a vinyl gold complex Au-3. But the hydrogen bond interaction between Au-3 and additive will reduce the positive charge on Au-3 and the hydrogen bond acceptor can act as proton shuttle and therefore facilitate protodeauration. This assumption is consistent with recent quantum mechanics calculations and experimental studies from various research groups. For example, Hashmi and co-workers proposed that in the hydration of alkynes, a cluster of 
water molecules might act as proton shuttle to facilitate the protodeauration of a protonated vinyl gold intermediate. ${ }^{130,136,137}$ Of course, in all these calculations, the assistance comes from the nucleophile, say, water or phenol; what we are proposing here is that a skillfully chosen additive may have a much greater influence.

Indeed, A16 cannot accelerate the protodeauration of a neutral vinyl gold complex (Figure 15). According to Figure 13, an additive will act as a reversible inhibitor to slow down stage 1.
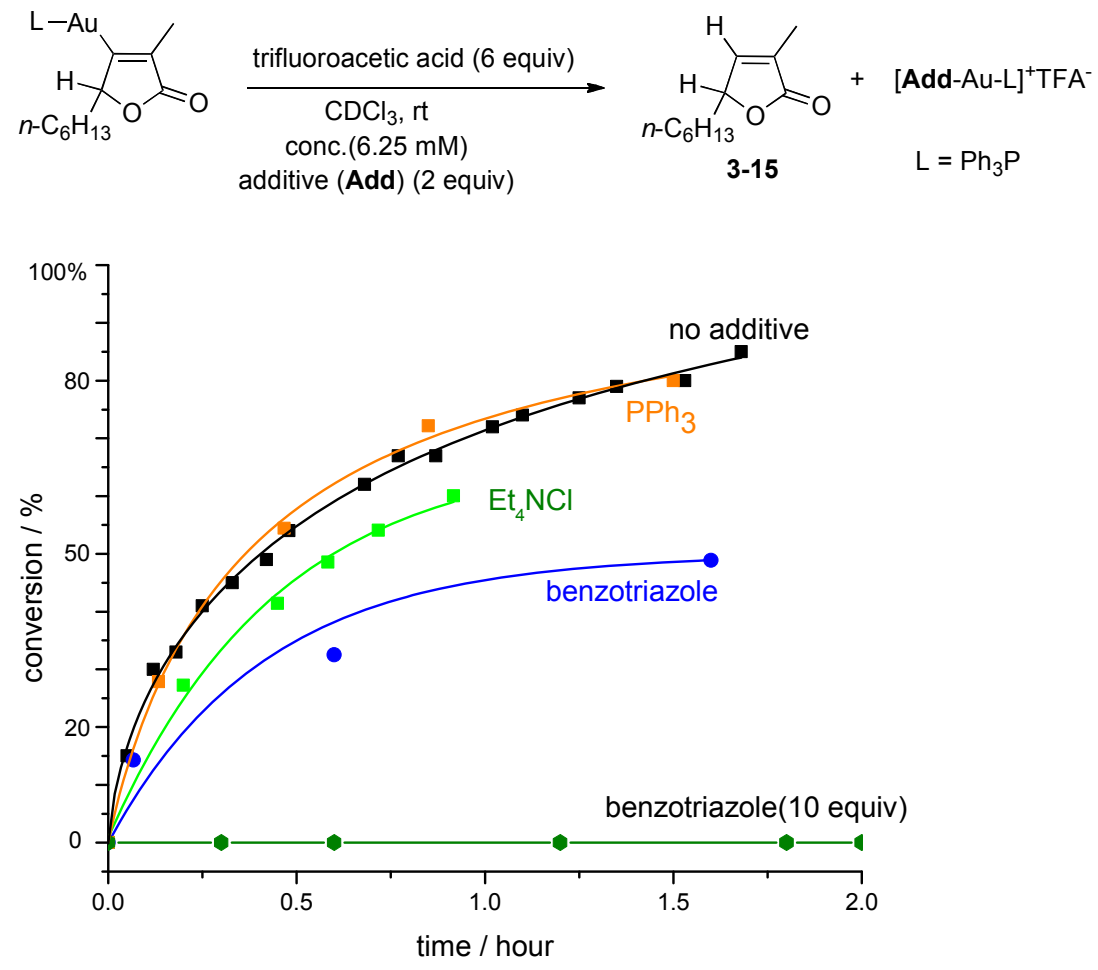

Figure 15. Additive effects on the protodeauration of Au-4

On the other hand, the cationic gold will coordinate with an additive to form a dynamic equilibrium, which will stabilize it against decay (stage 3). This was confirmed by our model reaction (Figure 15). Thus, the only reasonable 
explanation is that the additive can accelerate stage 2 (protodeauration ${ }^{119,138}$ ). Because additives with gold affinity will naturally have a tendency to complex with cationic gold, an acceleration effect on the kinetics of protodeauration may be possible because these additives would rather form a more stable cationic gold additive complex after protodeauration (e.g., $[\text { Add-Au-L }]^{+}$in ). We selected protodeauration of Au-4 as our model system because of our familiarity with this complex ${ }^{139}$ and because its reaction with acid gives a clean protodeauration product. ${ }^{29}$ We tested a number of additives, but all of them showed either similar or slower kinetic profile than the control. Even additives that are well known for their high affinity to cationic gold (e.g., $\mathrm{Ph}_{3} \mathrm{P}$, chloride) did not accelerate the protodeauration step. And when an excess amount (vs. acid) of an additive (e.g., benzotriazole) was used, the reaction was inhibited. This phenomenon can be rationalized by the competition of the additive for the proton (acid) in the reaction medium. These experimental results indicate that an additive may not be able to assist the protodeauration of neutral vinyl gold complexes based only on its affinity to cationic gold.

Although it is commonly assumed that the relative hydrogen-bond strength of an organic compound bears a simple correlation with its basicity $\left(p \mathrm{~K}_{\mathrm{aH}}\right)$, this assumption holds true only for structurally related compounds in a series. ${ }^{124,125}$ As shown in Figure 16, the lack of a discernible pattern in the graph of $\ln \left(\mathrm{v} / \mathrm{v}_{0}\right)$ (from our survey in Figure 13) vs. $p \mathrm{~K}_{\mathrm{aH}}$ underscores the fact that the $p \mathrm{~K}_{\mathrm{aH}}$ of additives is not a good forecast of their usefulness. 


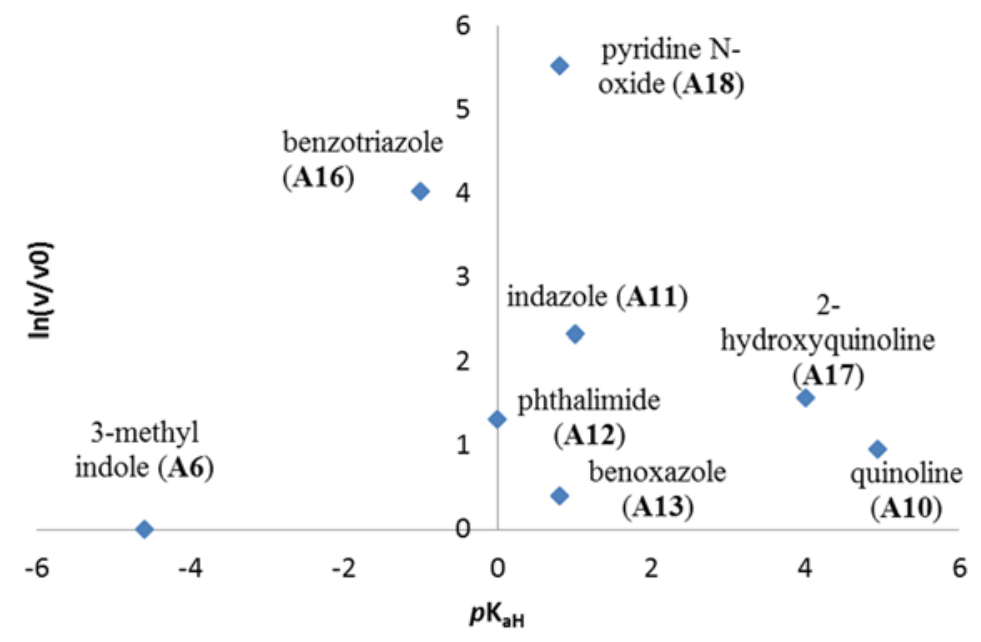

Figure 16. The activity of additives [measured by $\left.\ln \left(v^{\prime} / v_{0}\right)\right]$ vs. their basicity $\left(p K_{a H}\right)$.

Scheme 13 is showing how additives related to $p \mathrm{~K}_{\mathrm{BHX}}$ in gold-catalyzed cyclization of propargyl amide. In our case, charged vinyl gold complex acts as HBD (Lewis acid) and an additive acts as HBA (Lewis base). Using Laurence's data we were able to establish a quantitative correlation between the efficiency of an additive and its hydrogen-bond basicity (Figure 17).
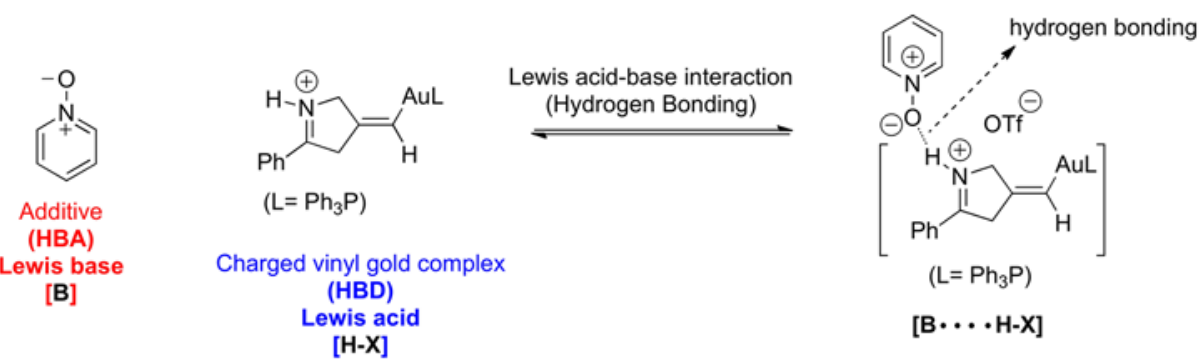

\section{Scheme 13. Hydrogen-bonding in our reaction system (cyclization of propargyl amide).}

The correlation in Figure 17 not only offers strong experimental support for the role of hydrogen bonding but it also serves as a practical guide for the selection of additives. Using Laurence's database as guide we selected other compounds that were good hydrogen bond acceptors $\left(p \mathrm{~K}_{\mathrm{BHX}}>2.6\right)$ and had low basicity $\left(p \mathrm{~K}_{\mathrm{aH}}<4\right)$, and found new hits such as DMPU, HMPA, and trimethylphosphine oxide 
$\left(v / v_{0}=18.7,23.9,30.2\right.$ respectively $)$. All these were excellent accelerators for the cyclization of 3-1 even though their structures were quite different.

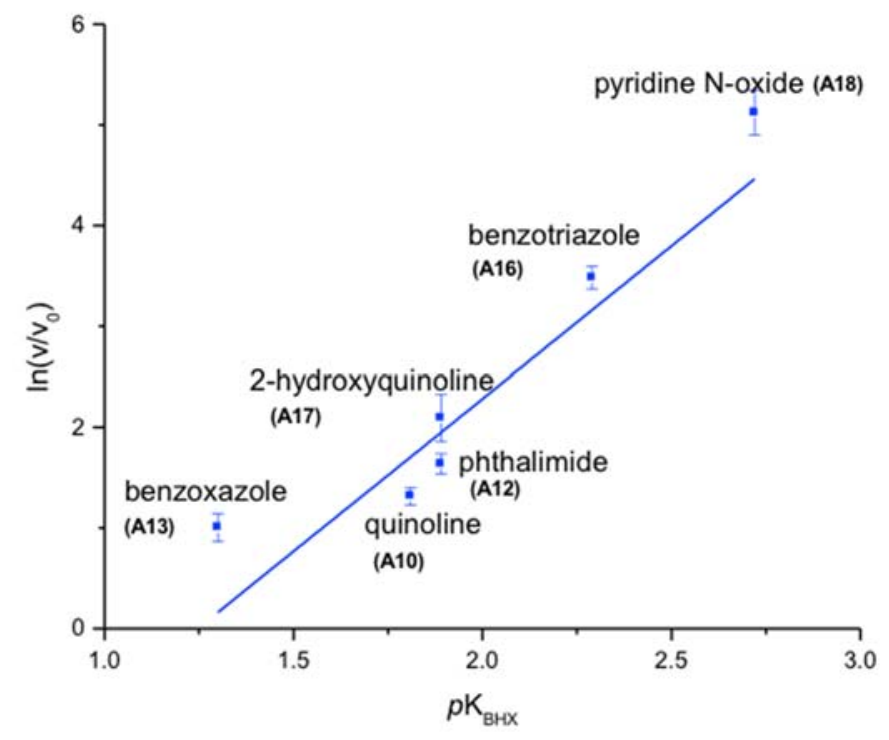

Figure 17. The activity of additives [measured by $\left.\ln \left(v / v_{0}\right)\right]$ vs. their hydrogen-bond basicity (measured by $\left.p K_{\mathrm{BHX}}\right) .{ }^{140}$

We also screened ionic additives (A19-A26) with different basicities and found that they too enhanced the kinetics of the reaction although their effects were moderate (Figure 13). Many ionic salts are also good hydrogen bonding acceptors ${ }^{123}$ but because no comprehensive $p \mathrm{~K}_{\mathrm{BHX}}$ data for ionic compounds is available, we could not correlate the reactivity of ionic additives with their $p \mathrm{~K}_{\mathrm{BHX}}$.

To increase our understanding of hydrogen bond effects we explored other gold catalyzed reactions (Scheme 14). First we investigated the intermolecular hydroamination of alkynes. ${ }^{29}$ As shown in Scheme 14a, a kinetic enhancement was observed in the presence of additives that had proven effective in the cyclization of 3-1 (e.g. pyridine $N$-oxide, benzotriazole), but the enhancement was less dramatic. We attributed this result to the fact that the starting material (amine) in the 
hydroamination is in itself a relatively good proton acceptor and also a good hydrogen bond acceptor. We also investigated the intermolecular addition of methanol to alkyne (Scheme 14b). We found that hydrogen bond acceptors with relatively high gold affinity (pyridine $N$-oxide, benzotriazole) inhibited or slowed down the reaction.
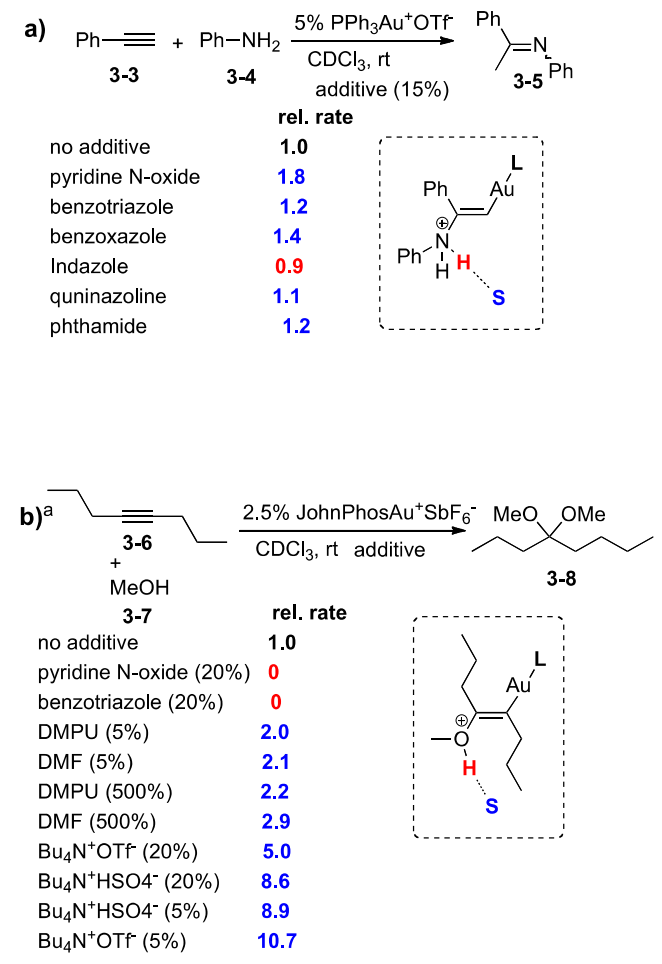
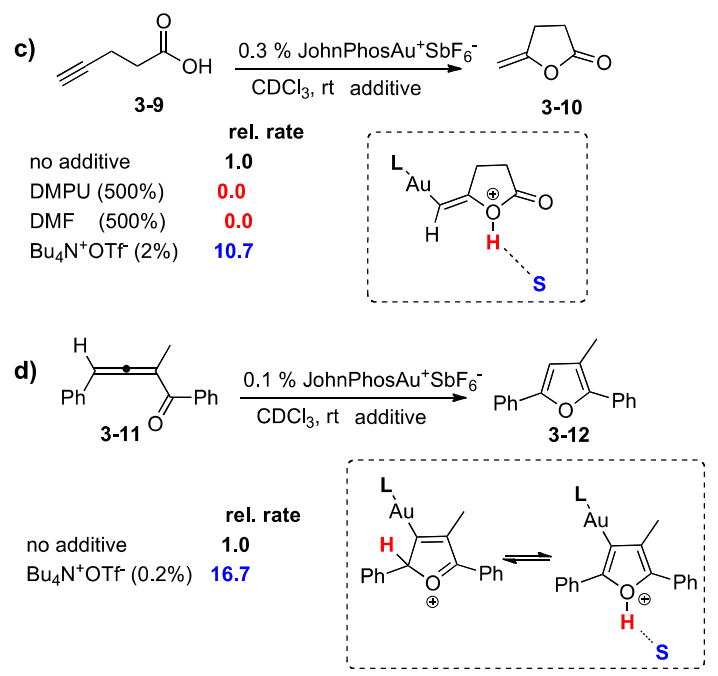

e)
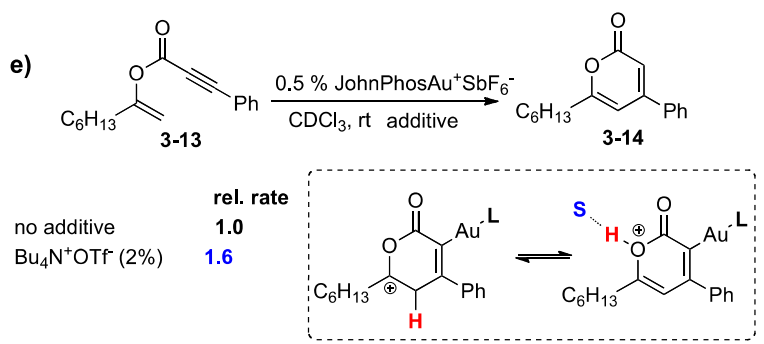

( ${ }^{\mathrm{a}}$ part of $\mathbf{6}$ was hydrolyzed to ketone by trace water).

Scheme 14. Additive effects on various gold catalyzed reactions $(S=$ hydrogen bond acceptor $)$.

This result was not surprising because stage 1 is the slow or rate-determining step in this intermolecular reaction in which the nucleophile $(\mathrm{MeOH})$ is weak compared to an amine. As expected, hydrogen bond acceptors with lower gold affinity (e.g., DMPU, DMF) ${ }^{141-148}$ enhanced the rate of reaction (Scheme 14b), and ionic hydrogen bond acceptors (e.g., $\mathrm{Bu}_{4} \mathrm{~N}^{+} \mathrm{OTf}{ }^{-}$) performed significantly better, 
possibly because of their even lower affinity towards cationic gold. Although the $p \mathrm{~K}_{\mathrm{BHX}}$ of $\mathrm{Bu}_{4} \mathrm{~N}^{+} \mathrm{OTf}{ }^{-}$was not reported in Laurence's database, the $p \mathrm{~K}_{\mathrm{BHX}}$ values of related salts, such as $\mathrm{Bu}_{4} \mathrm{~N}^{+} \mathrm{X}^{-}(\mathrm{X}=\mathrm{Cl}, \mathrm{I})$ had been tabulated $\left(p \mathrm{~K}_{\mathrm{BHX}}=2.8\right.$ and 4.2 respectively). ${ }^{123}$ These values demonstrated their good hydrogen-bond acceptor properties. Given its similarities with $\mathrm{Bu}_{4} \mathrm{~N}^{+} \mathrm{X}^{-}, \mathrm{Bu}_{4} \mathrm{~N}^{+} \mathrm{OTf}{ }^{-}$should also be a good hydrogen bond acceptor, but the latter has the added advantage of its low basicity and low affinity towards gold. We found that $\mathrm{Bu}_{4} \mathrm{~N}^{+} \mathrm{OTf}{ }^{-}$enhanced the reaction rates of other reactions like cycloisomerization of allenone $\mathbf{3 - 1 1},{ }^{149,150}$ cyclization of 4-pentynoic acid 3-9, ${ }^{151}$ and synthesis of $\alpha$-pyrone ${ }^{152}$ (Scheme 14c-e) substantially. In those reactions, neutral hydrogen bond acceptors were less effective, most likely because of their relatively high affinity towards cationic gold.

Other research groups reported that certain compounds improved the chemical yields in selected gold catalyzed reactions. ${ }^{153,154}$ One notable example is the $\mathrm{Ph}_{3} \mathrm{PAu}^{+} \mathrm{OTf}{ }^{-}$benzotriazole complex reported by Shi and coworkers; ${ }^{135,155-158}$ this complex performed better than $\mathrm{Ph}_{3} \mathrm{PAu}^{+} \mathrm{OTf}{ }^{-}$in a number of transformations, such as the Hashmi phenol synthesis or the rearrangement of propargyl esters. Our hydrogen bonding argument not only accounts for the $\mathrm{Ph}_{3} \mathrm{PAu}^{+} \mathrm{OTf}{ }^{-}$benzotriazole complex success but also offers a guide for the selection of other suitable hydrogen bond acceptors.

\subsection{Summary}

In summary, the turnover limiting stage for many gold catalyzed reactions actually occurs in the protodeauration stage. The easiness of the protodeauration stage 
depends on the stability of charged vinyl Au species in gold catalysis. Sometimes these compleses are so stable that they can be isolated and characterized by X-ray crystallography. The stability of a charged vinyl Au species limits the turnover number in catalysis because that makes protodeauration stage difficult to happen (positive charge is a deterrent for an incoming proton).

Our experimental studies support that although a strong base will remove the proton in $\mathbf{C}$, it will also quench any acid in the system and by doing so it will inhibit protodeauration. Later on, we observed that additives having high hydrogen bond acceptor capability with low basicity toward cationic gold could be better alternatives as compared to strong bases. We observed that an ideal hydrogen bond acceptor additive should have: (i) high hydrogen bonding basicity ( $p \mathrm{~K}_{\mathrm{BHX}}$ ), (ii) low basicity $\left(p \mathrm{~K}_{\mathrm{a}}\right)$, and (iii) low affinity towards cationic gold. Additives with high hydrogen bonding basicity often show high affinity towards cationic gold. In general, if stage 1 of a given reaction is very fast (as in the cyclization of 3-1), a good hydrogen bond acceptor with relatively high gold affinity (e.g., benzotriazole) will be useful because, even if it does slow down stage 1, its ability to speed up stage 2 will cause the overall reaction to be faster (because stage 1 is faster than stage 2). But if stage 1 in the target reaction is relatively slow, then the additive's high affinity towards cationic gold may slow down or inhibit the reaction. In this case, a hydrogen bond acceptor with a relatively low affinity towards cationic gold (e.g., DMPU, $\mathrm{Bu}_{4} \mathrm{~N}^{+} \mathrm{OTf}^{-}$) will be useful. Hence, the overall effectiveness of a hydrogen bond acceptor will depend on the balance between the two effects. All additives used in the study are commercially available compounds, 
a clear advantage to synthetic chemists. In conclusion, we investigated a new strategy to enhance the efficacy of gold catalyzed reactions through hydrogenbonding assisted protodeauration, using additives chosen by their $p \mathrm{~K}_{\mathrm{BHX}}$ (hydrogen-bond basicity) rather than by their $p \mathrm{~K}_{\mathrm{a}}$. In the future, we would like to explore the application of the hydrogen bond basicity concept to other metal catalysis and organocatalysis. The work described in this chapter was published in Org. Lett. 2014, 16, 636-639.

\subsection{Experimental}

\section{General}

${ }^{1} \mathrm{H},{ }^{13} \mathrm{C}$ and ${ }^{31} \mathrm{P}$ NMR spectra were recorded at 400, 100 and $162 \mathrm{MHz}$ respectively, using $\mathrm{CDCl}_{3}$ as a solvent. The chemical shifts are reported in $\delta(\mathrm{ppm})$ values relative to $\mathrm{CHCl}_{3}\left(\delta 7.26 \mathrm{ppm}\right.$ for ${ }^{1} \mathrm{H} \mathrm{NMR}$ and $\delta 77.0 \mathrm{ppm}$ for $\left.{ }^{13} \mathrm{C} \mathrm{NMR}\right)$ and $\mathrm{CFCl}_{3}\left(\delta 0 \mathrm{ppm}\right.$ for ${ }^{19} \mathrm{~F}$ NMR), multiplicities are indicated by $\mathrm{s}$ (singlet), $\mathrm{d}$ (doublet), t (triplet), q (quartet), p (pentet), h (hextet), m (multiplet) and br (broad). Coupling constants, $J$, are reported in Hertz. Coupling constants are reported in hertz $(\mathrm{Hz})$. All air and/or moisture sensitive reactions were carried out under argon atmosphere. Solvents (tetrahydrofuran, ether, dichloromethane and DMF) were chemically dried using a commercial solvent purification system. All other reagents and solvents were employed without further purification. The products were purified using a CombiFlash system or a regular glass column. TLC was developed on Merck silica gel 60 F254 aluminum sheets. All the commercial phosphine ligands were purchased from Aldrich or Strem. 


\section{General procedure for kinetic experiments using in situ NMR spectroscopy}

Standard stock solutions of catalyst were made by weighing the L-Au(I)Cl complex into a vial and adding corresponding deuterated solvent, then 1.2 equiv of $\mathrm{Ag}^{\mathrm{I}} \mathrm{OTf}$ was added, the vial was sonicated for 3-5 min at room temperature, then the vial was centrifuged and filtered through a pad of Celite 545. The model reaction was conducted in a NMR tube equipped with a screw cap and septum. All reactions were monitored using a Varian $400 \mathrm{MHz}$ NMR Spectrometer with the capacity to adjust the probe temperature and with robotic sample changer.

When ${ }^{31} \mathrm{P}$ NMR was used to monitor the progress of reaction, $85 \% \mathrm{H}_{3} \mathrm{PO}_{4}$ (sealed in a capillary tube) was used as external standard for NMR integration. When ${ }^{1} \mathrm{H}$ NMR was used to monitor the progress of a reaction, a solution of tetramethylsilane in $\mathrm{CDCl}_{3}$ (sealed in a capillary tube) was used as external standard for NMR integration. In some cases, 1,3,5-tri-tert-butylbenzene (internal standard) was used. The reactions were monitored by single pulse ${ }^{1} \mathrm{H}$ NMR. The concentrations of substrate and product were determined by relative integration to the t-butyl peak in the standard (tetramethylsilane or 1,3,5-tri-tert-butylbenzene).

\section{General synthesis of starting materials.}

Gold complexes. All gold complexes (L-AuCl) were synthesized using a slightly modified version of a literature method. ${ }^{116}$ These complexes were prepared via the following general procedure: Sodium tetrachloroaurate(III) dihydrate $(1 \mathrm{mmol})$ was dissolved in water, and the orange solution was cooled in ice. To this solution, 
2,2'-thiodiethanol (3 mmol) was slowly added (ca. $45 \mathrm{~min}$ ) with stirring. A solution of the phosphine ligand $(1 \mathrm{mmol})$ in $\mathrm{EtOH}$ (if the ligand could not be dissolved, more EtOH was used) was added dropwise to yield a white solid. The solid was filtered off, washed with water and then $\mathrm{EtOH}$, and dried in vacuum.

Compound 3-1 was synthesized using literature methods ${ }^{108,109,131,132}$ and ${ }^{1} \mathrm{H}-\mathrm{NMR}$ of obtained product 3-2 is consistent with literature reports. ${ }^{108,109,131,132}$ Compound 3-11 was synthesized using literature method ${ }^{149,150,159}$ and ${ }^{1} \mathrm{H}-\mathrm{NMR}$ of obtained product 3-12 is consistent with literature reports. ${ }^{149,150,159}$ Compound 3-13 was synthesized using literature method ${ }^{152}$ and ${ }^{1} \mathrm{H}-\mathrm{NMR}$ of obtained product 3-14 is

consistent with literature reports. ${ }^{152}{ }^{1} \mathrm{H}-\mathrm{NMR}$ of obtained product 3-10 is consistent with literature report. ${ }^{151}$

All other starting materials are commercial available from Aldrich, Alfa Aecar and Acros.

\section{Determination of the initial reaction rate for the cyclization of propargyl amide 3-1.}

Determination of the initial reaction rate for the cyclization of propargyl amide 3-1 without additive: following the general procedure for kinetic experiments using in situ NMR spectroscopy, $0.15 \mathrm{~mL}$ of a standard cationic gold solution in $\mathrm{CDCl}_{3}$ $(0.01 \mathrm{M})$ and $0.35 \mathrm{~mL} \mathrm{CDCl}_{3}$ were introduced into a NMR tube, and then compound 3-1 (16 mg, $0.1 \mathrm{mmol})$ and the internal standard were introduced in its solid state. The reaction was kept at room temperature and was monitored for conversion up to $25 \%$ by single pulse ${ }^{1} \mathrm{H}$ NMR. A representative plot of [3-2] (mol/L) versus time (h) is shown in Figure 18. Because at the initial period of 

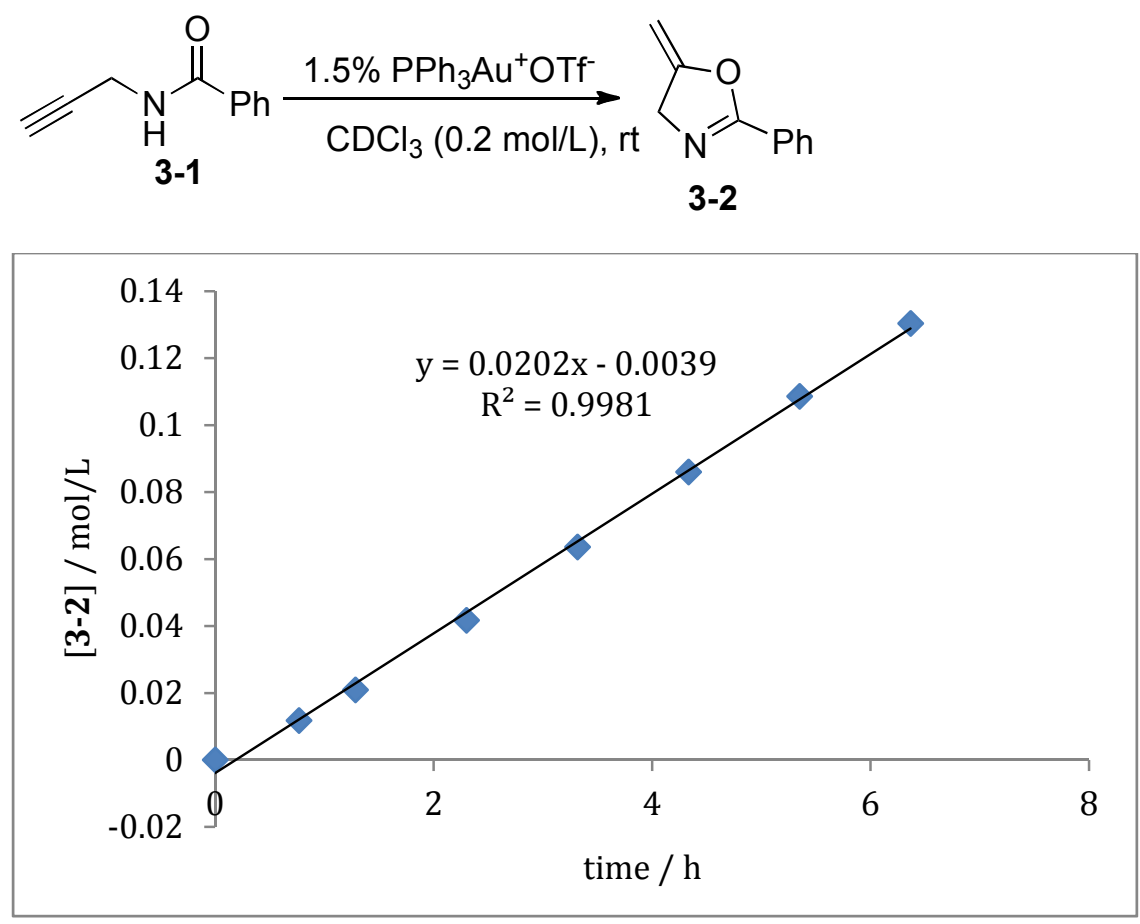

Figure 18. Determination of the initial reaction rate for the cyclization of propargyl amide 3-1. Table 3. Initial reaction rate for the cyclization of propargyl amide 3-1 in the presence of additives.

$\begin{array}{lccccccc} & \\ & & & & & & \\ \end{array}$

reaction, the kinetic curve appeared to be linear, we used linear least squares to fit the data to determine the slope (reaction rate $v_{0}$ ). Determination of $\mathrm{v}$ in the 
presence of an additive was conducted in a similar manner as above, except that the additive (15 mol\%) was introduced into the NMR tube before the introduction of the starting material 3-1 and the standard (Table 3). 


\section{CHAPTER 4. CATIONIC GOLD CATALYST POISONING AND RE-ACTIVATION}

\subsection{Background}

In kinetic studies of catalyzed reactions it is customary to study the relationship between the rate of reaction and the concentration of catalyst to learn more about the mechanism of the reaction. Although a linear correlation between the concentration of the catalyst and the initial rate data often exists when rate is plotted against concentration, numerous studies have shown that the regression line does not intersect with the origin (eq 1, A $\neq 0$; also, see Figure 19). If there is no background reaction, the rate should be zero when the catalyst concentration is zero, so A (intercept) should be zero, but this is not the case in many reactions (A is usually less than zero), ${ }^{30-32}$ indicating that a threshold catalyst concentration is required. Beyond implying some sort of catalyst poisoning, literature reports have not addressed the causes of this type of threshold. Although this phenomenon is ubiquitous in catalysis, relatively little effort has been spent on the investigation of this anomaly and the possible implications of this threshold phenomenon. ${ }^{30-32}$

$$
V=k[\text { catalyst }]+A
$$

During our research to improve the efficiency of gold catalysis, ${ }^{29,33-36}$ we found this threshold phenomenon is common in gold-catalysed reactions. We studied the correlation between rate and gold catalyst concentration in the cyclization of 
propargyl amide 4-1 (Figure 19). ${ }^{132,133}$ We found that there was a linear relationship between the rate of reaction and the concentration of gold catalyst with a negative intercept $\mathrm{A}$ (eq 1). If we extrapolate the data, the minimum gold concentration to start the reaction will be $0.9 \mathrm{mM}$, which represents a $0.9 \%$ gold loading. And indeed, the reaction didn't start at all when the catalyst loading is low (e.g. $0.3 \%$ loading). Other kinetic studies on gold catalyzed reactions showed similar trends. For example, Toste and coworkers have reported a linear relationship between rate and gold catalyst loading in the intermolecular hydroamination of allene $($ rate $=0.0423[\mathrm{Au}]-0.0355) .{ }^{32}$ Their data suggested that the minimum catalyst concentration to start the reaction was $1.2 \mathrm{mM}(0.81 \%$ loading).
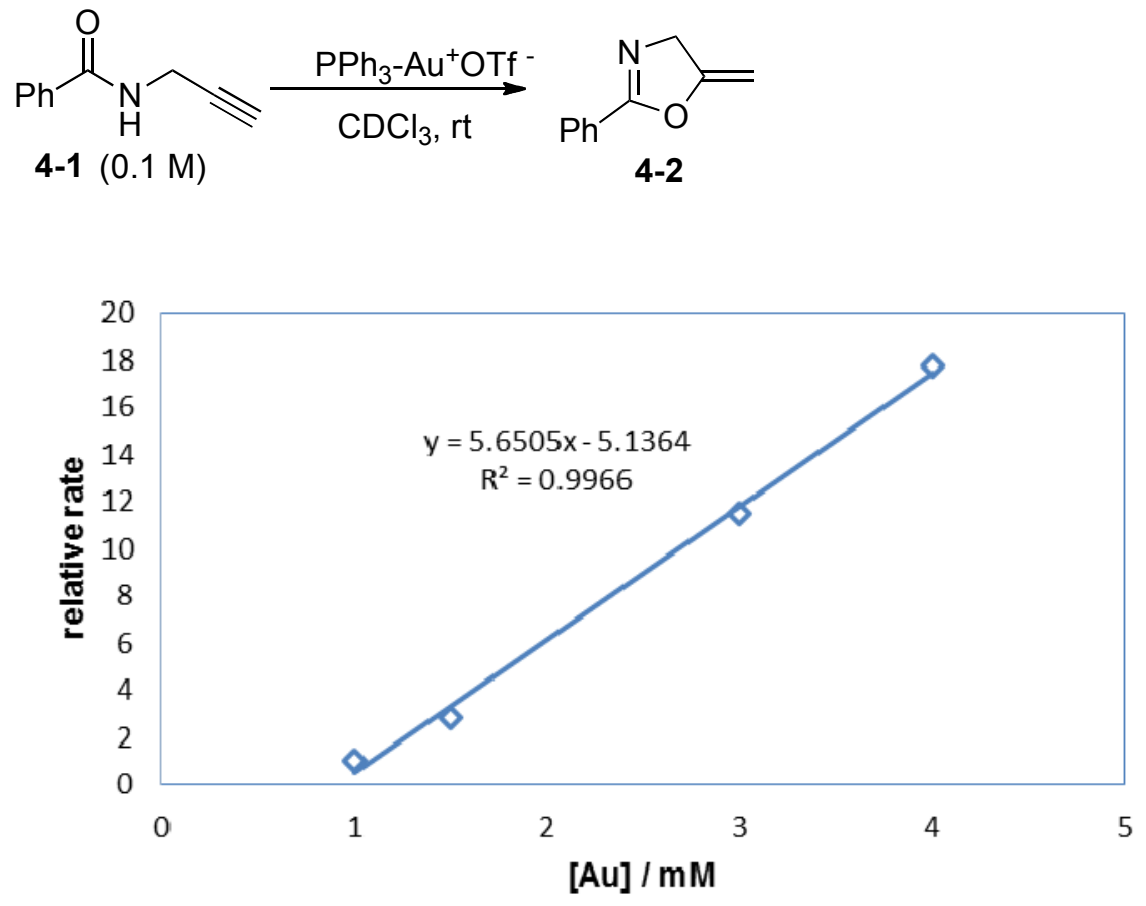

Figure 19. Correlation between rate and catalyst concentration. 
We found that the threshold phenomena mentioned above is not limited to the examples above. When we lowered the loading of the gold catalyst below a certain level, the reaction simply would not start (rate was zero for a prolonged time). This occurrence lowers the turnover number $(\mathrm{TON})$ in gold catalysis, and could be one of the main reasons why the TON in gold catalyzed reactions is generally low ( $1 \%$ or higher loading is usually required).

\subsection{Results and discussion}

A simple explanation for this threshold phenomenon is the poisoning of active catalyst. Impurities such as halides and basic alkali components are well known to contribute to catalyst poisoning in heterogeneous catalysis, ${ }^{160-162}$ but there are comparatively few studies on deactivation of homogeneous catalysts. ${ }^{163}$ Cationic gold catalyst is sought after because of its high tolerance towards moisture and oxygen (which means we can run reactions without special protection in most cases), but cationic gold has shown a very high affinity towards halides and basic components (e.g. $\left.\mathrm{OH}^{-}\right) .{ }^{147} \mathrm{~A}$ recent study by Maier and coworkers indicates that $\mathrm{OH}^{-}$or $\mathrm{Cl}^{-}$has approximately $10^{6}$ times higher affinity towards cationic gold compared to an alkyne. ${ }^{147}$

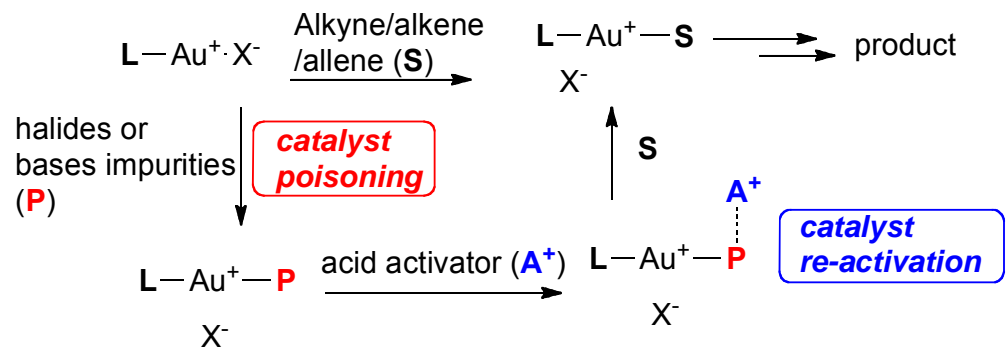

Scheme 15. Poisoning and re-activation of cationic gold catalyst. 
This means that just trace amounts of these catalyst poisons like halides and basic components, present in the solvent or starting material, are enough to block the active site of the gold catalyst (Scheme 15) and may completely inhibit the reaction when relatively relative low gold catalyst loading is used. Of course, use of highly purified starting materials and solvents may solve this problem, but we would need time-consuming purification processes, and, often, it is not possible to remove all relevant impurities even after stringent purification protocols. Use of highly purified starting materials and solvents is especially impractical in larger scale synthesis. We propose here that it is not necessary to eradicate all the traces of possible catalyst poisons; instead, the problem can be solved by directly adding a suitable acid activator to the reaction $\left(\mathrm{A}^{+}\right.$in Scheme 15). Acid activators that have high affinity towards $\mathbf{P}$ (catalyst poison) may re-activate the gold catalyst (Scheme 15). In other words, an acid activator $\left(\mathrm{A}^{+}\right)$acts as a sacrificial reagent to bind to possible catalyst poisons, so that the cationic gold is free to catalyze the reaction. Indeed, Nolan and coworkers had used Brønsted acids like HOTf to activate NHC-Au-OH complexes. ${ }^{164,165}$

We began our studies with the intramolecular hydroarylation of an alkyne ${ }^{166}$ (Figure 20). We chose this reaction because direct transformations of aromatic C$\mathrm{H}$ bonds represent a thriving field in organic chemistry, because it promotes efficient, atom economical construction of organic building blocks. We observed that when this reaction was carried at a higher gold catalyst loading ( $2 \%$ vs starting material), the reaction took place smoothly in $\mathrm{CDCl}_{3}\left(\mathrm{CDCl}_{3}\right.$ was used as received). But as we dropped down the catalyst loading to $0.2 \%$, surprisingly, the reaction 
didn't proceed at all (Figure 20). On the other hand, the reaction proceeded well at $0.2 \%$ loading using purified $\mathrm{CDCl}_{3}$ as solvent $\left(\mathrm{K}_{2} \mathrm{CO}_{3}\right.$-treated and freshly distilled). This result suggests that non-distilled $\mathrm{CDCl}_{3}$ have certain impurities (most likely chlorine/chloride containing compounds) ${ }^{167}$ that inhibit gold catalyst activity.

To make the influence of impurity in solvents more significant, we repeated the same reaction at a more diluted condition (changing [4-3] from $0.1 \mathrm{M}$ to $0.02 \mathrm{M}$, keeping gold loading at $0.2 \%$ ); the reaction still did not progress, even in freshly distilled $\mathrm{CDCl}_{3}$. The reaction performed better in $\mathrm{CD}_{2} \mathrm{Cl}_{2}$ (probably because there are less halide impurities) at $0.1 \mathrm{M}$, but when the concentration was decreased to $0.02 \mathrm{M}$, the reaction became sluggish. Catalyst poisons that either could not be completely removed by simple distillation, or were present in the starting material 4-3 itself may have caused this change of behavior.

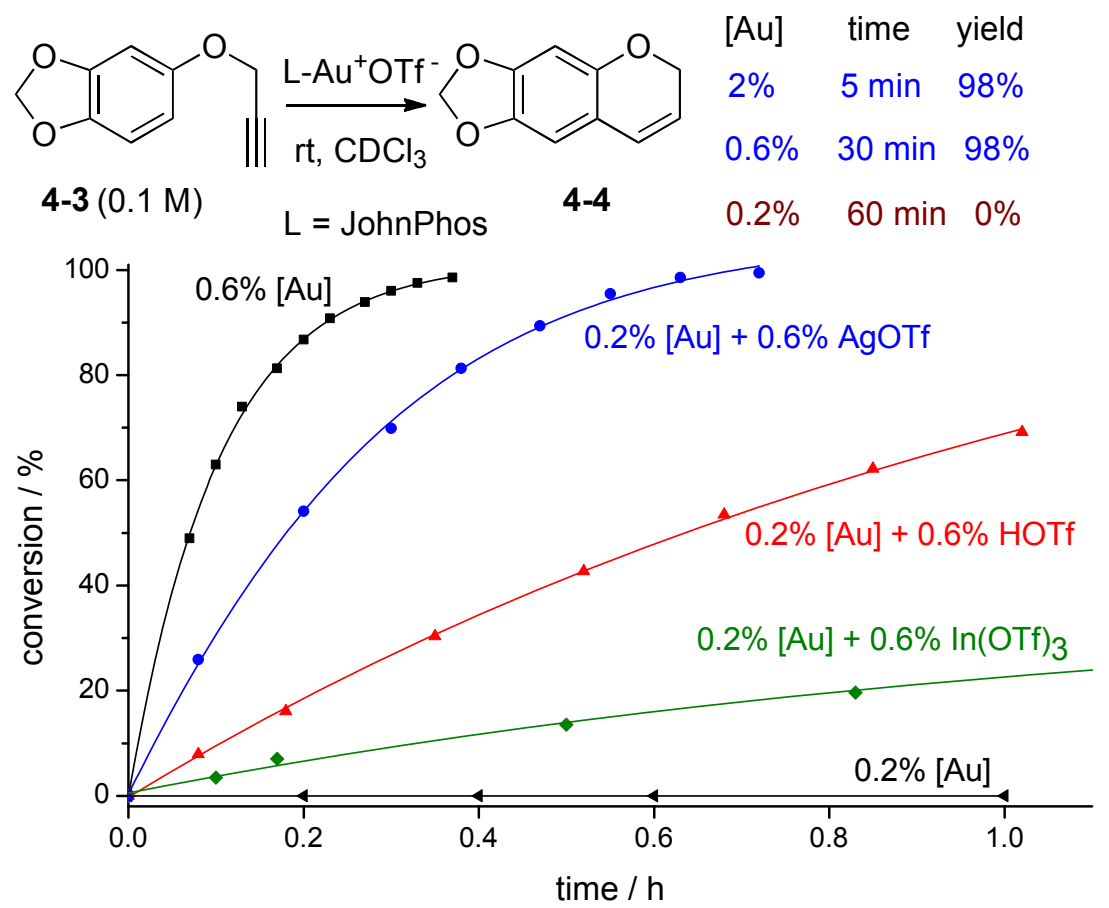

Figure 20. Influence of acid activators in alkyne hydroarylation reaction. 
Next, we inspected the effect of common Brønsted acids or Lewis acids in the reactivation of the gold catalyst (Figure 20). We found that AgOTf and $\mathrm{TfOH}$ worked very well. Other Lewis acids like $\mathrm{Ga}(\mathrm{OTf})_{3}, \mathrm{Eu}(\mathrm{OTf})_{3}, \mathrm{Y}(\mathrm{OTf})_{3}, \mathrm{Sn}(\mathrm{OTf})_{2}$, $\mathrm{Zn}(\mathrm{OTf})_{2},(\mathrm{CuOTf})_{2} \mathrm{C}_{6} \mathrm{H}_{6}$ did not show any activity in the re-activation of the gold catalyst. Moreover, we observed that the reaction didn't occur in the presence of Lewis acid or Brønsted acid alone, without gold catalyst, under, otherwise, the same conditions.

We next examined an ester assisted hydration reaction (Figure 21). ${ }^{168,169}$ We chose this reaction because it is a straightforward and atom-economical approach to the formation of carbonyl derivatives through alkyne hydration; it is not only environmentally benign, but also cost-effective.
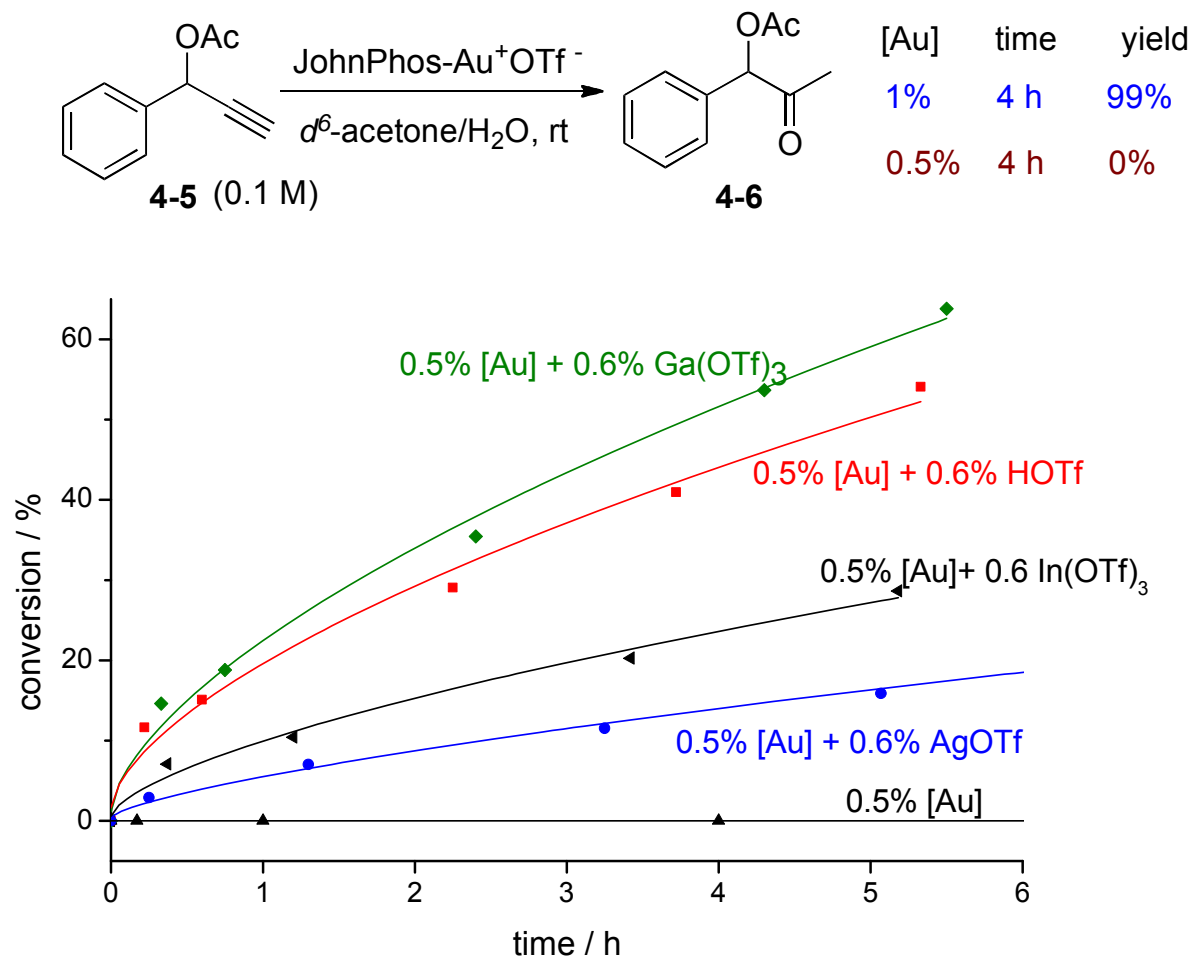

Figure 21. Influence of acid activators in hydration reaction of 4-5. 
Again, the reaction proceeded well at $1 \%$ gold loading, but when the gold loading was reduced to $0.5 \%$, the reaction did not proceed at all. Use of freshly distilled solvent (acetone) gave better results, but the reaction still did not ensue when the reaction was conducted at more diluted conditions. However, various acid activators re-started the reaction, among them, $\mathrm{Ga}(\mathrm{OTf})_{3}$ provided the best result (Figure 21).

In the cycloisomerization of enyne (Figure 22), ${ }^{170-172}$ we observed a similar effect as in previous reactions. We chose this reaction because cycloisomerizations of enynes have emerged as attractive tools for the synthesis of various types of cyclic compounds in an easy one-pot process in which a wide range of transition metal complexes can be used, either in a catalytic or stoichiometric manner.
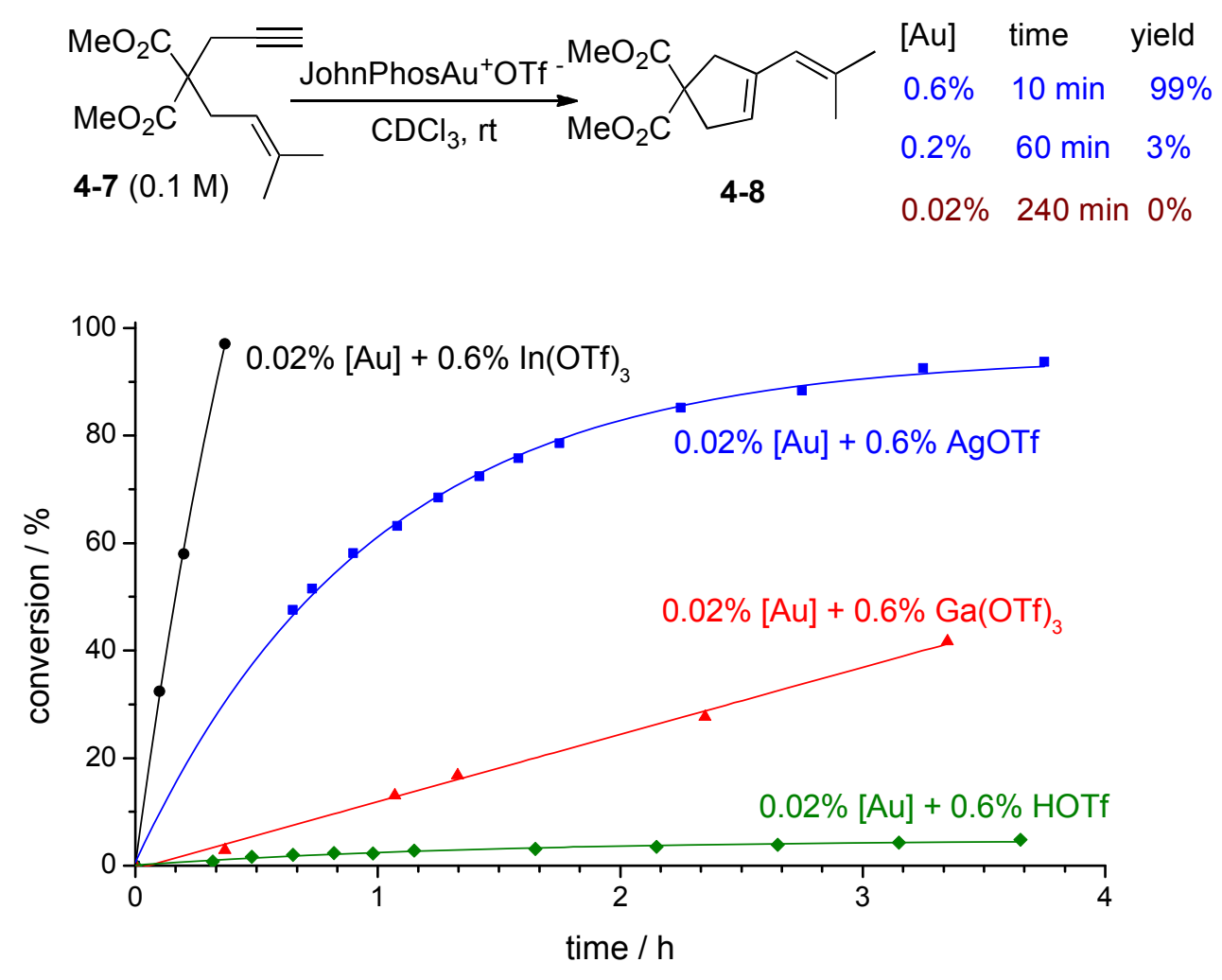

Figure 22. Influence of acid activators in cycloisomerization reaction. 
Cycloisomerization of 4-7 took place very smoothly at $0.6 \%$ catalyst loading, but it became much slower at $0.2 \%$ gold catalyst loading, and its rate decreased to zero when catalyst loading was reduced to $0.02 \%$. A Lewis acid activator, $\operatorname{In}(\mathrm{OTf})_{3}$ caused the reaction to be completed in less than $1 \mathrm{~h}$ at very low gold catalyst loading $(0.02 \%)$. In(OTf) 3 was very effective, but a Brønsted acid like HOTf was only marginally effective.

Then we focused our attention to the cyclization of hexynoic acid 4-9 (Figure 23). ${ }^{151,173} \mathrm{We}$ chose this reaction because it is a general, efficient, and convenient cyclization of alkynes bearing carboxylic acids to the corresponding lactones.
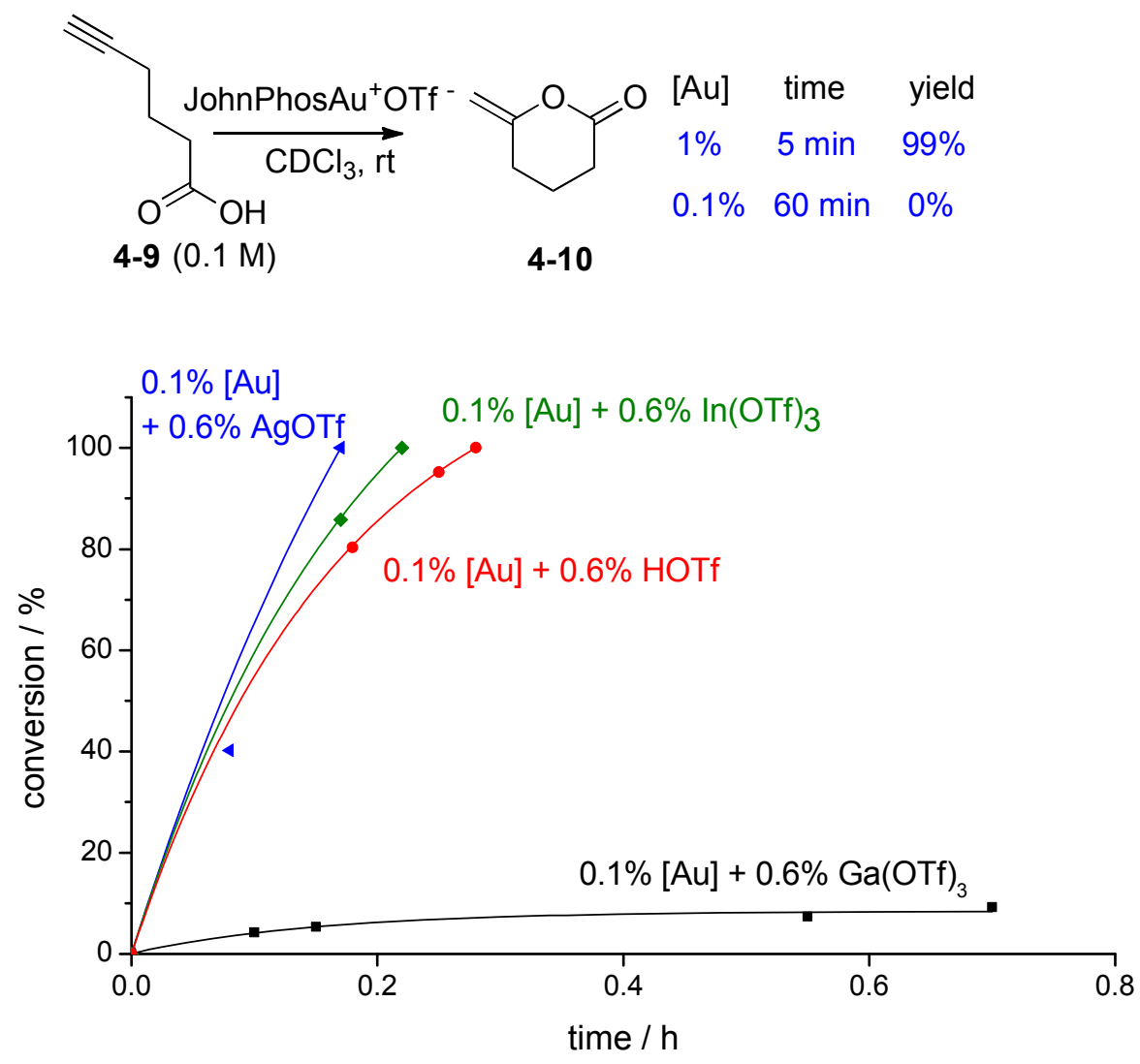

Figure 23. Influence of acid activators in cyclization of 4-9. 
Again, we observed that cyclization took place quickly at $1 \%$ gold catalyst loading, but the reaction rate dropped down to zero at $0.1 \%$ gold catalyst loading. And again, acid activators (AgOTf, $\operatorname{In}(\mathrm{OTf}) 3, \mathrm{TfOH})$ could re-activate the gold catalyst (Figure 23).

Furan has found its widest application in the synthesis of many natural products and gold catalysis play very important role as catalyst for the synthesis of furan. In the cycloisomerization of allenone 4-11 (Figure 24), ${ }^{149,159}$ the reaction with $0.2 \%$ gold catalyst loading was very fast. However, the same reaction with $0.04 \%$ catalyst loading was very sluggish.
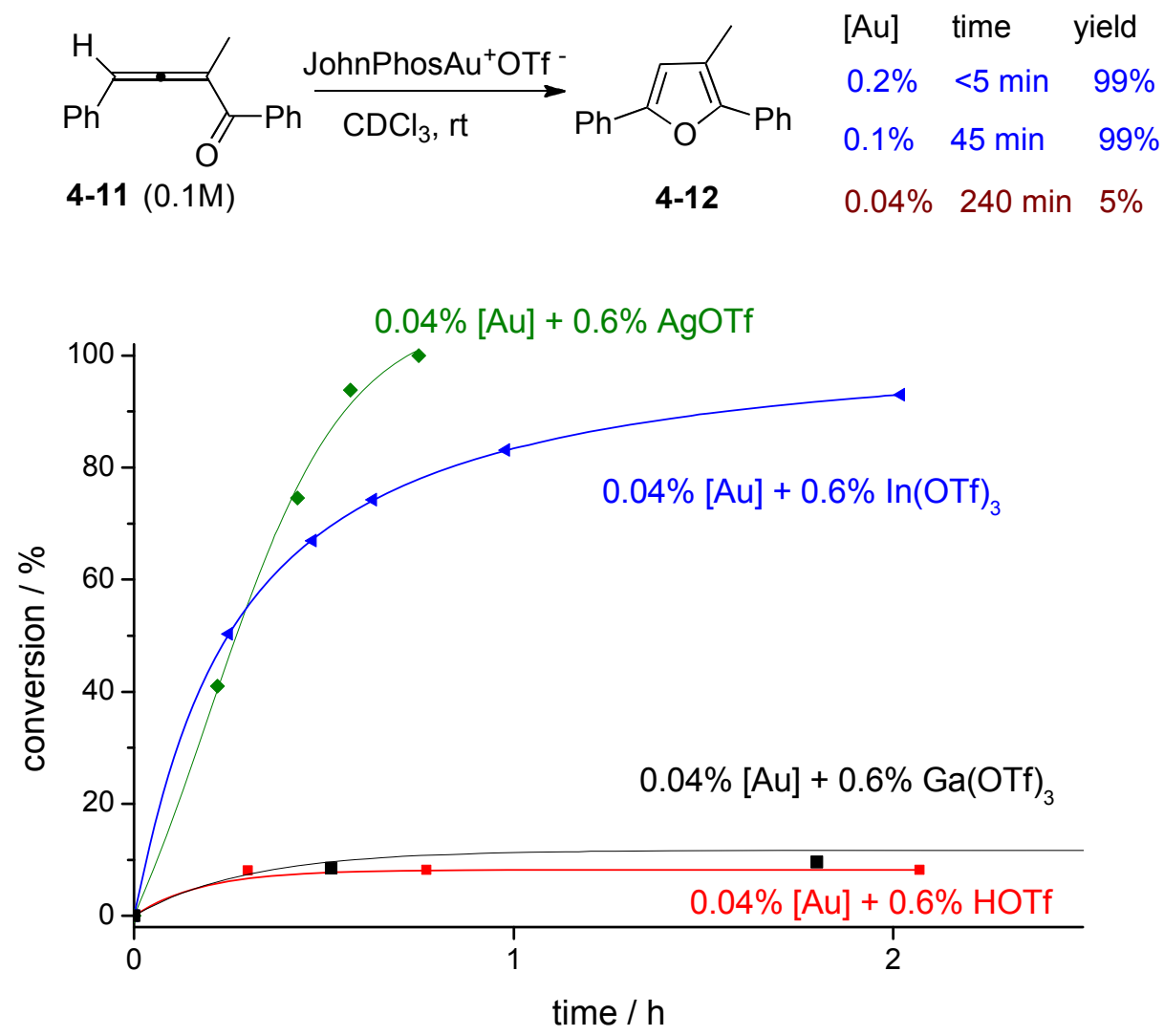

Figure 24. Influence of acid activators in cycloisomerization of 4-11. 
Activators like AgOTf and $\operatorname{In}(\mathrm{OTf})_{3}$ sped up the rate of reaction significantly; in contrast, $\mathrm{TfOH}$ and $\mathrm{Ga}(\mathrm{OTf})_{3}$ did not have much effect on the reaction rate (Figure 24).

Contamination in solvents or starting materials is not the only source of gold catalyst poisons. External reagents, such as drying agents (e.g. molecular sieves) and filtration aids (e.g. Celite) are also commonly used in synthesis. They may also contain possible gold catalyst poisons (P) like halides and alkali bases. For example, a commonly used filtration aid, Celite 545, is prepared from diatomaceous earth treated with a base - sodium carbonate (flux calcined). Indeed, the hydration of 4-5 proceeded well with untreated gold catalyst (2\%) loading (Table 4, entry 1) but when the gold catalyst (a solution in acetone) was pre-treated with molecular sieves $4 \AA$, or filtered through Celite 545, the reaction did not proceed with the same catalyst loading (Table 4, entries 2, 3).

Table 4. Influence of molecular sieves and filtration agent.

\begin{tabular}{lllll}
\hline entry & {$[\mathrm{Au}]$} & cat. pre-treatment & time & yield \\
\hline 1 & $2 \%$ & none & $3 \mathrm{~h}$ & $99 \%$ \\
2 & $2 \%$ & filteration through Celite 545 & $3 \mathrm{~h}$ & $0 \%$ \\
3 & $2 \%$ & dried over $\mathrm{MS} 4 \mathrm{~A}$ & $3 \mathrm{~h}$ & $0 \%$ \\
$4^{\mathrm{a}}$ & $0.2 \%$ & $\mathrm{Ga}(\mathrm{OTf})_{3} 0.6 \%$ added & $3 \mathrm{~h}$ & $25 \%$ \\
$5^{\mathrm{a}}$ & $0.2 \%$ & $\mathrm{Ga}(\mathrm{OTf})_{3} 0.6 \%$ added & $12 \mathrm{~h}$ & $89 \%$ \\
\hline
\end{tabular}

a catalyst from entry 3 was used. 
The inactive gold catalyst from entries 2 or 3 could be re-activated by the addition of an acid activator $\mathrm{Ga}(\mathrm{OTf})_{3}$ (Table 4, entries 4-5). These results are consistent with literature reports: $\mathrm{Yu}$ and coworkers reported that treatment of $\mathrm{Ph}_{3} \mathrm{PAu}^{+} \mathrm{OTf}{ }^{-}$ with molecular sieves led to the formation of much less reactive trigold oxonium complex $\left[\left(\left(\mathrm{Ph}{ }_{3} \mathrm{P}\right) \mathrm{Au}\right)_{3} \mathrm{O}\right]^{+} \mathrm{OTf}{ }^{-}$due to the presence of mild bases in molecular sieves. ${ }^{174}$ The loss of reactivity of the gold catalyst by Celite filtration is also consistent with a previous report by Shi and coworkers. ${ }^{169}$

We propose that the possible gold catalyst poisons are the halides, bases or other high gold affinity impurities. A direct proof would be isolation and identification of these impurities, and then investigation of these impurities on the reactivity. It is difficult to do this at this time because routine analytic tools commonly used in organic synthesis (NMR, GC-MS, HPLC-MS) are not effective. In order to give an indirect proof, we investigated the effect of halide and bases on the reactivity and ability of acidic promoters to restore the reactivity (Table 5).

Table 5. Influence of halide and base on hydration of 4-5.

\begin{tabular}{llcc}
\hline entry & additive & $4 \mathrm{~h}$ & $99 \%$ \\
\hline 1 & none & $24 \mathrm{~h}$ & $2 \%$ \\
3 & $\mathrm{Bu}_{4} \mathrm{~N}^{+} \mathrm{OH}^{-}(1 \%)$ & $24 \mathrm{~h}$ & $8 \%$ \\
4 & $\mathrm{Bu}_{4} \mathrm{~N}^{+} \mathrm{Cl}^{-}(1 \%)$ & $2 \mathrm{~h}$ & $99 \%$ \\
\hline $\mathrm{Ga}(\mathrm{OTf})_{3}(2 \%)$ added to entry 2 & $2 \mathrm{~h}$ & $99 \%$ \\
\hline
\end{tabular}


We still used hydration of 4-5 as our model reaction. Indeed, bases and halides like $\mathrm{Bu}_{4} \mathrm{~N}^{+} \mathrm{Cl}^{-}$and $\mathrm{Bu}_{4} \mathrm{~N}^{+} \mathrm{OH}^{-}$effectively inhibited the reaction (Table 5, entries 2 and 3). Similarly as Table $4, \mathrm{Ga}(\mathrm{OTf})_{3}$ effectively restored the reactivity (Table 5, entries 4 and 5).

It should be noted that the acid activators not only can re-activate the poisoned gold catalyst, but they can also positively influence the later stage in the gold catalytic cycle (e.g., protodeauration), acting as co-catalysts to speed-up the reactions. ${ }^{175}$

\subsection{Summary}

In summary, the threshold phenomenon is ubiquitous in gold catalysis; relatively little effort has been spent on the investigation of this anomaly and the possible implications of this threshold phenomenon. Threshold phenomenon means that a minimum concentration of catalyst is required to start the reaction. This occurrence lowers the turnover number (TON) in gold catalysis, and could be one of the main reasons why the TON in gold catalyzed reactions is generally low (1\% or higher loading is usually required). A simple explanation for this threshold phenomenon is the poisoning of active catalyst due to the presence of impurities such as halides $\left(\mathrm{Cl}^{-}\right)$and basic alkali components $\left(\mathrm{OH}^{-}\right)$in solvent and starting materials that block the active site of the catalyst or inhibit the reaction if low catalyst loading was used in the reaction. We proposed that, the problem can be solved by directly adding a suitable acid activator to the reaction, which acts as a sacrificial reagent to bind to possible catalyst poisons. 
Our experimental studies support that the reactions were carried smoothly at a higher gold catalyst loading. But as we dropped down the catalyst loading, surprisingly, the reactions did not proceed at all. This observation supports the catalyst poisoning that we described in the introduction. Later on, we observed that the common Brønsted acids or Lewis acids are helping in the re-activation of the gold catalyst even at low catalyst loading, which support the fact that acid activators reactivate the poisioned gold catalyst. Moreover, we also observed that contamination in solvents or starting materials is not the only source of gold catalyst poisons, but external reagents, such as drying agents (e.g. molecular sieves) and filtration aids (e.g. Celite) are also a source of poison in catalysis as described in the introduction. Furthermore, we observed that addition of impurities such as $\mathrm{Cl}^{-} \& \mathrm{OH}^{-}$in the reaction system poisoned the gold catalyst, but as we added an acid activator to the poisoned system, it re-activated the gold catalyst and completed the reaction very easily. In conclusion, high gold affinity impurities (halides, bases) in solvents, starting materials, filtration or drying agents could affect the reactivity of gold catalysts adversely, which may significantly reduce the TON of cationic gold catalyzed reactions. The use of a suitable acid activator (e.g. HOTf, In(OTf) 3 ) re-activates the gold catalyst and contributes to making the reaction proceed smoothly at low gold catalyst loading. A similar protocol could benefit other cationic metal catalysis. In future, we would like to investigate whether acid activators only serve to re-activate a poisoned catalyst, or if they also can act as a cocatalyst in gold-catalyzed reactions. The work described in this chapter was accepted in Org. Lett. 2014, 16, 3452-3455. 


\subsection{Experimental}

\section{General}

${ }^{1} \mathrm{H},{ }^{13} \mathrm{C}$, and ${ }^{31} \mathrm{P}$ NMR spectra were recorded with Varian spectrometers at 400 , $100,160 \mathrm{MHz}$ respectively, using $\mathrm{CDCl}_{3}$, dacetone as a solvent. The chemical shifts are reported in $\delta(\mathrm{ppm})$ values relative to $\mathrm{CDCl}_{3}\left(\delta 7.26 \mathrm{ppm}\right.$ for ${ }^{1} \mathrm{H}$ NMR and $(\delta$ $77.0 \mathrm{ppm}$ for ${ }^{13} \mathrm{C}$ NMR), relative to ${ }^{\mathrm{d}}$ acetone ( $\delta 2.05$ for ${ }^{1} \mathrm{H}$ NMR), multiplicities are indicated by s (singlet), $\mathrm{d}$ (doublet), $\mathrm{t}$ (triplet), q (quartet), $\mathrm{m}$ (multiplet), and br (broad). Coupling constants $(J)$ are reported in Hertz. All deuterated solvents used in the reactions were used as received. All simple solvents (e.g. dichloromethane) were chemically dried using a commercial solvent purification system. All other reagents and solvents were employed without further purification. TLC was developed on Merck silica gel 60 F254 aluminum sheets. All the commercial reagents, and solvents were purchased from Aldrich or Strem or Fisher, and used without purification except cyclohexene (cyclohexene was redistilled). FT-ICRMS - Fourier Transform-Ion Cyclotron Resonance-Mass Spectrometer was used for high resolution ESI-MS spectroscopy.

\section{Monitoring the reaction using in situ NMR spectroscopy}

When ${ }^{1} \mathrm{H}$ NMR was used to monitor the progress of a reaction, a solution of tetramethylsilane in $\mathrm{CDCl}_{3}$ (sealed in a capillary tube) was used as an external standard for NMR integration. In some cases, 1,3,5-tri-tert-butylbenzene (internal standard) was used. The reactions were monitored with ${ }^{1} \mathrm{H}$ NMR (single pulse or 1 
scan for fast reactions, 8 scans for slow reactions). Some NMR measurements were conducted using a NMR experiment array (a series of spectra measured at predetermined time intervals over a period of time by adjusting the pre-acquisition delay). NMR experiment array gives better precision for both concentration (via integration) and reaction time, because each measurement is conducted at almost identical shimming and temperature conditions.

\section{General procedure for preparation of starting materials}

\section{Synthesis of gold complexes ( $\mathrm{L}-\mathrm{AuCl})$.}

All gold complexes ( $\mathrm{L}-\mathrm{AuCl})$ were synthesized using a slightly modified version of a literature method. ${ }^{176}$ These complexes were prepared via either one of the following general procedures:

Method 1: Sodium tetrachloroaurate(III) dihydrate $(1 \mathrm{mmol})$ was dissolved in water, and the orange solution was cooled in ice. To this solution, 2,2'thiodiethanol (3 mmol) was slowly added (ca. $10 \mathrm{~min}$ ) with stirring. After stirring at $0^{\circ} \mathrm{C}$ for another $30 \mathrm{~min}$, a solution of the phosphine ligand $(1 \mathrm{mmol})$ in $\mathrm{EtOH}$ (if the ligand could not be dissolved, more EtOH was used) was added dropwise to yield a white solid. The solid was filtered off, washed with water followed by EtOH, and ultimately dried in vacuum.

Method 2: To a vial chloro(dimethylsulfide)gold(I) (1 mmol) was dissolved in dichloromethane and cooled in an ice bath. A solution of the phosphine ligand (1 mmol) in dichloromethane was added dropwise, and the resulting solution was allowed to warm to room temperature and stirred at room temperature for $3 \mathrm{~h}$. 
After TLC indicated complete consumption of the starting material, the reaction solution was concentrated to dryness under reduced pressure, and the gold complex product was further dried under high vacuum.

\section{Synthesis of starting materials.}

Compound 4-1 was synthesized using literature methods ${ }^{108,109,131,132}$ and ${ }^{1} \mathrm{H}-\mathrm{NMR}$ of obtained product 4-2 is consistent with literature reports. ${ }^{108,109,131,132}$ Compound 4-3 was synthesized using literature methods ${ }^{166}$ and ${ }^{1} \mathrm{H}-\mathrm{NMR}$ of obtained product 4-4 is consistent with literature reports. ${ }^{166}$ Compound 4-5 was synthesized using literature methods ${ }^{168}$ and ${ }^{1} \mathrm{H}-\mathrm{NMR}$ of obtained product 4-6 is consistent with literature reports. ${ }^{168}$ Compound 4-7 was synthesized using literature methods ${ }^{170}$ and ${ }^{1} \mathrm{H}-\mathrm{NMR}$ of obtained product $\mathbf{4 - 8}$ is consistent with literature reports. ${ }^{170}$ Compound 4-11 was synthesized using literature method ${ }^{152}$ and ${ }^{1} \mathrm{H}-\mathrm{NMR}$ of obtained product 4-12 is consistent with literature reports. ${ }^{152}{ }^{1} \mathrm{H}-\mathrm{NMR}$ of obtained product 4-10 is consistent with literature reports. ${ }^{149,150,159}$ All other starting materials are commercially available from Aldrich, Alfa Aecar and Acros.

\section{Preparation of cationic gold $\left(\mathrm{L}-\mathrm{Au}^{+} \mathrm{OTf}{ }^{-}\right)$stock solution.}

Standard stock solutions of cationic gold catalyst were made by weighing the L$\mathrm{Au}(\mathrm{I}) \mathrm{Cl}(0.1 \mathrm{mmol})$ complex into a vial and adding corresponding deuterated solvent, then 1.2 equiv of $\operatorname{Ag}^{\mathrm{I} O T f}(0.12 \mathrm{mmol})$ was added, the vial was sonicated for 3-5 min at room temperature, then the vial was centrifuged and the clear solution was transferred to a clean glass vial. The solution was kept in a freezer ($20^{\circ} \mathrm{C}$ ) until it was used. 
Preparation of stock solutions of activator (TfOH, AgOTf, In(OTf) 3 , and $\left.\operatorname{Ga}(\mathrm{OTf})_{3}\right)$.

Stock solutions of activator $(0.01 \mathrm{M})$ were prepared by weighing activator $(0.02$ mmol) in a glass vial and dissolved it in deuterated acetone $(2 \mathrm{~mL})$. The solution was kept in the freezer $\left(-20^{\circ} \mathrm{C}\right)$ until it was needed.

\section{Kinetic study for cyclization of 4-1 using initial rate method}

Determination of the initial reaction rate for the cyclization of propargyl amide 41: following the general procedure for kinetic experiments using in situ NMR spectroscopy, a standard solution of $\mathrm{Ph}_{3} \mathrm{PAu}^{+} \mathrm{OTf}^{-}(1 \mathrm{mM}$ to $4 \mathrm{mM}$, per aliquot) in $\mathrm{CDCl}_{3}(0.01 \mathrm{M})$ and different amount of $\mathrm{CDCl}_{3}$ were introduced into a NMR tube at four different concentrations of standard gold solution, and then compound 4-1 (8 $\mathrm{mg}, 0.1 \mathrm{M})$ and the internal standard (1,3,5-tri-tert-butyl benzene) were introduced in their solid state. The reaction was kept at room temperature and was monitored for conversion up to $20 \%$ by single pulse ${ }^{1} \mathrm{H}$ NMR. Because at the initial period of reaction, the kinetic curve appeared to be linear, we used linear least squares fit of the data to determine the slope (reaction rate $V_{\mathrm{o}}$ ).

\section{General procedure for the hydroarylation of alkyne (4-3)}

In the absence of acid activator: To a solution of alkyne 4-3 $(6.3 \mu \mathrm{L}, 0.05 \mathrm{mmol})$ in $\mathrm{CDCl}_{3}(0.484 \mathrm{~mL})$ inside the $\mathrm{NMR}$ tube, the stock solution of $\left[\mathrm{P}(t-\mathrm{Bu})_{2} O-\right.$ biphenyl] $\mathrm{Au}^{+} \mathrm{OTf}^{-}$in $\mathrm{CDCl}_{3}(10 \mu \mathrm{L}, 0.01 \mathrm{M}, 0.2 \mathrm{~mol} \%)$ was added to the reaction 
mixture in the NMR tube. Reaction was analyzed by ${ }^{1} \mathrm{H}-\mathrm{NMR}$ to monitor the progress of the reaction.

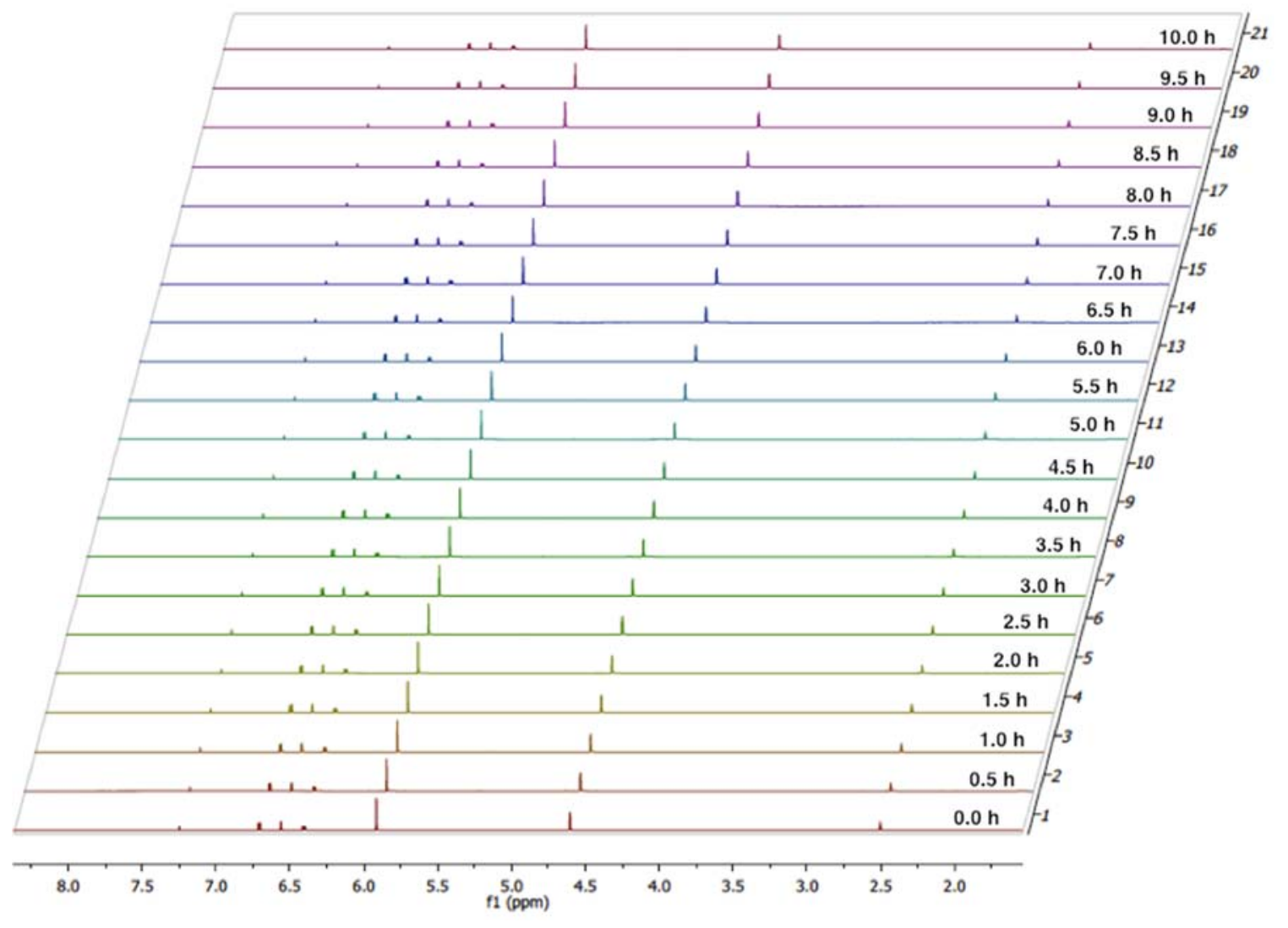

Figure 25. NMR array of hydroarylation 4-3 in the absence of acid activator.

In the presence of acid activator: To a solution of alkyne 4-3 $(6.3 \mu \mathrm{L}, 0.05$ mmol) in $\mathrm{CDCl}_{3}(0.454 \mathrm{~mL})$ inside the $\mathrm{NMR}$ tube, the stock solution of $[\mathrm{P}(t$ $\mathrm{Bu})_{20}$-biphenyl] $\mathrm{Au}^{+} \mathrm{OTf}^{-}$in $\mathrm{CDCl}_{3}(10 \mu \mathrm{L}, 0.01 \mathrm{M}, 0.2 \mathrm{~mol} \%)$ was added to the reaction mixture in the NMR tube. Different activator stock solutions $(30 \mu \mathrm{L}$, $0.01 \mathrm{M}, 0.6 \%$ ) were introduced into corresponding NMR tubes. The progress of the reaction was monitored by ${ }^{1} \mathrm{H}-\mathrm{NMR}$. 


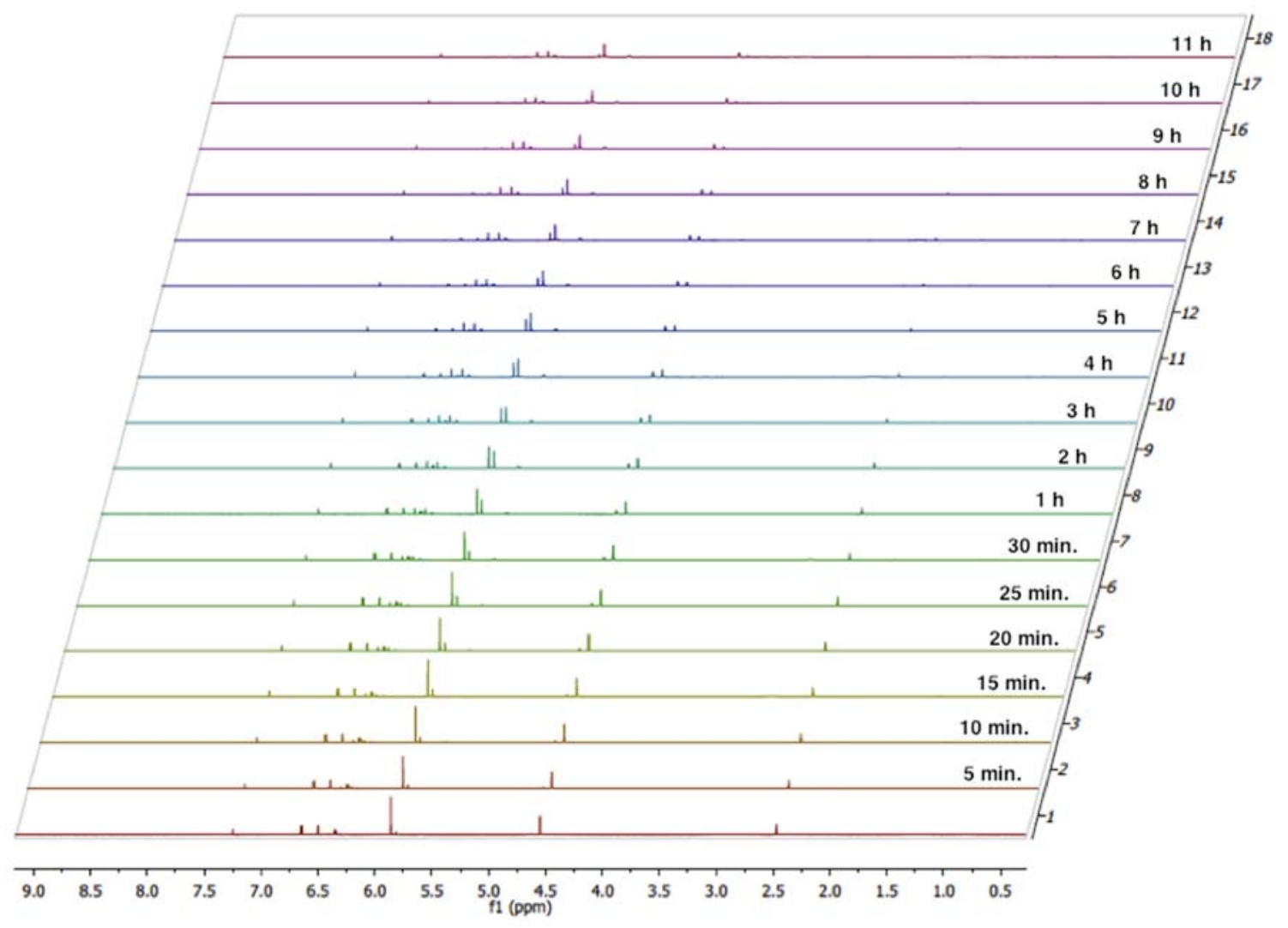

Figure 26. NMR array of hydroarylation of 4-3 in the presence of acid activators.

General procedure for the hydration of propargyl alkyne (4-5)

In the absence of acid activator: To a solution of propargyl ester 4-5 $(8.71 \mu \mathrm{L}$, $0.05 \mathrm{mmol})$ in ${ }^{d}$ acetone $(0.466 \mathrm{~mL})$ inside the NMR tube, the stock solution of $\left[\mathrm{P}(t-\mathrm{Bu})_{2} o\right.$-biphenyl $] \mathrm{Au}^{+} \mathrm{OTf}^{-}{ }^{-}$in ${ }^{d}$ acetone $(25 \mu \mathrm{L}, 0.01 \mathrm{M}, 0.5 \mathrm{~mol} \%)$ was added to the reaction mixture in the NMR tube. The progress of the reaction was monitored by ${ }^{1} \mathrm{H}-\mathrm{NMR}$.

In the presence of acid activator: To a solution of propargyl ester 4-5 (8.71 $\mu \mathrm{L}$, $0.05 \mathrm{mmol})$ in ${ }^{d}$ acetone $(0.437 \mathrm{~mL})$ inside the NMR tube. The stock solution of $\left[\mathrm{P}(t-\mathrm{Bu})_{2} o\right.$-biphenyl $] \mathrm{Au}^{+} \mathrm{OTf}^{-}{ }^{-}$in ${ }^{d}$ acetone $(25 \mu \mathrm{L}, 0.01 \mathrm{M}, 0.5 \mathrm{~mol} \%)$ was added to the reaction mixture in the NMR tube. Different activator stock solutions $(30 \mu \mathrm{L}$, 
$0.01 \mathrm{M}, 0.6 \mathrm{~mol} \%)$ were introduced into corresponding NMR tubes. The progress of reaction was monitored by ${ }^{1} \mathrm{H}-\mathrm{NMR}$.

\section{General procedure for the cycloisomerization of 1,6-enyne (4-7)}

In the absence of activator: To a solution of 1,6-enyne 4-7 (9.8 $\mu \mathrm{L}, 0.05 \mathrm{mmol})$ in $\mathrm{CDCl}_{3}(0.488 \mathrm{~mL})$ inside the NMR tube, the stock solution of $\left[\mathrm{P}(t-\mathrm{Bu})_{2} O\right.$ biphenyl] $\mathrm{Au}^{+} \mathrm{OTf}^{-}$in $\mathrm{CDCl}_{3}(2 \mu \mathrm{L}, 0.01 \mathrm{M}, 0.04 \mathrm{~mol} \%)$ was added to the reaction mixture in the NMR tube. The progress of the reaction was monitored by ${ }^{1} \mathrm{H}-\mathrm{NMR}$.

In the presence of acid activator: To a solution of 1,6-enyne 4-7 (9.8 $\mu \mathrm{L}, 0.05$ mmol) in $\mathrm{CDCl}_{3}(0.458 \mathrm{~mL})$ inside the NMR tube, the stock solution of $[\mathrm{P}(t-$ $\mathrm{Bu})_{2} o$-biphenyl] $\mathrm{Au}^{+} \mathrm{OTf}-$ in $\mathrm{CDCl}_{3}(2 \mu \mathrm{L}, 0.01 \mathrm{M}, 0.04 \mathrm{~mol} \%)$ was added to the reaction mixture in the NMR tube. Different activator stock solutions $(30 \mu \mathrm{L}$, $0.01 \mathrm{M}, 0.6 \mathrm{~mol} \%)$ were introduced into corresponding NMR tubes. The progress of the reaction was monitored by ${ }^{1} \mathrm{H}-\mathrm{NMR}$.

\section{General procedure for the cyclization of hexynoic acid (4-9)}

In the absence of acid activator: To a solution of hexynoic acid 4-9 $(6.25 \mu \mathrm{L}$, $0.05 \mathrm{mmol})$ in $\mathrm{CDCl}_{3}(0.489 \mathrm{~mL})$ inside the NMR tube, the stock solution of $[\mathrm{P}(t-$ $\mathrm{Bu})_{2}$ o-biphenyl] $\mathrm{Au}^{+} \mathrm{OTf}-{ }^{-}$in $\mathrm{CDCl}_{3}(5 \mu \mathrm{L}, 0.01 \mathrm{M}, 0.1 \mathrm{~mol} \%)$ was added to the reaction mixture in the NMR tube. The progress of the reaction was monitored by ${ }^{1} \mathrm{H}-\mathrm{NMR}$.

In the presence of acid activator: To a solution of hexynoic acid 4-9 $(6.25 \mu \mathrm{L}$, $0.05 \mathrm{mmol})$ in $\mathrm{CDCl}_{3}(0.459 \mathrm{~mL})$ inside the NMR tube, the stock solution of $[\mathrm{P}(t-$ 
$\mathrm{Bu})_{2} o$-biphenyl] $\mathrm{Au}^{+} \mathrm{OTf}{ }^{-}$in $\mathrm{CDCl}_{3}(5 \mu \mathrm{L}, 0.01 \mathrm{M}, 0.04 \mathrm{~mol} \%)$ was added to the reaction mixture in the NMR tube. Different activator stock solutions $(30 \mu \mathrm{L}$, $0.01 \mathrm{M}, 0.6 \mathrm{~mol} \%$ ) were introduced into corresponding NMR tubes. The progress of the reaction was monitored by ${ }^{1} \mathrm{H}-\mathrm{NMR}$.

\section{General procedure for the cycloisomerization of allenone (4-11)}

In the absence of acid activator: To a solution of allenone 4-11 (12.4 mg, 0.05 mmol) in $\mathrm{CDCl}_{3}(0.498 \mathrm{~mL})$ inside the NMR tube, the stock solution of $[\mathrm{P}(t-$ $\mathrm{Bu})_{20}$-biphenyl] $\mathrm{Au}^{+} \mathrm{OTf}{ }^{-}$in $\mathrm{CDCl}_{3}(2 \mu \mathrm{L}, 0.01 \mathrm{M}, 0.04 \mathrm{~mol} \%)$ was added to the reaction mixture in the NMR tube. The progress of the reaction was monitored by ${ }^{1} \mathrm{H}-\mathrm{NMR}$.

In the presence of acid activator: To a solution of allenone 4-11 (12.4 mg, 0.05 mmol) in $\mathrm{CDCl}_{3}(0.468 \mathrm{~mL})$ inside the NMR tube, the stock solution of $[\mathrm{P}(t-$ $\mathrm{Bu})_{2} \mathrm{O}$-biphenyl] $\mathrm{Au}^{+} \mathrm{OTf}{ }^{-}$in $\mathrm{CDCl}_{3}(2 \mu \mathrm{L}, 0.01 \mathrm{M}, 0.04 \mathrm{~mol} \%)$ was added to the reaction mixture in the NMR tube. Different activator stock solutions $(30 \mu \mathrm{L}$, $0.01 \mathrm{M}, 0.6 \mathrm{~mol} \%$ ) were introduced into corresponding NMR tubes. The progress of the reaction was monitored by ${ }^{1} \mathrm{H}-\mathrm{NMR}$. 


\section{CHAPTER 5. GOLD-CATALYZED ADDITION OF N-HYDROXY HETEROCYCLES TO ALKYNES AND SUBSEQUENT 3,3- SIGMATROPIC REARRANGEMENT}

\subsection{Background}

Gold catalyzed addition of $O$-nucleophiles to alkynes will first give synthetically important vinyl ether products, ${ }^{177}$ but these are usually not stable enough to be isolated by standard silica gel chromatography. ${ }^{177} \mathrm{We}$ found that a gold catalyzed addition of $N$-hydroxy heterocycles to alkynes gives an easily isolatable vinyl ether product 5-3, and the subsequent 3,3-sigmatropic rearrangement of 5-3 (Scheme 16a) gives access to pharmaceutically important functionalized $N$-heterocycles. ${ }^{37-}$ 39,42 Furthermore, reaction of 5-3 with an electrophile such as the electrophilic fluorinating reagent (Selectfluor), gives functionalized $\alpha$-fluoroketones. Functionalized benzotriazoles are important precursors for the synthesis of pyrimidine- or pyridine-based compounds used in the treatment of GSK3 mediated disorders because they inhibit glycogen synthase kinase (GSK3). ${ }^{48}$ Many functionalized benzotriazoles and indoles are also important synthetic intermediates. $^{49,50}$

Gold-catalyzed oxygen transfers are synthetically useful and attract a lot of attention. ${ }^{59-65,178-180}$ In 2009, Asensio and co-workers applied the oxygen transfer 
concept in their intermolecular gold-catalyzed sulfoxide addition to alkynes that allowed the preparation of sulfur containing arenes (Scheme 16b) ${ }^{181} \mathrm{~A}$ similar approach was employed by Zhang and co-workers in their synthesis of 2alkylindoles from $N$-arylhydroxylamines and terminal alkynes (Scheme 16c). ${ }^{182,183}$

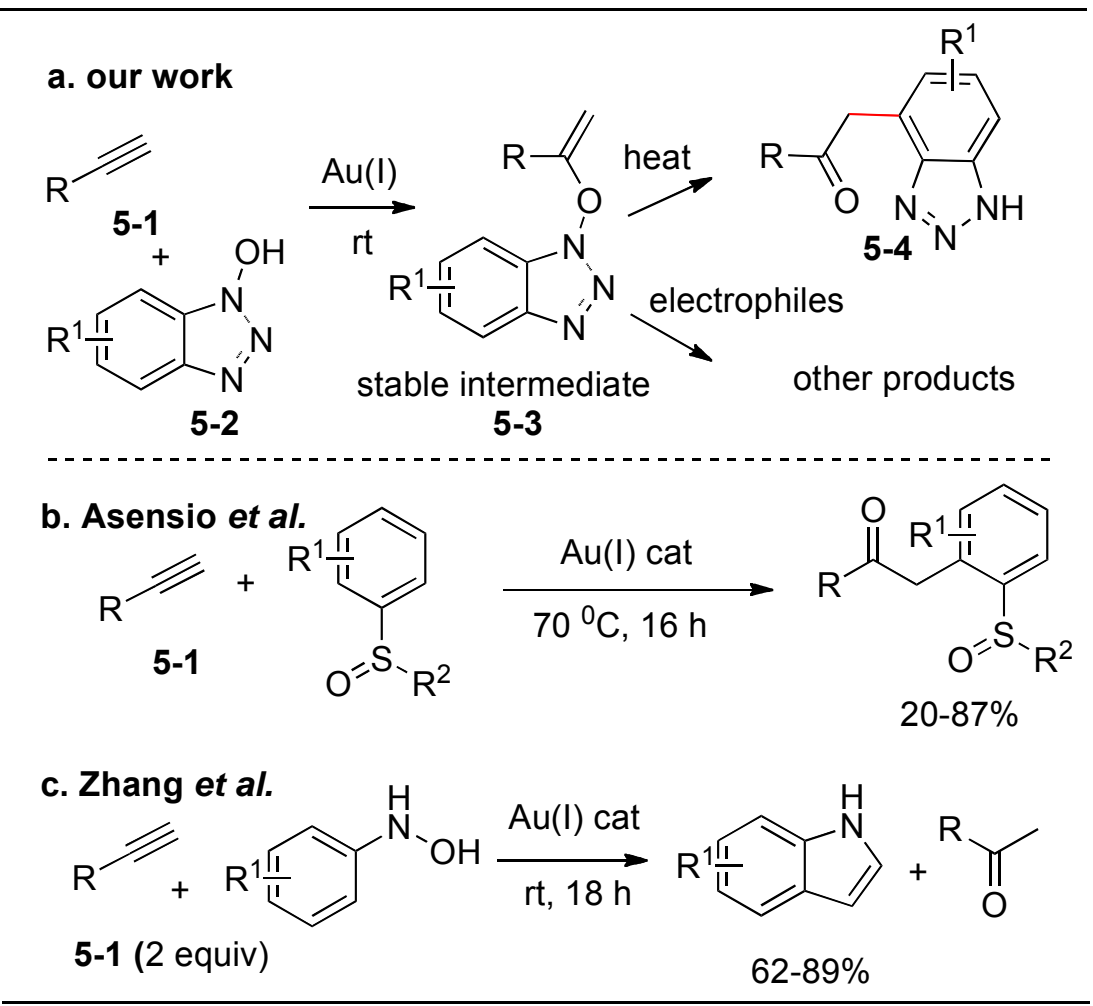

Scheme 16. Gold-catalyzed oxygen transfer reactions.

\subsection{Results and discussions}

We selected the reaction of 4-hydroxyhex-1-yne 5-1a with $\mathrm{N}$ hydroxybenzotriazole 5-2a as our model reaction (Table 6). To our delight, when we treated 5-1a ( 1 equiv) with 5-2a (1.1 equiv) in the presence of a standard gold catalyst, i.e., $\mathrm{Ph}_{3} \mathrm{PAuCl}(5 \%)$ with $\mathrm{AgOTf}(5 \%)$, we acquired a near quantitative isolated yield of the vinyl ether 5-3aa, using DCE (dichloroethane) as solvent at room temperature (Table 6 , entry 1 ). Reducing the loading of gold catalyst to $1 \%$ 
did not reduce the yield, although it lengthened the reaction time (Table 6, entry 2). When we reduced the amount of 5-2a from 1.5 equiv to 1.1 equiv, either in DCE or acetonitrile, the reaction yields were still excellent, although, the reaction was slower in acetonitrile (Table 6, entries 3-4). With optimized conditions in hand, we studied the scope for synthesis of other vinyl ethers 5-3 (Table 7).

Table 6. Reaction optimization for synthesis of vinyl ether 5-3.

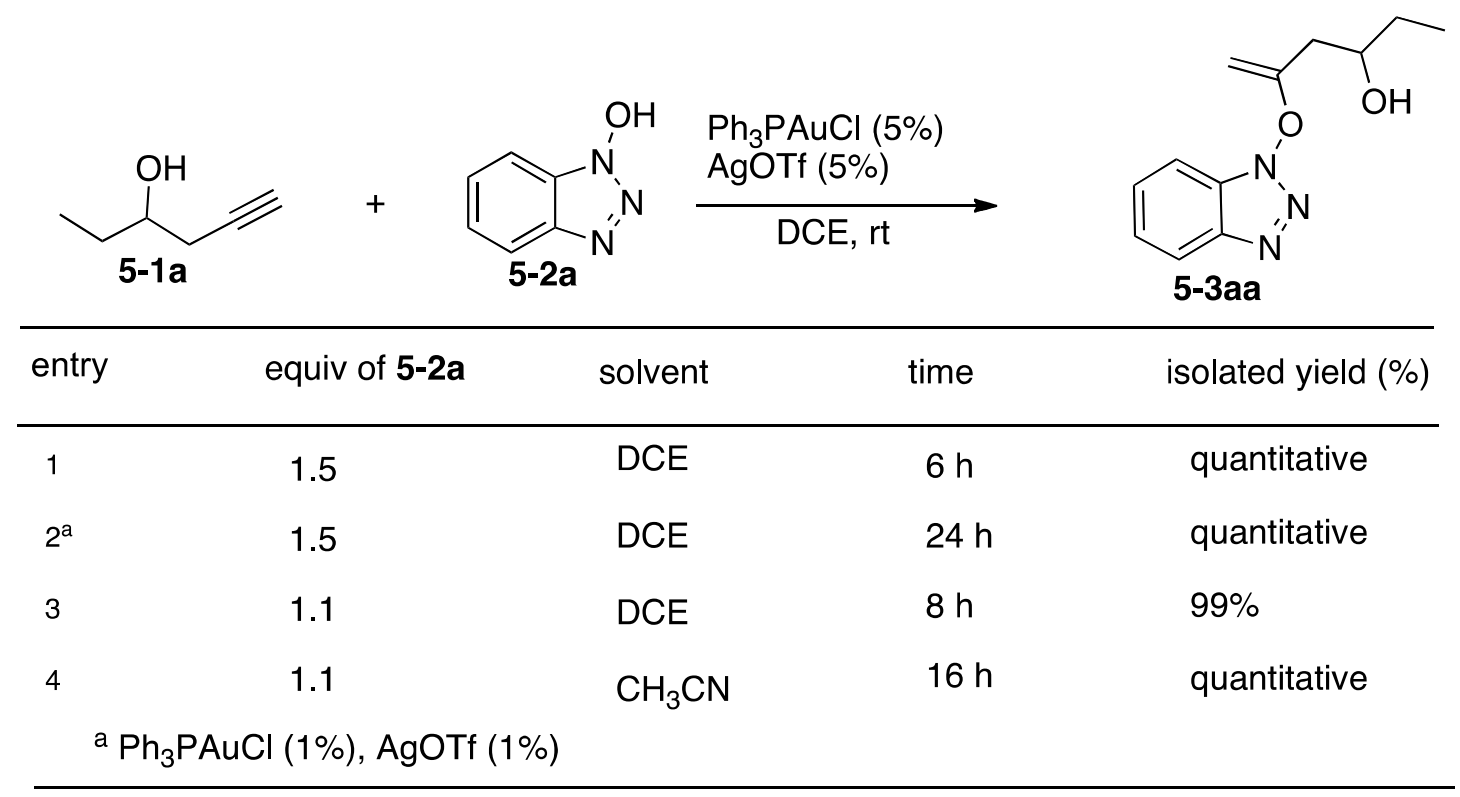

Terminal alkynes bearing aliphatic substituents (Table 7, entries 1, 3, 5, 7, 9) afforded good to excellent yields of the expected products. Functional groups like hydroxyl (Table 7, entries 1 and 7), methoxy (Table 7, entry 5) and alkenes (Table 7 , entry 6) were well tolerated. In the case of aromatic alkynes, the reaction also gave high yields (Table 7, entries 2, 4). When we reacted 1,6-heptadiyne with 2.2 equiv of 5-2a, an excellent yield of 5-3ha was obtained (Table 7, entry 8). When substituted $N$-hydroxybenzotriazoles (Table 7 , entries $10,11,12,13$ ) were screened, we found that $N$-hydroxybenzotriazoles substituted with electron 
donating groups (Table 7 , entries 12,13) or with electron withdrawing groups (Table 7, entries 10,11) gave excellent yields of product 5-3. Moreover, when we used $N$-hydroxy-7-azabenzotriazole, we also isolated high yields of the expected 7azabenzotriazole derivatives (Table 7 , entries $14,15,16$ ). We also investigated the use of an allene as a substrate (Table 7, entry 17). In this case, when allene 5-1k was treated with $N$-hydroxybenzotriazole 5-2a, we obtained 5-3qa in lower yield $(17 \%)$; the majority of unreacted allene $\mathbf{5 - 1 k}$ was recovered, indicating that an allene is less reactive than the corresponding alkyne under these conditions. Interestingly, 1-hydroxyindazole (5-2e),${ }^{184} \mathrm{~N}$-hydroxy-4-quinolone (5-2f),${ }^{185}$ and $N$-hydroxyquinazolinediones $(\mathbf{5 - 2 g})^{186}$ didn't react with alkynes under the same conditions (Table 7 , entries $18,19,20)$. The reasons for this are not clear to us at this point. Furthermore, we also examined few $N$-oxides such as benzo[c]cinnoline- $N$-oxide, and benzofuroxan, but they didn’t show any reactivity with alkynes under the same conditions. Moreover, we also tested reaction of internal alkynes such as 2-decyne, and 5-decyne with $N$-hydroxybenzotriazole (52a), but their reactions were very sluggish.

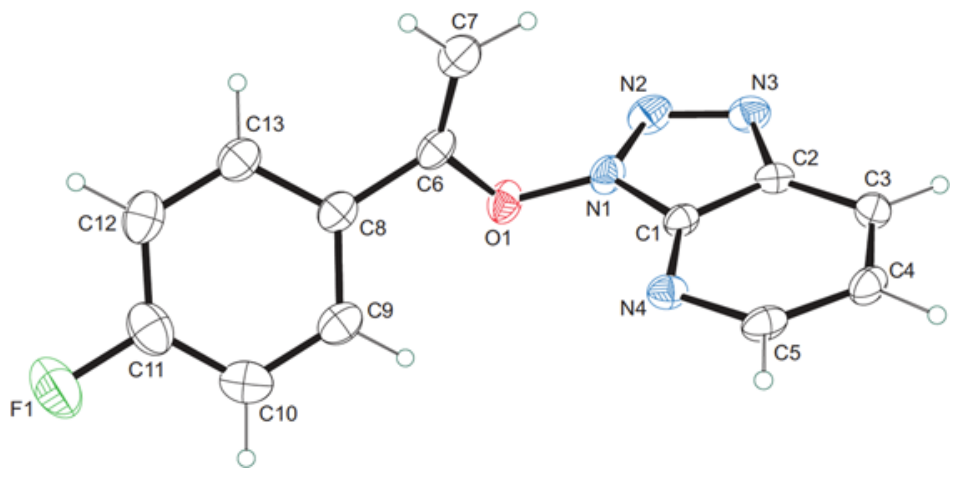

Figure 27. ORTEP-3 diagram of 5-3od showing 50\% ellipsoids. Selected bond lengths ( $(\AA)$ O1N1, 1.3697(18); O1-C6, 1.418(2); C6-C7, 1.313(3); N1-N2, 1.345(2); N2-N3, 1.309(2). 
Table 7. Synthesis of vinyl ether intermediates.

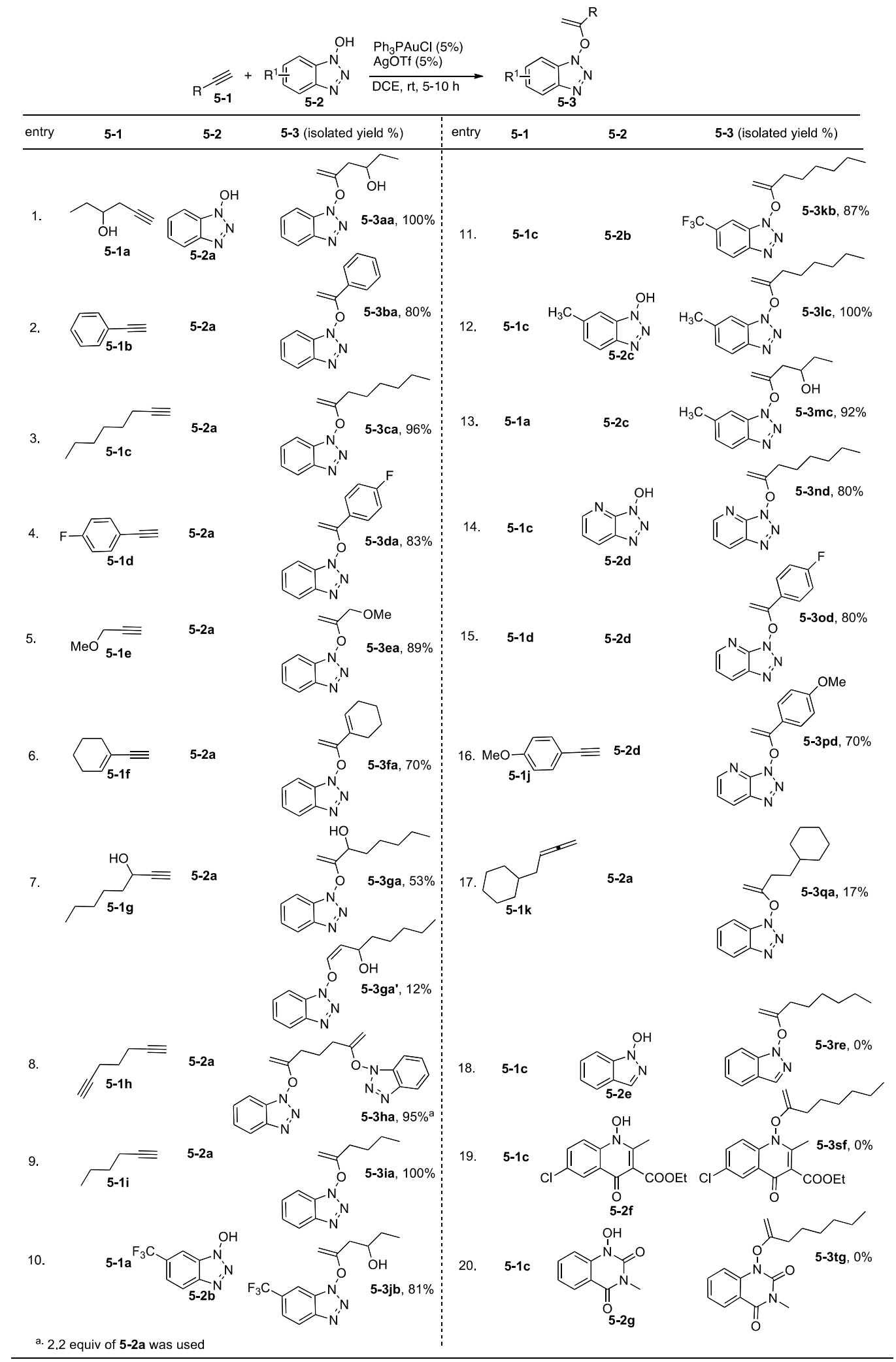


In nearly all cases, the reaction proceeds with exclusive regioselectivity. However, reaction of propargyl alcohol 5-1g (Table 7, entry 7) also led to formation of a minor regioisomer 5-3ga' (12\% yield), possibly due to steric reasons. The structure of 5-3od was confirmed by X-ray crystallography (Figure 27).

Next, we explored the use of vinyl ethers $\mathbf{5 - 3}$ as useful synthetic intermediates. We first investigated 3,3-sigmatropic rearrangements of $\mathbf{5 - 3}$, which would lead to formation of new $\mathrm{C}-\mathrm{C}$ bonds affording functionalized benzotriazoles. We investigated the effects of Lewis acids, bases, solvents, and temperature and found dioxane $/ 100{ }^{\circ} \mathrm{C}$ was the optimal condition for rearrangement. We found that $3,3-$ sigmatropic rearrangement of vinyl ethers $\mathbf{5 - 3}$ gives the 7 -substituted $1-\mathrm{H}-$ benzotriazoles 5-4 as the major product, but we also isolated the $N$-sustituted ketones 5-5 as a side products. A detailed mechanism explaining formation of 5-5 is not clear yet.
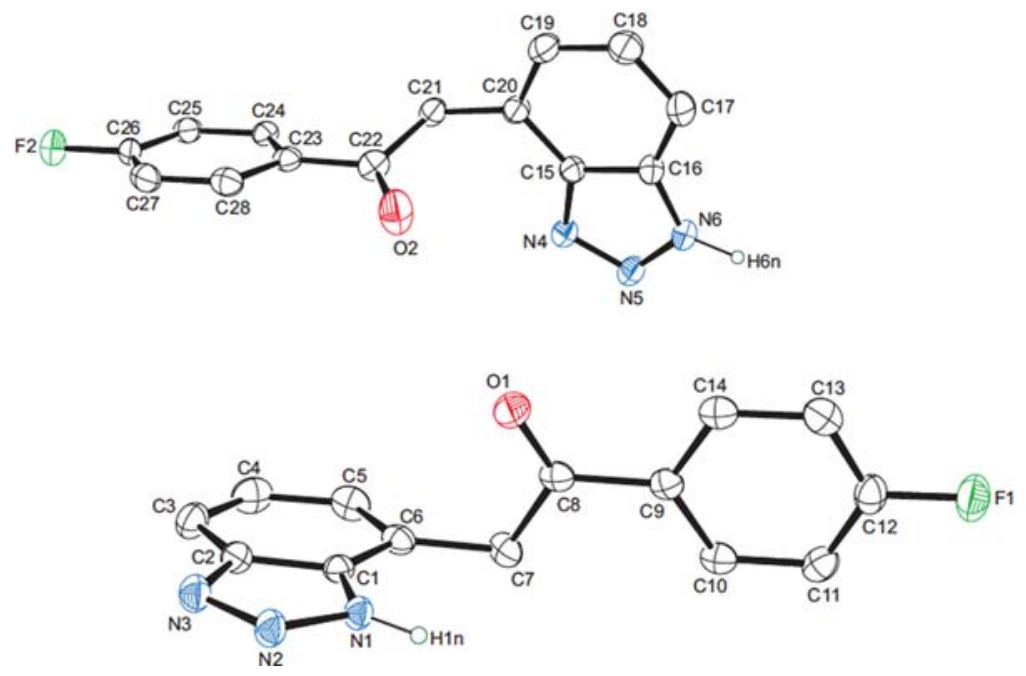

Figure 28. ORTEP-3 diagram of 5-4e illustrating two unique conformers present in the asymmetric unit shown at $50 \%$ ellipsoids. A third molecule identical to the top conformer in the asymmetric unit has been omitted for clarity. Additionally, only $\mathrm{H}$ atoms attached to $\mathbf{N}$ atoms are shown. Selected bond lengths (Å): O1-C8, 1.2238(19); C6-C7, 1.504(2); C7-C8, 1.516(2); N1-N2, 1.3497(17); N2-N3, 1.3130(19). 
The structure of 5-4e was confirmed unambiguously by X-ray crystallography (Figure 28). Depending on recrystallization conditions, either tautomer of 5-4e could be obtained. In order to determine the scope of this transformation, we investigated several different vinyl ethers (Scheme 17) as substrates. Conversion into the expected 7-substituted benzotriazoles $\mathbf{5}$ proceeded with moderate to good yield (40 -75\%).

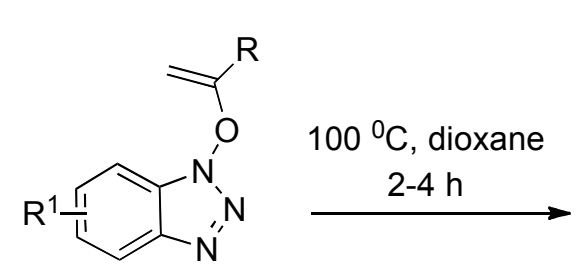

5-3

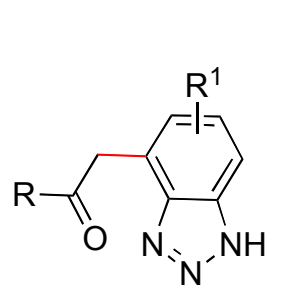

5-4 (major product)

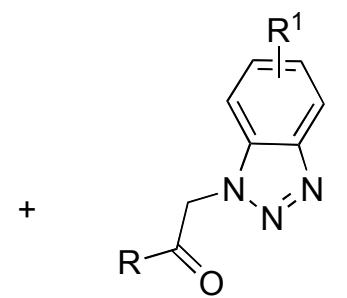

5-5 (minor product)

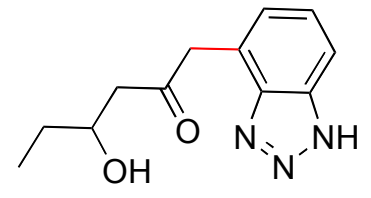

$5-4 a, 75 \%$

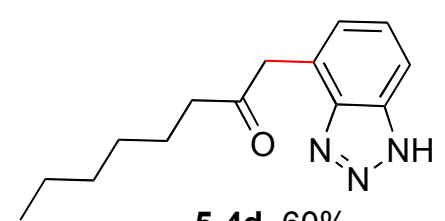

5-4d, $60 \%$

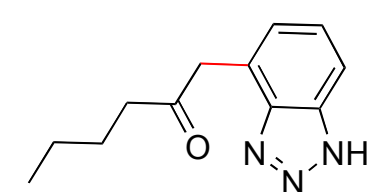

$5-4 b, 60 \%$

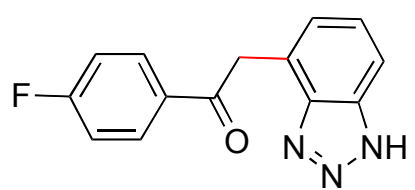

$5-4 e, 53 \%$

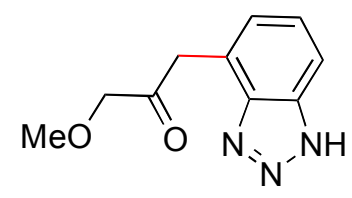

$5-4 c, 40 \%$

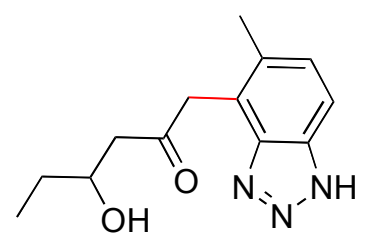

5-4f, $41 \%$

Scheme 17. Scope for 3,3-sigmatropic rearrangements of 5-3.

Encouraged by the utility of HOBt vinyl ethers in the synthesis of functionalised benzotriazoles, we explored their use in the synthesis of $\alpha$-fluoroketones. Fluoroketones are known to be important intermediates and targets in medicinal chemistry. ${ }^{93,187-189}$ However their regioselective synthesis is often non-trivial; we were pleased to discover that reaction of 5-3 with Selectfluor gave the functionalized fluoroketone 5-6 in $83 \%$ isolated yield and with high 
regioselectivity (eq 1). By contrast, many similar literature fluorination methods are known to suffer from poor regioselectivity. ${ }^{190}$

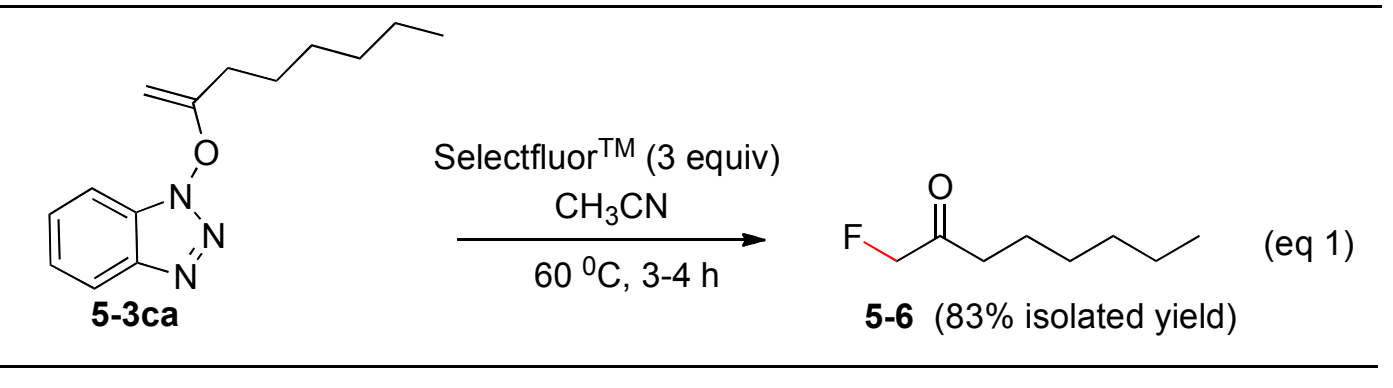

Equation 1. Electrophilic fluorination of vinyl ether products.

\subsection{Summary}

In summary, gold-catalyzed addition of $O$-nucleophiles to alkynes will give synthetically important vinyl ether products but these are usually not stable enough to be isolated by standard silica gel chromatography. In our case, vinyl ether products were very stable, easily isolated by standard silica gel chromatography. In this chapter, we developed a high yielding gold-catalyzed synthesis of HOBt derived vinyl ethers 5-3 from reaction of alkynes 5-1 with $N$-hydroxybenzotriazole 5-2a, and briefly explored their synthetic utility. To improve the substrate scope, we found that $N$-hydroxy-7-azabenzotriazole works very well under the same condition. However, 1-Hydroxyindazole, $\mathrm{N}$-hydroxy-4-quinolone, and $\mathrm{N}$ hydroxyquinazolinediones didn't react with alkynes under the same conditions. Moreover, $N$-oxides such as cinnoline- $N$-oxide, and benzofuroxan also didn't show any reactivity with alkynes under the same conditions. We also tested reactions of internal alkynes such as 2-decyne, and 5-decyne with $N$-hydroxybenzotriazole 52a, but these reactions were very sluggish, even after one week. Reaction of propargyl alcohol also led to the formation of a minor regioisomer, possibly due to 
steric reasons. When allene 5-1k was treated with $N$-hydroxybenzotriazole 5-2a, we obtained 5-3qa in lower yield (17\%); the majority of unreacted allene 5-1 k was recovered, indicating that an allene is less reactive than the corresponding alkyne under these conditions.

In closing, 3,3-sigmatropic rearrangement of 5-3 gives access to functionalized $\mathrm{N}$ heterocycles, while electrophilic fluorination of 5-3 gives high yielding regioselective access to a functionalized fluoroketone. Conversion into the expected 7-substituted benzotriazoles 5-4 proceeded with moderate to good yield (40 -75\%). In some cases, we also observed low yield of $\mathbf{5 - 4}$, because we also isolated the $N$-sustituted ketones $\mathbf{5 - 5}$ as a side products.The two-step sequence (nucleophilic addition / sigmatropic rearrangement) represents an efficient protocol for transfer of a nucleophilic oxygen atom to an alkyne group. The work described in this chapter was published in Org. Lett. 2013, 15, 724-727.

\subsection{Experimental}

\section{General}

${ }^{1} \mathrm{H}$ and ${ }^{13} \mathrm{C}$ NMR spectra were recorded at 500 and 126 (or 400 and 101) $\mathrm{MHz}$ respectively, using $\mathrm{CDCl}_{3}$ as a solvent. The chemical shifts are reported in $\delta(\mathrm{ppm})$ values $\left({ }^{1} \mathrm{H}\right.$ and ${ }^{13} \mathrm{C}$ NMR relative to $\mathrm{CHCl}_{3}, \delta 7.26 \mathrm{ppm}$ for ${ }^{1} \mathrm{H}$ NMR and $\delta 77.0$ ppm for ${ }^{13} \mathrm{C}$ NMR and $\mathrm{CFCl}_{3}\left(\delta 0 \mathrm{ppm}\right.$ for ${ }^{19} \mathrm{~F}$ NMR), multiplicities are indicated by $\mathrm{s}$ (singlet), d (doublet), $\mathrm{t}$ (triplet), $\mathrm{q}$ (quartet), $\mathrm{p}$ (pentet), $\mathrm{h}$ (hextet), $\mathrm{m}$ (multiplet) and br (broad). Coupling constants, $J$, are reported in Hertz (Hz). Solvents (tetrahydrofuran, ether, dichloromethane and DMF) were chemically 
dried using a commercial solvent purification system. All other reagents and solvents were employed without further purification. The products were purified using a commercial flash chromatography system or a regular glass column. TLC was developed on silica gel 60 F254 aluminum sheets. Exact molecular weight of new compound was obtained by high-resolution electrospray ionization mass spectrometry (HREIMS).

\section{Synthesis of $N$-hydroxybenzotriazole and $N$-hydroxyindole}

Compound 5-2a, 5-2b, 5-2d are available commercially. Compounds 5-2e, 5-2f, 52 g were synthesized following literature procedures. ${ }^{184-186}$

\section{Procedure for preparation of 5-2c.}

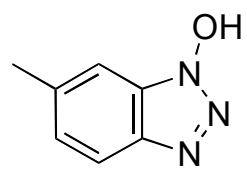

\section{$5-2 c$}

A mixture of 4-chloro-3-nitrotoluene $(2 \mathrm{~g}, 11.655 \mathrm{mmol})$ and hydrazine hydrate (3.3 $\mathrm{mL}, 116.6 \mathrm{mmol})$ in dry EtOH was heated under reflux for $20 \mathrm{~h}$ and then cooled to room temperature. From the reaction mixture, EtOH was evaporated under reduced pressure. This left a residue to which $\mathrm{MeOH}(20 \mathrm{~mL})$ was added and the mixture was acidified with conc. $\mathrm{HCl}$. This addition induced precipitation of a yellowish white solid, which was filtered. Evaporation of the solvent from the filtrate afforded additional amount of yellowish solid. The combined residues were taken up in $\mathrm{CHCl}_{3}$. The chloroform solution was washed repeatedly with water and phases were separated. Then the organic layer was dried over anhyd. $\mathrm{Na}_{2} \mathrm{SO}_{4}$, and 
the solvent was evaporated to afford a yellowish solid which was further purified by column chromatography over silica gel with using Hexane/EtOAc to give 5-2c as a yellowish solid (2.7 g, $63 \%$ ); mp 177-179 ${ }^{\circ} \mathrm{C}$; ${ }^{1} \mathrm{H}-\mathrm{NMR}$ (Acetone-d6, 400 MHz) $7.79(\mathrm{~d}, 1 \mathrm{H}), 7.47$ (s, 1H), $7.25(\mathrm{~d}, 1 \mathrm{H}), 2.52(\mathrm{~s}, 3 \mathrm{H}) ;{ }^{13} \mathrm{C}-\mathrm{NMR}$ (Acetone-d6, $400 \mathrm{MHz})$ 141.8, 137.9, 128.7, 126.7, 118.6, 108.2, 20.8; High Res MS (ES $\left.{ }^{+}\right)$ Calculated for $\left[\mathrm{C}_{7} \mathrm{H}_{8} \mathrm{~N}_{3} \mathrm{O}\right]^{+}\left(\mathrm{MH}^{+}\right)$: 150.0662; Found: 150.0663 .

\section{General procedure for the preparation for 5-3}

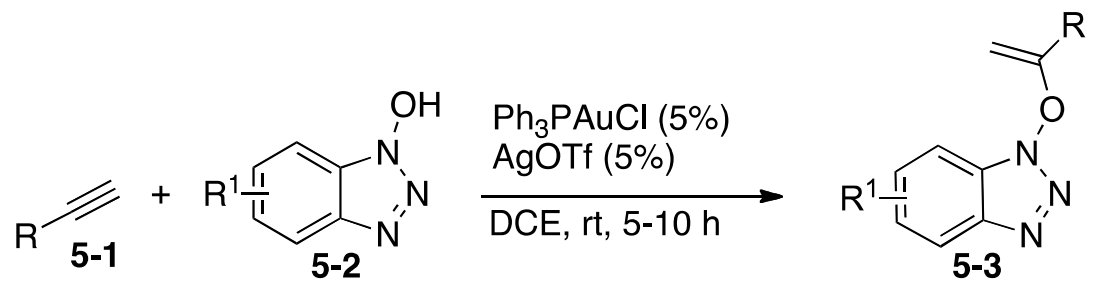

$N$-hydroxybenzotriazole 5-2 (45 $\mathrm{mg}, 0.336 \mathrm{mmol}, 1.1$ equiv) was added into a solution of the alkyne/allene 5-1 (30 mg, $0.306 \mathrm{mmol}), \mathrm{Ph}_{3} \mathrm{PAuCl}$ (7.6 mg, 0.0153 mmol, $5 \mathrm{~mol} \%$ ) in $2 \mathrm{~mL} \mathrm{DCE}$ (dichloroethane). The reaction was stirred at the room temperature for $8 \mathrm{~h}$. The solvent was removed under reduced pressure to give crude product, the crude product was purified by flash silica gel chromatography to give the product 5-3 (53\%-100\%) yield.

5-((1H-benzo[d][1,2,3]triazol-1-yl)oxy)hex-5-en-3-ol (5-3aa)

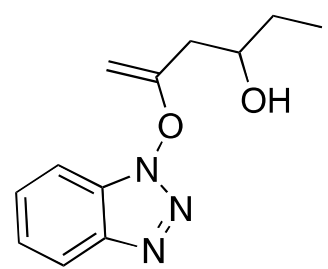

5-3aa 
Compound 5-3aa was prepared in $100 \%$ yield according to the general procedure (eluents: ethylacetate: hexane $=1: 4) .{ }^{1} \mathrm{H} \mathrm{NMR}\left(400 \mathrm{MHz}, \mathrm{CDCl}_{3}\right) \delta 8.01(\mathrm{~d}, 1 \mathrm{H}, J$ $=8.4 \mathrm{~Hz}), 7.46-7.54(\mathrm{~m}, 2 \mathrm{H}), 7.35-7.39(\mathrm{~m}, 1 \mathrm{H}), 4.34(\mathrm{~d}, 1 \mathrm{H}, J=4 \mathrm{~Hz}), 4.05(\mathrm{~m}$, 1H), $3.68(\mathrm{~d}, 1 \mathrm{H}, J=4 \mathrm{~Hz}), 2.95(\mathrm{br}, 1 \mathrm{H}), 2.64(\mathrm{dd}, 1 \mathrm{H}, J=16 \mathrm{~Hz}), 2.51$ (dd, $1 \mathrm{H}, J$ $=16 \mathrm{~Hz}), 1.55(\mathrm{~m}, 2 \mathrm{H}), 1.02(\mathrm{t}, 3 \mathrm{H}, J=4 \mathrm{~Hz}) ;{ }^{13} \mathrm{C} \mathrm{NMR}\left(100 \mathrm{MHz}, \mathrm{CDCl}_{3}\right) \delta 161.3$, 143.2, 128.5, 127.6, 124.9, 120.2, 108.9, 89.3, 70.3, 39.2, 29.9, 9.9; High Res MS $\left(\mathrm{ES}^{+}\right)$Calculated for $\left[\mathrm{C}_{12} \mathrm{H}_{16} \mathrm{~N}_{3} \mathrm{O}_{2}\right]^{+}\left(\mathrm{MH}^{+}\right)$: 234.1237; Found: 234.1238 .

1-((1-phenylvinyl)oxy)-1H-benzo[d][1,2,3]triazole (5-3ba)

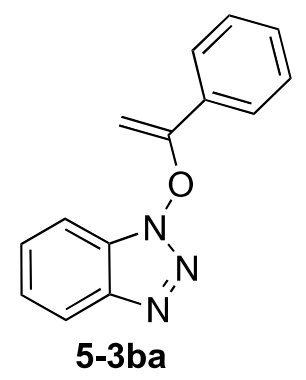

Compound 5-3ba was prepared in $80 \%$ yield according to the general procedure (eluents: ethylacetate: hexane $=1: 10) .{ }^{1} \mathrm{H} \mathrm{NMR}\left(400 \mathrm{MHz}, \mathrm{CDCl}_{3}\right) \delta 8.07(\mathrm{~d}, 1 \mathrm{H}$, $J=8 \mathrm{~Hz}), 7.77-7.79(\mathrm{~m}, 2 \mathrm{H}), 7.46-7.55(\mathrm{~m}, 2 \mathrm{H}), 7.42-7.45(\mathrm{~m}, 4 \mathrm{H}), 4.94(\mathrm{~d}, 1 \mathrm{H}, J$ $=4.4 \mathrm{~Hz}), 3.98(\mathrm{~d}, 1 \mathrm{H}, J=4.4 \mathrm{~Hz}) ;{ }^{13} \mathrm{C} \mathrm{NMR}\left(100 \mathrm{MHz}, \mathrm{CDCl}_{3}\right) \delta 161.2,143.4$, 131.4, 130.0, 128.7, 128.6, 127.7, 125.8, 124.9, 120.4, 108.7, 88.4; High Res MS $\left(\mathrm{ES}^{+}\right)$Calculated for $\left[\mathrm{C}_{14} \mathrm{H}_{12} \mathrm{~N}_{3} \mathrm{O}\right]^{+}\left(\mathrm{MH}^{+}\right)$: 238.0980; Found: 238.0980 .

1-(oct-1-en-2-yloxy)-1H-benzo[d][1,2,3]triazole (5-3ca) 


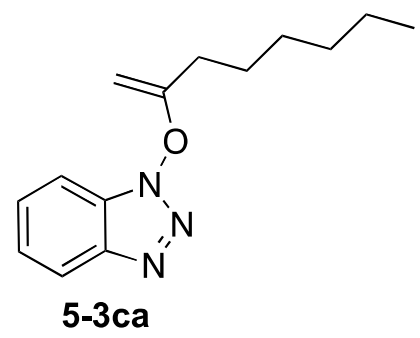

Compound 5-3ca was prepared in $96 \%$ yield according to the general procedure (eluents: ethylacetate: hexane $=1: 10) .{ }^{1} \mathrm{H}$ NMR $\left(400 \mathrm{MHz}, \mathrm{CDCl}_{3}\right) \delta 8.06(\mathrm{~d}, 1 \mathrm{H}$, $J=8.4 \mathrm{~Hz}), 7.47-7.56(\mathrm{~m}, 2 \mathrm{H}), 7.40-7.44(\mathrm{~m}, 1 \mathrm{H}), 4.24(\mathrm{~d}, 1 \mathrm{H}, J=4.0 \mathrm{~Hz}), 3.63$ (d, 1H, $J=4 \mathrm{~Hz}), 2.45(\mathrm{t}, 2 \mathrm{H}, J=8 \mathrm{~Hz}), 1.74(\mathrm{p}, 2 \mathrm{H}), 1.44-1.49(\mathrm{~m}, 2 \mathrm{H}), 1.34-$ $1.40(\mathrm{~m}, 4 \mathrm{H}), 0.93(\mathrm{t}, 3 \mathrm{H}, J=8 \mathrm{~Hz}) ;{ }^{13} \mathrm{C}$ NMR $\left(100 \mathrm{MHz}, \mathrm{CDCl}_{3}\right) \delta 164.2,143.3$, 128.3, 127.7, 124.7, 120.4, 108.7, 86.8, 31.5, 31.3, 28.6, 26.9, 22.5, 14.1; High Res MS $\left(\mathrm{ES}^{+}\right)$Calculated for $\left[\mathrm{C}_{14} \mathrm{H}_{20} \mathrm{~N}_{3} \mathrm{O}\right]^{+}\left(\mathrm{MH}^{+}\right)$:246.1601; Found: 246.1604 .

1-((1-(4-fluorophenyl)vinyl)oxy)-1H-benzo[d][1,2,3]triazole (5-3da)

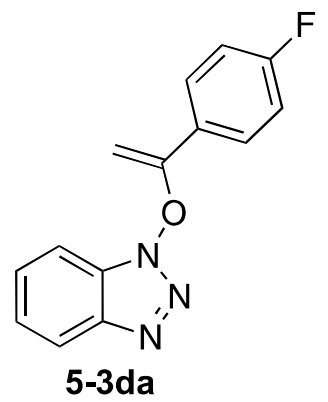

Compound 5-3da was prepared in $83 \%$ yield according to the general procedure (eluents: ethylacetate: hexane $=1: 10) .{ }^{1} \mathrm{H}$ NMR $\left(400 \mathrm{MHz}, \mathrm{CDCl}_{3}\right) \delta 8.10(\mathrm{~d}, 1 \mathrm{H}$, $J=8 \mathrm{~Hz}), 7.77-7.81(\mathrm{~m}, 2 \mathrm{H}), 7.56-7.57(\mathrm{~m}, 2 \mathrm{H}), 7.44-7.47$ (m, 1H), 7.17 (t, $2 \mathrm{H}, J$ $=8.8) 4.90(\mathrm{~d}, 1 \mathrm{H}, J=4.8 \mathrm{~Hz}), 3.98(\mathrm{~d}, 1 \mathrm{H}, J=4.0 \mathrm{~Hz}) ;{ }^{13} \mathrm{C} \mathrm{NMR}(100 \mathrm{MHz}$, $\left.\mathrm{CDCl}_{3}\right) \delta 164.9,162.4,160.3,143.4,128.6,127.9,126.4(\mathrm{~d}, J=290.4 \mathrm{~Hz}), 120.5$, 
115.9, 115.7, 108.6, 88.3; High Res $\mathrm{MS}\left(\mathrm{ES}^{+}\right)$Calculated for $\left[\mathrm{C}_{14} \mathrm{H}_{11} \mathrm{FN}_{3} \mathrm{O}\right]^{+}$ $\left(\mathrm{MH}^{+}\right)$: 255.0881; Found: 256.0883 .

1-((3-methoxyprop-1-en-2-yl)oxy)-1H-benzo[d][1,2,3]triazole (5-3ea)

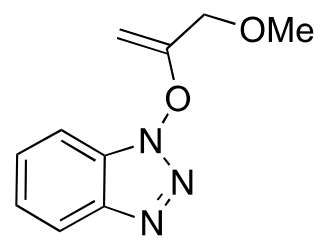

5-3ea

Compound 5-3ea was prepared in $89 \%$ yield according to the general procedure (eluents: ethylacetate: hexane $=1: 10) .{ }^{1} \mathrm{H}$ NMR $\left(400 \mathrm{MHz}, \mathrm{CDCl}_{3}\right) \delta 8.00(\mathrm{~d}, 1 \mathrm{H}$, $J=8.4 \mathrm{~Hz}), 7.49-7.50(\mathrm{~m}, 2 \mathrm{H}), 7.37-7.38(\mathrm{~m}, 1 \mathrm{H}), 4.57(\mathrm{~d}, 1 \mathrm{H}, J=3.6 \mathrm{~Hz}), 4.16(\mathrm{~s}$, 2H), $3.99(\mathrm{~d}, 1 \mathrm{H}, J=4.0 \mathrm{~Hz}), 3.44(\mathrm{~s}, 3 \mathrm{H}) ;{ }^{13} \mathrm{C} \mathrm{NMR}\left(100 \mathrm{MHz}, \mathrm{CDCl}_{3}\right) \delta$ 159.7, 143.3, 128.6, 127.5, 124.9, 120.3, 108.8, 91.6, 69.7, 58.4; High Res MS (ES $\left.{ }^{+}\right)$ Calculated for $\left[\mathrm{C}_{10} \mathrm{H}_{12} \mathrm{~N}_{3} \mathrm{O}_{2}\right]^{+}$: 206.0924; Found: 206.0926 .

1-((1-(cyclohex-1-en-1-yl)vinyl)oxy)-1H-benzo[d][1,2,3]triazole (5-3fa)

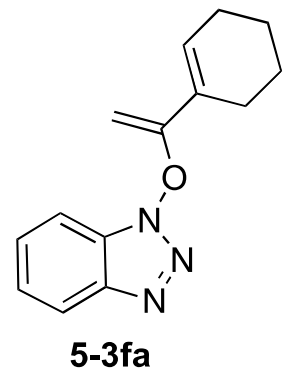

Compound 5-3fa was prepared in $70 \%$ yield according to the general procedure (eluents: ethylacetate: hexane $=1: 10) .{ }^{1} \mathrm{H} \mathrm{NMR}\left(400 \mathrm{MHz}, \mathrm{CDCl}_{3}\right) \delta 8.03(\mathrm{~d}, 1 \mathrm{H}$, $J=8.4 \mathrm{~Hz}), 7.50-7.51(\mathrm{~m}, 2 \mathrm{H}), 7.37-7.41(\mathrm{~m}, 1 \mathrm{H}), 6.64(\mathrm{br}, 1 \mathrm{H}), 4.43(\mathrm{~d}, 1 \mathrm{H}, J=$ $4.4 \mathrm{~Hz}), 3.68(\mathrm{~d}, 1 \mathrm{H}, J=4.0 \mathrm{~Hz}), 2.22-2.23(\mathrm{~m}, 4 \mathrm{H}), 1.73-1.78(\mathrm{~m}, 2 \mathrm{H}), 1.62-1.68$ 
$(\mathrm{m}, 2 \mathrm{H}) ;{ }^{13} \mathrm{C} \mathrm{NMR}\left(100 \mathrm{MHz}, \mathrm{CDCl}_{3}\right) \delta 161.6,143.4,128.3,128.2,127.8,124.8$ 120.3, 108.9, 86.3, 25.4, 25.2, 22.3, 21.7; High Res $\mathrm{MS}\left(\mathrm{ES}^{+}\right)$Calculated for $\left[\mathrm{C}_{14} \mathrm{H}_{16} \mathrm{~N}_{3} \mathrm{O}\right]^{+}\left(\mathrm{MH}^{+}\right): 242.1288$; Found: 242.1289 .

2-((1H-benzo[d][1,2,3]triazol-1-yl)oxy)oct-1-en-3-ol (5-3ga)

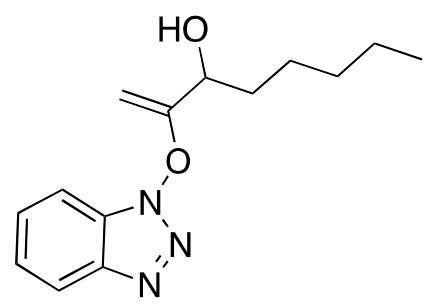

5-3ga

Compound 5-3ga was prepared in 53\% yield according to the general procedure (eluents: ethylacetate: hexane $=1: 4) .{ }^{1} \mathrm{H}$ NMR $\left(400 \mathrm{MHz}, \mathrm{CDCl}_{3}\right) \delta 8.05(\mathrm{~d}, 1 \mathrm{H}, J$ $=8.0 \mathrm{~Hz}), 7.50-7.53(\mathrm{~m}, 2 \mathrm{H}), 7.39-7.43(\mathrm{~m}, 1 \mathrm{H}), 4.58(\mathrm{~d}, 1 \mathrm{H}, J=4.0 \mathrm{~Hz}), 4.45(\mathrm{~m}$, $1 \mathrm{H}), 3.78(\mathrm{~d}, 1 \mathrm{H}, J=4.0 \mathrm{~Hz}), 2.53(\mathrm{br}, 1 \mathrm{H}), 1.87-2.53(\mathrm{~m}, 2 \mathrm{H}), 1.51-1.61(\mathrm{~m}, 2 \mathrm{H})$, 1.37-1.41 (m, 2H), $0.92(\mathrm{t}, 3 \mathrm{H}, J=7.2 \mathrm{~Hz}) ;{ }^{13} \mathrm{C} \mathrm{NMR}\left(100 \mathrm{MHz}, \mathrm{CDCl}_{3}\right) \delta 165.1$, $143.3,128.6,127.6,124.9,120.4,108.8,87.8,70.5,34.8,31.6,25.1,22.6,14.0$; High Res MS (ES $\left.{ }^{+}\right)$Calculated for $\left[\mathrm{C}_{14} \mathrm{H}_{20} \mathrm{~N}_{3} \mathrm{O}_{2}\right]^{+}\left(\mathrm{MH}^{+}\right)$: 262.1550; Found: 262.1555 .

1,1'-(hepta-1,6-diene-2,6-diylbis(oxy))bis(1H-benzo[d][1,2,3]triazole) (5-3ha)

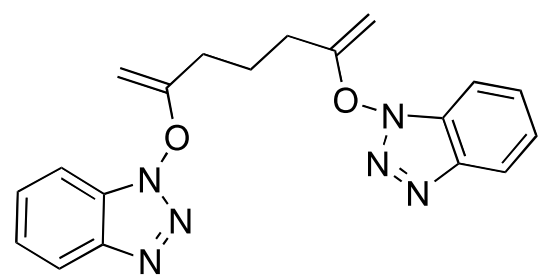

5-3ha 
2.2 equiv of 5-2a was used instead of 1.1 equiv in the reaction. Compound 5-3ha was prepared in 95\% yield according to the general procedure (eluents: ethylacetate: hexane $=1: 10) .{ }^{1} \mathrm{H}$ NMR $\left(400 \mathrm{MHz}, \mathrm{CDCl}_{3}\right) \delta 8.75(\mathrm{~d}, 1 \mathrm{H}, J=8.8$ Hz), 7.52-7.58 (m, 2H), 7.41-7.46 (m, 1H), 4.37 (d, 1H, $J=4.0 \mathrm{~Hz}), 3.76(\mathrm{~d}, 1 \mathrm{H}, J$ $=3.6 \mathrm{~Hz}), 2.67(\mathrm{t}, 2 \mathrm{H}, J=7.6 \mathrm{~Hz}), 2.21-2.29(\mathrm{~m}, 1 \mathrm{H}) ;{ }^{13} \mathrm{C} \mathrm{NMR}(100 \mathrm{MHz}$, $\left.\mathrm{CDCl}_{3}\right) \delta 162.9,143.4,128.6,127.7,124.9,120.5,108.6,88.1,30.6,24.3$; High Res MS (ES ${ }^{+}$) Calculated for $\left[\mathrm{C}_{19} \mathrm{H}_{19} \mathrm{~N}_{6} \mathrm{O}_{2}\right]^{+}: 363.1564$; Found: 363.1567.

1-(hex-1-en-2-yloxy)-1H-benzo[d][1,2,3]triazole (5-3ia)

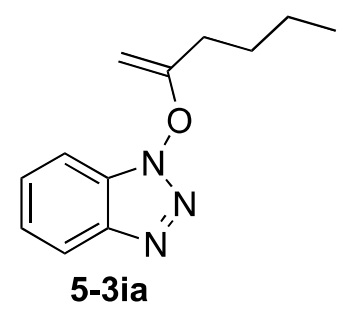

Compound 5-3ia was prepared in $100 \%$ yield according to the general procedure (eluents: ethylacetate: hexane $=1: 10) .{ }^{1} \mathrm{H}$ NMR $\left(400 \mathrm{MHz}, \mathrm{CDCl}_{3}\right) \delta 8.02(\mathrm{~d}, 1 \mathrm{H}$, $J=8.4 \mathrm{~Hz}), 7.44-7.52(\mathrm{~m}, 2 \mathrm{H}), 7.36-7.40(\mathrm{~m}, 1 \mathrm{H}), 4.21(\mathrm{~d}, 1 \mathrm{H}, J=3.6 \mathrm{~Hz}), 3.60$ (d, $1 \mathrm{H}, J=4.0 \mathrm{~Hz}), 2.42(\mathrm{t}, 2 \mathrm{H}, J=7.6 \mathrm{~Hz}), 1.67-1.74(\mathrm{p}, 2 \mathrm{H}), 1.42-1.52(\mathrm{~m}, 2 \mathrm{H})$, $0.97(\mathrm{t}, 3 \mathrm{H}, J=7.6 \mathrm{~Hz}) ;{ }^{13} \mathrm{C} \mathrm{NMR}\left(100 \mathrm{MHz}, \mathrm{CDCl}_{3}\right) \delta 164.2,143.3,128.4,127.7$, 124.7, 120.3, 108.7, 86.8, 31.0, 29.0, 22.1, 13.8; High Res MS $\left(\mathrm{ES}^{+}\right)$Calculated for $\left[\mathrm{C}_{12} \mathrm{H}_{16} \mathrm{~N}_{3} \mathrm{O}\right]^{+}\left(\mathrm{MH}^{+}\right)$: 218.1288; Found: 218.1289 .

5-((6-(trifluoromethyl)-1H-benzo[d][1,2,3]triazol-1-yl)oxy)hex-5-en-3-ol (5-3jb) 


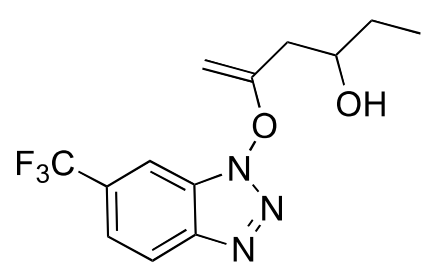

$5-3 j b$

Compound 5-3jb was prepared in $81 \%$ yield according to the general procedure (eluents: ethylacetate: hexane $=1: 4) .{ }^{1} \mathrm{H}$ NMR $\left(400 \mathrm{MHz}, \mathrm{CDCl}_{3}\right) \delta 8.16(\mathrm{~d}, 1 \mathrm{H}, J$ $=8.8 \mathrm{~Hz}), 7.91(\mathrm{~s}, 1 \mathrm{H}), 7.63(\mathrm{~d}, 1 \mathrm{H}, J=8.8 \mathrm{~Hz}), 4.42(\mathrm{~d}, 1 \mathrm{H}, J=3.6 \mathrm{~Hz}), 4.04-$ $4.10(\mathrm{~m}, 1 \mathrm{H}), 3.72(\mathrm{~d}, 1 \mathrm{H}, J=4.0 \mathrm{~Hz}), 2.67-2.71(\mathrm{dd}, 1 \mathrm{H}, J=14.8 \mathrm{~Hz}), 2.51-2.57$ (dd, 1H, $J=15.2 \mathrm{~Hz}), 2.49(\mathrm{br}, 1 \mathrm{H}), 1.61-1.74(\mathrm{~m}, 2 \mathrm{H}), 1.05(\mathrm{t}, 3 \mathrm{H}, J=7.6 \mathrm{~Hz})$; ${ }^{13} \mathrm{C}$ NMR (100 MHz, $\left.\mathrm{CDCl}_{3}\right) \delta 161.6,144.4,130.8(\mathrm{q}, J=32.5 \mathrm{~Hz}), 127.1,123.5$ $(\mathrm{q}, J=272.1 \mathrm{~Hz}), 121.6(\mathrm{q}, J=3.1 \mathrm{~Hz}), 121.5,107.5(\mathrm{q}, J=4.6 \mathrm{~Hz}), 89.7,70.4$, 39.1, 30.1, 9.8; High Res $\mathrm{MS}\left(\mathrm{ES}^{+}\right)$Calculated for $\left[\mathrm{C}_{13} \mathrm{H}_{15} \mathrm{~F}_{3} \mathrm{~N}_{3} \mathrm{O}_{2}\right]^{+}\left(\mathrm{MH}^{+}\right)$: 302.1111; Found: 302.1113

1-(oct-1-en-2-yloxy)-6-(trifluoromethyl)-1H-benzo[d][1,2,3]triazole (5-3kb)

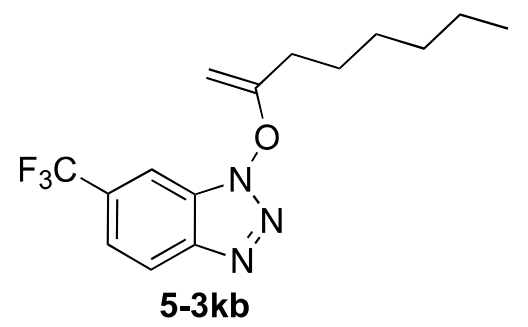

Compound 5-3kb was prepared in $87 \%$ yield according to the general procedure (eluents: ethylacetate: hexane $=1: 10) .{ }^{1} \mathrm{H}$ NMR $\left(400 \mathrm{MHz}, \mathrm{CDCl}_{3}\right) \delta 8.19(\mathrm{~d}, 1 \mathrm{H}$, $J=8.8 \mathrm{~Hz}), 7.81(\mathrm{~s}, 1 \mathrm{H}), 7.65(\mathrm{~d}, 1 \mathrm{H}, J=8.8 \mathrm{~Hz}), 4.29(\mathrm{~d}, 1 \mathrm{H}, J=4.0 \mathrm{~Hz}), 3.63(\mathrm{~d}$, $1 \mathrm{H}, J=4.4 \mathrm{~Hz}), 2.47(\mathrm{t}, 2 \mathrm{H}, J=7.6 \mathrm{~Hz}), 1.71-1.79(\mathrm{~m}, 2 \mathrm{H}), 1.46-1.49(\mathrm{~m}, 2 \mathrm{H})$, 1.34-1.39 (m, 4H), $\left.0.93(\mathrm{t}, 3 \mathrm{H}, J=7.2 \mathrm{~Hz}) ;{ }^{13} \mathrm{C} \mathrm{NMR} \mathrm{(100} \mathrm{MHz,} \mathrm{CDCl}_{3}\right) \delta 164.5$, 
144.4, $130.7(\mathrm{q}, J=32.5 \mathrm{~Hz}), 127.2,123.6(\mathrm{q}, J=271.9 \mathrm{~Hz}), 121.6(\mathrm{q}, J=3.9 \mathrm{~Hz})$, 121.5, $107.2(\mathrm{q}, J=4.7 \mathrm{~Hz}), 87.2,31.5,31.3,28.6,26.8,22.5,14.0$; High Res MS $\left(\mathrm{ES}^{+}\right)$Calculated for $\left[\mathrm{C}_{15} \mathrm{H}_{19} \mathrm{~F}_{3} \mathrm{~N}_{3} \mathrm{O}\right]^{+}\left(\mathrm{MH}^{+}\right): 314.1475$; Found: 314.1476

6-methyl-1-(oct-1-en-2-yloxy)-1H-benzo[d][1,2,3]triazole (5-3lc)

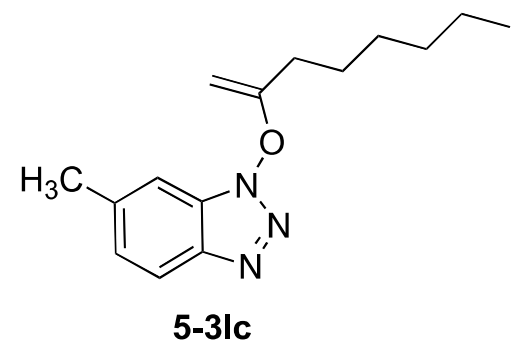

Compound 5-3lc was prepared in $100 \%$ yield according to the general procedure (eluents: ethylacetate: hexane $=1: 10) .{ }^{1} \mathrm{H} \mathrm{NMR}\left(400 \mathrm{MHz}, \mathrm{CDCl}_{3}\right) \delta 7.89(\mathrm{~d}, 1 \mathrm{H}$, $J=8.8 \mathrm{~Hz}), 7.20-7.22(\mathrm{~m}, 2 \mathrm{H}), 4.21(\mathrm{~d}, 1 \mathrm{H}, J=4.0 \mathrm{~Hz}), 3.61(\mathrm{~d}, 1 \mathrm{H}, J=3.6 \mathrm{~Hz})$, $2.51(\mathrm{~s}, 3 \mathrm{H}), 2.42(\mathrm{t}, 2 \mathrm{H}, J=7.6 \mathrm{~Hz}), 1.69-1.76(\mathrm{p}, 2 \mathrm{H}), 1.42-1.47(\mathrm{~m}, 2 \mathrm{H}), 1.33-$ $1.37(\mathrm{~m}, 4 \mathrm{H}), 0.91(\mathrm{t}, 3 \mathrm{H}, J=7.2 \mathrm{~Hz}) ;{ }^{13} \mathrm{C} \mathrm{NMR}\left(100 \mathrm{MHz}, \mathrm{CDCl}_{3}\right) \delta 164.2,142.1$, $139.3,128.1,127.1,119.8107 .7,86.7,31.5,31.3,28.7,26.9,22.6,21.9,14.1$; High Res MS $\left(\mathrm{ES}^{+}\right)$Calculated for $\left[\mathrm{C}_{15} \mathrm{H}_{22} \mathrm{~N}_{3} \mathrm{O}\right]^{+}\left(\mathrm{MH}^{+}\right)$: 260.1757 ; Found: 260.1760

5-((6-methyl-1H-benzo[d][1,2,3]triazol-1-yl)oxy)hex-5-en-3-ol (5-3mc)

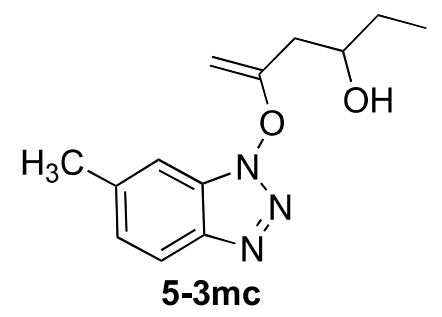


Compound 5-3mc was prepared in $92 \%$ yield according to the general procedure (eluents: ethylacetate: hexane $=1: 4) .{ }^{1} \mathrm{H}$ NMR $\left(400 \mathrm{MHz}, \mathrm{CDCl}_{3}\right) \delta 7.81(\mathrm{~d}, 1 \mathrm{H}, J$ $=8.8 \mathrm{~Hz}), 7.20(\mathrm{~s}, 1 \mathrm{H}), 7.13(\mathrm{~d}, 1 \mathrm{H}, J=8.4 \mathrm{~Hz}) 4.26(\mathrm{~d}, 1 \mathrm{H}, J=4.0 \mathrm{~Hz}), 3.95-4.02$ (m, 1H), $3.62(\mathrm{~d}, 1 \mathrm{H}, J=4 \mathrm{~Hz}), 2.70(\mathrm{bs}, 1 \mathrm{H}), 2.56-2.61(\mathrm{dd}, 1 \mathrm{H}, J=14.8 \mathrm{~Hz})$, $2.45(\mathrm{t}, 1 \mathrm{H}, J=8.4 \mathrm{~Hz}), 2.42(\mathrm{~s}, 3 \mathrm{H}), 1.53-1.61(\mathrm{~m}, 2 \mathrm{H}), 0.97(\mathrm{t}, 3 \mathrm{H}, J=7.2 \mathrm{~Hz})$ ${ }^{13} \mathrm{C}$ NMR $\left(100 \mathrm{MHz}, \mathrm{CDCl}_{3}\right) \delta 161.2,141.9,139.6,128.0,127.3,119.7,107.8$, 89.3, 70.3, 39.3, 29.9, 21.9, 9.9; High Res MS $\left(\mathrm{ES}^{+}\right)$Calculated for $\left[\mathrm{C}_{13} \mathrm{H}_{18} \mathrm{~N}_{3} \mathrm{O}_{2}\right]^{+}$ $\left(\mathrm{MH}^{+}\right): 248.1394$; Found: 248.1396

3-(oct-1-en-2-yloxy)-3H-[1,2,3]triazolo[4,5-b]pyridine (5-3nd)

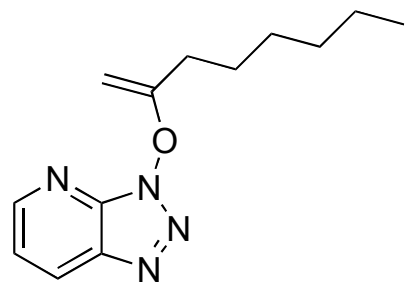

5-3nd

Compound 5-3nd was prepared in $80 \%$ yield according to the general procedure (eluents: ethylacetate: hexane $=1: 4) .{ }^{1} \mathrm{H}$ NMR $\left(400 \mathrm{MHz}, \mathrm{CDCl}_{3}\right) \delta 8.76(\mathrm{~d}, 1 \mathrm{H}, J$ $=5.6 \mathrm{~Hz}), 8.42(\mathrm{~d}, 1 \mathrm{H}, J=10.0 \mathrm{~Hz}), 7.44(\mathrm{dd}, 1 \mathrm{H}, J=13.2 \mathrm{~Hz}) 4.29(\mathrm{~d}, 1 \mathrm{H}, J=$ $4.4 \mathrm{~Hz}), 3.69$ (d, 1H, $J=4 \mathrm{~Hz}), 2.50(\mathrm{t}, 2 \mathrm{H}, J=15.2), 1.80-1.73(\mathrm{~m}, 2 \mathrm{H}), 1.52-1.45$ (m, 2H), 1.40-1.34 (m, 4H), $0.92(\mathrm{t}, 3 \mathrm{H}, J=6.8 \mathrm{~Hz}) ;{ }^{13} \mathrm{C} \mathrm{NMR}\left(100 \mathrm{MHz}, \mathrm{CDCl}_{3}\right)$ $\delta 164.9,151.6,139.9,134.9,129.3,120.7,86.9,31.5,31.3,28.6,26.7,22.5,14.9$;

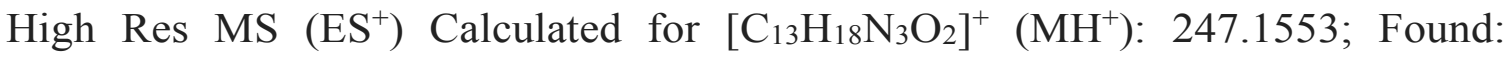
247.1555

3-((1-(4-fluorophenyl)vinyl)oxy)-3H-[1,2,3]triazolo[4,5-b]pyridine (5-3od) 


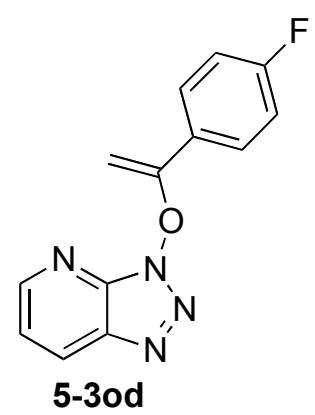

Compound 5-3od was prepared in $80 \%$ yield according to the general procedure (eluents: ethylacetate: hexane $=1: 4) .{ }^{1} \mathrm{H}$ NMR $\left(400 \mathrm{MHz}, \mathrm{CDCl}_{3}\right) \delta 8.78(\mathrm{~d}, 1 \mathrm{H}, J$ $=6 \mathrm{~Hz}), 8.45(\mathrm{~d}, 1 \mathrm{H}, J=10.0 \mathrm{~Hz}), 7.87-7.83(\mathrm{~m}, 2 \mathrm{H}), 7.49-7.45(\mathrm{~m}, 1 \mathrm{H}), 7.15(\mathrm{~m}$, 2H) $4.95(\mathrm{~d}, 1 \mathrm{H}, J=4.8 \mathrm{~Hz}), 4.15(\mathrm{~d}, 1 \mathrm{H}, J=4.8 \mathrm{~Hz}) ;{ }^{13} \mathrm{C}$ NMR $(100 \mathrm{MHz}$, $\left.\mathrm{CDCl}_{3}\right) \delta 164.9,162.4,160.9,151.8,139.9,134.9,129.4,127.9(\mathrm{~d}, J=290.4 \mathrm{~Hz})$, 120.9, 115.8, 115.6, 89.2; High Res MS $\left(\mathrm{ES}^{+}\right)$Calculated for $\left[\mathrm{C}_{13} \mathrm{H}_{18} \mathrm{~N}_{3} \mathrm{O}_{2}\right]^{+}$ $\left(\mathrm{MH}^{+}\right)$: 257.0833; Found: 257.0835

3-((1-(4-methoxyphenyl)vinyl)oxy)-3H-[1,2,3]triazolo[4,5-b]pyridine (5-3pd)

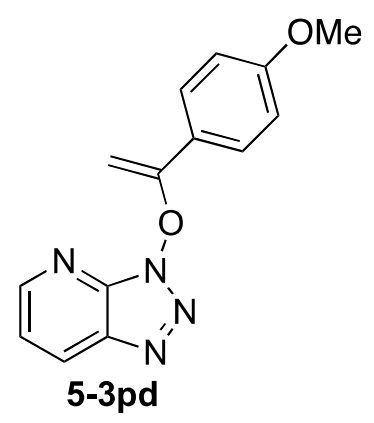

Compound 5-3pd was prepared in $70 \%$ yield according to the general procedure (eluents: ethylacetate: hexane $=1: 4) .{ }^{1} \mathrm{H}$ NMR $\left(400 \mathrm{MHz}, \mathrm{CDCl}_{3}\right) \delta 8.78(\mathrm{~d}, 1 \mathrm{H}, J$ $=4.4 \mathrm{~Hz}), 8.44(\mathrm{dd}, 1 \mathrm{H}, J=7.2 \mathrm{~Hz}), 7.79(\mathrm{~m}, 2 \mathrm{H}), 7.47-7.44(\mathrm{~m}, 2 \mathrm{H}), 6.97(\mathrm{~m}$, 2H) $4.88(\mathrm{~d}, 1 \mathrm{H}, J=4.4 \mathrm{~Hz}), 4.05(\mathrm{~d}, 1 \mathrm{H}, J=4.0 \mathrm{~Hz}), 3.87(\mathrm{~s}, 3 \mathrm{H}) ;{ }^{13} \mathrm{C} \mathrm{NMR}(100$ $\left.\mathrm{MHz}, \mathrm{CDCl}_{3}\right) \delta 161.9,160.9,151.8,140.0,134.9,129.4,127.8,124.0,120.9$, 
113.9, 87.6, 55.4; High Res MS (ES $\left.{ }^{+}\right)$Calculated for $\left[\mathrm{C}_{13} \mathrm{H}_{18} \mathrm{~N}_{3} \mathrm{O}_{2}\right]^{+}\left(\mathrm{MH}^{+}\right)$: 269.1033; Found: 269.1035

1-(1H-benzo[d][1,2,3]triazol-4-yl)-4-cyclohexylbutan-2-one (5-3qa)

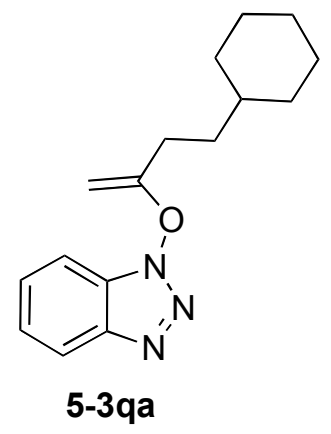

Compound 5-3qa was prepared in $17 \%$ yield according to the general procedure (eluents: ethylacetate: hexane $=1: 40) .{ }^{1} \mathrm{H}$ NMR $\left(400 \mathrm{MHz}, \mathrm{CDCl}_{3}\right) \delta 8.05(\mathrm{~d}, 2 \mathrm{H}$, $J=8.0 \mathrm{~Hz}), 7.47-7.55(\mathrm{~m}, 2 \mathrm{H}), 7.39-7.43(\mathrm{~m}, 1 \mathrm{H}), 4.23(\mathrm{~d}, 1 \mathrm{H}, J=3.6 \mathrm{~Hz}), 3.62$ (d, $1 \mathrm{H}, J=4.0 \mathrm{~Hz}), 2.45(\mathrm{t}, 2 \mathrm{H}, J=8.0 \mathrm{~Hz}), 1.61-1.81(\mathrm{~m}, 7 \mathrm{H}), 1.38-1.41(\mathrm{~m}, 1 \mathrm{H})$, 1.16-1.29 (m, 3H), 0.96-1.02 (m, 2H); ${ }^{13} \mathrm{C}$ NMR $\left(100 \mathrm{MHz}, \mathrm{CDCl}_{3}\right) \delta$ 164.7, 143.4, 128.3, 127.7, 124.7, 120.4, 108.8, 86.6, 37.1, 34.6, 33.1, 28.8, 26.6, 26.2; High Res MS $\left(\mathrm{ES}^{+}\right)$Calculated for $\left[\mathrm{C}_{16} \mathrm{H}_{22} \mathrm{~N}_{3} \mathrm{O}\right]^{+}: 272.1757$; Found: 272.1762.

\section{General procedure for the preparation of 5-4}

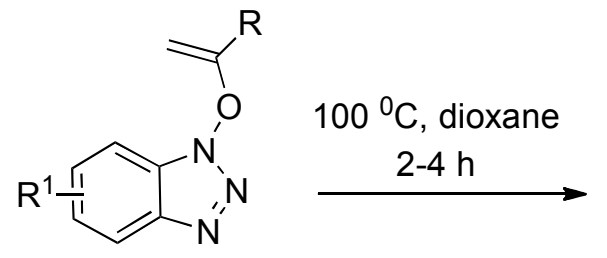

5-3

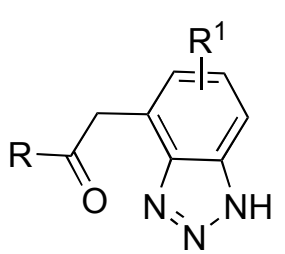

5-4

Vinyl ether intermediate 5-3 $(50 \mathrm{mg})$ was dissolved in dioxane $(2 \mathrm{~mL})$. The mixture was stirred at $100{ }^{\circ} \mathrm{C}$ for $2-4 \mathrm{~h}$. The solvent was removed under reduced 
pressure to give crude product, the crude product was purified by flash silica gel chromatography to give the product 5-4 (40\%-75\%) yield.

1-(1H-benzo[d][1,2,3]triazol-4-yl)-4-hydroxyhexan-2-one (5-4a)

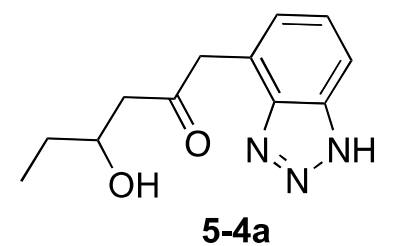

Compound 5-4a was prepared in $75 \%$ yield according to the general procedure (eluents: ethylacetate: hexane $=1: 2) .{ }^{1} \mathrm{H}$ NMR $\left(400 \mathrm{MHz}, \mathrm{CDCl}_{3}\right) \delta 7.70(\mathrm{~d}, 1 \mathrm{H}, J$ $=8.4 \mathrm{~Hz}), 7.31(\mathrm{t}, 1 \mathrm{H}, J=8.4 \mathrm{~Hz}), 7.18(\mathrm{~d}, 1 \mathrm{H}, J=6.8 \mathrm{~Hz}), 4.25(\mathrm{~s}, 2 \mathrm{H}), 4.11(\mathrm{~m}$, 1H), $2.79(\mathrm{~m}, 2 \mathrm{H}), 1.55$ (m, 2H), 0.93 (t, 3H, $J=7.2 \mathrm{~Hz}$ ); ${ }^{13} \mathrm{C}$ NMR (100 MHz, $\left.\mathrm{CDCl}_{3}\right) \delta 208.7,138.7,126.8,126.1,121.8,113.9,69.8,49.2,46.6,29.7,9.8$; High Res MS (ES ${ }^{+}$Calculated for $\left[\mathrm{C}_{12} \mathrm{H}_{16} \mathrm{~N}_{3} \mathrm{O}_{2}\right]^{+}\left(\mathrm{MH}^{+}\right)$: 234.1237; Found: 234.1239. 1-(1H-benzo[d][1,2,3]triazol-4-yl)hexan-2-one (5-4b)

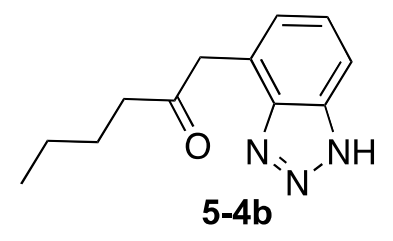

Compound 5-4b was prepared in $60 \%$ yield according to the general procedure (eluents: ethylacetate: hexane $=1: 4) .{ }^{1} \mathrm{H}$ NMR $\left(400 \mathrm{MHz}, \mathrm{CDCl}_{3}\right) \delta 7.73(\mathrm{~d}, 1 \mathrm{H}, J$ $=8.0 \mathrm{~Hz}), 7.34(\mathrm{t}, 1 \mathrm{H}, J=8.4 \mathrm{~Hz}), 7.22(\mathrm{~d}, 1 \mathrm{H}, J=6.8 \mathrm{~Hz}), 4.16(\mathrm{~s}, 2 \mathrm{H}), 2.59(\mathrm{t}$, $2 \mathrm{H}, J=7.6 \mathrm{~Hz}), 1.51(\mathrm{~m}, 2 \mathrm{H}), 1.22(\mathrm{~m}, 2 \mathrm{H}), 0.81(\mathrm{t}, 3 \mathrm{H}, J=7.6 \mathrm{~Hz}) ;{ }^{13} \mathrm{C} \mathrm{NMR}$ $\left(100 \mathrm{MHz}, \mathrm{CDCl}_{3}\right) \delta 208.8,138.8,138.6,126.4,126.2,122.0,113.8,42.5,25.6$, 
22.1, 13.7; High Res MS (ES $\left.{ }^{+}\right)$Calculated for $\left[\mathrm{C}_{12} \mathrm{H}_{16} \mathrm{~N}_{3} \mathrm{O}\right]^{+}\left(\mathrm{MH}^{+}\right)$: 218.1288; Found: 218.1291.

1-(1H-benzo[d][1,2,3]triazol-4-yl)-3-methoxypropan-2-one (5-4c)

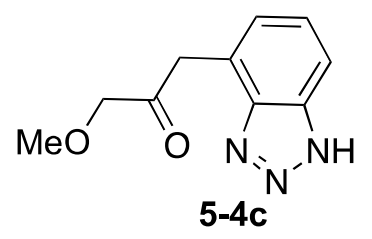

Compound 5-4c was prepared in $40 \%$ yield according to the general procedure (eluents: ethylacetate: hexane $=1: 2) .{ }^{1} \mathrm{H}$ NMR $\left(400 \mathrm{MHz}\right.$, Acetone- $\left.\mathrm{d}_{6}\right) \delta 7.78(\mathrm{~d}$, $1 \mathrm{H}, J=8.4 \mathrm{~Hz}), 7.42(\mathrm{t}, 1 \mathrm{H}, J=7.6 \mathrm{~Hz}), 7.27(\mathrm{~d}, 1 \mathrm{H}, J=6.8 \mathrm{~Hz}), 4.29(\mathrm{~s}, 2 \mathrm{H})$, $4.25(\mathrm{~s}, 2 \mathrm{H}), 3.39(\mathrm{~s}, 3 \mathrm{H}) ;{ }^{13} \mathrm{C} \mathrm{NMR}\left(100 \mathrm{MHz}, \mathrm{CDCl}_{3}\right) \delta 204.4,125.9,125.8$, 112.6, 76.9, 58.4; High Res MS $\left(\mathrm{ES}^{+}\right)$Calculated for $\left[\mathrm{C}_{10} \mathrm{H}_{12} \mathrm{~N}_{3} \mathrm{O}_{2}\right]^{+}:$206.0924; Found: 206.0927.

1-(1H-benzo[d][1,2,3]triazol-4-yl)octan-2-one (5-4d)

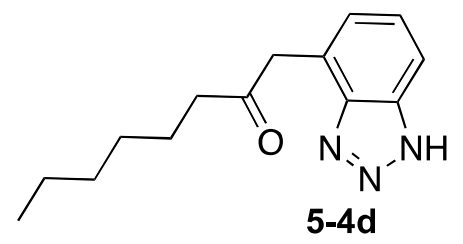

Compound 5-4d was prepared in $60 \%$ yield according to the general procedure (eluents: ethylacetate: hexane $=1: 4) .{ }^{1} \mathrm{H}$ NMR $\left(400 \mathrm{MHz}, \mathrm{CDCl}_{3}\right) \delta 7.70(\mathrm{~d}, 1 \mathrm{H}, J$ $=8.4 \mathrm{~Hz}), 7.34(\mathrm{t}, 1 \mathrm{H}, J=7.6 \mathrm{~Hz}), 7.21(\mathrm{~d}, 1 \mathrm{H}, J=6.8 \mathrm{~Hz}), 4.23(\mathrm{~s}, 2 \mathrm{H}), 2.58(\mathrm{t}$, $2 \mathrm{H}, J=7.2 \mathrm{~Hz}), 1.56(\mathrm{~m}, 2 \mathrm{H}), 1.18(\mathrm{~m}, 6 \mathrm{H}), 0.80(\mathrm{t}, 3 \mathrm{H}, J=7.2 \mathrm{~Hz}) ;{ }^{13} \mathrm{C} \mathrm{NMR}$ $\left(100 \mathrm{MHz}, \mathrm{CDCl}_{3}\right) \delta 208.9,139.6,138.0,126.3,125.9,122.6,113.6,45.6,42.8$, 
31.4, 28.6, 23.5, 22.4, 13.9; High Res MS $\left(\mathrm{ES}^{+}\right)$Calculated for $\left[\mathrm{C}_{14} \mathrm{H}_{20} \mathrm{~N}_{3} \mathrm{O}\right]^{+}$ $\left(\mathrm{MH}^{+}\right): 246.1601$; Found: 246.1602 .

2-(1H-benzo[d][1,2,3]triazol-4-yl)-1-(4-fluorophenyl)ethanone (5-4e)

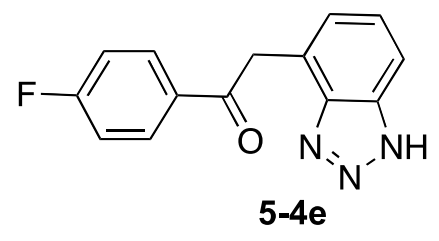

Compound 5-4e was prepared in 53\% yield according to the general procedure (eluents: ethylacetate: hexane $=1: 4) .{ }^{1} \mathrm{H} \mathrm{NMR}\left(400 \mathrm{MHz}, \mathrm{CDCl}_{3}\right) \delta 8.20(\mathrm{~m}, 2 \mathrm{H})$, $7.78(\mathrm{~d}, 1 \mathrm{H}, J=8.4 \mathrm{~Hz}), 7.42(\mathrm{t}, 1 \mathrm{H}, J=7.6 \mathrm{~Hz}), 7.26(\mathrm{~m}, 3 \mathrm{H}) 4.85\left(\mathrm{~s}, 2 \mathrm{H} ;{ }^{13} \mathrm{C}\right.$ $\operatorname{NMR}\left(100 \mathrm{MHz}, \mathrm{CDCl}_{3}\right) \delta 195.5,167.2,164.7,133.1,131.0,126.3,125.9(\mathrm{~d}, J=$ $290.4 \mathrm{~Hz}), 115.4,115.2$, 113.6, 40.7; High Res $\mathrm{MS}\left(\mathrm{ES}^{+}\right)$Calculated for $\left[\mathrm{C}_{14} \mathrm{H}_{11} \mathrm{FN}_{3} \mathrm{O}\right]^{+}\left(\mathrm{MH}^{+}\right): 255.0881$; Found: 256.0882 .

4-hydroxy-1-(5-methyl-1H-benzo[d][1,2,3]triazol-4-yl)hexan-2-one (5-4f)

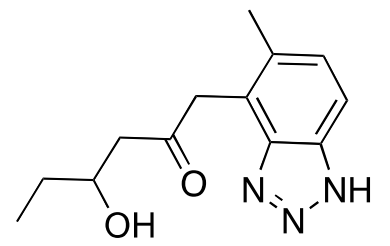

\section{5-4f}

Compound 5-4f was prepared in $41 \%$ yield according to the general procedure (eluents: ethylacetate: hexane $=2: 3) .{ }^{1} \mathrm{H} \mathrm{NMR}\left(400 \mathrm{MHz}, \mathrm{CDCl}_{3}\right) \delta 7.60(\mathrm{~d}, 1 \mathrm{H}, J$ $=8.8 \mathrm{~Hz}), 7.22(\mathrm{~d}, 1 \mathrm{H}, J=8.4 \mathrm{~Hz}), 4.27(\mathrm{~s}, 2 \mathrm{H}), 4.10(\mathrm{~m}, 1 \mathrm{H}), 2.73(\mathrm{~m}, 2 \mathrm{H}), 2.4(\mathrm{~s}$, $3 \mathrm{H}), 1.53(\mathrm{~m}, 2 \mathrm{H}), 0.93(\mathrm{t}, 3 \mathrm{H}, J=7.2 \mathrm{~Hz}) ;{ }^{13} \mathrm{C} \mathrm{NMR}\left(100 \mathrm{MHz}, \mathrm{CDCl}_{3}\right) \delta 208.4$, 
139.6, 137.5, 134.6, 129.4, 119.1, 113.3, 70.0, 48.9, 43.7, 29.8, 18.9, 9.8; High Res MS (ES $\left.{ }^{+}\right)$Calculated for $\left[\mathrm{C}_{13} \mathrm{H}_{18} \mathrm{~N}_{3} \mathrm{O}_{2}\right]^{+}\left(\mathrm{MH}^{+}\right)$: 248.1394; Found: 248.1395 
${ }^{1} \mathrm{H}$ and ${ }^{13} \mathrm{C}$ NMR spectra of compounds 5-3 

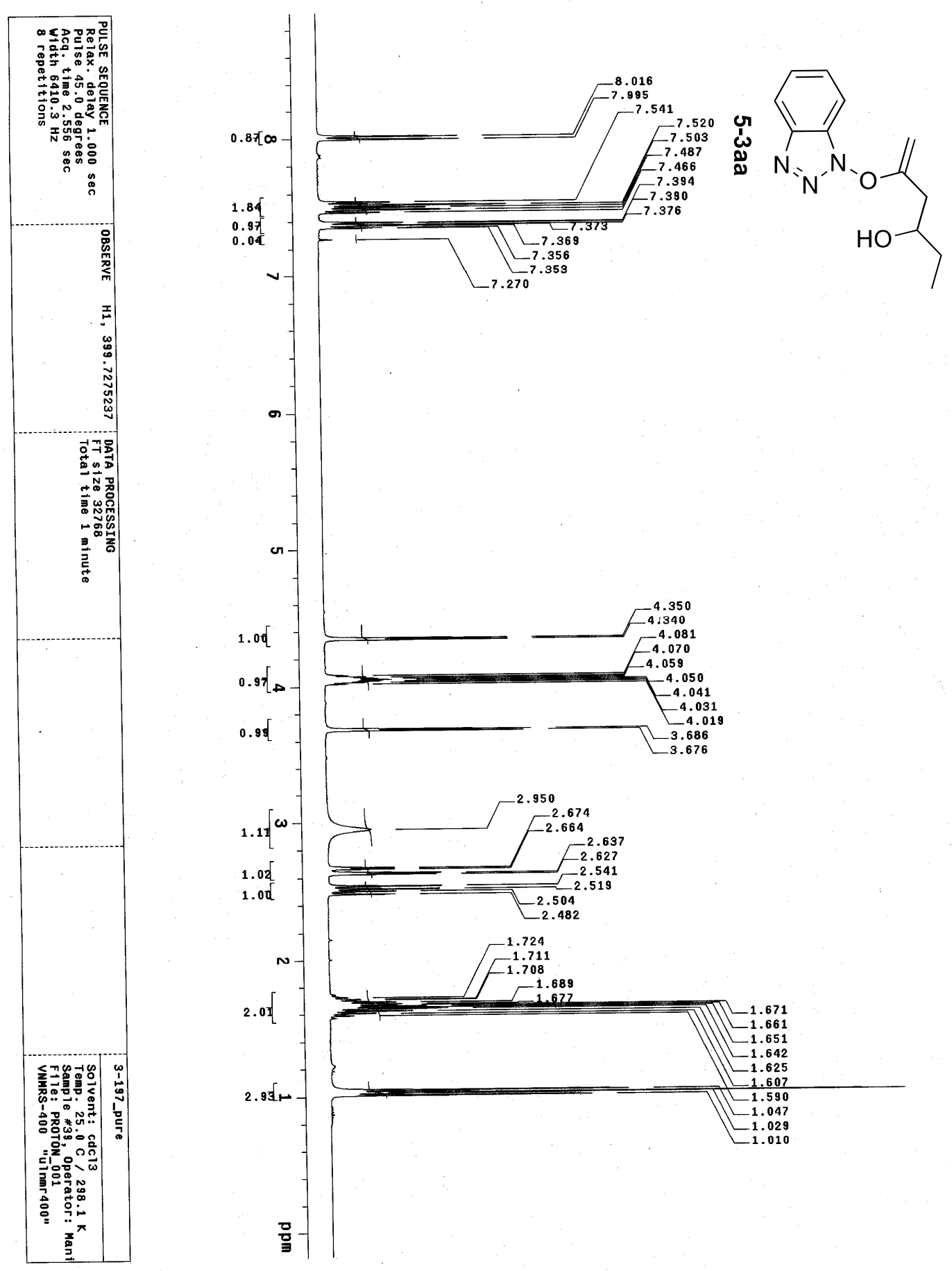

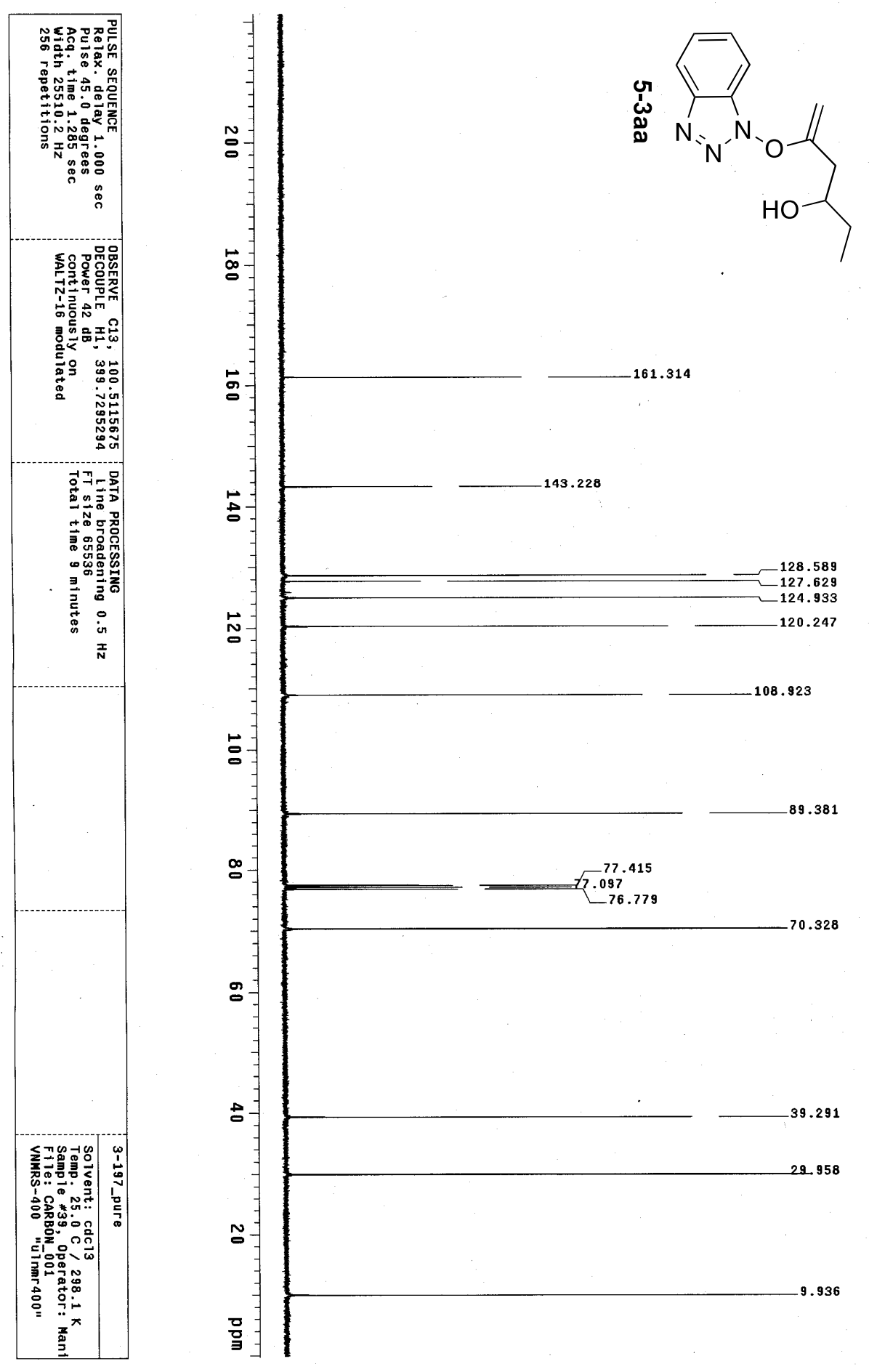

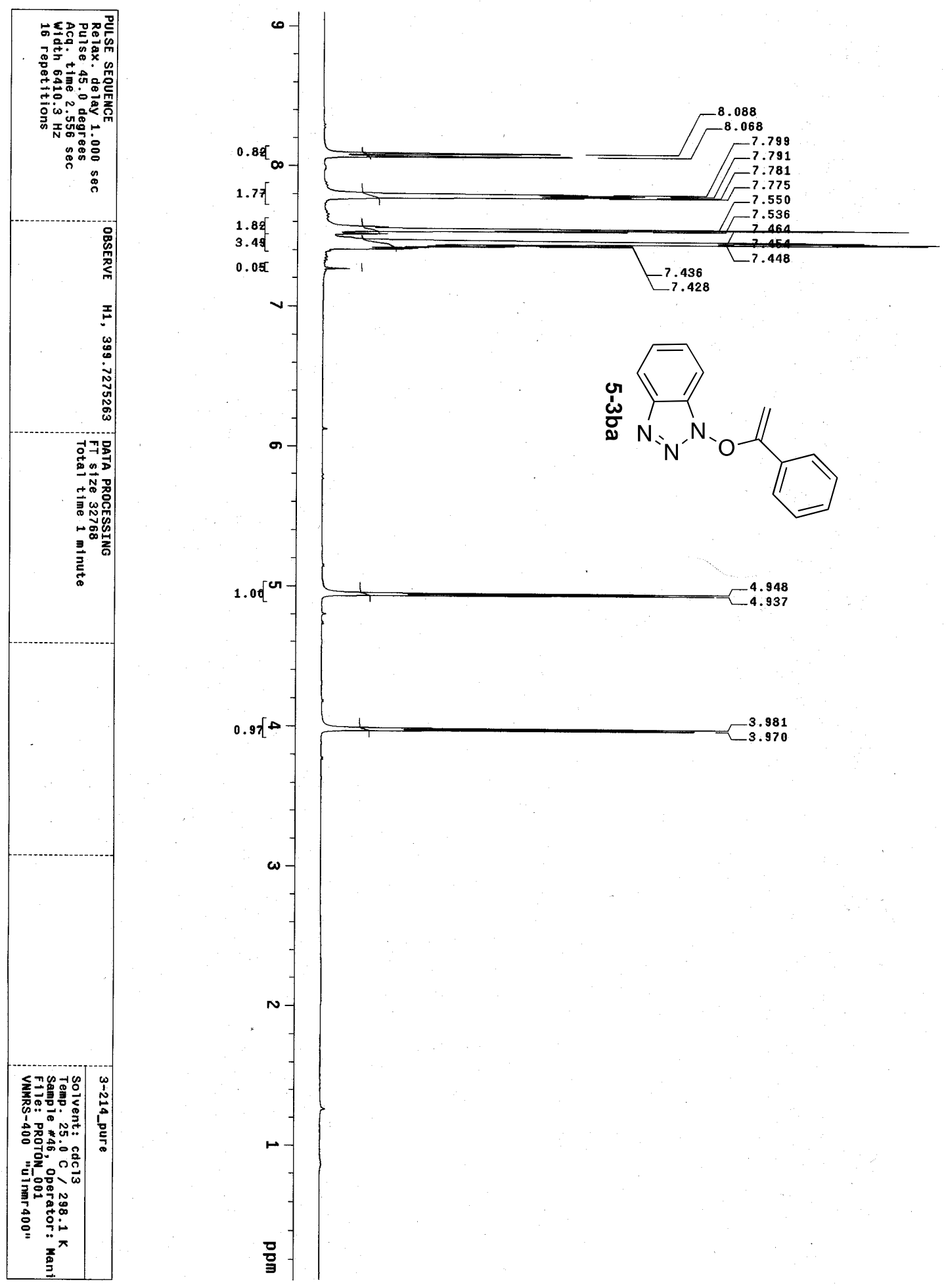


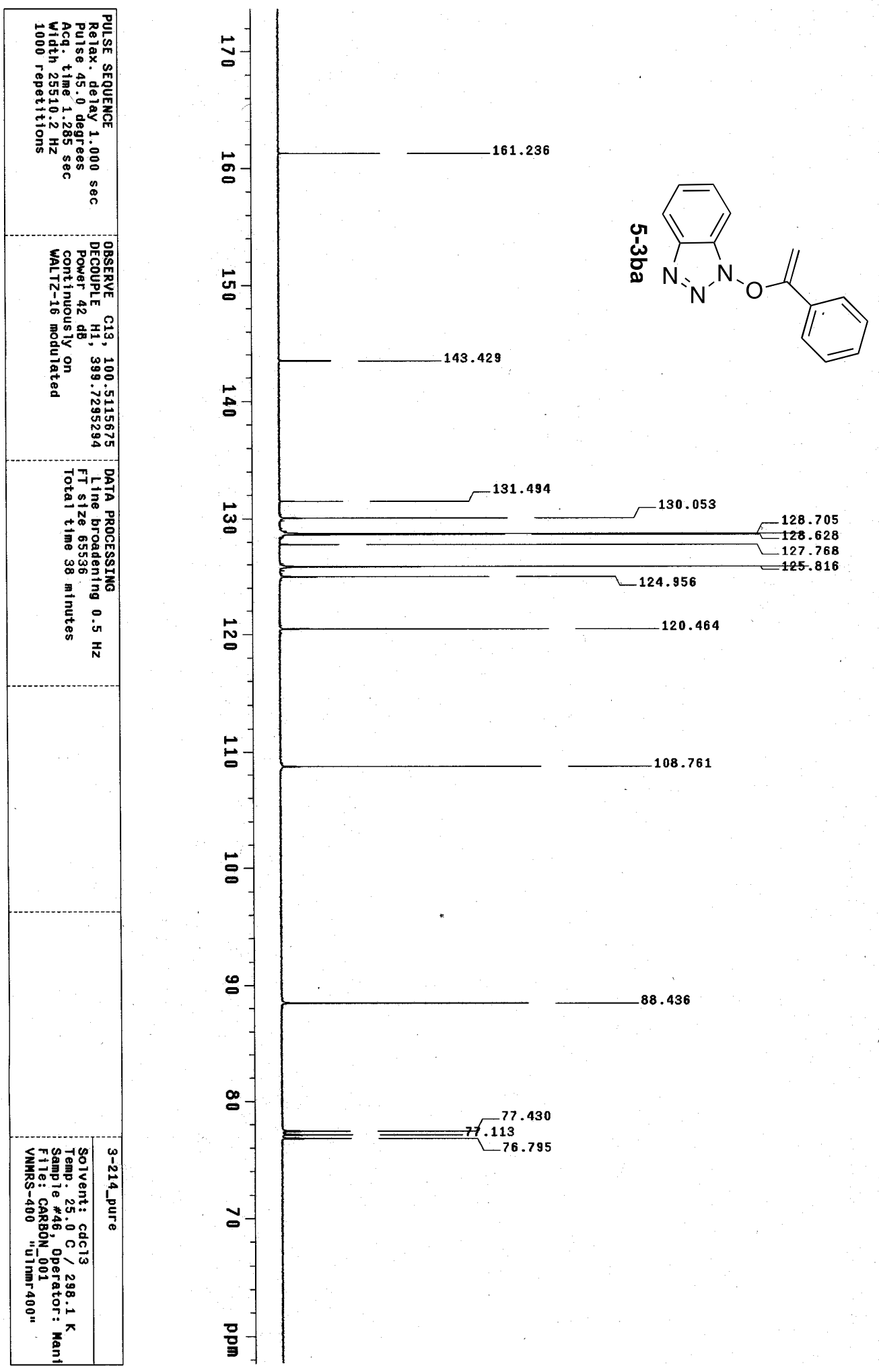



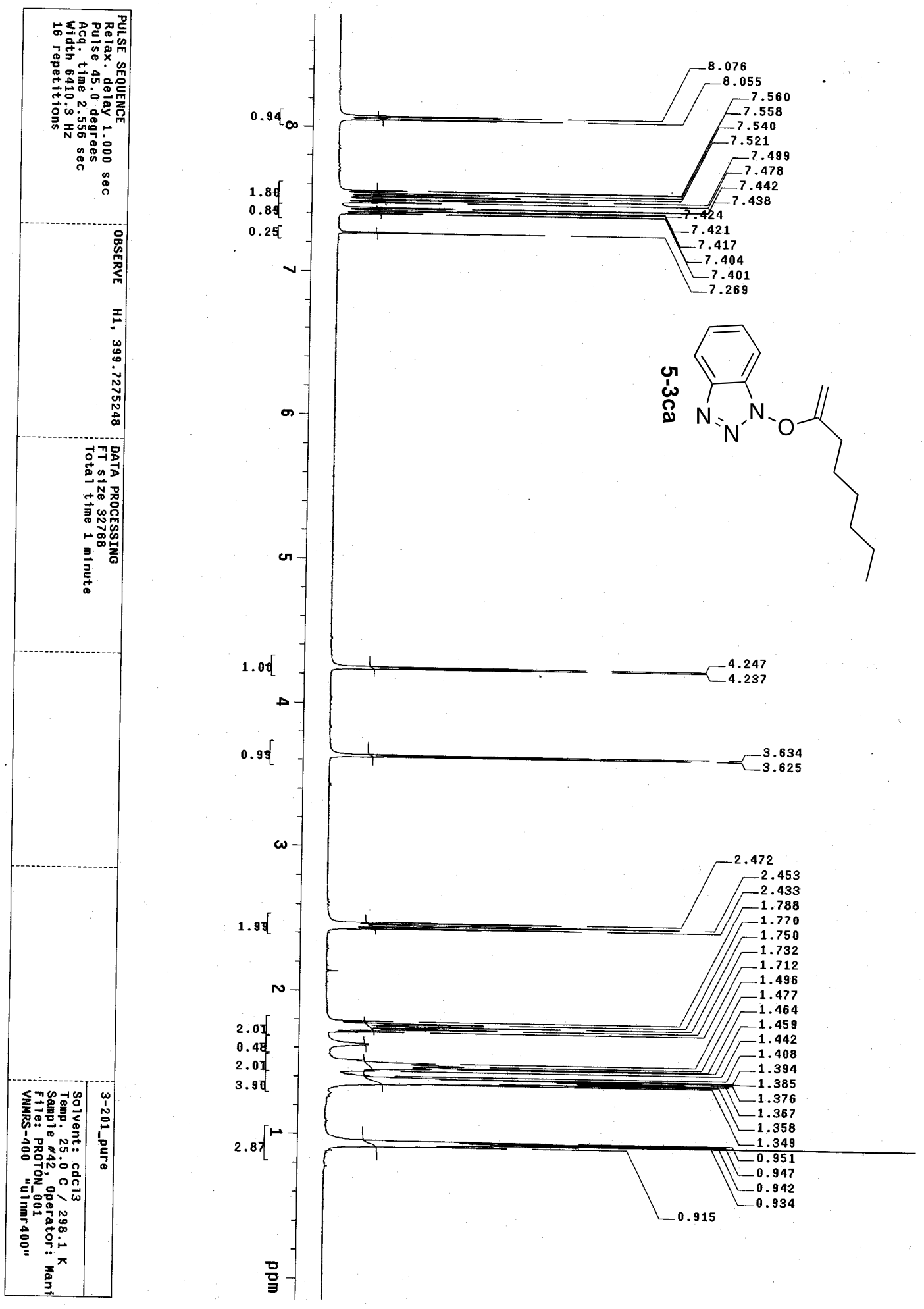


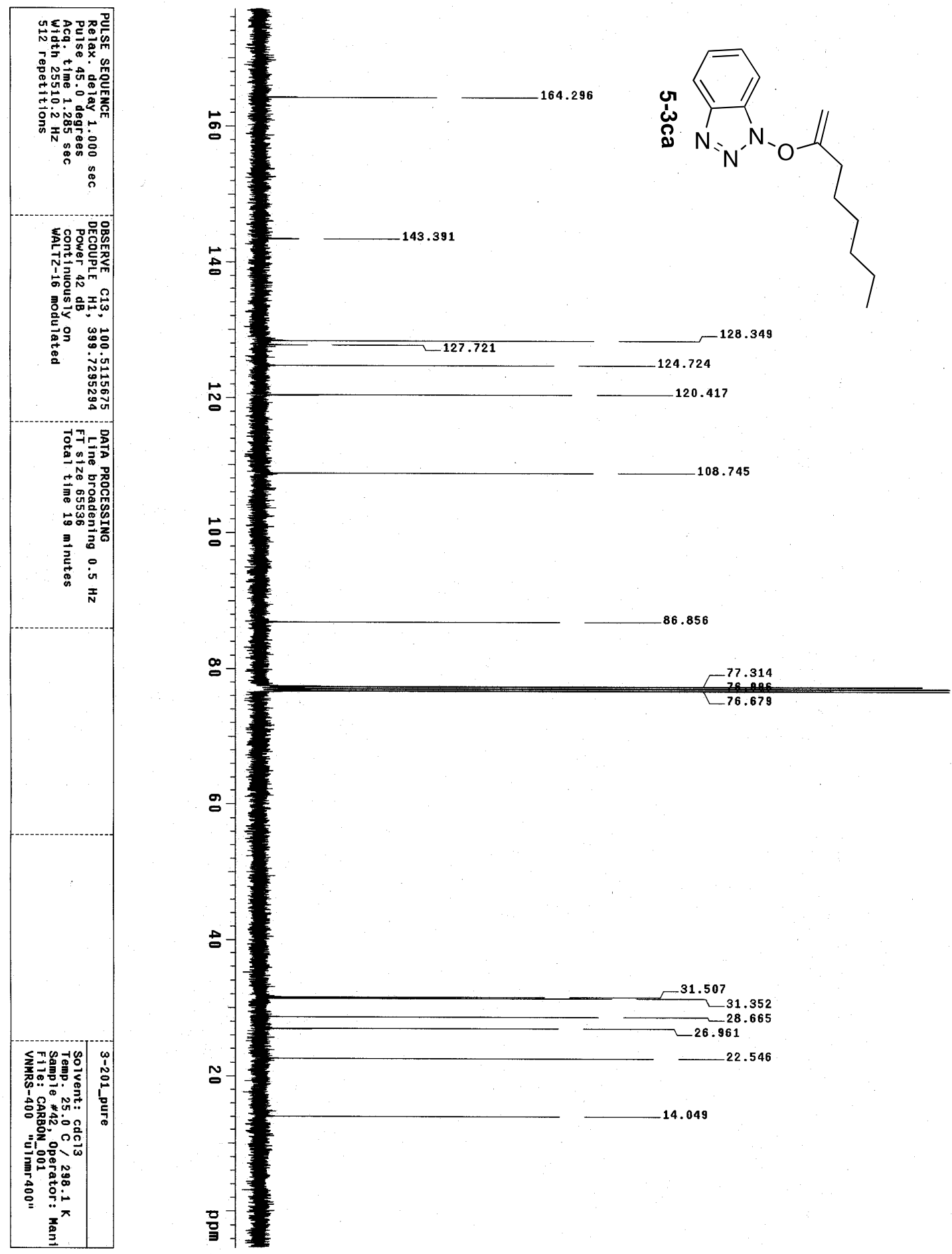



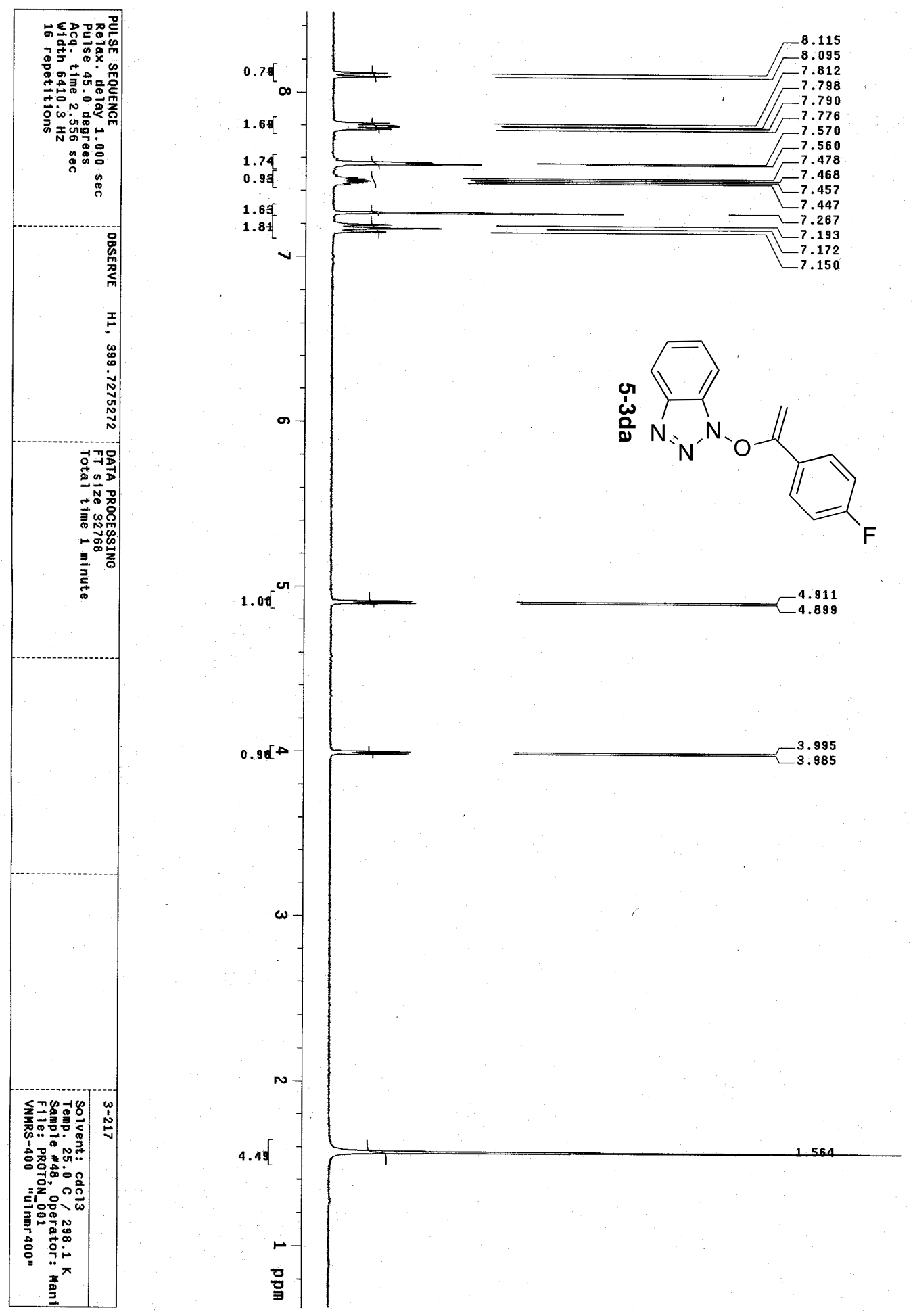


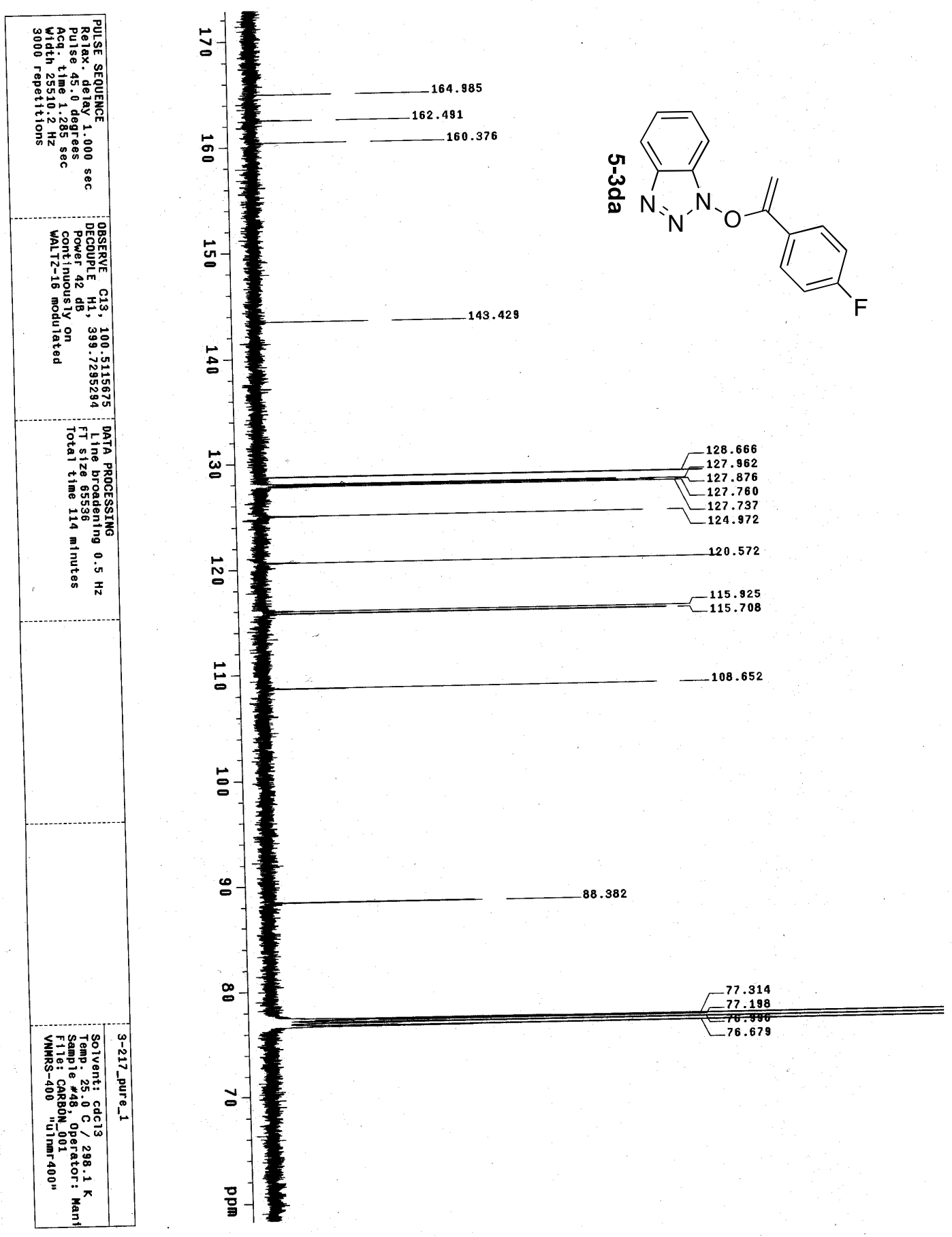



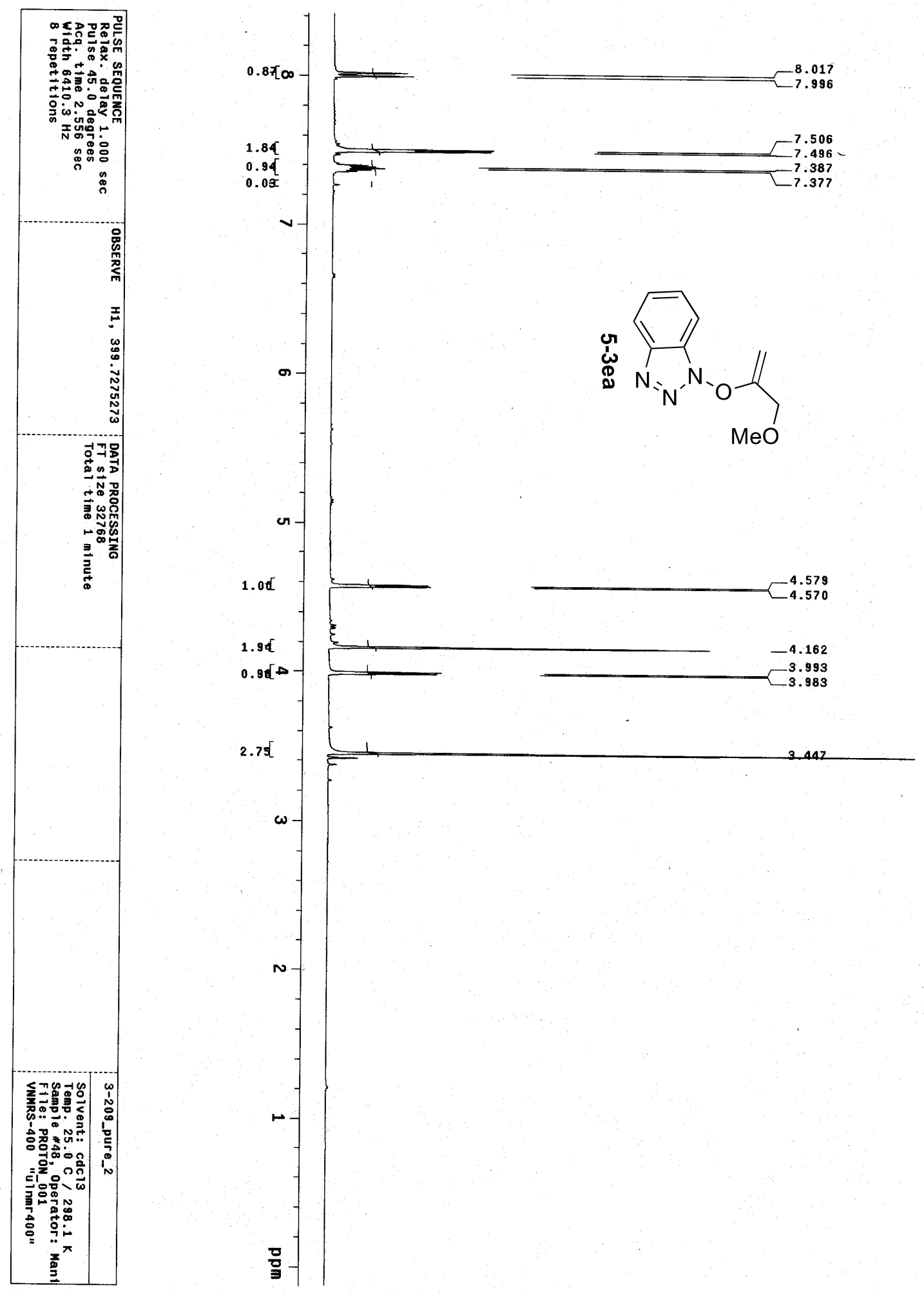


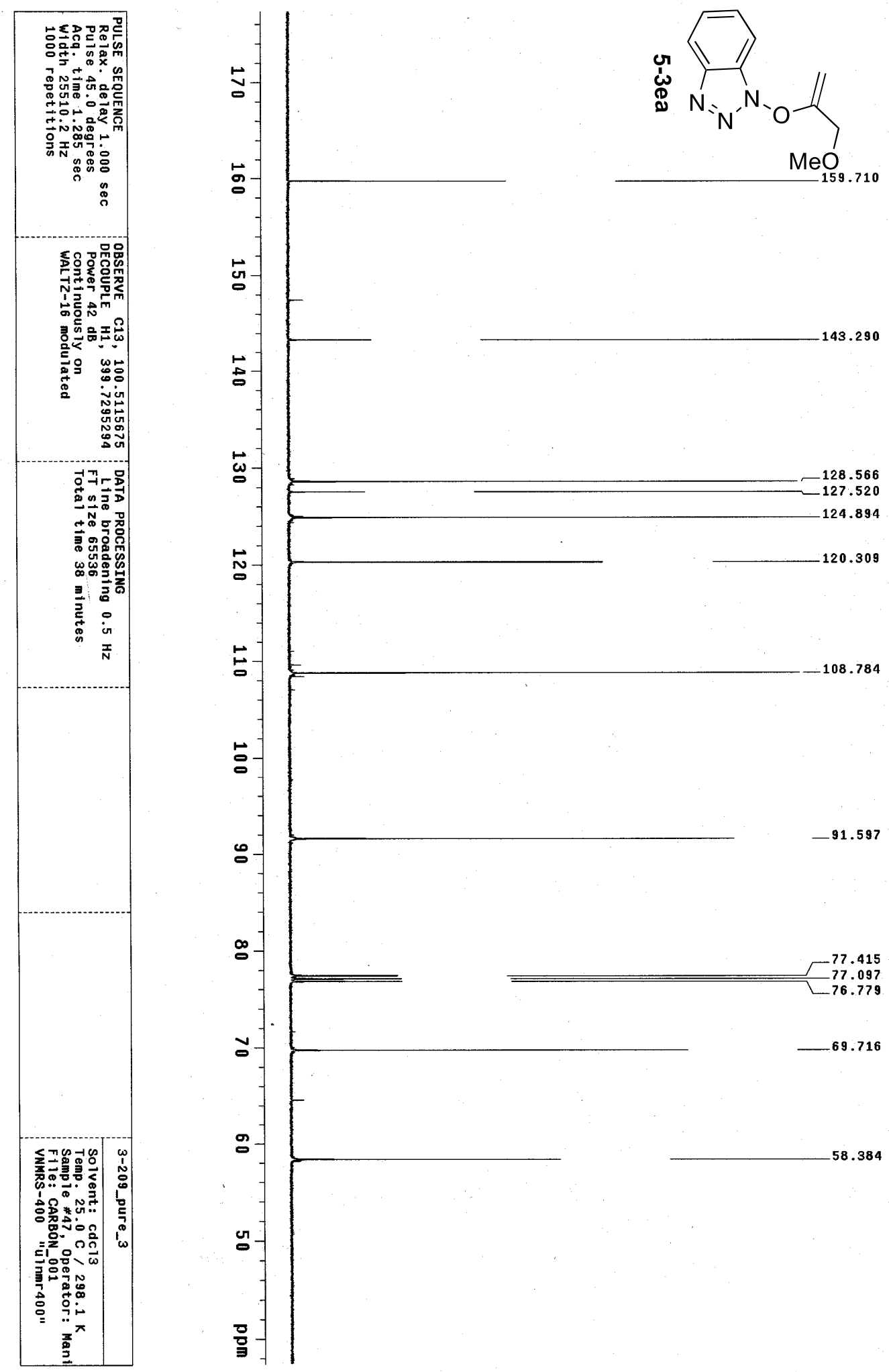




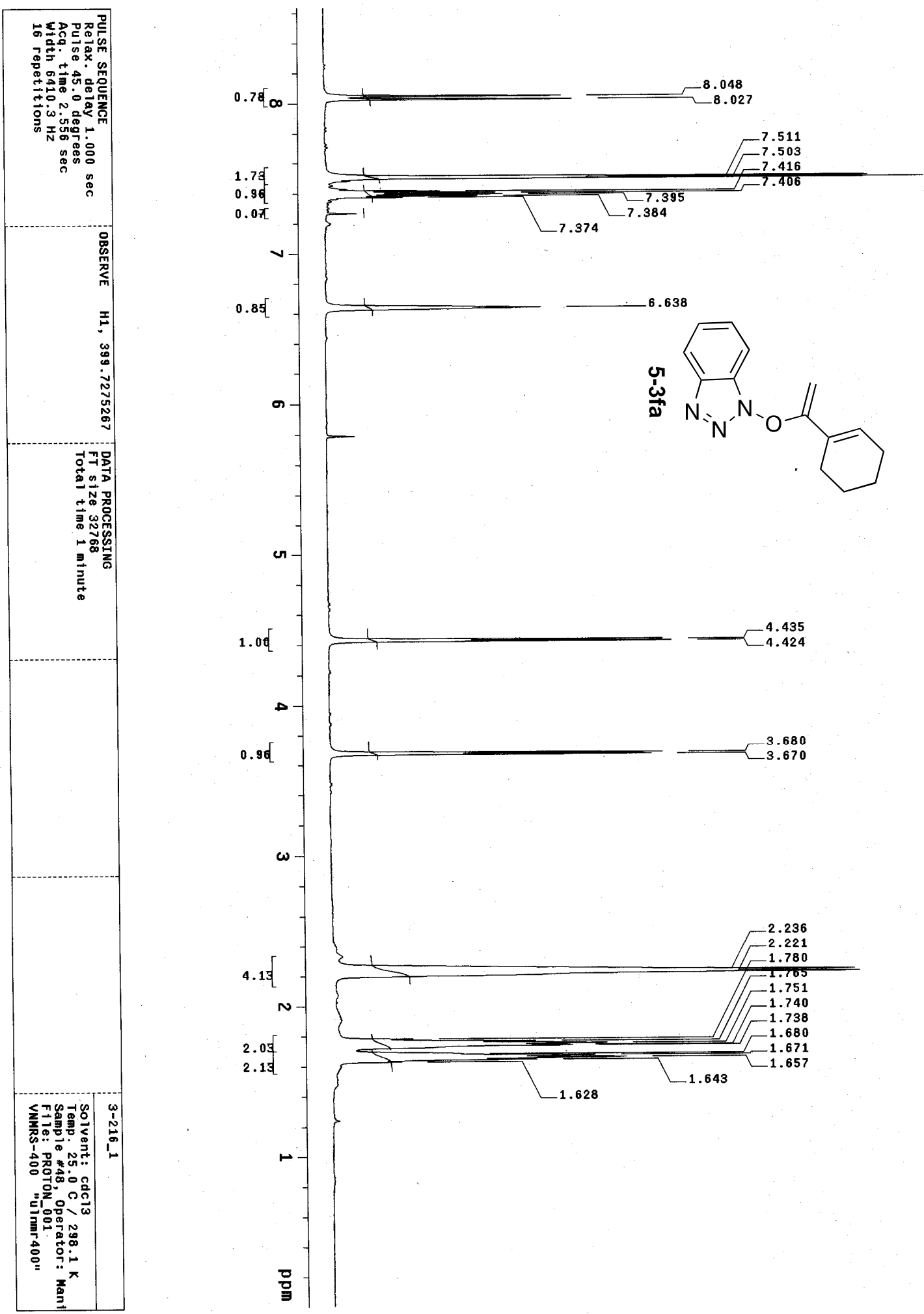




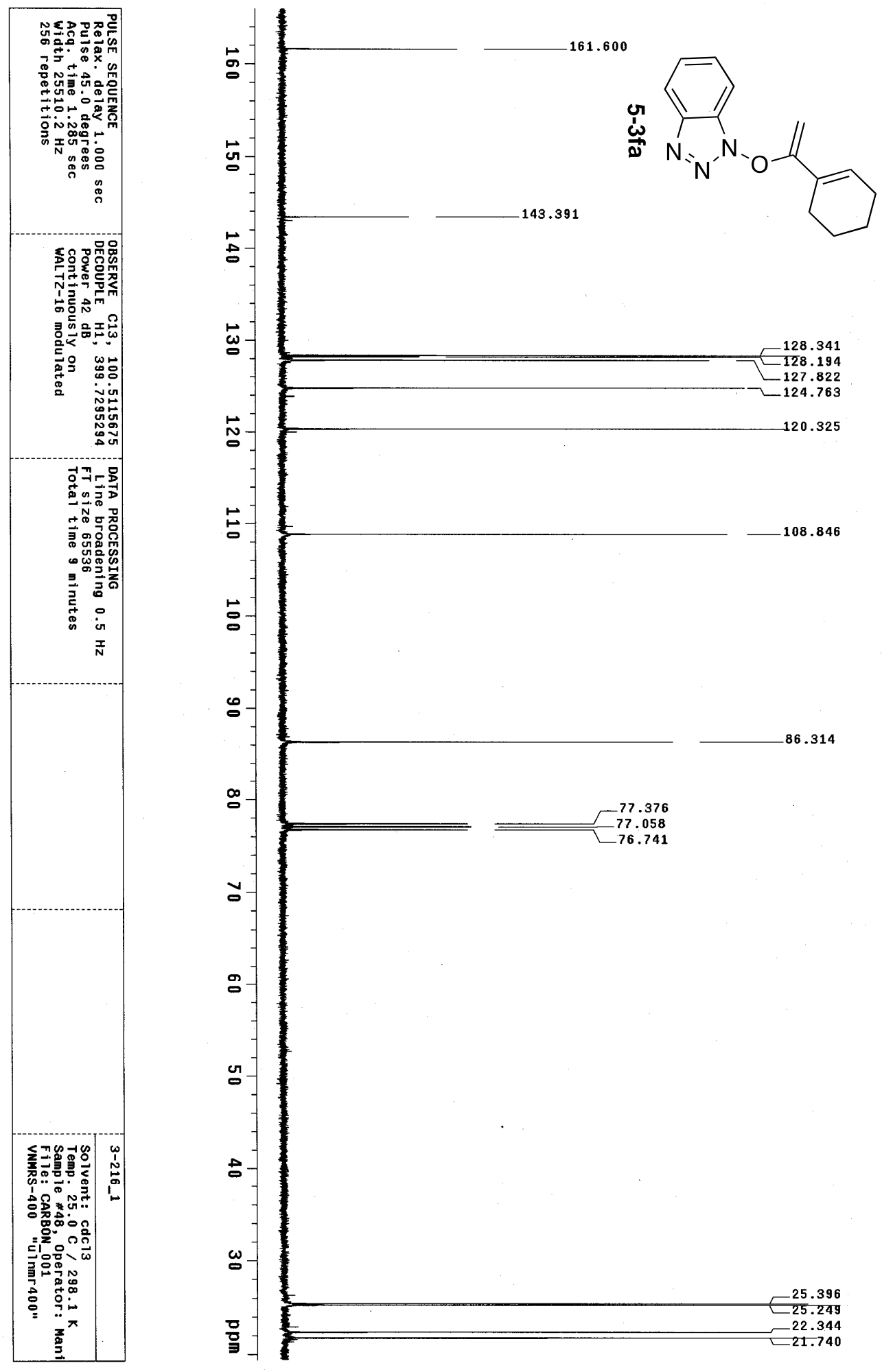



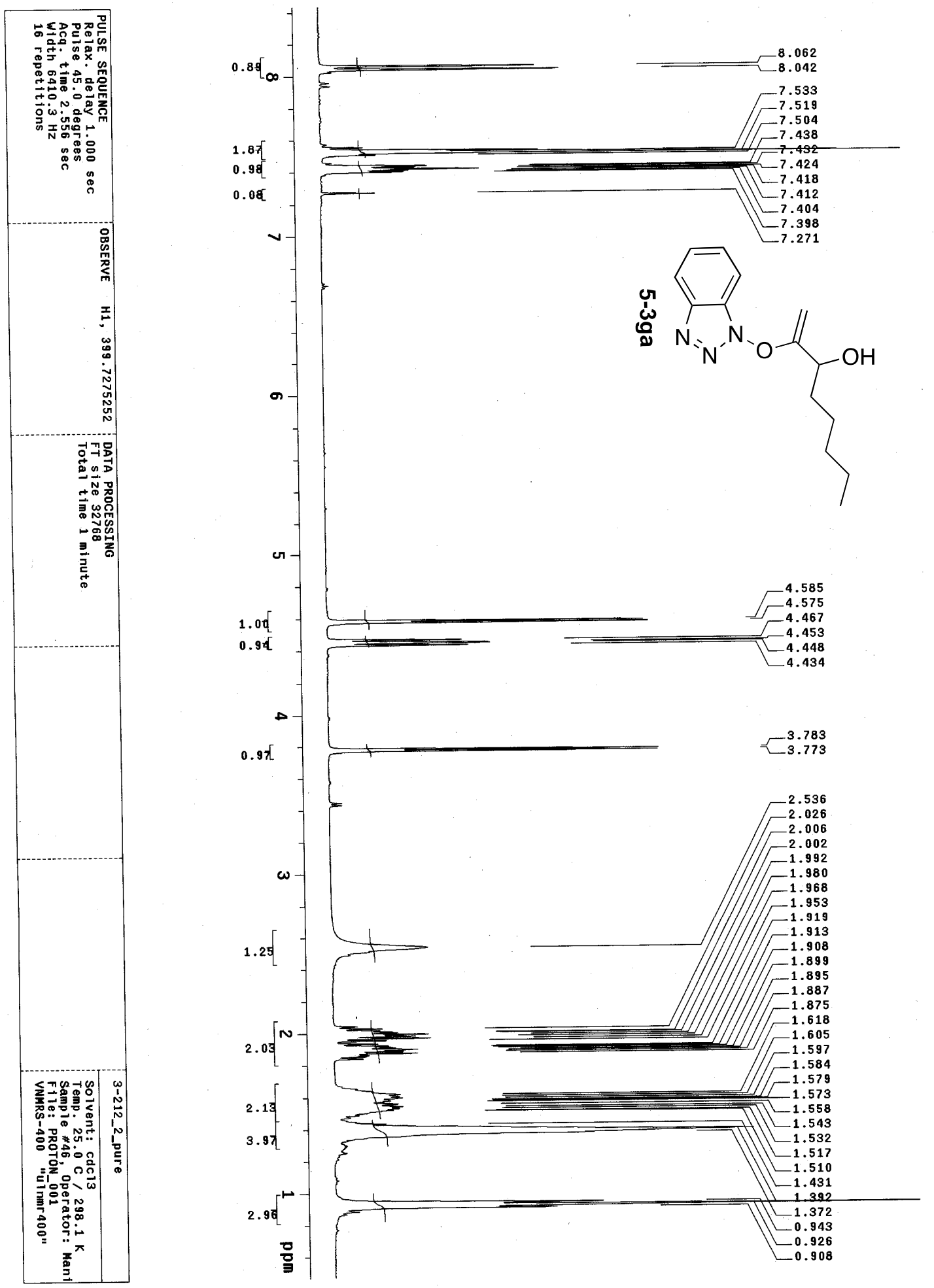

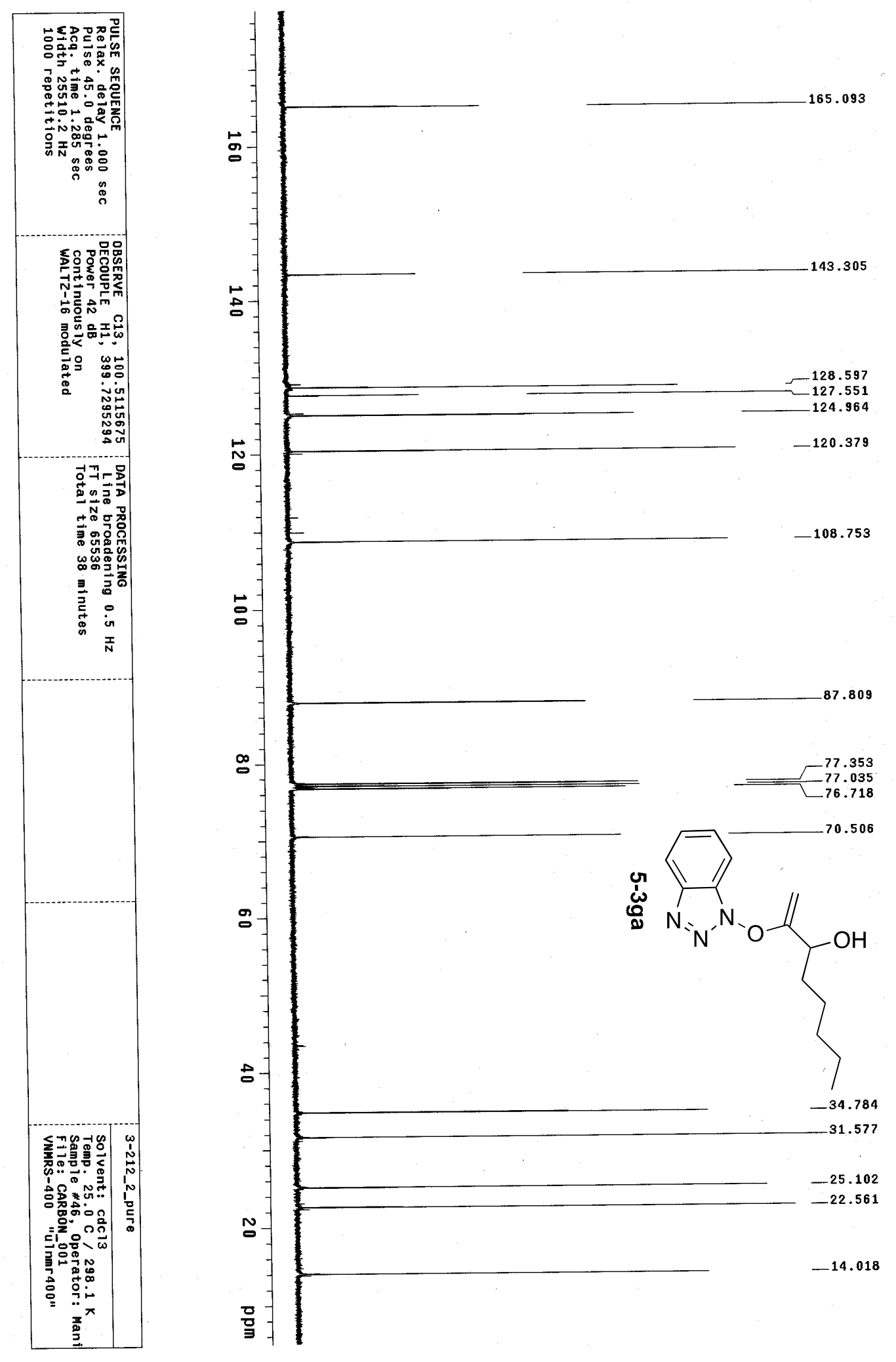

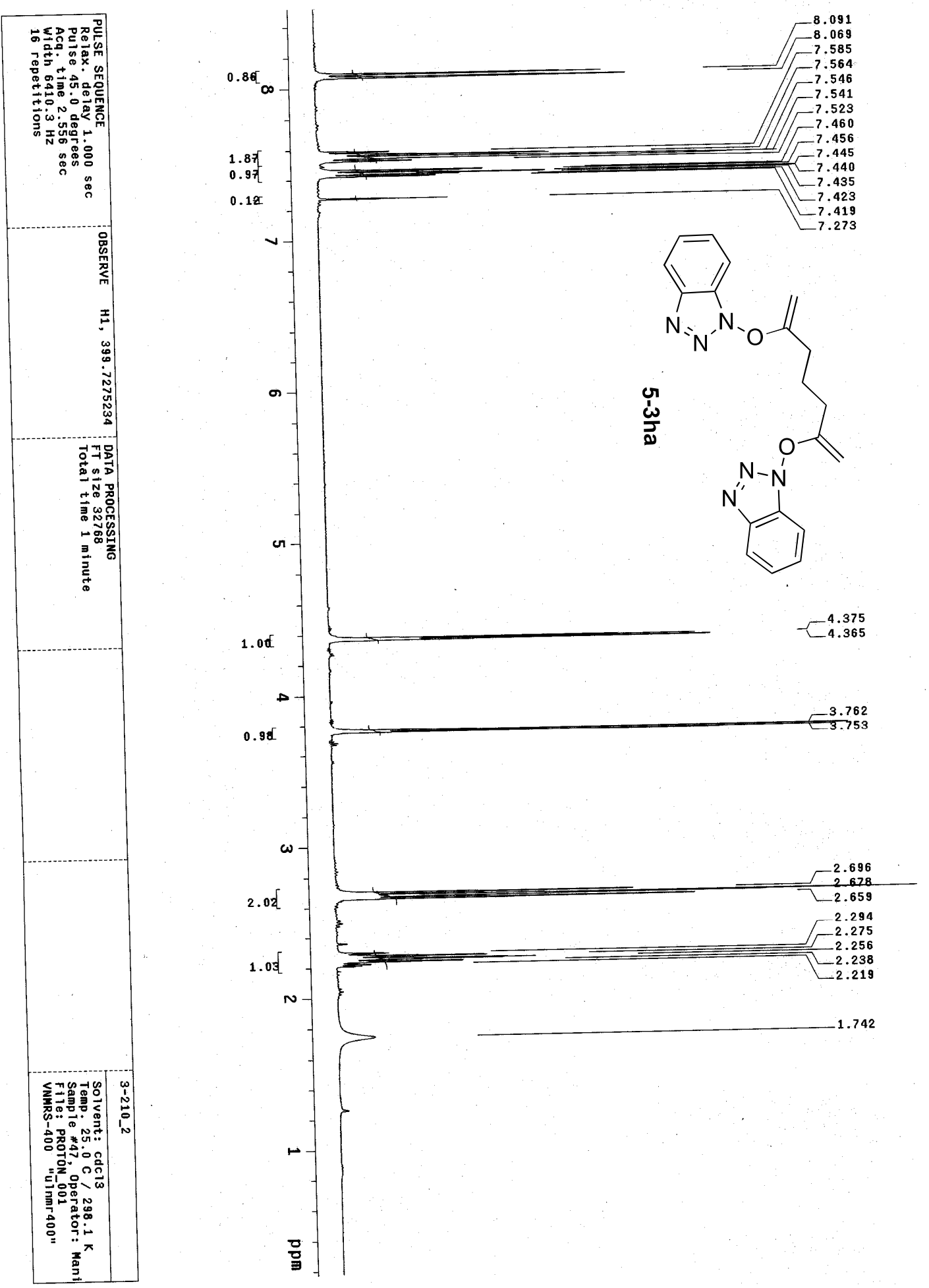


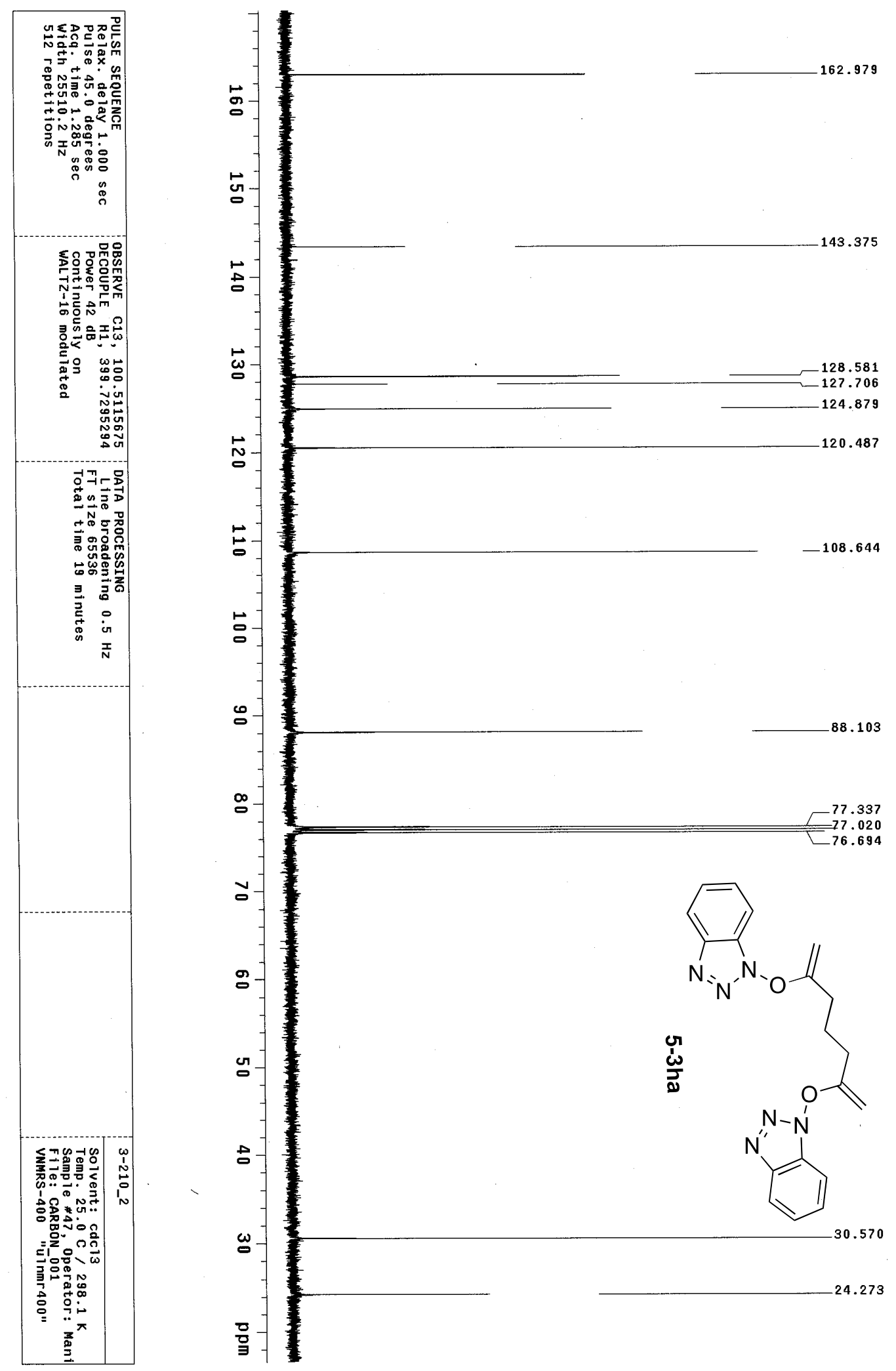



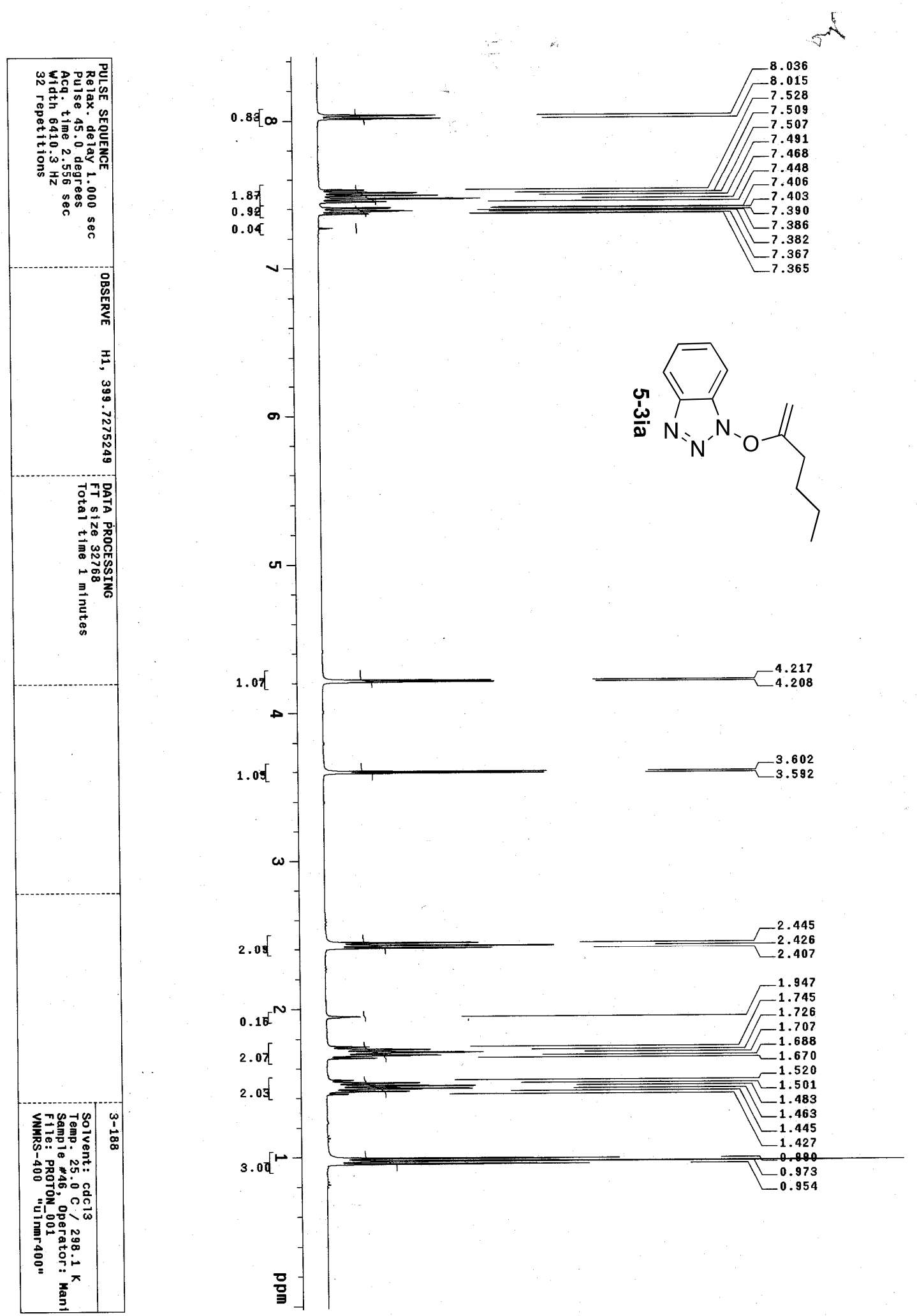


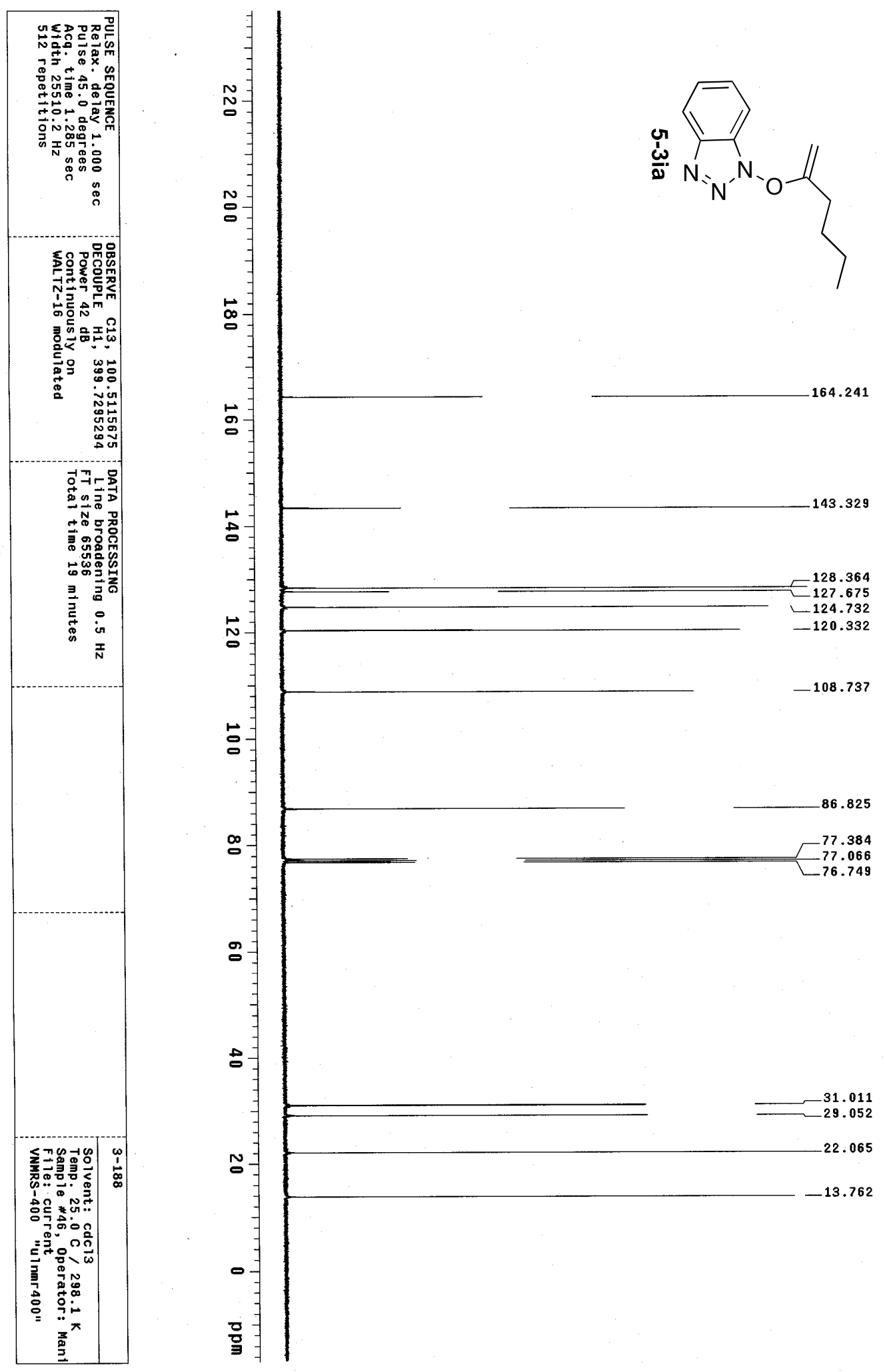



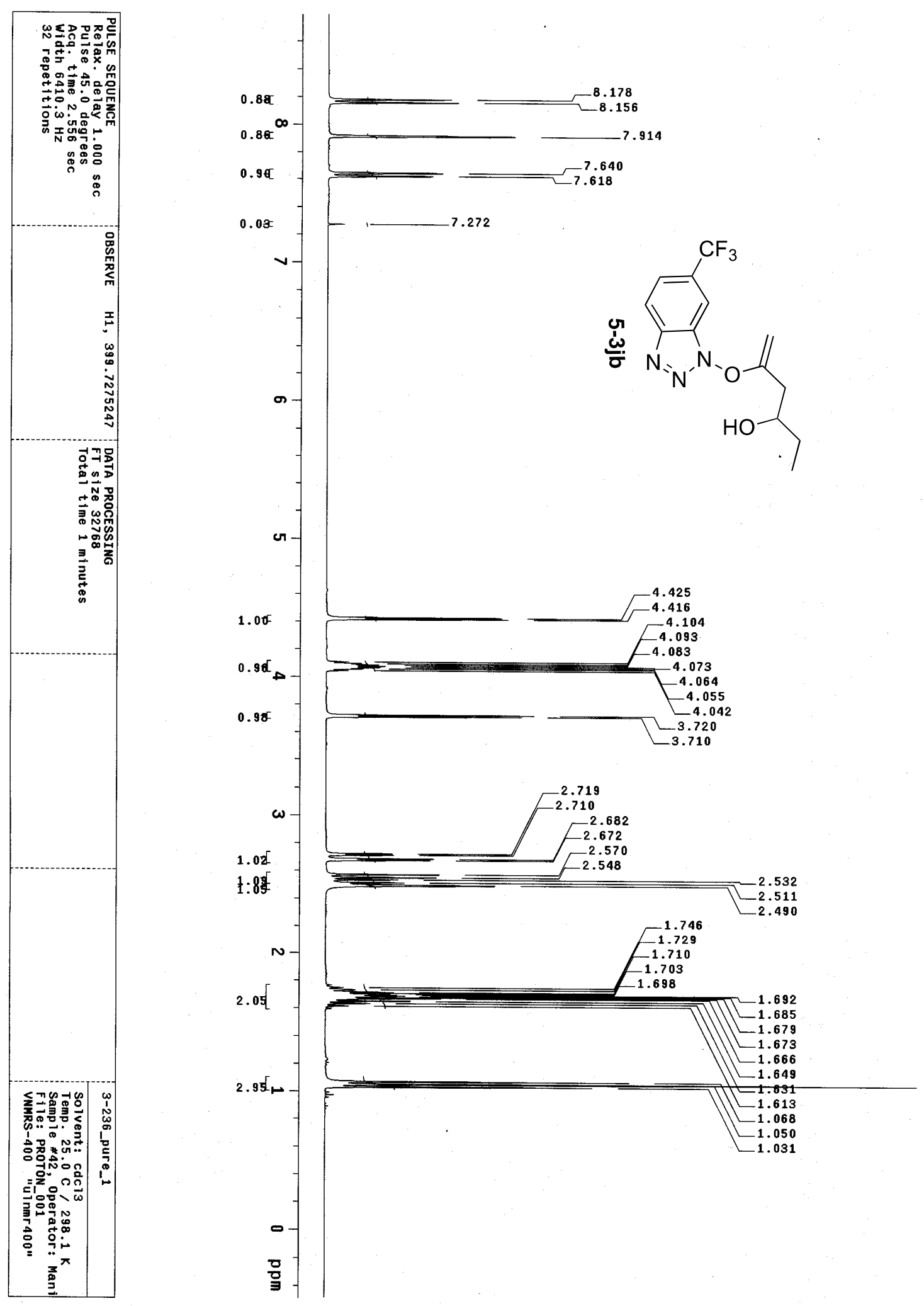

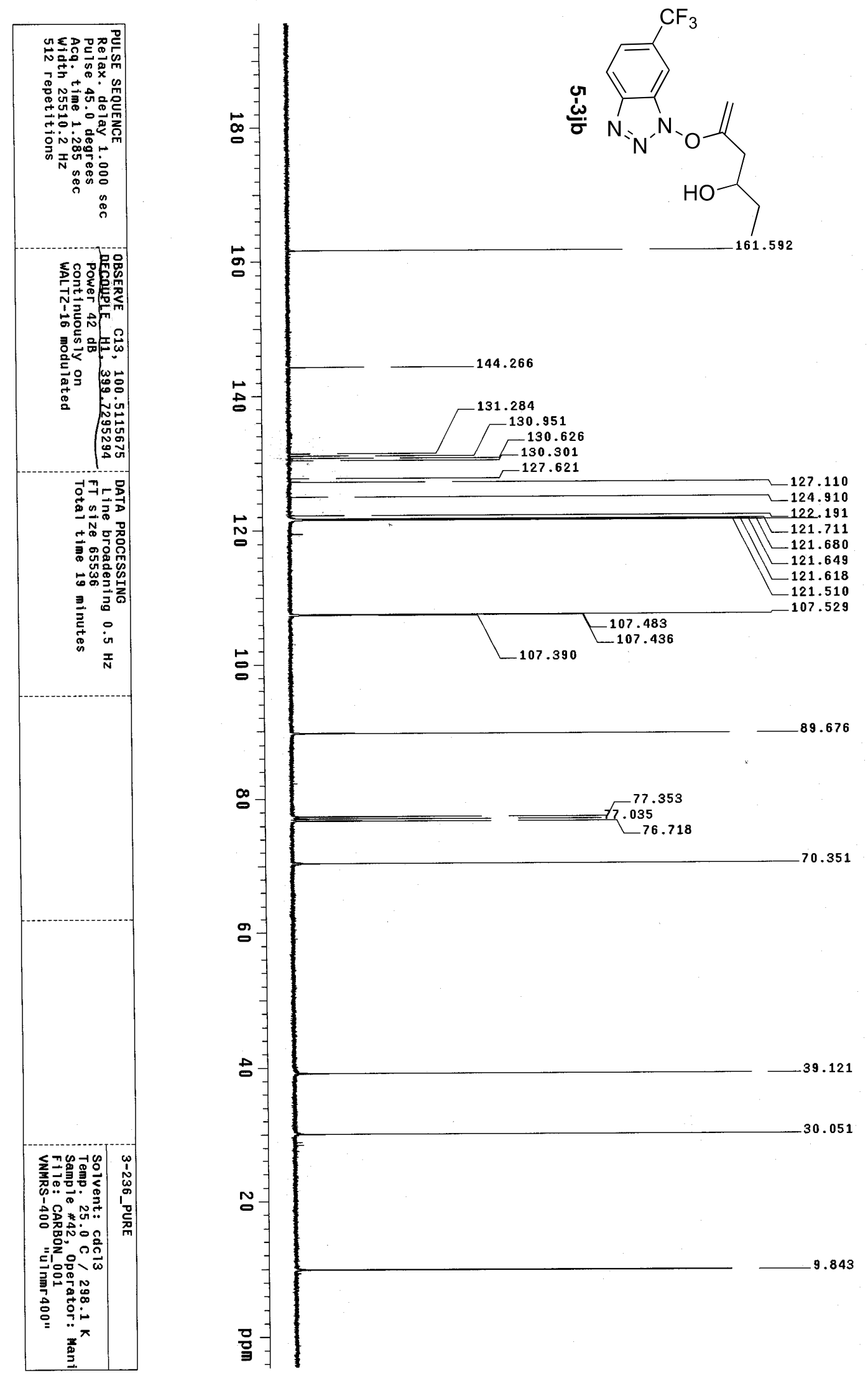

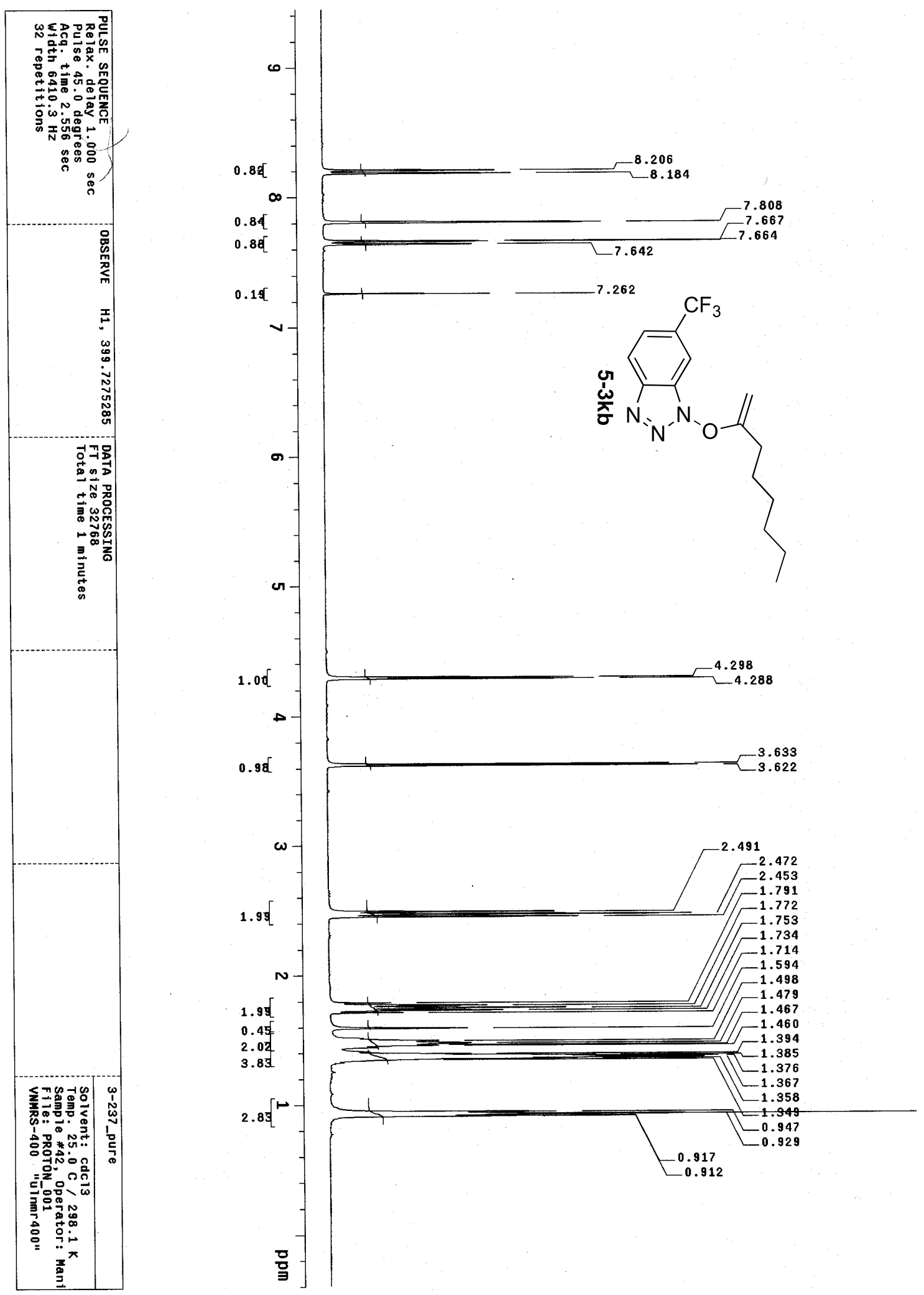


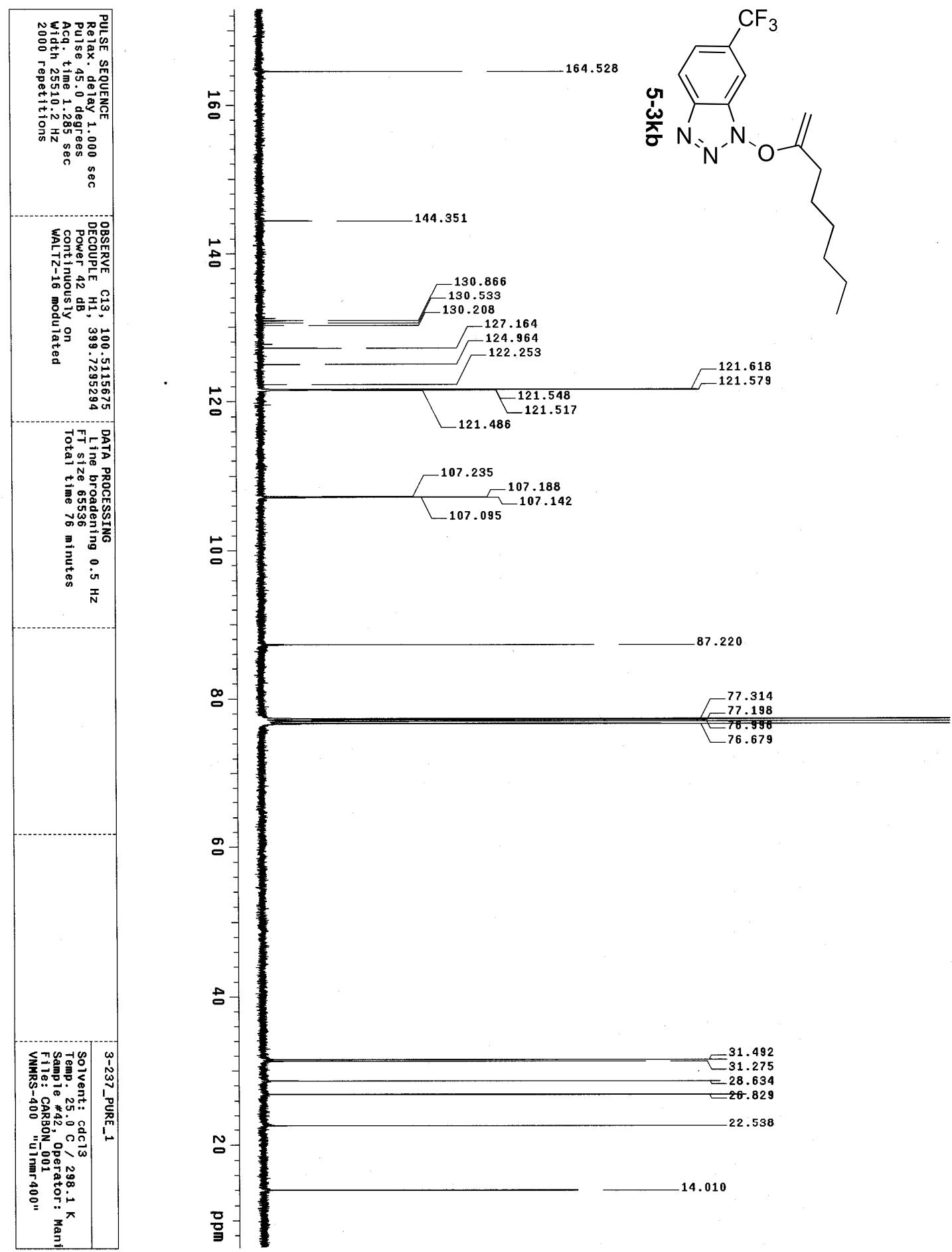



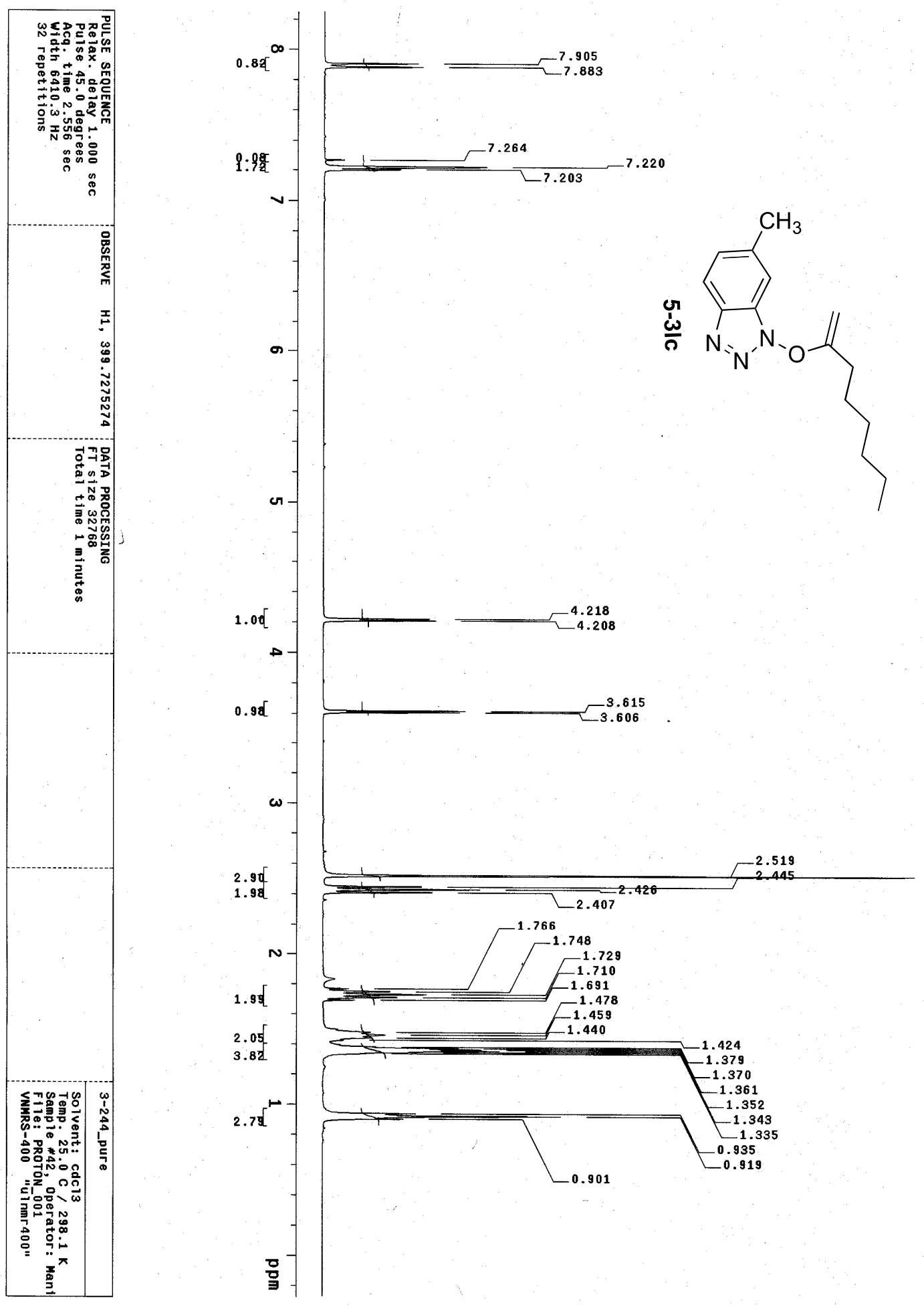

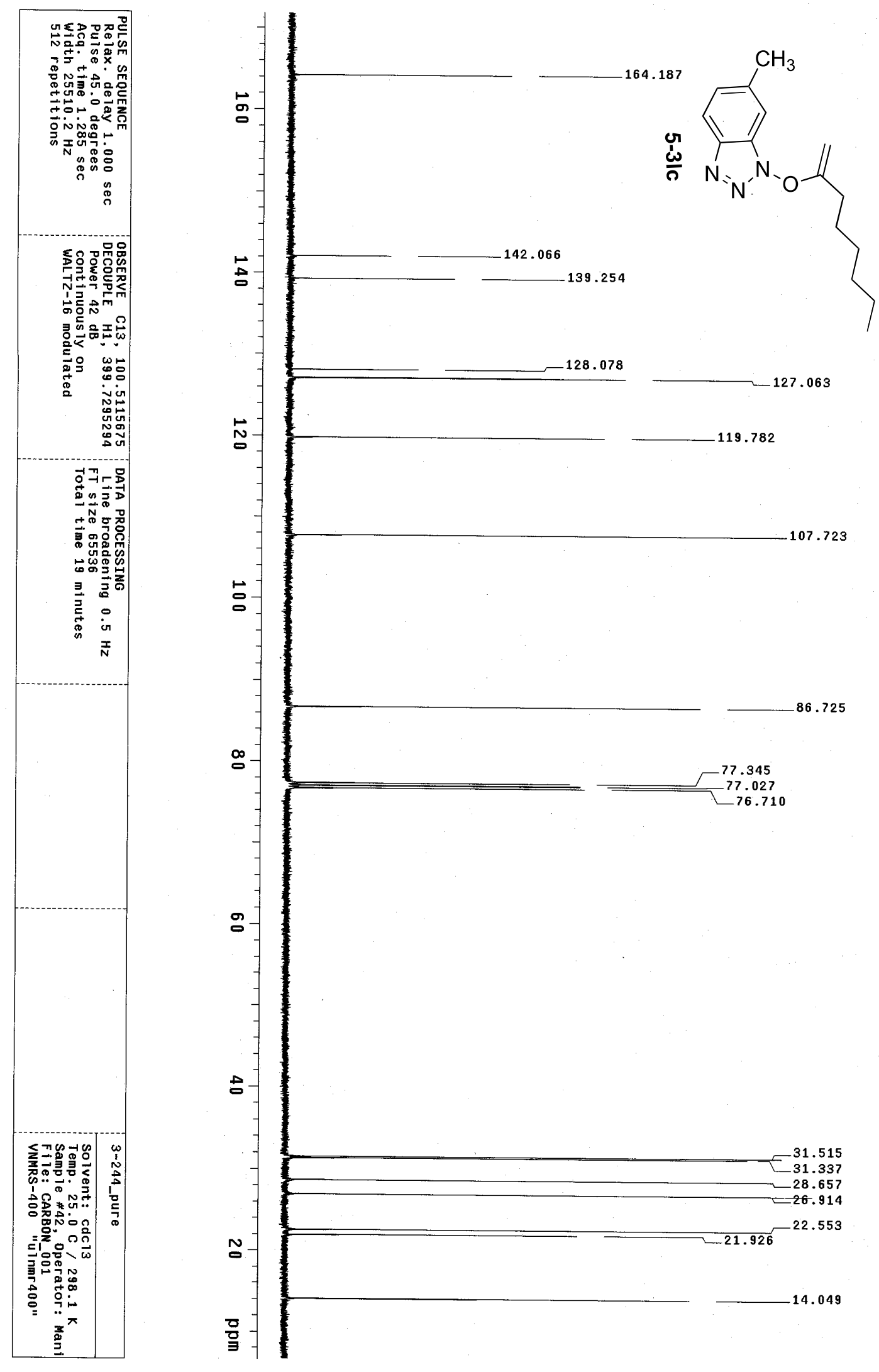

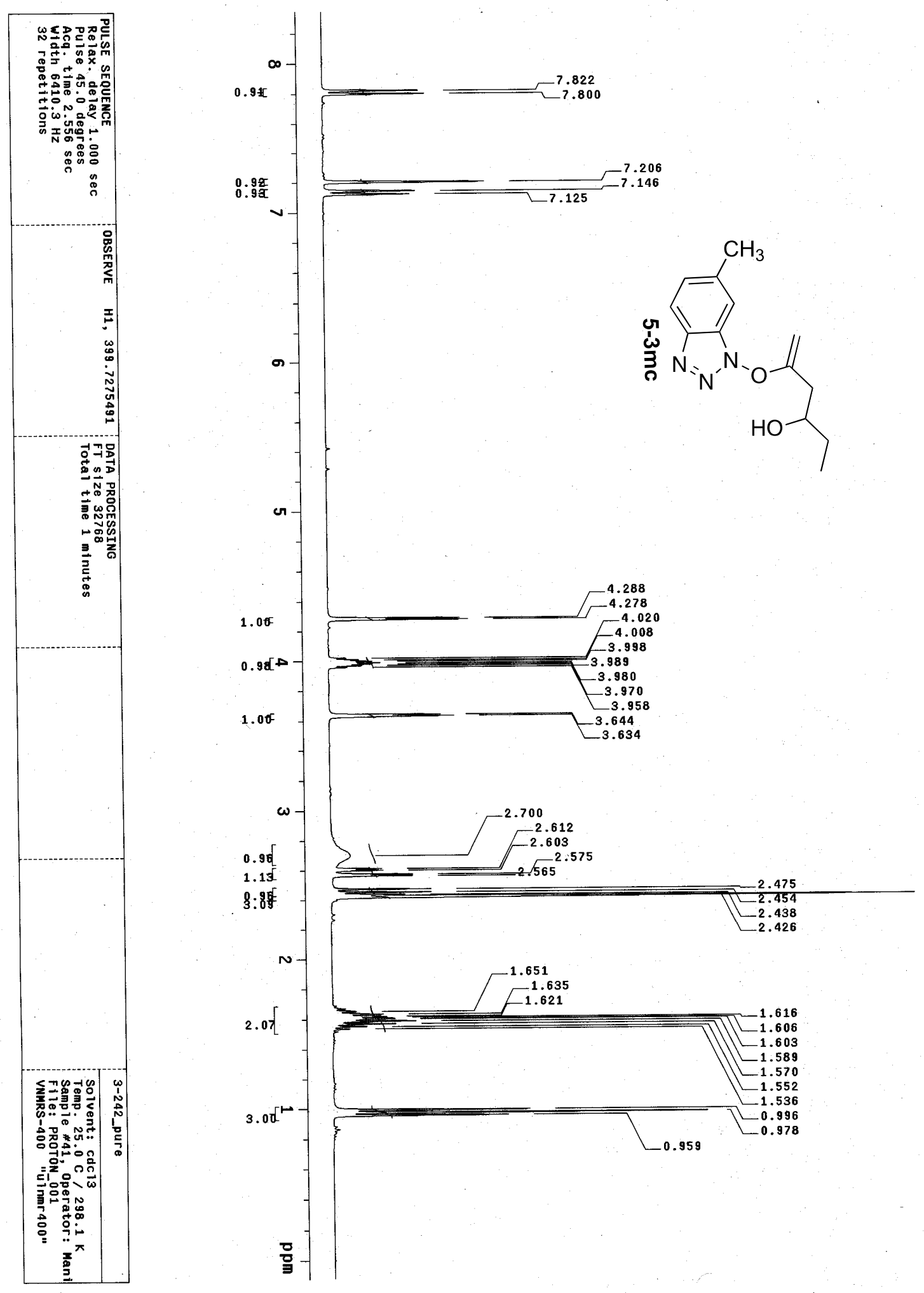

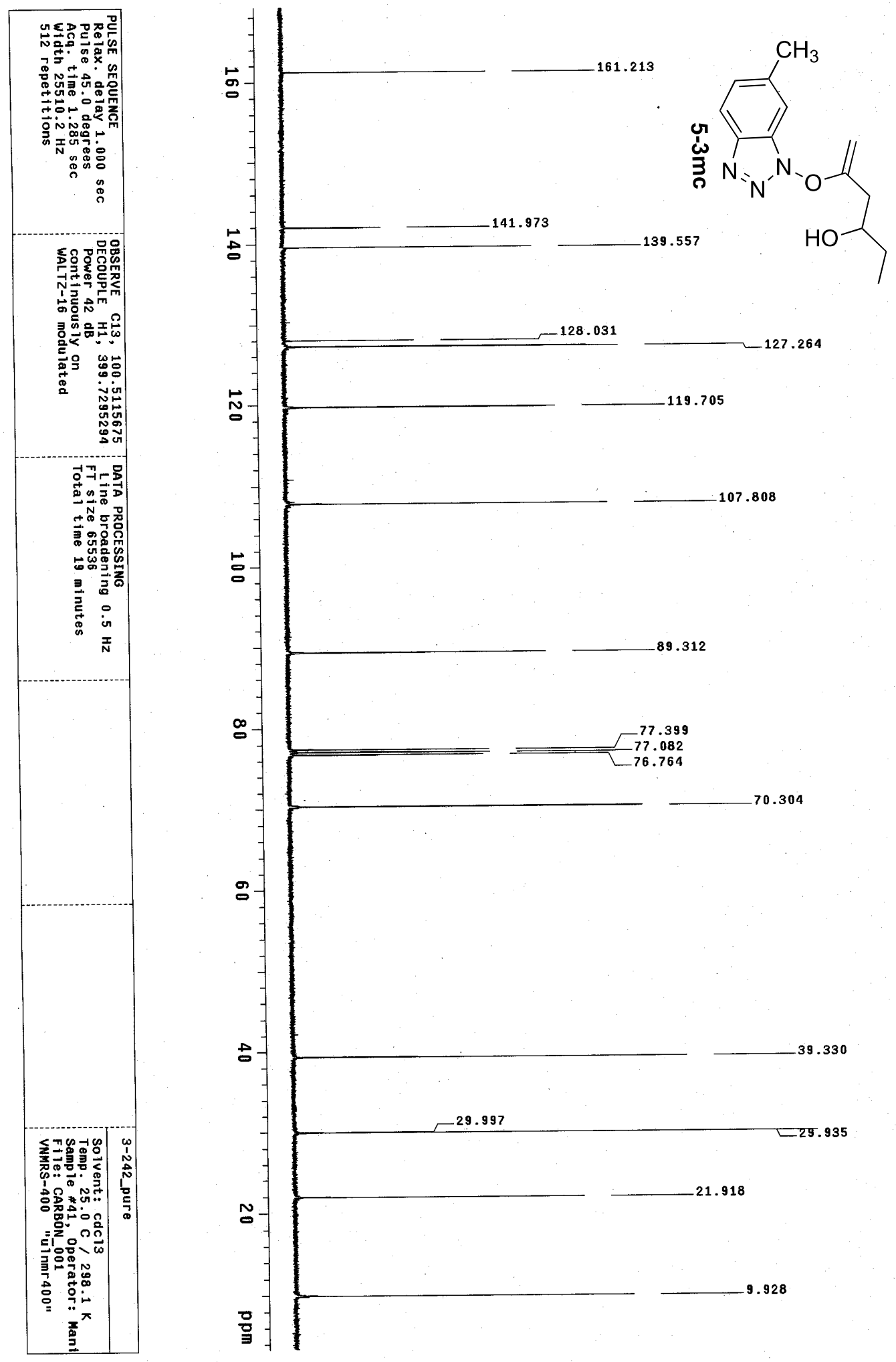


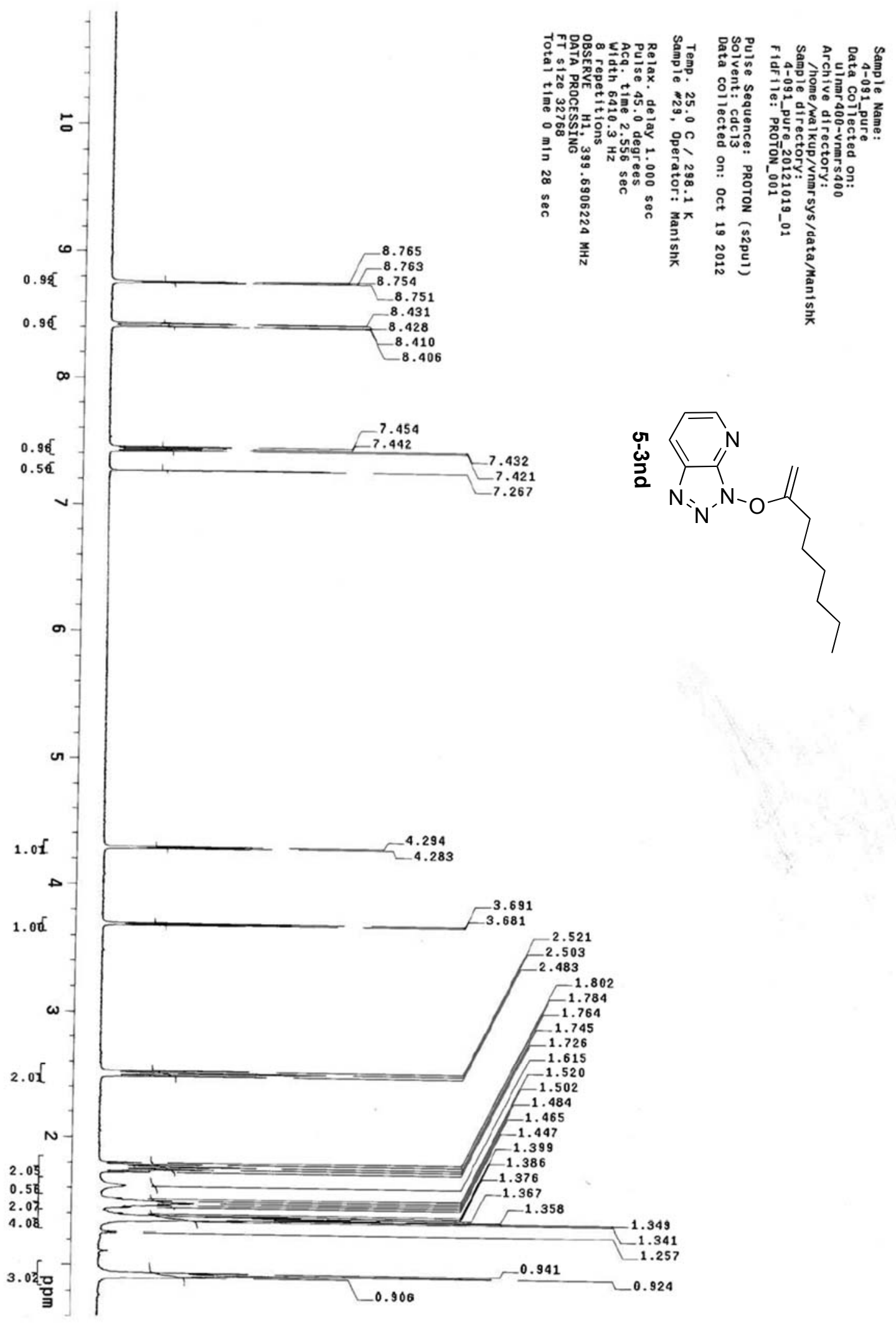




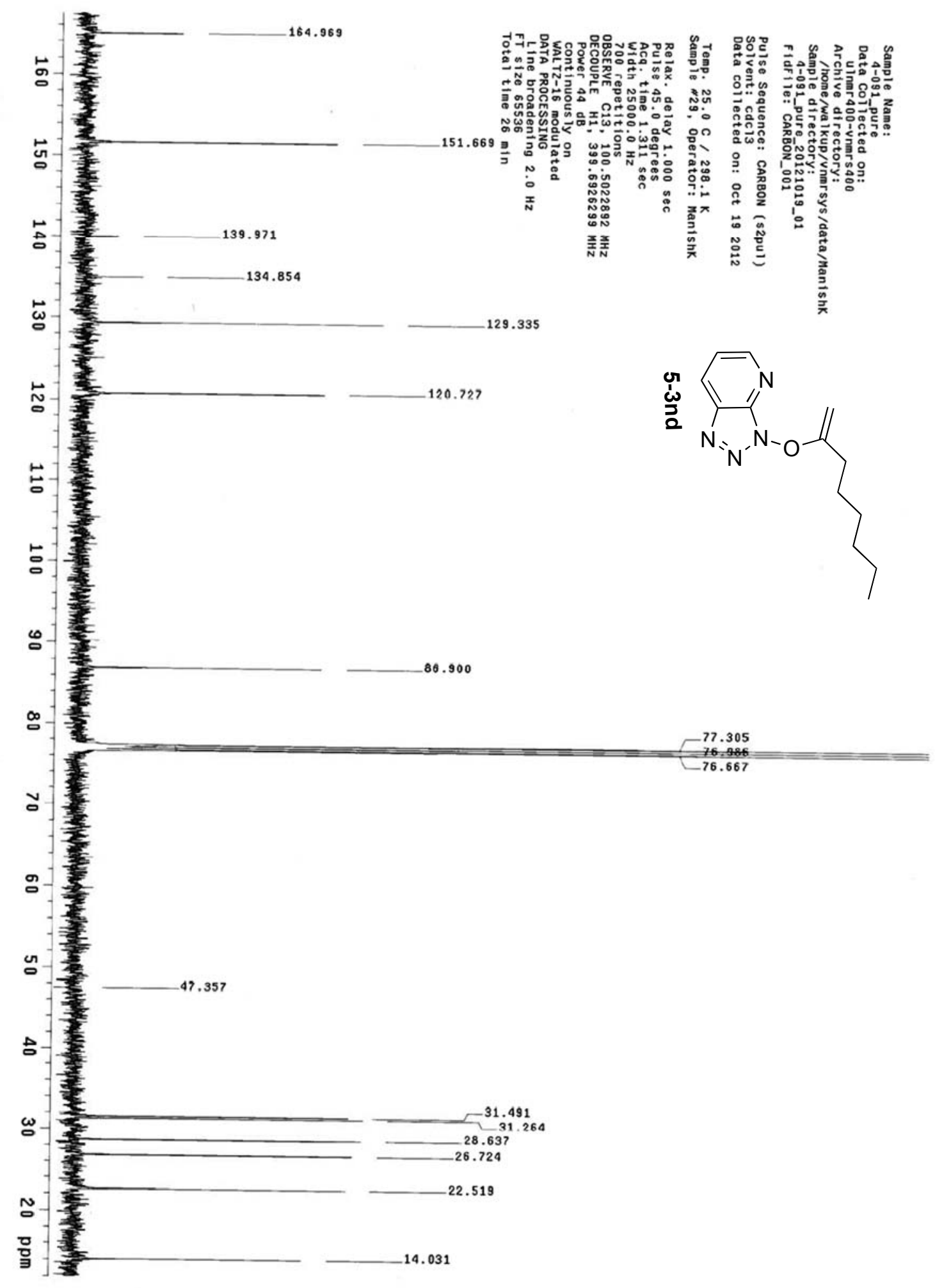




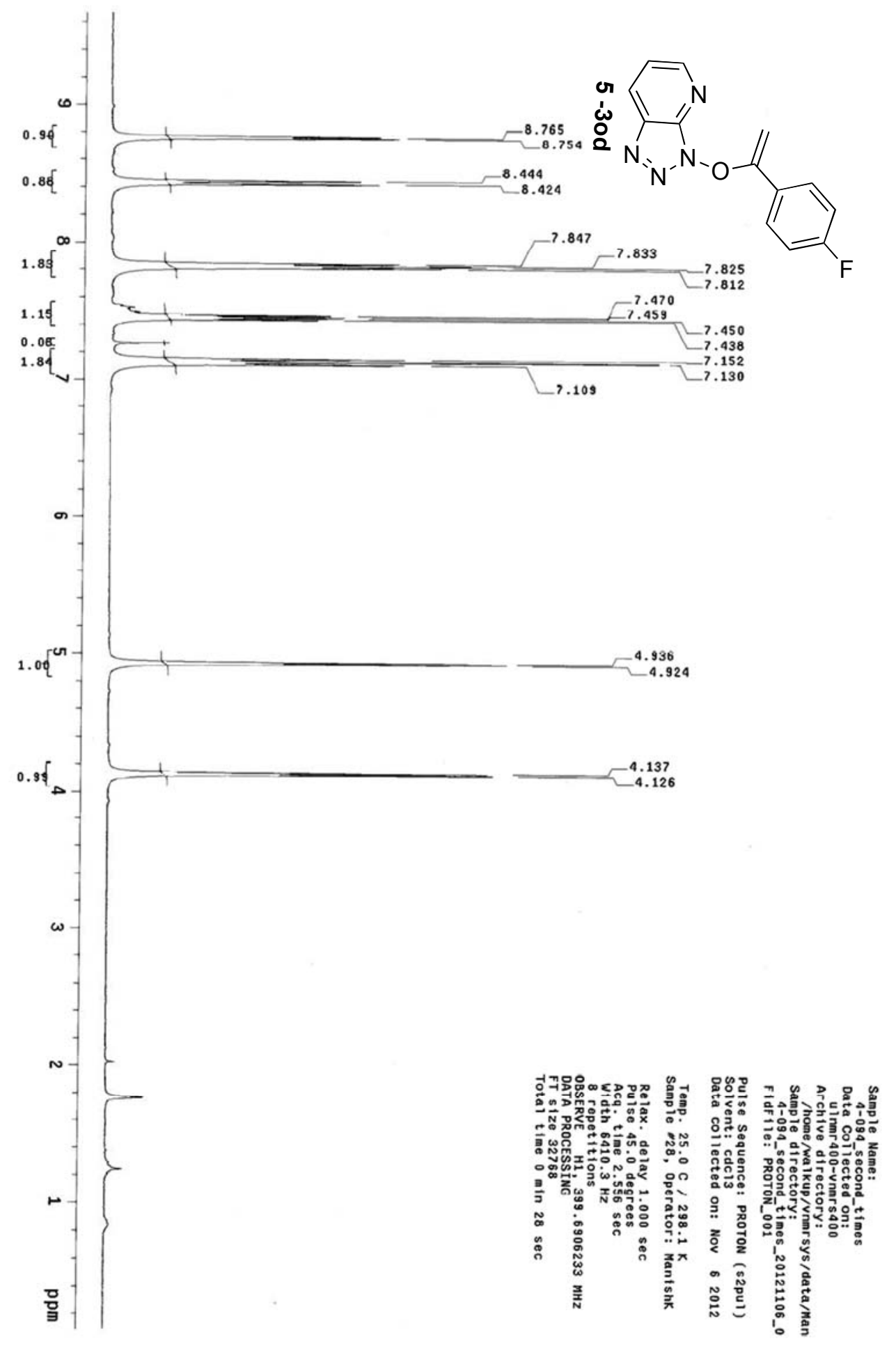



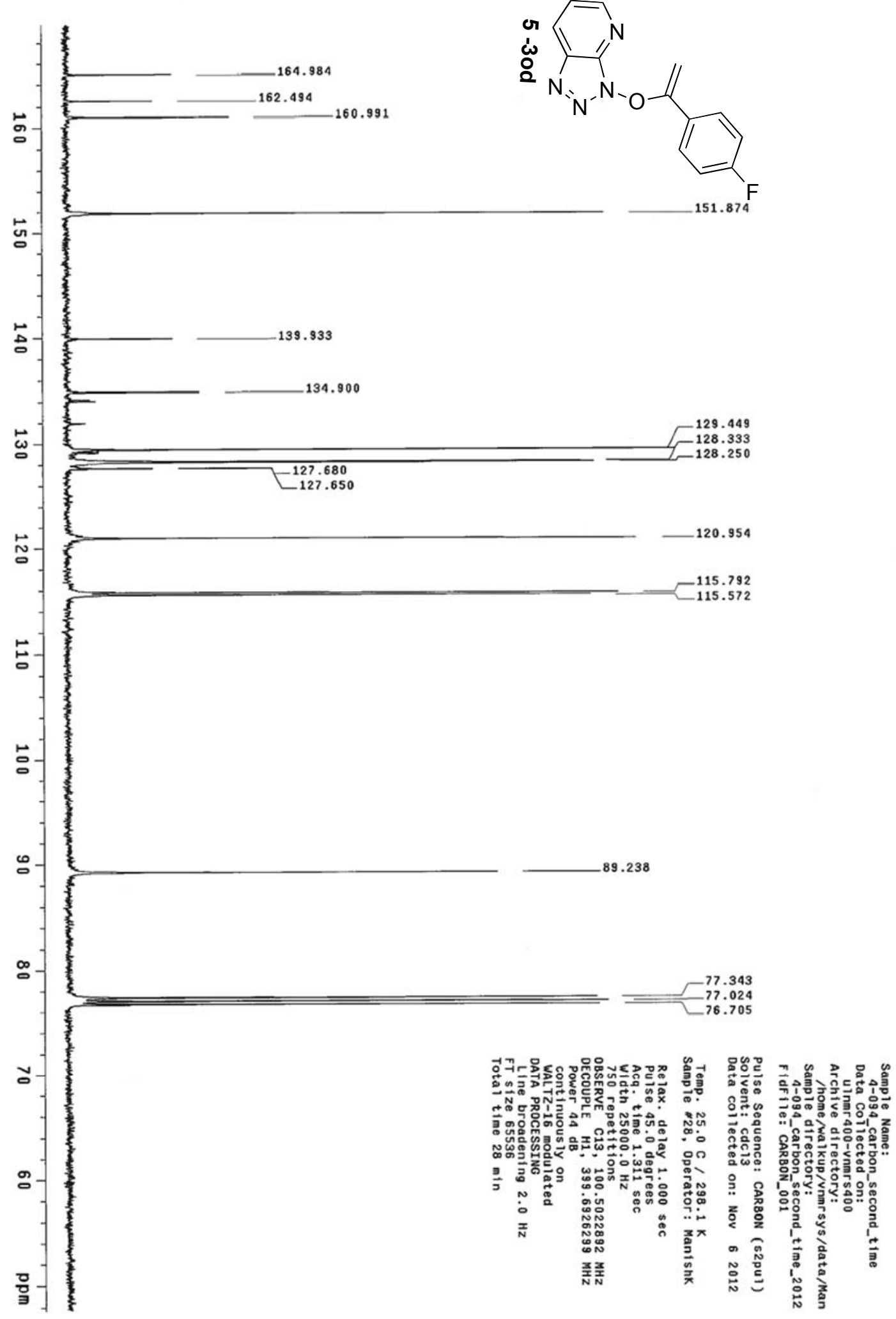


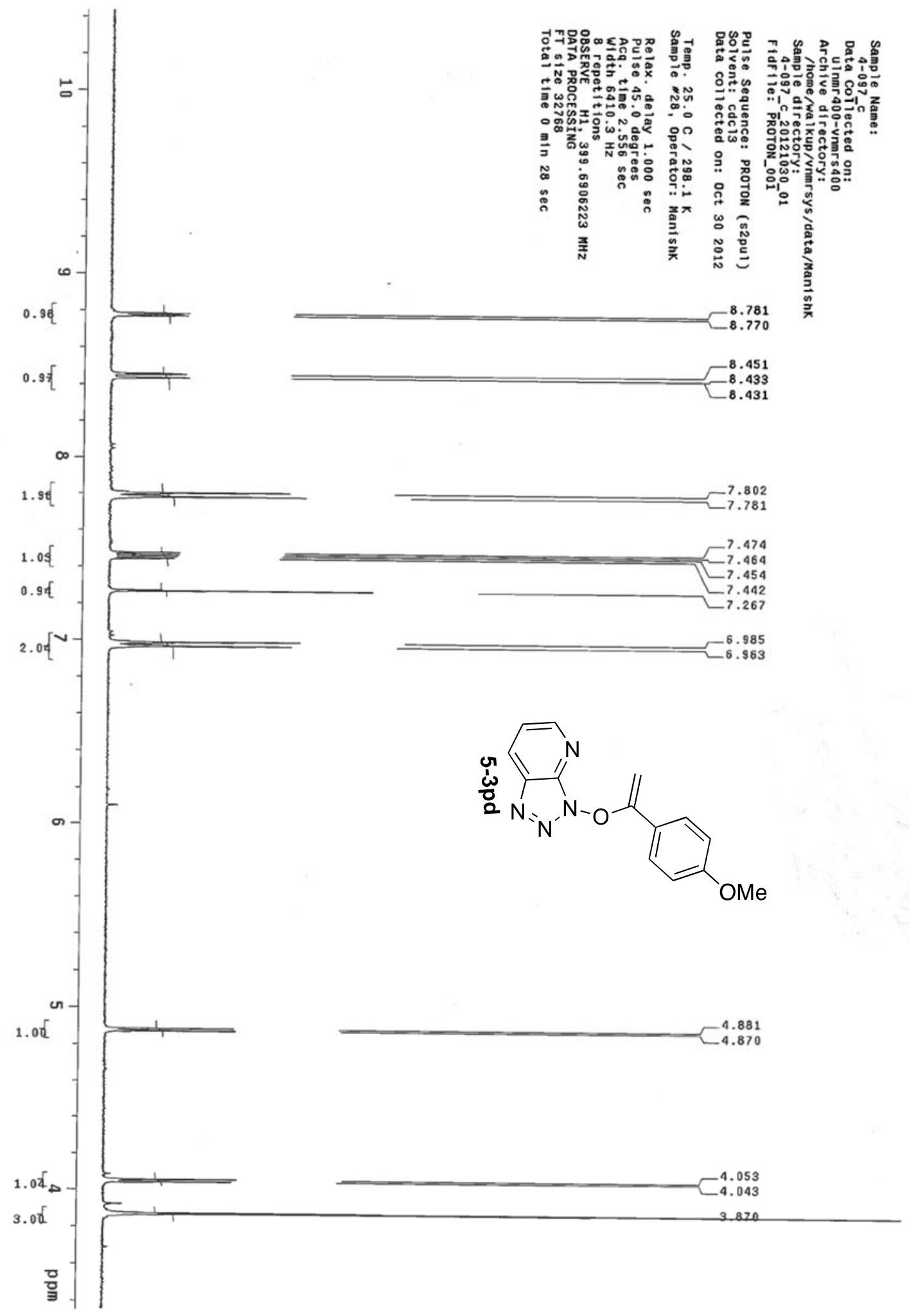




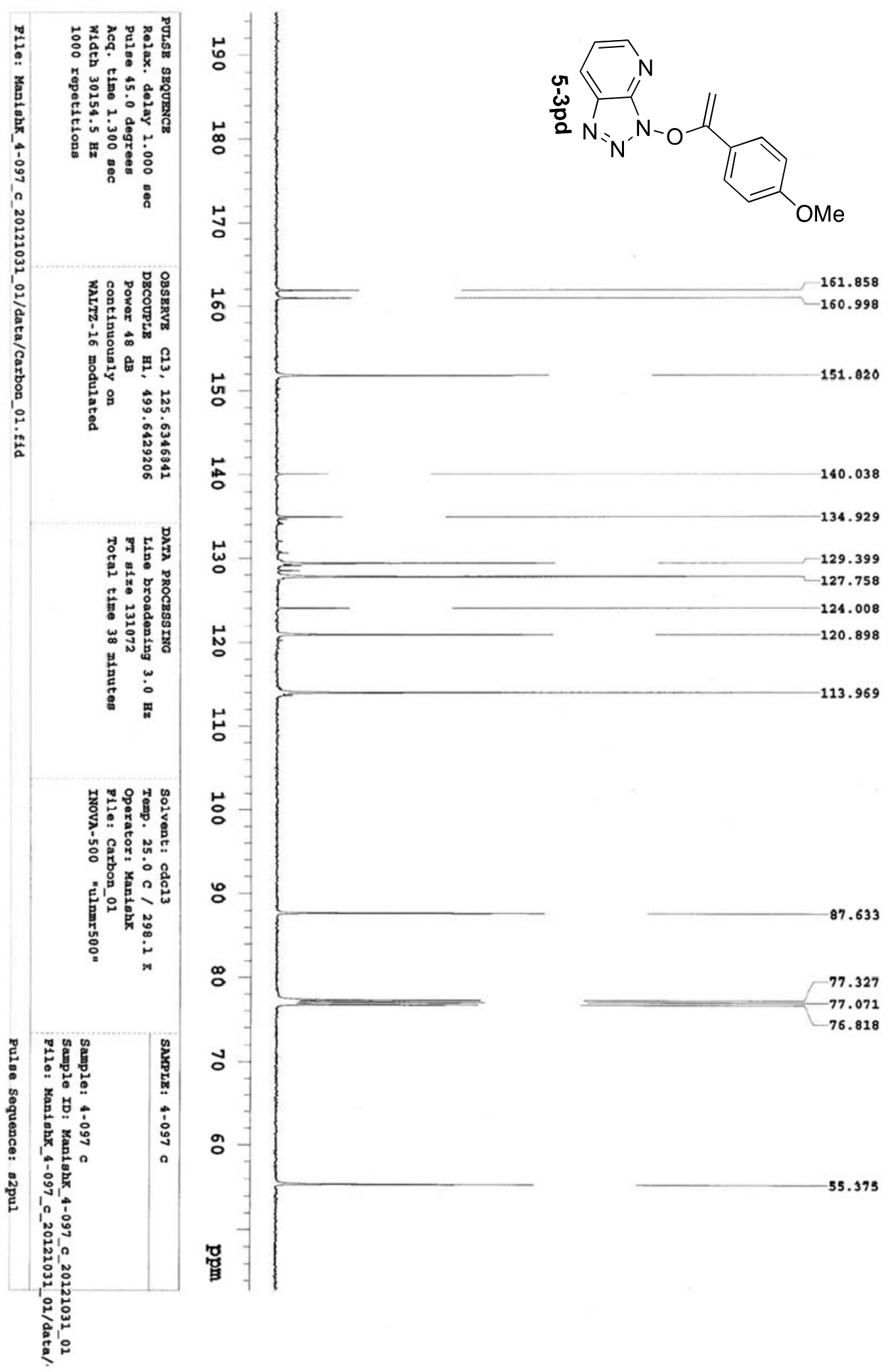



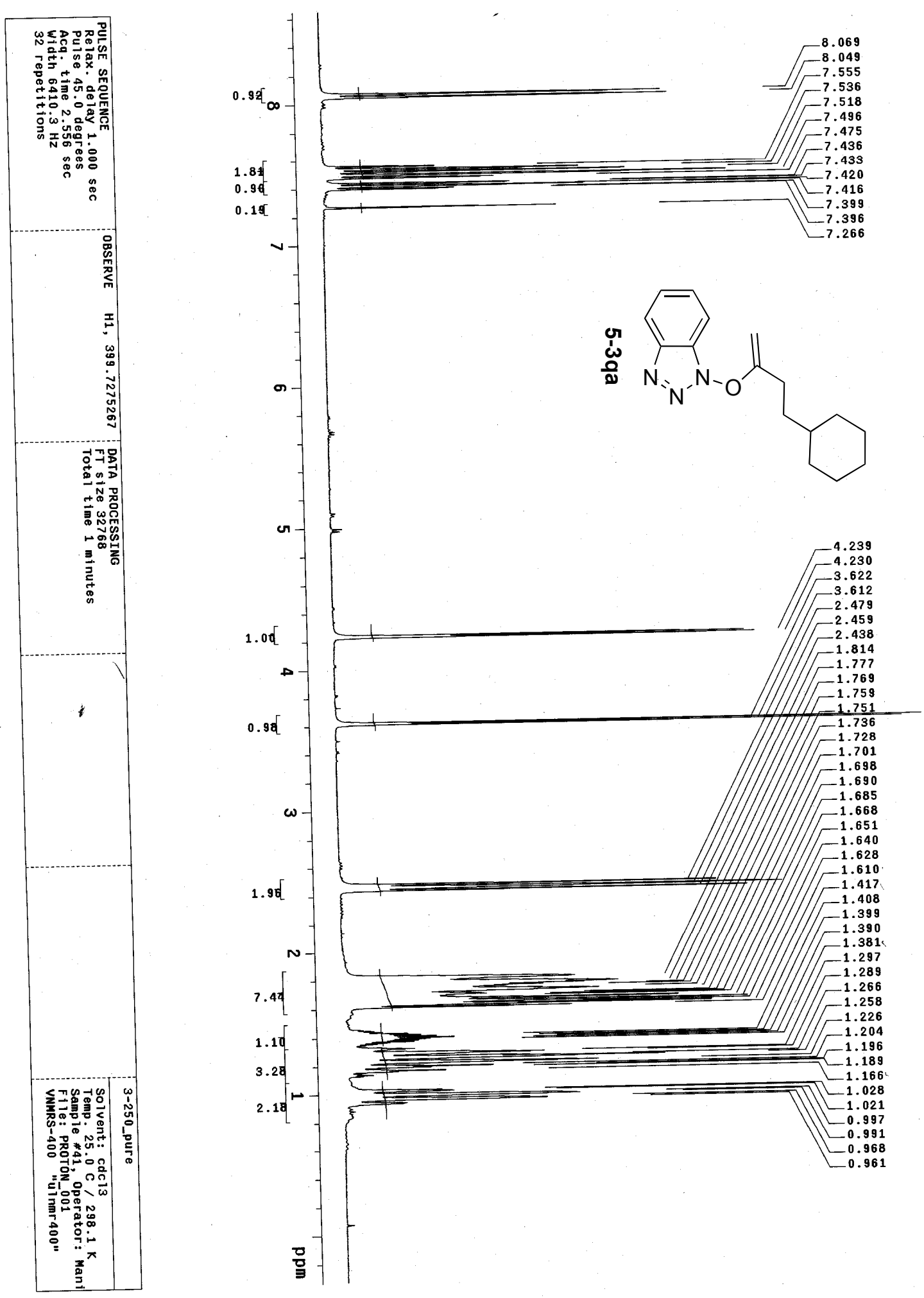


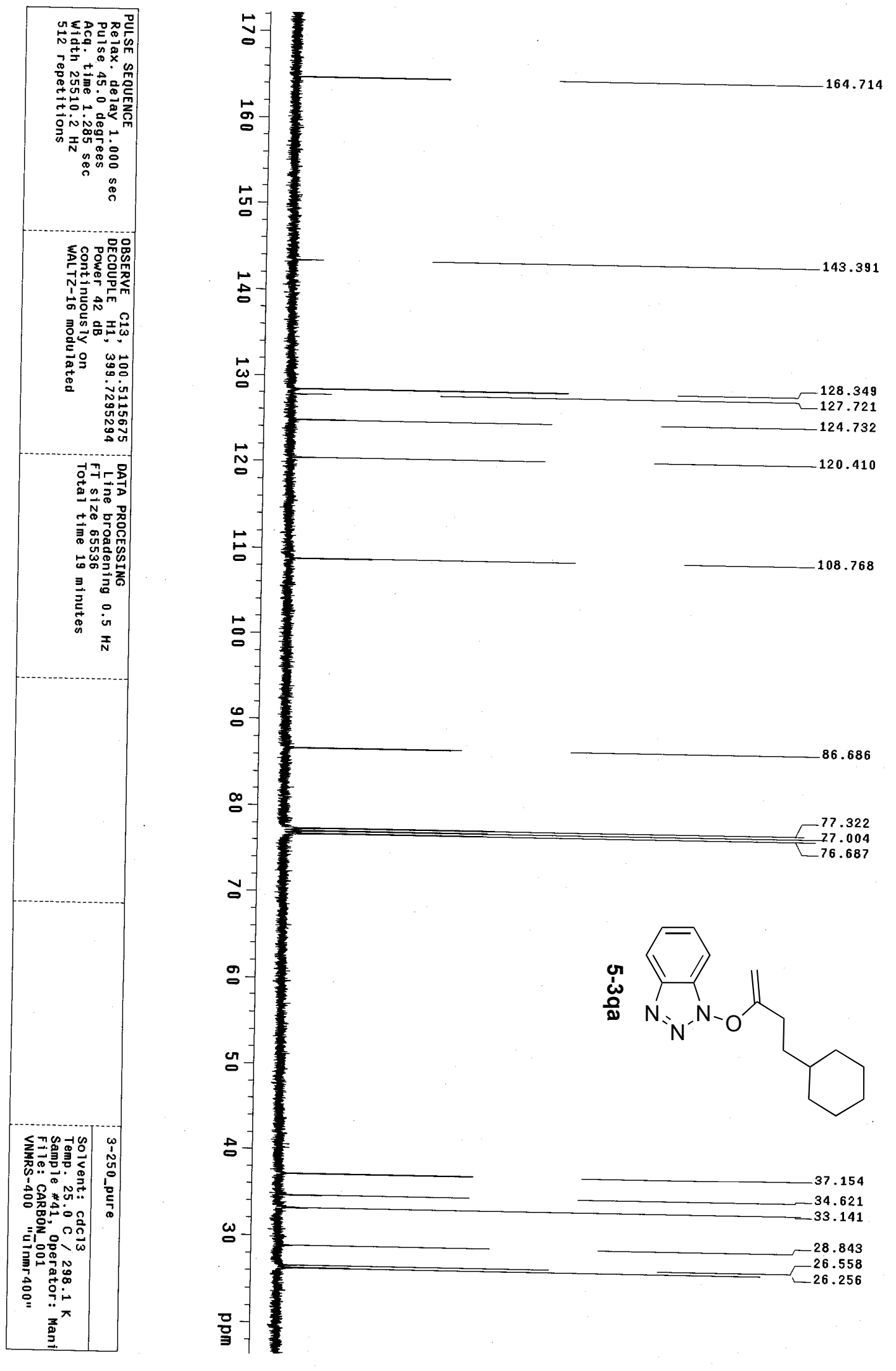


${ }^{1} \mathrm{H}$ and ${ }^{13} \mathrm{C}$ NMR spectra of compounds 5-4 


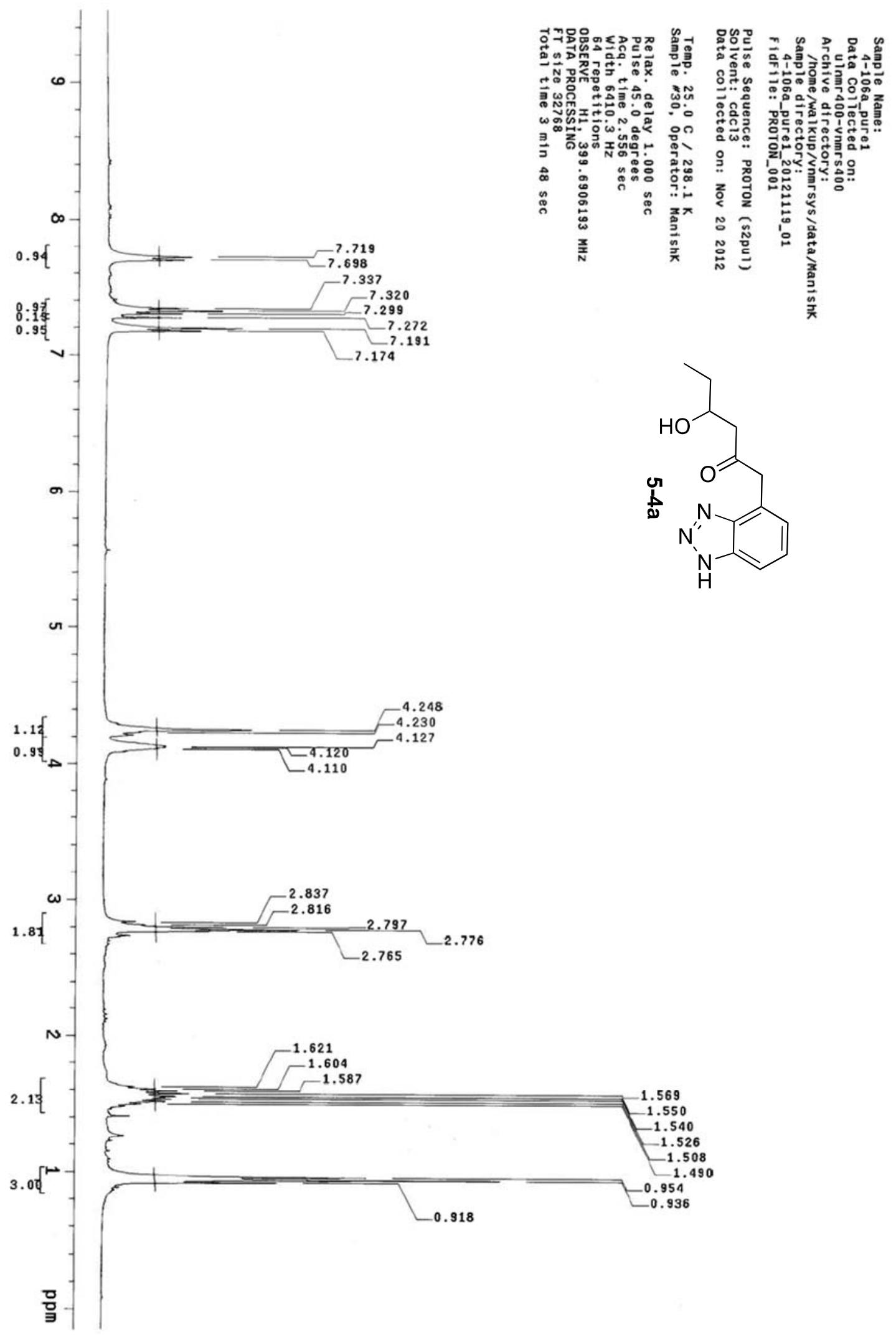




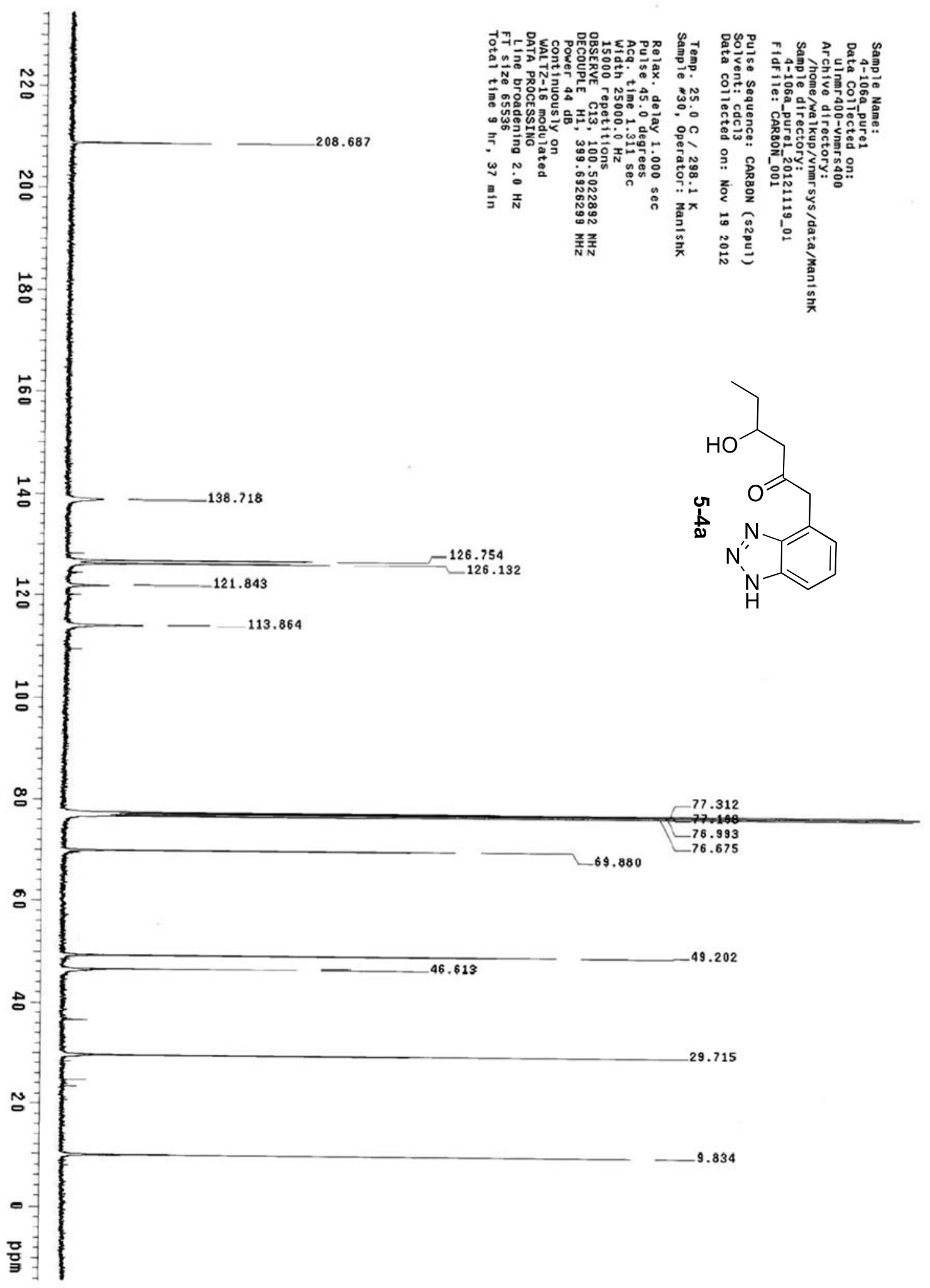




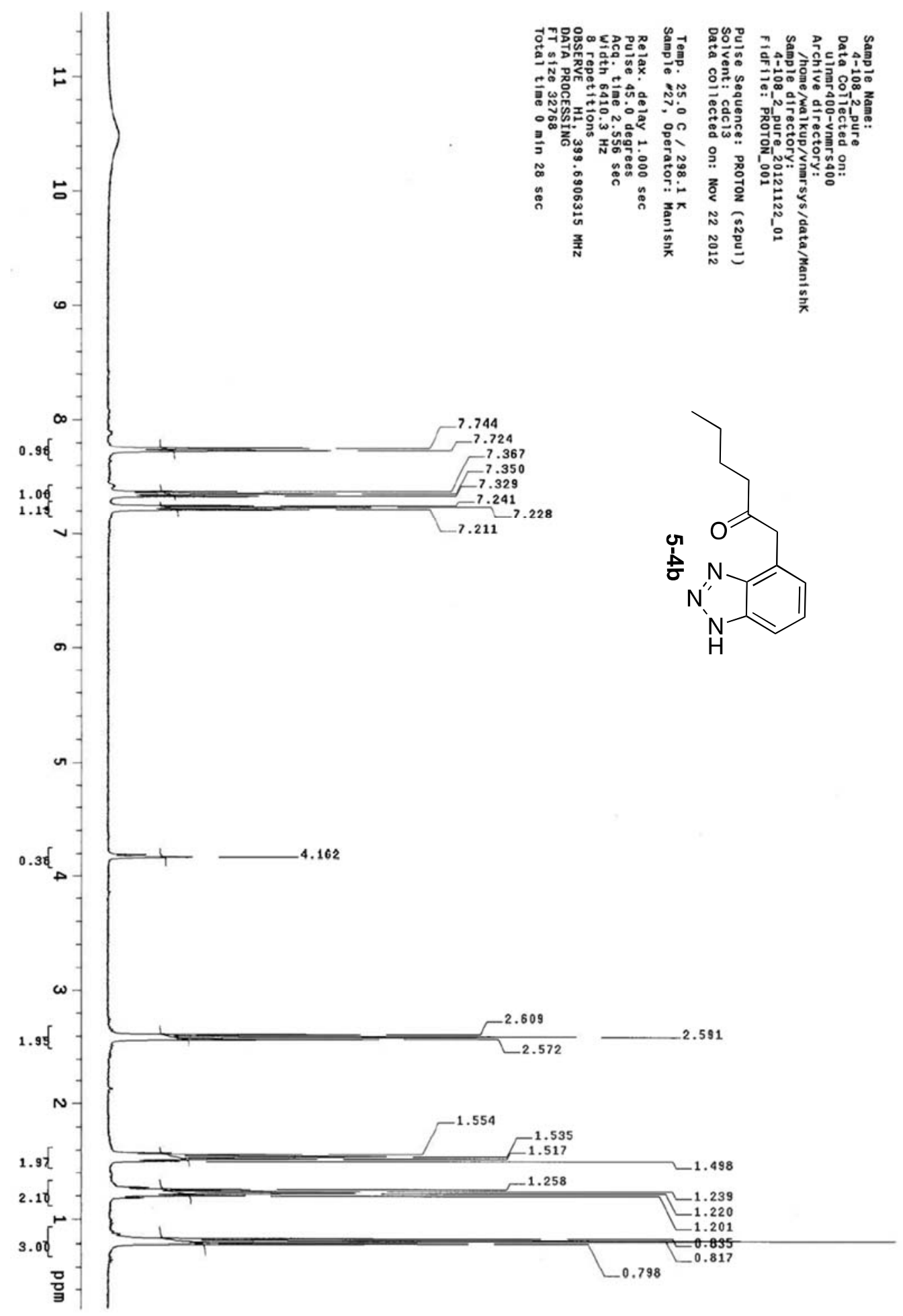




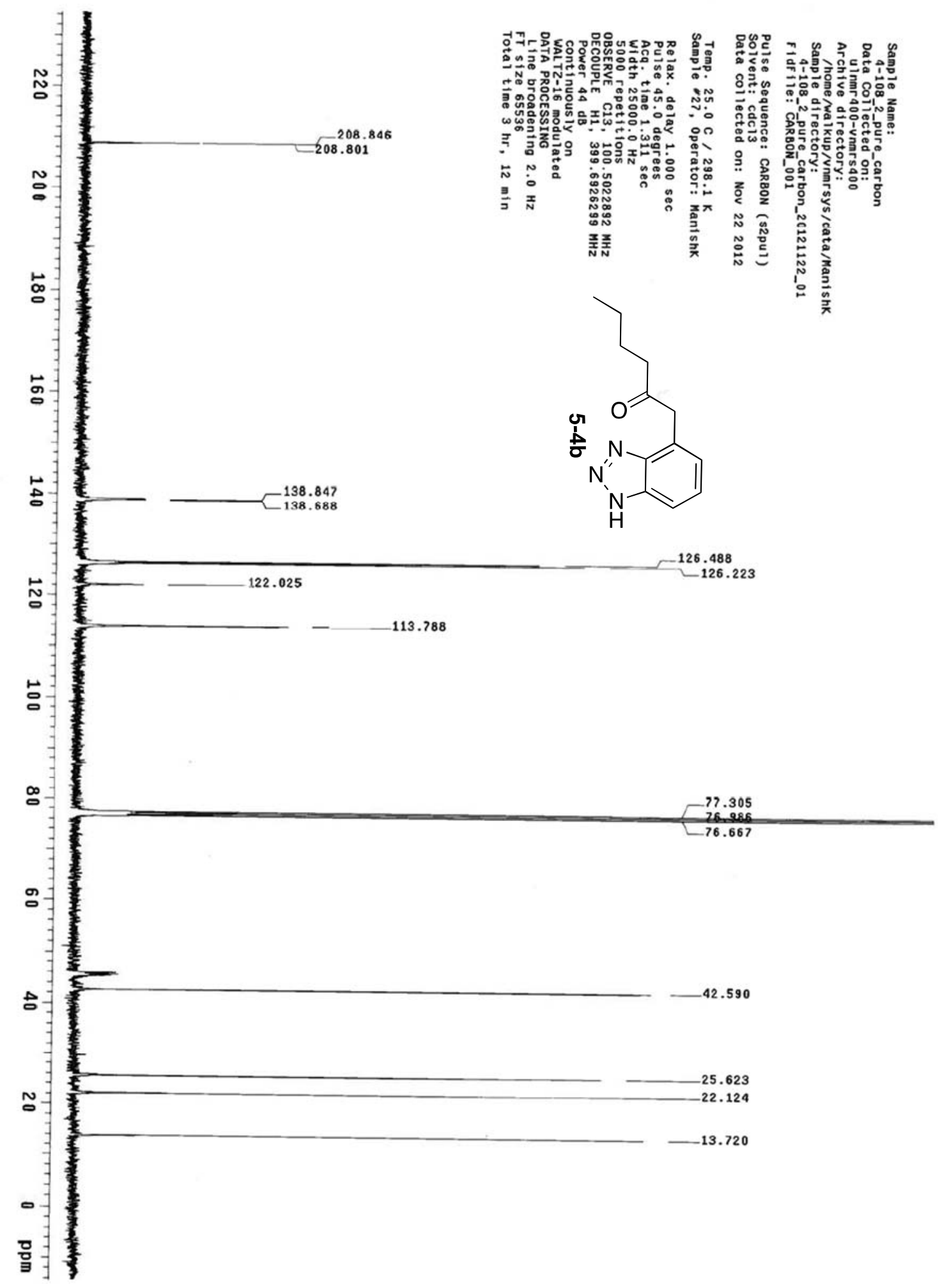




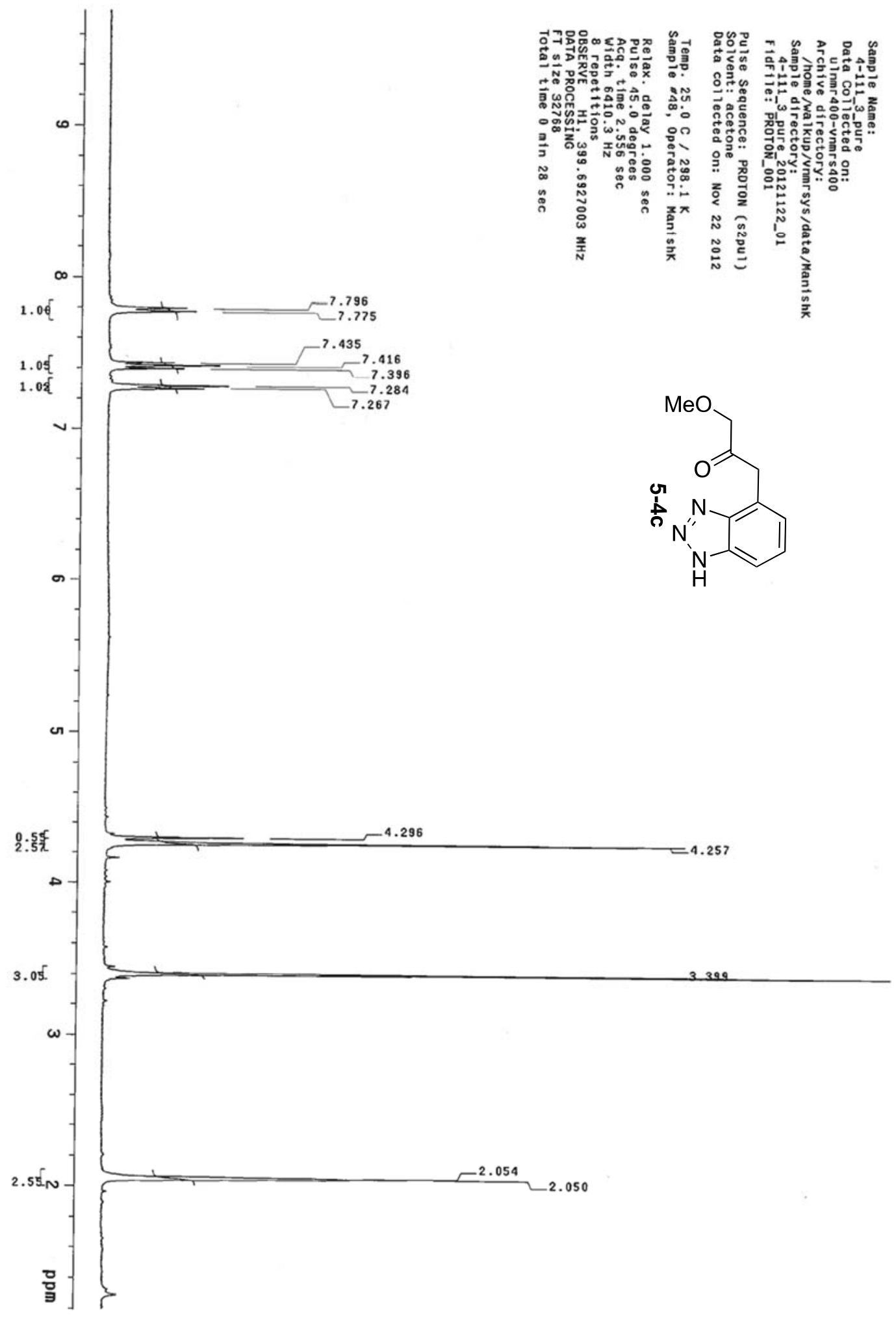




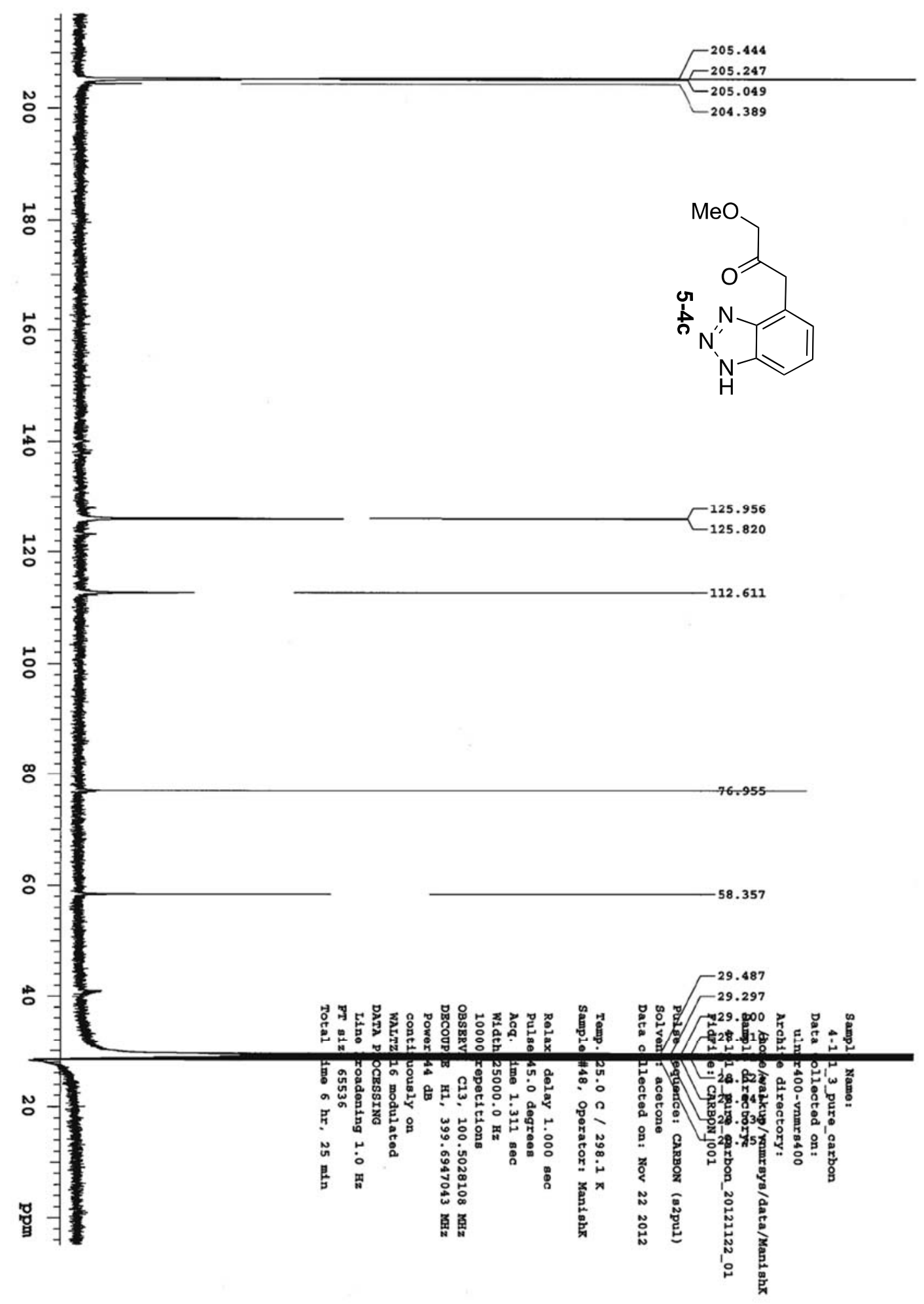




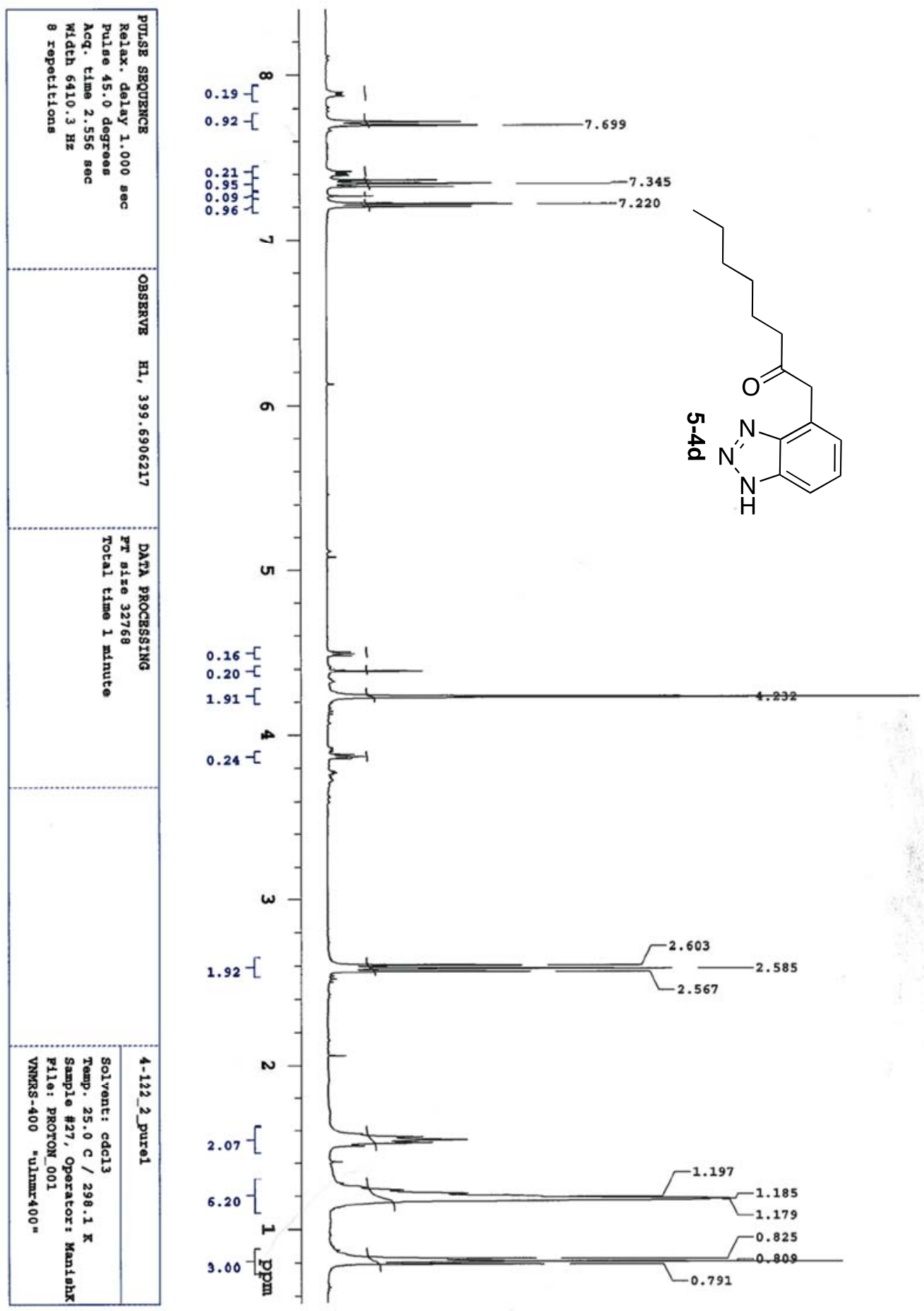




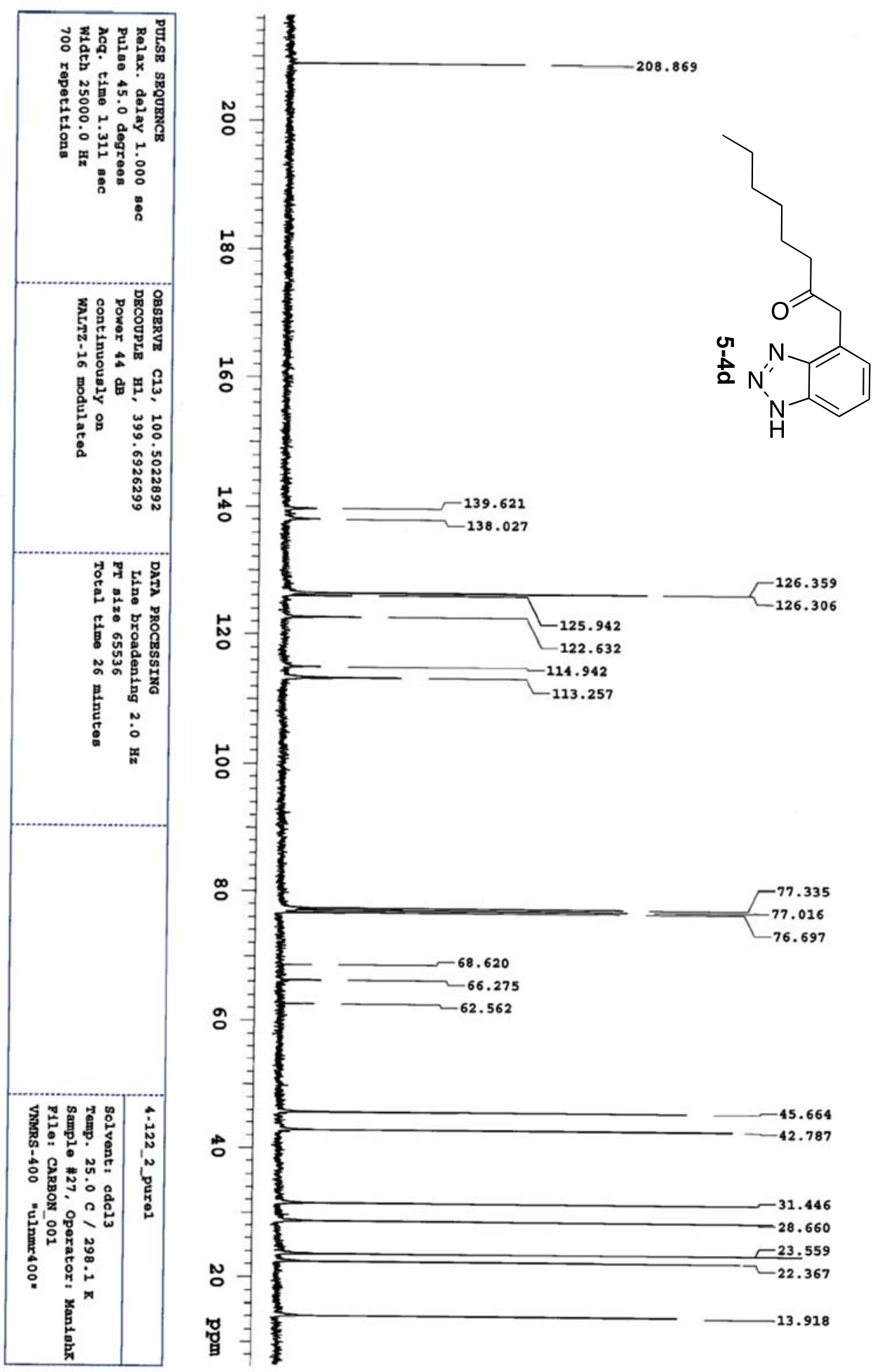



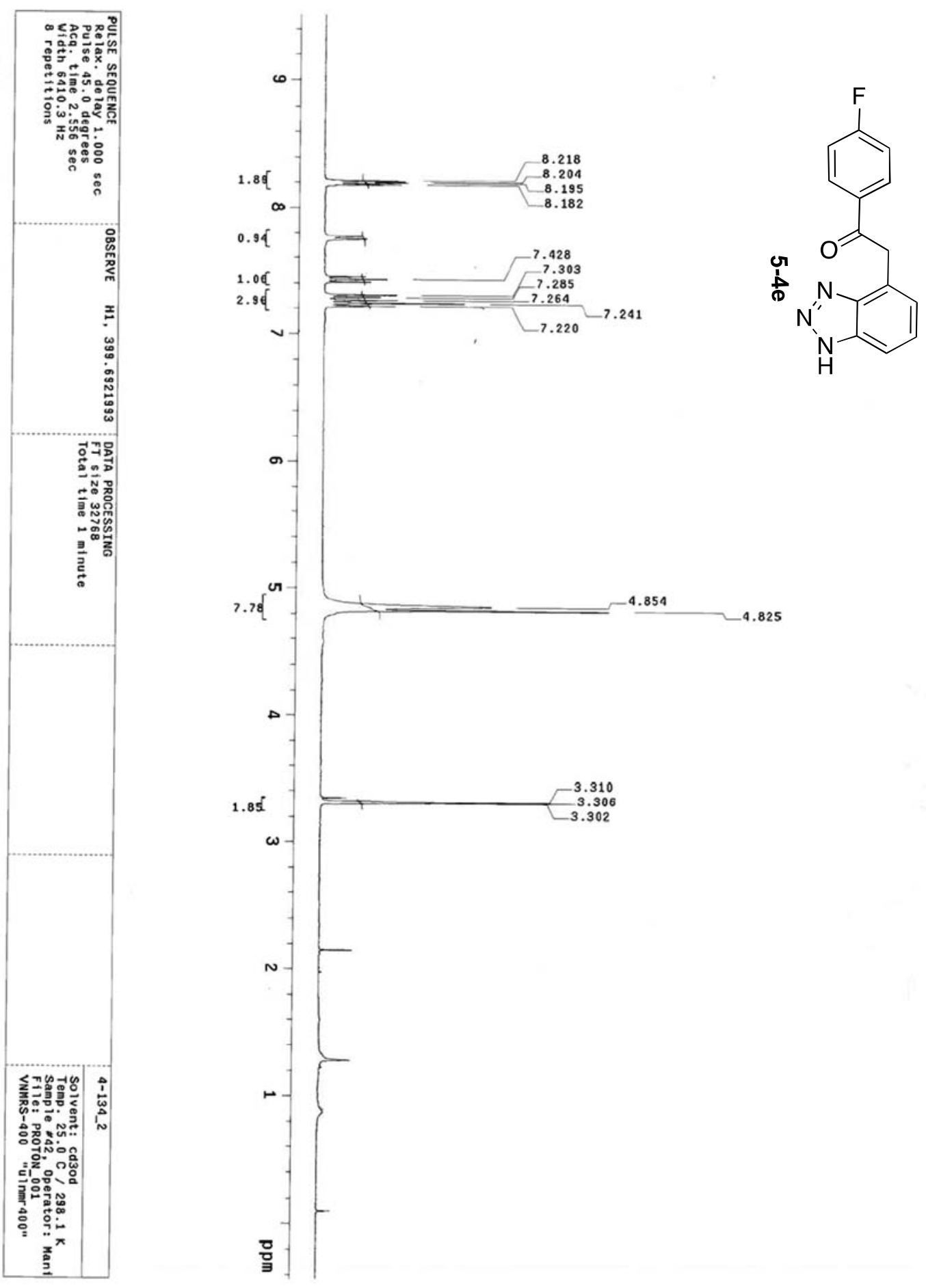


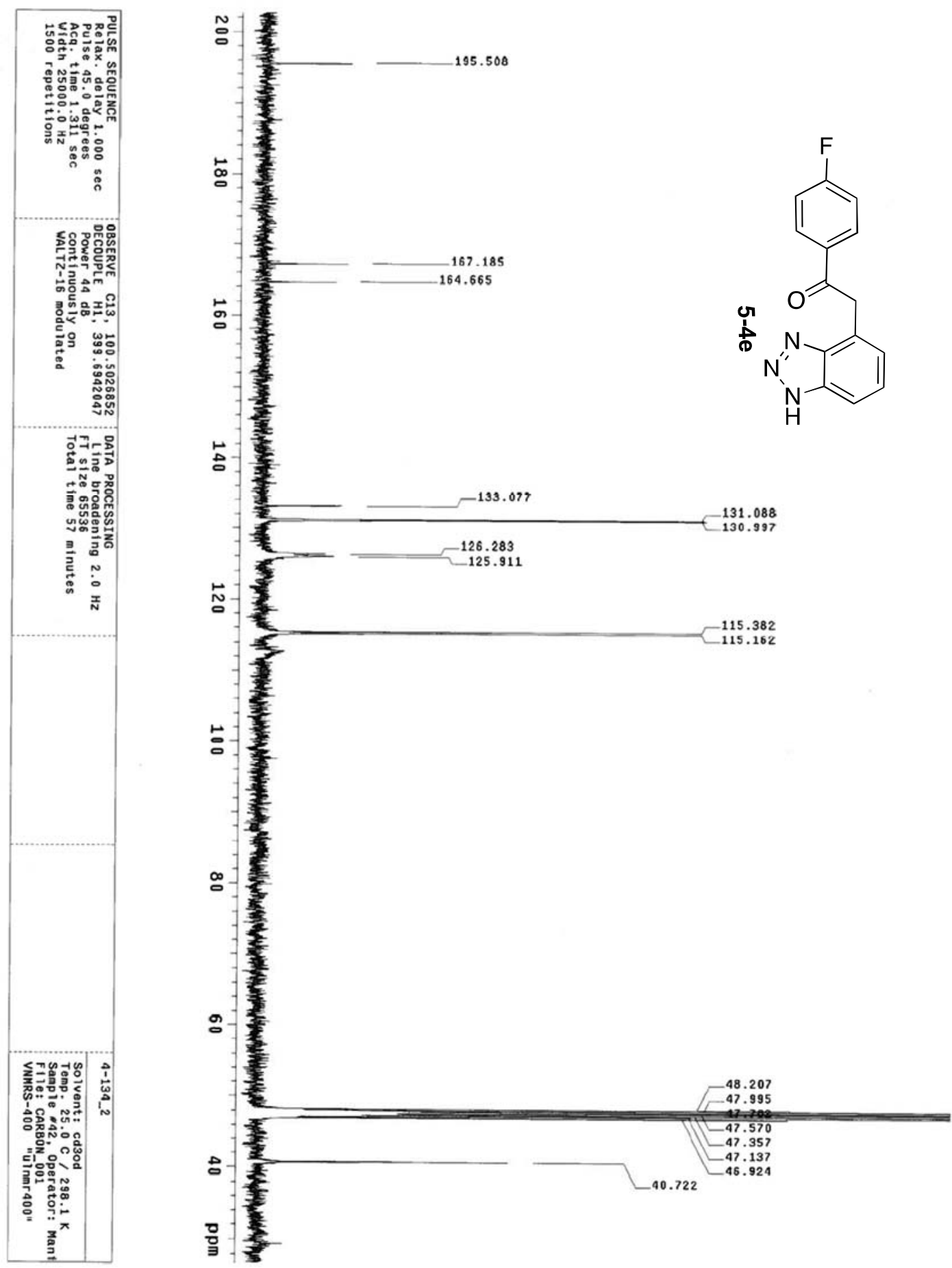



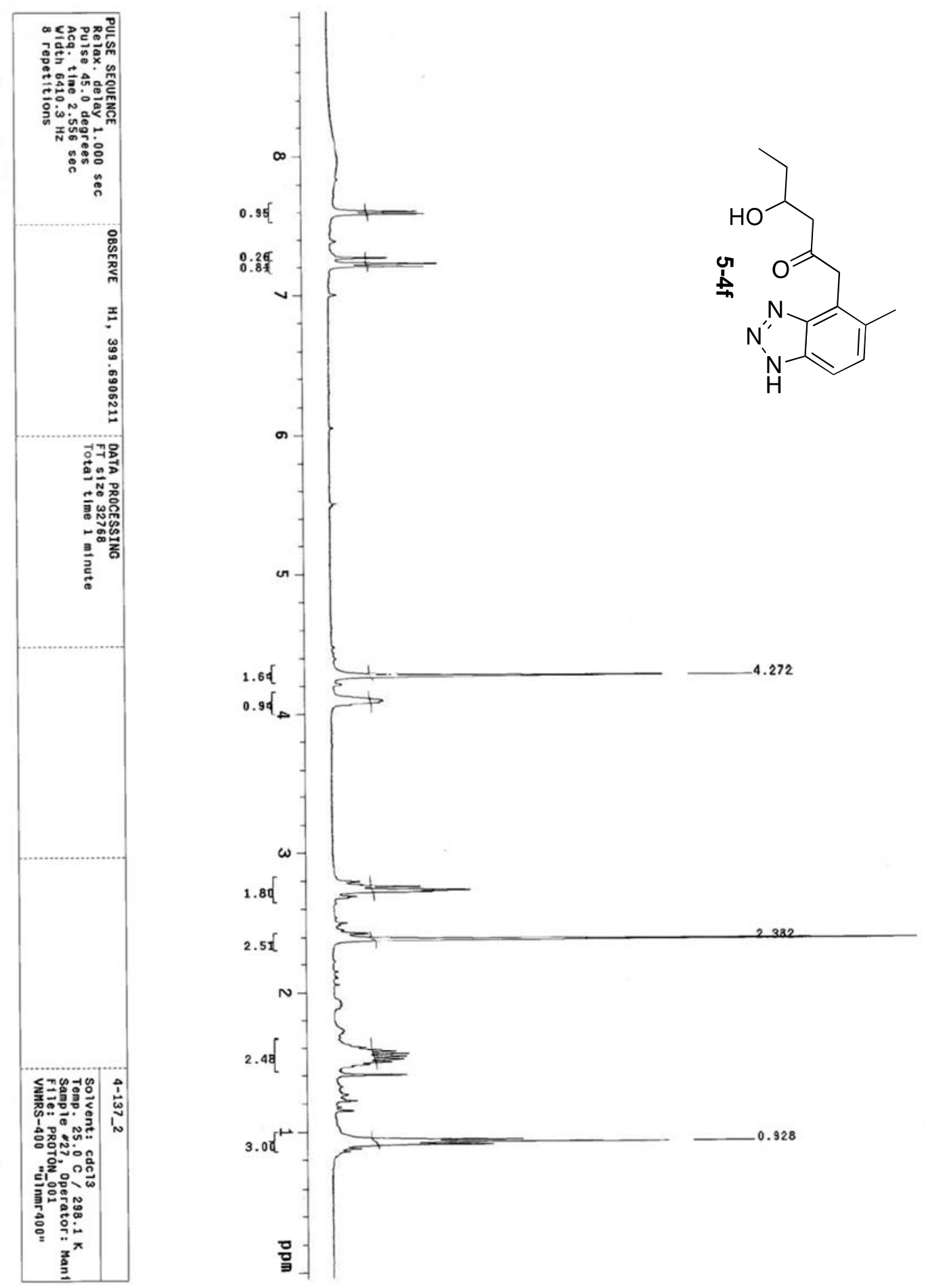


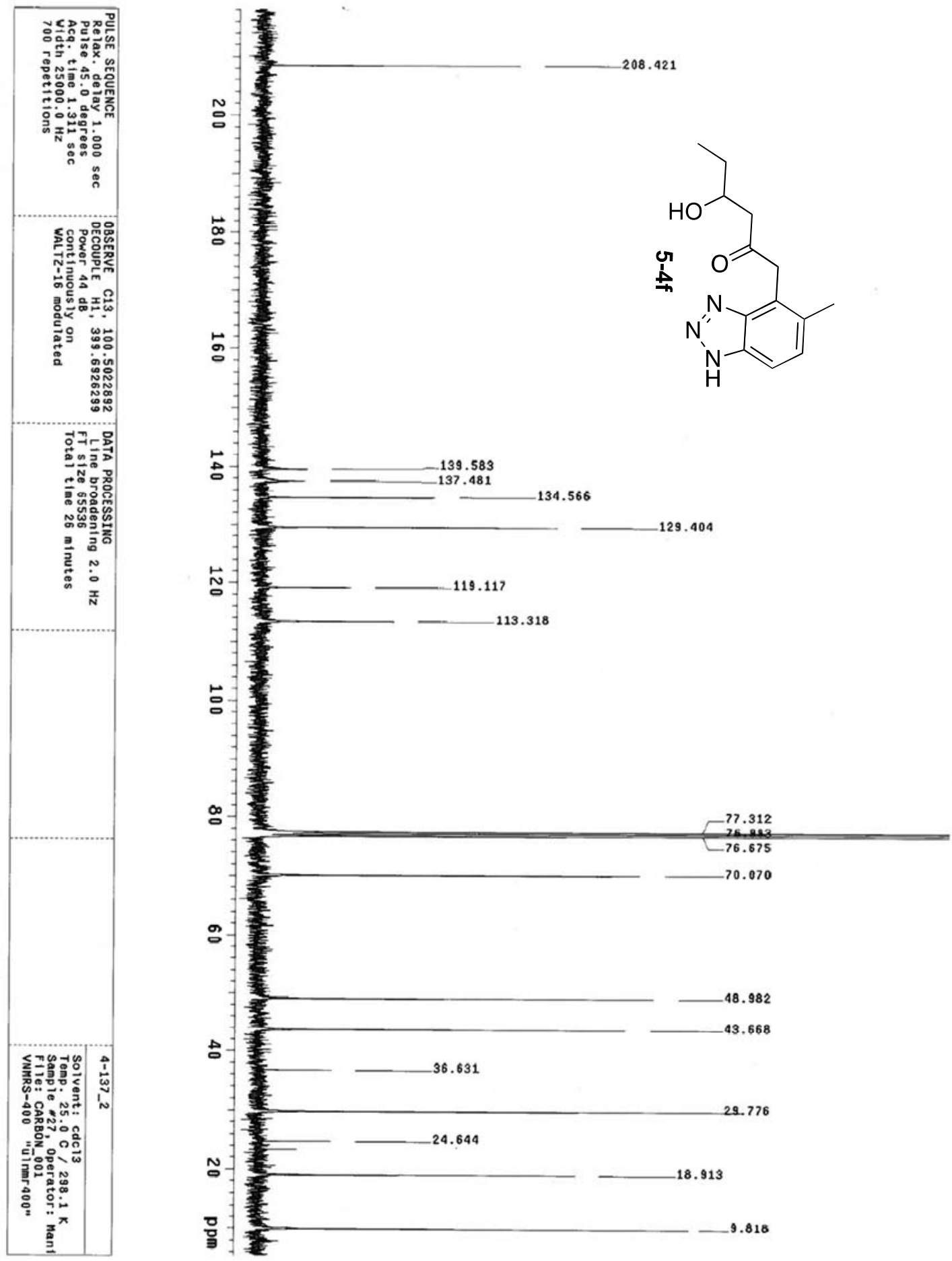




\section{Crystallographic studies}

Crystals of 5-3od for X-ray diffraction studies were grown by evaporation from a 50:50 methanol/hexane solution. $\mathrm{C}_{13} \mathrm{H}_{9} \mathrm{FN} 4 \mathrm{O}$ : colorless plate, $0.33 \times 0.24 \times 0.07$ $\mathrm{mm}^{3}$, monoclinic, space group $P 21 / \mathrm{c}, a=21.920(3) \AA, b=7.6412(7) \AA, c=$ 7.0921(6) $\AA, a=g=90^{\circ}, b=94.339(11)^{\circ} V=1184.5(2) \AA^{3}, D_{\text {calc }}=1.437 \mathrm{Mg} / \mathrm{m}^{3}$, $Z=4$. Data were collected on an Agilent Technologies/Oxford Diffraction Gemini CCD diffractometer at $100 \mathrm{~K}$ using MoKa radiation (0.71073 $\AA$ ). For 3177 unique reflections $I>2 \mathrm{~s}(\mathrm{I})[\mathrm{R}$ (int) 0.043$]$ the final anisotropic full matrix least-squares refinement on $\mathrm{F}^{2}$ for 208 variables converged at $\mathrm{R} 1=0.060$ and $\mathrm{wR} 2=0.101$ with a GOF of 1.06. Crystals of 5-4e, $\mathrm{C}_{14} \mathrm{H}_{10} \mathrm{FN}_{3} \mathrm{O}$ : colorless plate, $0.34 \times 0.25 \times 0.05$ $\mathrm{mm}^{3}$, monoclinic, space group $P 2{ }_{1} / \mathrm{n}, a=13.6216(11) \AA, b=19.5088(9) \AA, c=$ 15.1173(9) $\AA, a=g=90^{\circ}, b=116.200(9){ }^{\circ}, V=3604.6(4) \AA^{3}, D_{\text {calc }}=1.411$ $\mathrm{Mg} / \mathrm{m}^{3}, \mathrm{Z}=12$. Data were collected on an Agilent Technologies/Oxford Diffraction Gemini CCD diffractometer at $100 \mathrm{~K}$ using MoK $\alpha$ radiation $(0.71073$ $\AA$ ). For 7909 independent reflections $\mathrm{I}>2 \mathrm{~s}(\mathrm{I})[\mathrm{R}$ (int) 0.034$]$ the final anisotropic full matrix least-squares refinement on $\mathrm{F}^{2}$ for 634 variables converged at $\mathrm{R} 1=$ 0.045 and $w R 2=0.089$ with a GOF of 1.07. 


\section{CONCLUSIONS}

In the last decade there have been numerous reviews and publications on new gold catalyzed transformations. During the last few years our group has also developed new gold methodologies for the synthesis of interesting compounds and improved the efficiency of gold catalysis through ligand design. Specifically, some group members worked on ligand design and others focused on new reaction developments. Our experience with gold catalysis taught us that the major problem with this metal is the high catalyst loading (or low turnover number) required for most gold-catalyzed reactions. A major focus of this thesis is the investigation of basic mechanistic insights in gold-catalyzed reactions with the aim of reducing catalyst loading and improve overall efficiency.

We conducted detailed experimental studies to understand the mechanism of deactivation of gold active species. Based on the combination of experimental data, we proposed that disproportionation was preferred, as compared to reduction of active gold catalyst. We found that the substrate (alkyne/allene/alkene) may play a key role in the decay process. Moreover, we also found out that additives, coordinating counterions and solvents could play an important role in stopping the deactivation of the gold catalyst. To address the high resistance toward protodeauration in gold catalysis, we explored a new strategy to enhance the efficacy of gold-catalyzed reactions through hydrogen-bonding assisted 
protodeauration using additives chosen for their $\mathrm{p} K_{\mathrm{BHX}}$ (hydrogen-bond basicity) rather than for their $\mathrm{p} K$ a. We found out that an ideal hydrogen bond acceptor additive should have (i) high hydrogen bonding basicity, (ii) low basicity, and (iii) low affinity toward cationic gold. Our studies suggested that additives with high hydrogen bonding basicity are often helpful when stage 2 in the target reaction is relatively slow as compared to stage 1 . Additives with low basicity and low affinity toward cationic gold are useful when stage 1 in the target reaction is relatively slow as compared to stage 2 . Hence, the overall effectiveness of a hydrogen bond acceptor will depend upon on the balance between the two effects. To address the threshold phenomenon in gold-catalyzed reactions, we examined what were the effects of impurities with high gold affinity impurities (halides, bases) in solvents, starting materials, filtration or drying agents on the reactivity of the gold catalyst. We found that these impurities had an adverse effect on gold catalyzed reactions, which may, in turn, significantly reduce the TON of cationic gold catalyzed reactions. We found that the use of a suitable acid activator (e.g. HOTf, $\left.\operatorname{In}(\mathrm{OTf})_{3}\right)$ re-activates the gold catalyst and makes the reaction proceed smoothly at low gold catalyst loading. It should be noted that acid activators not only can re-activate the poisoned gold catalyst, but they can also positively influence the later stage in the gold catalytic cycle (e.g., protodeauration), acting as co-catalysts to speed-up the reaction.

To explore the reactivity of $\mathrm{Au}$ catalysts towards oxygen-atom transfer reactions, we investigated the gold-catalyzed addition of $O$-nucleophiles to alkynes to produce synthetically important vinyl ether products in excellent yields and 
regioselectivities at room temperature. At higher temperatures, 3,3-sigmatropic rearrangement of vinyl ether products gives access to highly functionalized benzotriazoles. This two-step sequence represents an efficient oxygen transfer protocol of a nucleophilic oxygen atom to an alkyne group. Reaction of vinyl ether products with an electrophilic fluorinating reagent (Selectfluor) gives a fluorinated ketone in good yield and exclusive regioselectivity.

In the future, and as a corollary to our finding that additives play a very important role in catalysis, we would like to expand the use of additives, such as LiNTf 2 , not only to other types of gold catalysis but also to other metal catalyzed reactions. Moreover, we would like to explore the application of the hydrogen bond basicity concept to other metal catalysis and organocatalysis. Finally, we would like to investigate whether acid activators only serve to re-activate a poisoned catalyst, or if they also can act as a co-catalysts in gold-catalyzed reactions. 


\section{REFERENCES}

(1) Hashmi, A. S. K. Gold-Catalyzed Organic Reactions. Chem. Rev. 2007, 107, 3180-3211.

(2) Garcia, P.; Malacria, M.; Aubert, C.; Gandon, V.; Fensterbank, L. Gold-Catalyzed Cross-Couplings: New Opportunities for C-bond-C Bond Formation. ChemCatChem 2010, 2, 493-497.

(3) Arcadi, A. Alternative Synthetic Methods through New Developments in Catalysis by Gold. Chem. Rev. 2008, 108, 3266-3325.

(4) Gorin, D. J.; Sherry, B. D.; Toste, F. D. Ligand Effects in Homogeneous Au Catalysis. Chem. Rev. 2008, 108, 3351-3378.

(5) Jimenez-Nunez, E.; Echavarren, A. M. Gold-Catalyzed Cycloisomerizations of Enynes: A Mechanistic Perspective. Chem. Rev. 2008, 108, 3326-3350.

(6) Li, Z.; Brouwer, C.; He, C. Gold-Catalyzed Organic Transformations. Chem. Rev. 2008, 108, 3239-3265.

(7) Hashmi, A. S. K.; Rudolph, M. Gold catalysis in total synthesis. Chem. Soc. Rev. 2008, 37, 1766-1775.

(8) Widenhoefer, R. A. Recent developments in enantioselective gold(I) catalysis. Chem. Eur. J. 2008, 14, 5382-5391.

(9) Hashmi, A. S. K.; Schwarz, L.; Choi, J.-H.; Frost, T. M. A New Gold-Catalyzed C-C Bond Formation. Angew. Chem., Int. Ed. 2000, 39, 2285-2288.

(10) Leyva-Pérez, A.; Corma, A. Similarities and Differences between the "Relativistic" Triad Gold, Platinum, and Mercury in Catalysis. Angew. Chem., Int. Ed. 2012, 51, 614-635.

(11) Pernpointner, M.; Hashmi, A. S. K. Fully relativistic, comparative investigation of gold and platinum alkyne complexes of relevance for the catalysis of nucleophilic additions to alkynes. J. Chem. Theory Comput. 2009, 5, 2717-2725. 
(12) Gorin, D. J.; Toste, F. D. Relativistic effects in homogeneous gold catalysis. Nature 2007, 446, 395-403.

(13) Pyykko, P.; Desclaux, J. P. Relativity and the periodic system of elements. Acc. Chem. Res. 1979, 12, 276-281.

(14) Bender, C. F.; Widenhoefer, R. A. Room Temperature Hydroamination of NAlkenyl Ureas Catalyzed by a Gold(I) N-Heterocyclic Carbene Complex. Org. Lett. 2006, 8, 5303-5305.

(15) Jung, H. H.; Floreancig, P. E. Gold-Catalyzed Heterocycle Synthesis Using Homopropargylic Ethers as Latent Electrophiles. Org. Lett. 2006, 8, 1949-1951.

(16) Zhang, J.; Yang, C.-G.; He, C. Gold(I)-Catalyzed Intra- and Intermolecular Hydroamination of Unactivated Olefins. J. Am. Chem. Soc. 2006, 128, 17981799.

(17) Dombray, T.; Blanc, A. 1.; Weibel, J.-M.; Pale, P. Gold(I)-Catalyzed Cycloisomerization of $\beta$-Alkynylpropiolactones to Substituted $\alpha$-Pyrones. Org. Lett. 2010, 12, 5362-5365.

(18) Yao, X.; Li, C.-J. Highly Efficient Addition of Activated Methylene Compounds to Alkenes Catalyzed by Gold and Silver. J. Am. Chem. Soc. 2004, 126, 6884-6885.

(19) Hirano, K.; Inaba, Y.; Watanabe, T.; Oishi, S.; Fujii, N.; Ohno, H. GoldCatalyzed Intramolecular Alkyne Cycloisomerization Cascade: Direct Synthesis of Aryl-Annulated[a]carbazoles from Aniline-Substituted Diethynylarenes. Adv. Synth. Catal. 2010, 352, 368-372.

(20) Widenhoefer, R. A.; Han, X. Gold-Catalyzed Hydroamination of C-C Multiple Bonds. Eur. J. Org. Chem. 2006, 2006, 4555-4563.

(21) Zeng, X.; Soleilhavoup, M.; Bertrand, G. Gold-Catalyzed Intermolecular Markovnikov Hydroamination of Allenes with Secondary Amines. Org. Lett. 2009, 11, 3166-3169.

(22) LaLonde, R. L.; Brenzovich, J. W. E.; Benitez, D.; Tkatchouk, E.; Kelley, K.; Goddard, I. I. I. W. A.; Toste, F. D. Alkylgold complexes by the intramolecular aminoauration of unactivated alkenes. Chem. Sci. 2010, 1, 226-233. 
(23) Eisenstein, O.; Hoffmann, R. Transition-metal complexed olefins: how their reactivity toward a nucleophile relates to their electronic structure. J. Am. Chem. Soc. 1981, 103, 4308-4320.

(24) Brown, T. J.; Weber, D.; Gagné, M. R.; Widenhoefer, R. A. Mechanistic Analysis of Gold(I)-Catalyzed Intramolecular Allene Hydroalkoxylation Reveals an OffCycle Bis(gold) Vinyl Species and Reversible C-O Bond Formation. J. Am. Chem. Soc. 2012, 134, 9134-9137.

(25) Benitez, D.; Shapiro, N. D.; Tkatchouk, E.; Wang, Y.; Goddard, W. A.; Toste, F. D. A bonding model for gold(I) carbene complexes. Nat. Chem. 2009, 1, 482-486.

(26) Shen, Q.; Shekhar, S.; Stambuli, J. P.; Hartwig, J. F. Highly Reactive, General, and Long-Lived Catalysts for Coupling Heteroaryl and Aryl Chlorides with Primary Nitrogen Nucleophiles. Angew. Chem., Int. Ed. 2005, 44, 1371-1375.

(27) Zhang, G.; Huang, X.; Li, G.; Zhang, L. Au-Containing All-Carbon 1,4-Dipoles: Generation and [4 +2] Annulation in the Formation of Carbo-/Heterocycles. $J$. Am. Chem. Soc. 2008, 130, 1814-1815.

(28) Hashmi, A. S. K. Homogeneous Gold Catalysis Beyond Assumptions and Proposals-Characterized Intermediates. Angew. Chem. Int. Ed. 2010, 49, $5232-$ 5241.

(29) Wang, W.; Hammond, G. B.; Xu, B. Ligand Effects and Ligand Design in Homogeneous Gold(I) Catalysis. J. Am. Chem. Soc. 2012, 134, 5697-5705.

(30) Hardacre, C.; Katdare, S. P.; Milroy, D.; Nancarrow, P.; Rooney, D. W.; Thompson, J. M. A catalytic and mechanistic study of the Friedel-Crafts benzoylation of anisole using zeolites in ionic liquids. J. Catal. 2004, 227, 44-52.

(31) Mukherjee, A.; Sen, T. K.; Ghorai, P. K.; Mandal, S. K. The Non-innocent Phenalenyl Unit: An Electronic Nest to Modulate the Catalytic Activity in Hydroamination Reaction. Sci. Rep. 2013, 3.

(32) Wang, Z. J.; Benitez, D.; Tkatchouk, E.; Goddard Iii, W. A.; Toste, F. D. Mechanistic Study of Gold(I)-Catalyzed Intermolecular Hydroamination of Allenes. J. Am. Chem. Soc. 2010, 132, 13064-13071. 
(33) Wang, W.; Kumar, M.; Hammond, G. B.; Xu, B. Enhanced Reactivity in Homogeneous Gold Catalysis through Hydrogen Bonding. Org. Lett. 2014, 16, 636-639.

(34) Malhotra, D.; Mashuta, M. S.; Hammond, G. B.; Xu, B. A Highly Efficient and Broadly Applicable Cationic Gold Catalyst. Angew. Chem. Int. Ed. 2014, 53, 4456-4459.

(35) Kumar, M.; Jasinski, J.; Hammond, G. B.; Xu, B. Alkyne/Alkene/Allene-Induced Disproportionation of Cationic Gold(I) Catalyst. Chem. Eur. J. 2014, 20, 31133119.

(36) Kumar, M.; Scobie, M.; Mashuta, M. S.; Hammond, G. B.; Xu, B. GoldCatalyzed Addition of N-Hydroxy Heterocycles to Alkynes and Subsequent 3,3Sigmatropic Rearrangement. Org. Lett. 2013, 15, 724-727.

(37) Zhang, C.; De, C. K.; Mal, R.; Seidel, D. Alpha-amination of nitrogen heterocycles: ring-fused aminals. J. Am. Chem. Soc. 2008, 130, 416-7.

(38) Trost, B. M.; Maulide, N.; Livingston, R. C. A Ruthenium-Catalyzed, AtomEconomical Synthesis of Nitrogen Heterocycles. J. Am. Chem. Soc. 2008, $16502-$ 16503.

(39) Fustero, S.; Moscardo, J.; Jimenez, D.; Perez-Carrion, M. D.; Sanchez-Rosello, M.; Del Pozo, C. Organocatalytic approach to benzofused nitrogen-containing heterocycles: enantioselective total synthesis of (+)-angustureine. Chemistry 2008, 14, 9868-72.

(40) Vicario, J. L.; Badia, D.; Carrillo, L. New methods for the asymmetric synthesis of nitrogen heterocycles 2005; Research Signpost: Kerala, India, 2005.

(41) El Ashry, E. S. H.; El-Nemr, A. Synthesis of naturally occurring nitrogen heterocycles from carbohydrates; Blackwell Pub.: Oxford, UK ; Ames, Iowa, 2005.

(42) Wu, W.; Su, W. Mild and Selective Ru-Catalyzed Formylation and Fe-Catalyzed Acylation of Free ( $N-H)$ Indoles Using Anilines as the Carbonyl Source. J. Am. Chem. Soc. 2011, 133, 11924-11927. 
(43) Shen, L.; Zhang, M.; Wu, Y.; Qin, Y. Efficient Assembly of an Indole Alkaloid Skeleton by Cyclopropanation: Concise Total Synthesis of ( \pm )-Minfiensine. Angew. Chem., Int. Ed. 2008, 47, 3618-3621.

(44) Gabriele, B.; Mancuso, R.; Salerno, G.; Lupinacci, E.; Ruffolo, G.; Costa, M. Versatile Synthesis of Quinoline-3-Carboxylic Esters and Indol-2-Acetic Esters by Palladium-Catalyzed Carbonylation of 1-(2-Aminoaryl)-2-Yn-1-Ols. J. Org. Chem. 2008, 73, 4971-4977.

(45) Nakamura, M.; Ilies, L.; Otsubo, S.; Nakamura, E. 2,3-Disubstituted Benzofuran and Indole by Copper-Mediated C-C Bond Extension Reaction of 3Zinciobenzoheterole. Org. Lett. 2006, 8, 2803-2805.

(46) Potavathri, S.; Pereira, K. C.; Gorelsky, S. I.; Pike, A.; LeBris, A. P.; DeBoef, B. Regioselective Oxidative Arylation of Indoles Bearing N-Alkyl Protecting Groups: Dual C-H Functionalization via a Concerted Metalation-Deprotonation Mechanism. J. Am. Chem. Soc. 2010, 132, 14676-14681.

(47) Newhouse, T.; Lewis, C. A.; Eastman, K. J.; Baran, P. S. Scalable Total Syntheses of N-Linked Tryptamine Dimers by Direct Indole-Aniline Coupling:

Psychotrimine and Kapakahines B and F. J. Am. Chem. Soc. 2010, 132, 71197137.

(48) Nuss, J. M.; Harrison, S. D.; Ring, D. B.; Boyce, R. S.; johnson, K.; Pfister, K. B.; Ramurthy, S.; Seely, L.; Wagman, A. S.; Desai, M. C.; Levine, B. H., 2006; Vol. US 7,045,519 B2.

(49) Katritzky, A. R.; Rachwal, S. Synthesis of Heterocycles Mediated by Benzotriazole. 1. Monocyclic Systems. Chem. Rev. 2009, 110, 1564-1610.

(50) Katritzky, A. R.; Rachwal, S. Synthesis of Heterocycles Mediated by Benzotriazole. 2. Bicyclic Systems. Chem. Rev. 2011, 111, 7063-7120.

(51) Krause, N.; Winter, C. Gold-Catalyzed Nucleophilic Cyclization of Functionalized Allenes: A Powerful Access to Carbo- and Heterocycles. Chem. Rev. 2011, 111, 1994-2009.

(52) Widenhoefer, R. A. Recent Developments in Enantioselective Gold(I) Catalysis. Chem. Eur. J. 2008, 14, 5382-5391. 
(53) Fürstner, A.; Davies, P. W. Catalytic Carbophilic Activation: Catalysis by Platinum and Gold $\pi$ Acids. Angew. Chem., Int. Ed. 2007, 46, 3410-3449.

(54) Hashmi, A. S. K.; Hutchings, G. J. Gold Catalysis. Angew. Chem., Int. Ed. 2006, 45, 7896-7936.

(55) Hashmi, A. S. K. The Catalysis Gold Rush: New Claims. Angew. Chem., Int. Ed. 2005, 44, 6990-6993.

(56) Gorin, D. J.; Toste, F. D. Nature 2007, 446, 395-403.

(57) Jimenez-Nunez, E.; Echavarren, A. M. Molecular diversity through gold catalysis with alkynes. Chem. Commun. 2007, 333-346.

(58) Marion, N.; Nolan, S. P. Propargylic Esters in Gold Catalysis: Access to Diversity. Angew. Chem., Int. Ed. 2007, 46, 2750-2752.

(59) Xiao, J.; Li, X. Gold $\alpha$-Oxo Carbenoids in Catalysis: Catalytic Oxygen-Atom Transfer to Alkynes. Angew. Chem., Int. Ed. 2011, 50, 7226-7236.

(60) Ye, L.; Cui, L.; Zhang, G.; Zhang, L. Alkynes as Equivalents of $\alpha$-Diazo Ketones in Generating $\alpha$-Oxo Metal Carbenes: A Gold-Catalyzed Expedient Synthesis of Dihydrofuran-3-ones. J. Am. Chem. Soc. 2010, 132, 3258-3259.

(61) Ye, L.; He, W.; Zhang, L. Gold-Catalyzed One-Step Practical Synthesis of Oxetan-3-ones from Readily Available Propargylic Alcohols. J. Am. Chem. Soc. 2010, 132, 8550-8551.

(62) Lu, B.; Li, C.; Zhang, L. Gold-Catalyzed Highly Regioselective Oxidation of C-C Triple Bonds without Acid Additives: Propargyl Moieties as Masked $\alpha, \beta$ Unsaturated Carbonyls. J. Am. Chem. Soc. 2010, 132, 14070-14072.

(63) He, W.; Li, C.; Zhang, L. An Efficient [2+2+1] Synthesis of 2,5-Disubstituted Oxazoles via Gold-Catalyzed Intermolecular Alkyne Oxidation. J. Am. Chem. Soc. 2011, 133, 8482-8485.

(64) Cui, L.; Zhang, G.; Peng, Y.; Zhang, L. Gold or No Gold: One-Pot Synthesis of Tetrahydrobenz[b]azepin-4-ones from Tertiary N-(But-3-ynyl)anilines. Org. Lett. 2009, 11, 1225-1228.

(65) Luo, Y.; Zhang, G.; Hwang, E. S.; Wilcoxon, T. A.; Zhang, L. Beilstein J. Org. Chem. 2011, 7, 596-600. 
(66) Rudolph, M.; Hashmi, A. S. K. Gold catalysis in total synthesis-an update. Chem. Soc. Rev. 2012, 41, 2448-2462.

(67) Garcia, P.; Malacria, M.; Aubert, C.; Gandon, V.; Fensterbank, L. Gold-Catalyzed Cross-Couplings: New Opportunities for C-C Bond Formation. ChemCatChem 2010, 2, 493-497.

(68) Teles, J. H.; Brode, S.; Chabanas, M. Cationic Gold(I) Complexes: Highly Efficient Catalysts for the Addition of Alcohols to Alkynes. Angew. Chem. Int. Ed. 1998, 37, 1415-1418.

(69) Mizushima, E.; Sato, K.; Hayashi, T.; Tanaka, M. Highly efficient AuI-catalyzed hydration of alkynes. Angew. Chem. Int. Ed. 2002, 41, 4563-4565.

(70) Marion, N.; Ramon, R. S.; Nolan, S. P. [(NHC)AuI]-Catalyzed Acid-Free Alkyne Hydration at Part-per-Million Catalyst Loadings. J. Am. Chem. Soc. 2009, 131, 448-449.

(71) Blanco Jaimes, M. C.; Böhling, C. R. N.; Serrano-Becerra, J. M.; Hashmi, A. S. K. Highly Active Mononuclear NAC-Gold(I) Catalysts. Angew. Chem. Int. Ed. 2013, 52, 7963-7966.

(72) Oliver-Meseguer, J.; Cabrero-Antonino, J. R.; Domínguez, I.; Leyva-Pérez, A.; Corma, A. Small Gold Clusters Formed in Solution Give Reaction Turnover Numbers of 107 at Room Temperature. Science 2012, 338, 1452-1455.

(73) Hashmi, A. S. K. Sub-Nanosized Gold Catalysts. Science 2012, 338, 1434.

(74) Lavallo, V.; Wright, J. H.; Tham, F. S.; Quinlivan, S. Perhalogenated Carbacloso-dodecaborate Anions as Ligand Substituents: Applications in Gold Catalysis. Angew. Chem., Int. Ed. 2013, 52, 3172-3176.

(75) Duan, H.; Sengupta, S.; Petersen, J. L.; Akhmedov, N. G.; Shi, X. Triazole-Au(I) Complexes: A New Class of Catalysts with Improved Thermal Stability and Reactivity for Intermolecular Alkyne Hydroamination. J. Am. Chem. Soc. 2009, 131, 12100-12102.

(76) Brown, T. J.; Dickens, M. G.; Widenhoefer, R. A. Syntheses, X-ray Crystal Structures, and Solution Behavior of Monomeric, Cationic, Two-Coordinate Gold(I) $\pi$-Alkene Complexes. J. Am. Chem. Soc. 2009, 131, 6350-6351. 
(77) Shapiro, N. D.; Toste, F. D. Synthesis and structural characterization of isolable phosphine coinage metal $\pi$-complexes. Proc. Natl. Acad Sci. 2008, 105, 27792782.

(78) Guérinot, A.; Fang, W.; Sircoglou, M.; Bour, C.; Bezzenine-Lafollée, S.; Gandon, V. Copper Salts as Additives in Gold(I)-Catalyzed Reactions. Angew. Chem., Int. Ed. 2013, 52, 5848-5852.

(79) Lemière, G.; Gandon, V.; Agenet, N.; Goddard, J.-P.; de Kozak, A.; Aubert, C.; Fensterbank, L.; Malacria, M. Gold(I)- and Gold(III)-Catalyzed Cycloisomerization of Allenynes: A Remarkable Halide Effect. Angew. Chem., Int. Ed. 2006, 45, 7596-7599.

(80) Bartholomew, C. H. Mechanisms of catalyst deactivation. Appl. Catal., A 2001, $212,17-60$.

(81) Hashmi, A. S. K. Homogeneous gold catalysts and alkynes: A successful liaison. Gold Bull. 2003, 36, 3-9.

(82) Hashmi, A. S. K.; Schuster, A. M.; Litters, S.; Rominger, F.; Pernpointner, M. Gold Catalysis: 1,3-Oxazines by Cyclisation of Allene Amides. Chem. Eur. J. 2011, 17, 5661-5667.

(83) Yang, C.-G.; He, C. Gold(I)-Catalyzed Intermolecular Addition of Phenols and Carboxylic Acids to Olefins. J. Am. Chem. Soc. 2005, 127, 6966-6967.

(84) Brenzovich, W. E.; Benitez, D.; Lackner, A. D.; Shunatona, H. P.; Tkatchouk, E.; Goddard, W. A.; Toste, F. D. Gold-Catalyzed Intramolecular Aminoarylation of Alkenes: C-C Bond Formation through Bimolecular Reductive Elimination. Angew. Chem. Int. Ed. 2010, 49, 5519-5522.

(85) Bardaji, M.; Uznanski, P.; Amiens, C.; Chaudret, B.; Laguna, A. Aurophilic complexes as gold atom sources in organic media. Chem. Commun. 2002, 598599.

(86) Attar, S.; Bearden, W. H.; Alcock, N. W.; Alyea, E. C.; Nelson, J. H. Phosphole complexes of gold(I) halides: comparison of solution and solid-state structures by a combination of solution and CP/MAS phosphorus-31 NMR spectroscopy and $x$ ray crystallography. Inorg. Chem. 1990, 29, 425-433. 
(87) Mézailles, N.; Ricard, L.; Gagosz, F. Phosphine Gold(I) Bis-

(trifluoromethanesulfonyl)imidate Complexes as New Highly Efficient and Air-

Stable Catalysts for the Cycloisomerization of Enynes. Org. Lett. 2005, 7, 41334136.

(88) Bergamini, G.; Ceroni, P.; Balzani, V.; Gingras, M.; Raimundo, J.-M.; Morandi, V.; Merli, P. G. Synthesis of small gold nanoparticles: Au(i) disproportionation catalyzed by a persulfurated coronene dendrimer. Chem. Commun. 2007, 0 , 4167-4169.

(89) Koelle, U.; Laguna, A. Electrochemistry of Au-complexes. Inorg. Chim. Acta 1999, 290, 44-50.

(90) Connelly, N. G.; Geiger, W. E. Chemical Redox Agents for Organometallic Chemistry. Chem. Rev. 1996, 96, 877-910.

(91) Au, L.; Lu, X.; Xia, Y. A Comparative Study of Galvanic Replacement Reactions Involving $\mathrm{Ag}$ Nanocubes and $\mathrm{AuCl}_{2}{ }^{-}$or $\mathrm{AuCl}_{4}^{-}$. Adv. Mater. 2008, 20, 2517-2522.

(92) Choy, J.-H.; Kim, Y.-I. Gold Valence in $\left(\mathrm{AuI}_{3}\right) 0.25 \mathrm{Bi}_{2} \mathrm{Sr}_{2} \mathrm{CaCu}_{2} \mathrm{Oy}$ by XPS and XANES Spectroscopy. J. Phys. Chem. B 2003, 107, 3348-3350.

(93) Wang, W.; Jasinski, J.; Hammond, G. B.; Xu, B. Fluorine-enabled cationic gold catalysis: Functionalized hydration of alkynes. Angew. Chem. Int. Ed. 2010, 49, 7247-7252.

(94) Casaletto, M. P.; Longo, A.; Martorana, A.; Prestianni, A.; Venezia, A. M. XPS study of supported gold catalysts: the role of $A u^{0}$ and $A u^{+\delta}$ species as active sites. Surf. Interface Anal. 2006, 38, 215-218.

(95) de Almeida, M. P.; Martins, L. M. D. R. S.; Carabineiro, S. A. C.; Lauterbach, T.; Rominger, F.; Hashmi, A. S. K.; Pombeiro, A. J. L.; Figueiredo, J. L. Homogeneous and heterogenised new gold C-scorpionate complexes as catalysts for cyclohexane oxidation. Catal. Sci. Technol. 2013, 3, 3056-3069.

(96) Colton, R.; D'Agostino, A.; Traeger, J. C. Electrospray mass spectrometry applied to inorganic and organometallic chemistry. Mass Spectrom. Rev. 1995, 14, 79-106.

(97) Henderson, W.; Nickleson, B. K.; McCaffrey, L. J. Polyhedron 1998, 17, 42914313. 
(98) Xu, B.; Wang, W.; Hammond, G. B. Library-friendly synthesis of fluorinated ketones through functionalized hydration of alkynes and investigation of the reaction mechanism. J. Fluorine Chem. 2011, 132, 804-810.

(99) Döpp, R.; Lothschütz, C.; Wurm, T.; Pernpointner, M.; Keller, S.; Rominger, F.; Hashmi, A. S. K. Gold Catalysis: Hydrolysis of Di(alkoxy)carbenium Ion Intermediates as a Sensor for the Electronic Properties of Gold(I) Complexes. Organometallics 2011, 30, 5894-5903.

(100) Cheeseman, T. P.; Odell, A. L.; Raethel, H. A. trans-Effect order for alkene, alkyne, phosphine, arsine, stibine, and sulphide ligands from studies of diethylamine exchange reactions of $\mathrm{L}_{2} \mathrm{PtCl}_{2},[14 \mathrm{C}] \mathrm{NHEt}_{2}$ in various solvents. Chem. Commun. 1968, 0, 1496-1498.

(101) Christopher H. Gammons; Yunmei Yu; Williams-Jones, A. E. Geochim. Cosmochim. Acta 1997, 61, 1971-1983.

(102) Dias, H. V. R.; Fianchini, M.; Cundari, T. R.; Campana, C. F. Synthesis and Characterization of the Gold(I) Tris(ethylene) Complex [Au(C2H4)3][SbF6]. Angew. Chem., Int. Ed. 2008, 47, 556-559.

(103) Das, A.; Dash, C.; Yousufuddin, M.; Celik, M. A.; Frenking, G.; Dias, H. V. R. Isolable Tris(alkyne) and Bis(alkyne) Complexes of Gold(I). Angew. Chem., Int. Ed. 2012, 51, 3940-3943.

(104) Das, A.; Dash, C.; Celik, M. A.; Yousufuddin, M.; Frenking, G.; Dias, H. V. R. Tris(alkyne) and Bis(alkyne) Complexes of Coinage Metals: Synthesis and Characterization of (cyclooctyne) $3 M+(M=C u, A g)$ and (cyclooctyne) $2 \mathrm{Au}+$ and Coinage Metal $(M=C u, A g, A u)$ Family Group Trends. Organometallics 2013, $32,3135-3144$.

(105) Fianchini, M.; Dai, H.; Dias, H. V. R. Organometallic wheels based on coinage metal ions and norbornene: syntheses and structural characterization of [M(norbornene)3][SbF6] (M=Au, Ag, Cu). Chem. Commun. 2009, 0, 63736375.

(106) Braunstein, P.; Lehner, H.; Matt, D.; Burgess, K.; Ohlmeyer, M. J. In Inorg. Synth.; John Wiley \& Sons, Inc., 2007. 
(107) $\mathrm{Ph}_{3} \mathrm{P}(\mathrm{OTf})_{2}$ and even $\mathrm{Ph}_{3} \mathrm{PO}$ are not detected in ${ }^{31} \mathrm{P}$ NMR in the decay solutions, possible reason is their ${ }^{31} \mathrm{P}$ NMR peaks are broad in reaction system.

(108) Hashmi, A. S. K.; Weyrauch, J. P.; Frey, W.; Bats, J. W. Gold Catalysis: Mild Conditions for the Synthesis of Oxazoles from N-Propargylcarboxamides and Mechanistic Aspects. Org. Lett. 2004, 6, 4391-4394.

(109) Doherty, S.; Smyth, C. H.; Knight, J. G.; Hashmi, S. A. K. Synthesis of an electron-rich KITPHOS monophosphine, preparation of derived metal complexes and applications in catalysis. Nat. Protocols 2012, 7, 1870-1883.

(110) Hashmi, A. S. K.; Loos, A.; Doherty, S.; Knight, J. G.; Robson, K. J.; Rominger, F. Gold-Catalyzed Cyclizations: A Comparative Study of ortho,ortho'-Substituted KITPHOS Monophosphines with their Biaryl Monophosphine Counterpart SPHOS. Adv. Synth. Catal. 2011, 353, 749-759.

(111) Hashmi, A. S. K.; Loos, A.; Littmann, A.; Braun, I.; Knight, J.; Doherty, S.; Rominger, F. Gold(I) Complexes of KITPHOS Monophosphines: Efficient Cycloisomerisation Catalysts. Adv. Synth. Catal. 2009, 351, 576-582.

(112) Hashmi, A. S. K.; Frost, T. M.; Bats, J. W. Highly Selective Gold-Catalyzed Arene Synthesis. J. Am. Chem. Soc. 2000, 122, 11553-11554.

(113) Mhamed Touil; Benjamin Bechem; A. Stephen K. Hashmi; Bernd Engels; Mohammad A. Omary; Rabaâ, H. Journal of Molecular Structure: THEOCHEM 2010, 957, 21-25.

(114) Leyva, A.; Corma, A. Isolable Gold(I) Complexes Having One Low-Coordinating Ligand as Catalysts for the Selective Hydration of Substituted Alkynes at Room Temperature without Acidic Promoters. J. Org. Chem. 2009, 74, 2067-2074.

(115) Canseco-Gonzalez, D.; Petronilho, A.; Mueller-Bunz, H.; Ohmatsu, K.; Ooi, T.; Albrecht, M. Carbene Transfer from Triazolylidene Gold Complexes as a Potent Strategy for Inducing High Catalytic Activity. J. Am. Chem. Soc. 2013, 135, 13193-13203.

(116) Nieto-Oberhuber, C.; López, S.; Echavarren, A. M. Intramolecular [4 + 2] Cycloadditions of 1,3-Enynes or Arylalkynes with Alkenes with Highly Reactive Cationic Phosphine Au(I) Complexes. J. Am. Chem. Soc. 2005, 127, 6178-6179. 
(117) Choy, J.-H.; Kim, Y.-I. Gold Valence in (AuI3)0.25Bi2Sr2CaCu2Oy by XPS and XANES Spectroscopy. J. Phys. Chem. B 2003, 107, 3348-3350.

(118) Grapperhaus, C. A.; Poturovic, S. Electrochemical Investigations of the [Tris(2(diphenylphosphino)thiaphenolato)ruthenate(II)] Monoanion Reveal Metal-and Ligand-Centered Events: Radical, Reactivity, and Rate. Inorg. Chem. 2004, 43, 3292-3298.

(119) Roth, K. E.; Blum, S. A. Relative Kinetic Basicities of Organogold Compounds. Organometallics 2010, 29, 1712-1716.

(120) Egorova, O. A.; Seo, H.; Kim, Y.; Moon, D.; Rhee, Y. M.; Ahn, K. H. Characterization of Vinylgold Intermediates: Gold-Mediated Cyclization of Acetylenic Amides. Angew. Chem. Int. Ed. 2011, 50, 11446-11450.

(121) Chen, Y.; Wang, D.; Petersen, J. L.; Akhmedov, N. G.; Shi, X. Synthesis and characterization of organogold complexes containing an acid stable Au-C bond through triazole-yne 5-endo-dig cyclization. Chem. Commun. 2010, 46, 61476149.

(122) Zeng, X.; Kinjo, R.; Donnadieu, B.; Bertrand, G. Serendipitous Discovery of the Catalytic Hydroammoniumation and Methylamination of Alkynes. Angew. Chem. Int. Ed. 2010, 49, 942-945.

(123) Laurence, C.; Brameld, K. A.; Graton, J. r. m.; Le Questel, J.-Y.; Renault, E. The $p \mathrm{~K}_{B H X}$ Database: Toward a Better Understanding of Hydrogen-Bond Basicity for Medicinal Chemists. J. Med. Chem. 2009, 52, 4073-4086.

(124) Laurence, C.; Graton, J. r. m.; Berthelot, M.; Besseau, F. o.; Le Questel, J.-Y.; Luçon, M.; Ouvrard, C.; Planchat, A. 1.; Renault, E. An Enthalpic Scale of Hydrogen-Bond Basicity. 4. Carbon $\pi$ Bases, Oxygen Bases, and Miscellaneous Second-Row, Third-Row, and Fourth-Row Bases and a Survey of the 4Fluorophenol Affinity Scale. J. Org. Chem. 2010, 75, 4105-4123.

(125) Reed, A. E.; Curtiss, L. A.; Weinhold, F. Intermolecular interactions from a natural bond orbital, donor-acceptor viewpoint. Chem. Rev. 1988, 88, 899-926.

(126) Ault, A. General Acid and General Base Catalysis. J. Chem. Educ. 2007, 84, 38.

(127) Kwan, E. E. The Rate of Proton Transfer. J. Chem. Educ. 2007, 84, 39. 
(128) Wilson, T. J.; Li, N.-S.; Lu, J.; Frederiksen, J. K.; Piccirilli, J. A.; Lilley, D. M. J. Nucleobase-mediated general acid-base catalysis in the Varkud satellite ribozyme. Proc. Natl. Acad. Sci. USA, Early Ed. 2010, 1-6, 6 pp.

(129) Kath-Schorr, S.; Wilson, T. J.; Li, N.-S.; Lu, J.; Piccirilli, J. A.; Lilley, D. M. J. General Acid-Base Catalysis Mediated by Nucleobases in the Hairpin Ribozyme. J. Am. Chem. Soc. 2012, 134, 16717-16724.

(130) Krauter, C. M.; Hashmi, A. S. K.; Pernpointner, M. A New Insight into Gold(I)Catalyzed Hydration of Alkynes: Proton Transfer. ChemCatChem 2010, 2, 12261230.

(131) Weyrauch, J. P.; Hashmi, A. S. K.; Schuster, A.; Hengst, T.; Schetter, S.; Littmann, A.; Rudolph, M.; Hamzic, M.; Visus, J.; Rominger, F.; Frey, W.; Bats, J. W. Cyclization of Propargylic Amides: Mild Access to Oxazole Derivatives. Chem. Eur. J. 2010, 16, 956-963.

(132) Hashmi, A. S. K.; Schuster, A. M.; Rominger, F. Gold Catalysis: Isolation of Vinylgold Complexes Derived from Alkynes. Angew. Chem. Int. Ed. 2009, 48, 8247-8249.

(133) Hashmi, A. S. K.; Schuster, A. M.; Gaillard, S.; Cavallo, L.; Poater, A.; Nolan, S. P. Selectivity Switch in the Synthesis of Vinylgold(I) Intermediates. Organometallics 2011, 30, 6328-6337.

(134) ${ }^{13} \mathrm{C}$ NMR of good quality (Au-4) can't be obtained due to the broadening of peaks. According to report by Hashmi and coworkers, the vinyl carbon is not visible in the ${ }^{13} \mathrm{C}$ NMR spectrum even in isolated form of Au-1.

(135) Duan, H.; Sengupta, S.; Petersen, J. L.; Akhmedov, N. G.; Shi, X. Triazole-Au(I) Complexes: A New Class of Catalysts with Improved Thermal Stability and Reactivity for Intermolecular Alkyne Hydroamination. J. Am. Chem. Soc. 2009, $131,12100-12102$.

(136) Lein, M.; Rudolph, M.; Hashmi, S. K.; Schwerdtfeger, P. Homogeneous Gold Catalysis: Mechanism and Relativistic Effects of the Addition of Water to Propyne. Organometallics 2010, 29, 2206-2210. 
(137) Hashmi, A. S. K.; Pernpointner, M.; Hansmann, M. M. Theoretical insights into the superior activity of gold catalysts and reactions of organogold intermediates with electrophiles. Faraday Discuss. 2011, 152, 179-184.

(138) Hashmi, A. S. K.; Braun, I.; Rudolph, M.; Rominger, F. The Role of Gold Acetylides as a Selectivity Trigger and the Importance of gem-Diaurated Species in the Gold-Catalyzed Hydroarylating-Aromatization of Arene-Diynes. Organometallics 2012, 31, 644-661.

(139) Liu, L.-P.; Xu, B.; Mashuta, M. S.; Hammond, G. B. Synthesis and Structural Characterization of Stable Organogold(I) Compounds. Evidence for the Mechanism of Gold-Catalyzed Cyclizations. J. Am. Chem. Soc. 2008, 130, 1764217643.

(140) Not all additives are shown because lack of data about their $p \mathrm{~K}_{\mathrm{BHX}}$; some $p \mathrm{~K}_{\mathrm{BHX}}$ data have been estimated from the $p \mathrm{~K}_{\mathrm{BHX}}$ of structural analogs.

(141) Brown, T. J.; Sugie, A.; Leed, M. G. D.; Widenhoefer, R. A. Structures and Dynamic Solution Behavior of Cationic, Two-Coordinate Gold(I)- $\pi$-Allene Complexes. Chem. Eur. J. 2012, 18, 6959-6971.

(142) Brown, T. J.; Dickens, M. G.; Widenhoefer, R. A. Syntheses, X-ray Crystal Structures, and Solution Behavior of Monomeric, Cationic, Two-Coordinate Gold(I) pi-Alkene Complexes. J. Am. Chem. Soc. 2009, 131, 6350-6351.

(143) Brown, T. J.; Dickens, M. G.; Widenhoefer, R. A. Syntheses and X-ray crystal structures of cationic, two-coordinate gold(i) pi-alkene complexes that contain a sterically hindered o-biphenylphosphine ligand. Chem. Commun. 2009, 64516453.

(144) Brooner, R. E. M.; Widenhoefer, R. A. Syntheses, X-ray Crystal Structures, and Solution Behavior of Cationic, Two-Coordinate Gold(I) $\eta 2-D i e n e ~ C o m p l e x e s$. Organometallics 2011, 30, 3182-3193.

(145) Brown, T. J.; Sugie, A.; Dickens, M. G.; Widenhoefer, R. A. Solid-State and Dynamic Solution Behavior of a Cationic, Two-Coordinate Gold(I) $\pi$-Allene Complex. Organometallics 2010, 29, 4207-4209. 
(146) Brown, T. J.; Widenhoefer, R. A. Cationic Gold(I) $\pi$-Complexes of Terminal Alkynes and Their Conversion to Dinuclear $\sigma, \pi$-Acetylide Complexes. Organometallics 2011, 30, 6003-6009.

(147) Zhdanko, A.; Ströbele, M.; Maier, M. E. Coordination Chemistry of Gold Catalysts in Solution: A Detailed NMR Study. Chem. Eur. J. 2012, 18, 1473214744.

(148) Zhu, Y.; Day, C. S.; Jones, A. C. Synthesis and Structure of Cationic Phosphine Gold(I) Enol Ether Complexes. Organometallics 2012, 31, 7332-7335.

(149) Hashmi, A. S. K.; Schwarz, L.; Choi, J.-H.; Frost, T. M. A New Gold-Catalyzed C-C Bond Formation. Angew. Chem. Int. Ed. 2000, 39, 2285-2288.

(150) Zhou, C.-Y.; Chan, P. W. H.; Che, C.-M. Gold(III) Porphyrin-Catalyzed Cycloisomerization of Allenones. Org. Lett. 2005, 8, 325-328.

(151) Tomás-Mendivil, E.; Toullec, P. Y.; Díez, J.; Conejero, S.; Michelet, V.; Cadierno, V. Cycloisomerization versus Hydration Reactions in Aqueous Media: A Au(III)-NHC Catalyst That Makes the Difference. Org. Lett. 2012, 14, 25202523.

(152) Luo, T.; Dai, M.; Zheng, S.-L.; Schreiber, S. L. Syntheses of $\alpha$-Pyrones Using Gold-Catalyzed Coupling Reactions. Org. Lett. 2011, 13, 2834-2836.

(153) Cui, D.-M.; Meng, Q.; Zheng, J.-Z.; Zhang, C. Gold-catalyzed addition of sulfonic acids to alkynes to form vinyl sulfonates. Chem. Commun. 2009, $1577-$ 1579.

(154) Ye, L.; Wang, Y.; Aue, D. H.; Zhang, L. Experimental and Computational Evidence for Gold Vinylidenes: Generation from Terminal Alkynes via a Bifurcation Pathway and Facile C-H Insertions. J. Am. Chem. Soc. 2011, 134, 31-34.

(155) Chen, Y.; Yan, W.; Akhmedov, N. G.; Shi, X. 1,2,3-Triazole as a Special "XFactor" in Promoting Hashmi Phenol Synthesis. Org. Lett. 2010, 12, 344-347.

(156) Wang, D.; Gautam, L. N. S.; Bollinger, C.; Harris, A.; Li, M.; Shi, X. 1,2,3Triazole Bound Au(I) (TA-Au) as Chemoselective Catalysts in Promoting Asymmetric Synthesis of Substituted Allenes. Org. Lett. 2011, 13, 2618-2621. 
(157) Wang, D.; Zhang, Y.; Cai, R.; Shi, X. Triazole-Au(I) complex as chemoselective catalyst in promoting propargyl ester rearrangements. Beilstein J. Org. Chem. 2011, 7, 1014-1020, No. 115.

(158) Wang, D.; Zhang, Y.; Harris, A.; Gautam, L. N. S.; Chen, Y.; Shi, X. Triazolegold-promoted, effective synthesis of enones from propargylic esters and alcohols: A catalyst offering chemoselectivity, acidity and ligand economy. Adv. Synth. Catal. 2011, 353, 2584-2588.

(159) Zhou, C.-Y.; Chan, P. W. H.; Che, C.-M. Gold(III) Porphyrin-Catalyzed Cycloisomerization of Allenones. Org. Lett. 2005, 8, 325-328.

(160) Oxford, S. M.; Henao, J. D.; Yang, J. H.; Kung, M. C.; Kung, H. H. Understanding the effect of halide poisoning in $\mathrm{CO}$ oxidation over Au/TiO2. Appl. Catal., A. 2008, 339, 180-186.

(161) Chandler, B. D.; Kendell, S.; Doan, H.; Korkosz, R.; Grabow, L. C.; Pursell, C. J. $\mathrm{NaBr}$ Poisoning of $\mathrm{Au} / \mathrm{TiO}_{2}$ Catalysts: Effects on Kinetics, Poisoning Mechanism, and Estimation of the Number of Catalytic Active Sites. ACS Catal. 2012, 2, 684694.

(162) Bartholomew, C. H. Mechanisms of catalyst deactivation. Appl. Catal., A. 2001, $212,17-60$.

(163) O. Simone, D.; Kennelly, T.; 1. brungard, n.; J. Farrauto*, R. Reversible poisoning of palladium catalysts for methane oxidation. Appl. Catal. 1991, 70, 87-100.

(164) Gaillard, S.; Bosson, J.; Ramón, R. S.; Nun, P.; Slawin, A. M. Z.; Nolan, S. P. Development of Versatile and Silver-Free Protocols for Gold(I) Catalysis. Chem. Eur. J. 2010, 16, 13729-13740.

(165) Gómez-Suárez, A.; Oonishi, Y.; Meiries, S.; Nolan, S. P. [\{Au(NHC) $\} 2(\mu-$ OH)][BF4]: Silver-Free and Acid-Free Catalysts for Water-Inclusive GoldMediated Organic Transformations. Organometallics 2013, 32, 1106-1111.

(166) Nevado, C.; Echavarren, A. M. Intramolecular Hydroarylation of Alkynes Catalyzed by Platinum or Gold: Mechanism and endo Selectivity. Chem. Eur. J. 2005, 11, 3155-3164.

(167) Burfield, D. R.; Goh, E. H.; Ong, E. H.; Smithers, R. H. Storage and decomposition of chloroform. Gazz. Chim. Ital. 1983, 113, 841-3. 
(168) Ghosh, N.; Nayak, S.; Sahoo, A. K. Gold-Catalyzed Regioselective Hydration of Propargyl Acetates Assisted by a Neighboring Carbonyl Group: Access to $\alpha-$ Acyloxy Methyl Ketones and Synthesis of (土)-Actinopolymorphol B广. J. Org. Chem. 2010, 76, 500-511.

(169) Wang, D.; Cai, R.; Sharma, S.; Jirak, J.; Thummanapelli, S. K.; Akhmedov, N. G.; Zhang, H.; Liu, X.; Petersen, J. L.; Shi, X. "Silver Effect” in Gold(I) Catalysis: An Overlooked Important Factor. J. Am. Chem. Soc. 2012, 134, 90129019.

(170) Nieto-Oberhuber, C.; Muñoz, M. P.; Buñuel, E.; Nevado, C.; Cárdenas, D. J.; Echavarren, A. M. Cationic Gold(I) Complexes: Highly Alkynophilic Catalysts for the exo- and endo-Cyclization of Enynes. Angew. Chem. Int. Ed. 2004, 43, $2402-$ 2406.

(171) Bartolomé, C.; Ramiro, Z.; Pérez-Galán, P.; Bour, C.; Raducan, M.; Echavarren, A. M.; Espinet, P. Gold(I) Complexes with Hydrogen-Bond Supported Heterocyclic Carbenes as Active Catalysts in Reactions of 1,6-Enynes. Inorg. Chem. 2008, 47, 11391-11397.

(172) Bartolomé, C.; Ramiro, Z.; García-Cuadrado, D.; Pérez-Galán, P.; Raducan, M.; Bour, C.; Echavarren, A. M.; Espinet, P. Nitrogen Acyclic Gold(I) Carbenes: Excellent and Easily Accessible Catalysts in Reactions of 1,6-Enynes. Organometallics 2010, 29, 951-956.

(173) Toullec, P. Y.; Genin, E.; Antoniotti, S.; Genêt, J.-P.; Michelet, V. Au2O3 as a Stable and Efficient Catalyst for the Selective Cycloisomerization of $\gamma$-Acetylenic Carboxylic Acids to $\gamma$-Alkylidene- $\gamma$-Butyrolactones. Synlett 2008, 2008, 707-711.

(174) Tang, Y.; Yu, B. Identification of (phosphine)gold(i) hydrates and their equilibria in wet solutions. RSC Adv. 2012, 2, 12686-12689.

(175) Xi, Y.; Wang, D.; Ye, X.; Akhmedov, N. G.; Petersen, J. L.; Shi, X. Synergistic Au/Ga Catalysis in Ambient Nakamura Reaction. Org. Lett. 2013, 16, 306-309.

(176) Johansson, M. J.; Gorin, D. J.; Staben, S. T.; Toste, F. D. Gold(I)-Catalyzed Stereoselective Olefin Cyclopropanation. J. Am. Chem. Soc. 2005, 127, 1800218003. 
(177) Muzart, J. Gold-catalysed reactions of alcohols: isomerisation, inter-and intramolecular reactions leading to $C-C$ and $C$-heteroatom bonds. Tetrahedron 2008, 64, 5815-5849.

(178) Shapiro, N. D.; Toste, F. D. Rearrangement of Alkynyl Sulfoxides Catalyzed by Gold(I) Complexes. J. Am. Chem. Soc. 2007, 129, 4160-4161.

(179) Li, G.; Zhang, L. Gold-Catalyzed Intramolecular Redox Reaction of Sulfinyl Alkynes: Efficient Generation of $\alpha$-Oxo Gold Carbenoids and Application in Insertion into R-CO Bonds. Angew. Chem., Int. Ed. 2007, 46, 5156-5159.

(180) Fang, R.; Yang, L. Mechanism of the Gold(I)-Catalyzed Rearrangement of Alkynyl Sulfoxides: A DFT Study. Organometallics 2012, 31, 3043-3055.

(181) Cuenca, A. B.; Montserrat, S.; Hossain, K. M.; Mancha, G.; Lledós, A.; MedioSimón, M.; Ujaque, G.; Asensio, G. Gold(I)-Catalyzed Intermolecular Oxyarylation of Alkynes: Unexpected Regiochemistry in the Alkylation of Arenes. Org. Lett. 2009, 11, 4906-4909.

(182) Wang, Y.; Ye, L.; Zhang, L. Au-catalyzed synthesis of 2-alkylindoles from Narylhydroxylamines and terminal alkynes. Chem. Commun. 2011, 47, 7815-7817.

(183) Wang, Y.; Liu, L.; Zhang, L. Combining Zn ion catalysis with homogeneous gold catalysis: an efficient annulation approach to N-protected indoles. Chem. Sci. 2013, 4, 739-746.

(184) Lehmann, F.; Koolmeister, T.; Odell, L. R.; Scobie, M. A Versatile New Synthetic Route to 1N-Hydroxyindazoles. Org. Lett. 2009, 11, 5078-5081.

(185) Loudon, J. D.; Tennant, G. Substituent interactions in ortho-substituted nitrobenzenes. Quarterly Rev., Chem. Soc. 1964, 18, 389-413.

(186) Spence, T. W. M.; Tennant, G. The chemistry of nitro-compounds. Part II. The scope and mechanism of the base-catalysed transformations of someNNdisubstituted o-nitrobenzamides. J. Chem. Soc., Perkin Trans. 1 1972, 0, 97-102.

(187) Guo, Y.; Twamley, B.; Shreeve, J. n. M. Pd-catalyzed arylation of silyl enol ethers of substituted alpha -fluoroketones. Org. Biomol. Chem. 2009, 7, 17161722.

(188) Kim, K.-Y.; Kim, B. C.; Lee, H. B.; Shin, H. Nucleophilic Fluorination of Triflates by Tetrabutylammonium Bifluoride. J. Org. Chem. 2008, 73, 8106-8108. 
(189) Prakash, G. K. S.; Beier, P. Construction of Asymmetric Fluorinated Carbon Centers. Angew. Chem. Int. Ed. 2006, 45, 2172-2174.

(190) de Haro, T.; Nevado, C. Gold-Catalyzed Synthesis of $\alpha$-Fluoro Acetals and $\alpha$ Fluoro Ketones from Alkynes. Adv. Synth. Catal. 2010, 352, 2767-2772. 


\section{APPENDIX- LIST OF ABBREVIATIONS}

CV: Cyclic voltammetry

CoCp* ${ }_{2}$ : Decamethylcobaltocene

DCM: Dichloromethane

DMSO: Dimethylsulfonyl Oxide

DCE: Dichloroethane

DMPU: 1,3-Dimethyl-3,4,5,6-tetrahydro-2(1H)-pyrimidinone

ESI-MS: Electrospray Ionization mass spectrometry

EtOAc: Ethyl Acetate

GC: Gas Liquid Chromatography

h: Hour

HOMO: Highest occupied molecular orbital

HRMS: High resolution mass spectroscopy

Hz: Hertz

HOBt: Hydroxybenzotriazole

HCl: Hydrochloric acid

HMPA: Hexamethylphosphoramide 
LUMO: Lowest unoccupied molecular orbital

L: Ligand

MHz: Megahertz

M: Molar

mg: Milligram

min: Minute

mL: Milliliter

mmol: Millimole

mM: Millimolar

$\mathbf{m} / \mathbf{z}$ : Mass to charge ratio

NHC: N-Heterocyclic carbene

Nu: Nucleophile

NMR: Nuclear magnetic resonance spectroscopy

NTf 2 : Bis(trifluoromethanesulfonyl)imide

ppm: Parts per million

rt: Room temperature

AgOTf: Silver triflate

AgSbF $_{6}$ : Silver hexafluoroantimonate

TBAHFP: Tetrabutylammonium hexafluorophosphate 
TfOH: Trifluoromethanesulfonic acid

TLC: Thin layer chromatography

tert: Tertiary

THF: Tetrahydrofuran

TON: Turnover number

TfO: Triflate

THF: Tetrahydrofuran

$\mathbf{P h}_{3} \mathbf{P}$ : Triphenyl phosphine

PPN: Bis(triphenylphosphine)iminium

XPS: X-ray photoelectron spectroscopy

$\alpha$ : Alpha

$\beta$ : Beta

$\boldsymbol{\delta}$ : Delta

$\gamma:$ Gamma

m: Meta

o: Ortho

p: Para 


\section{APPENDIX- COPYRIGHT PERMISSION}


This is a License Agreement between Manish Kumar ("You") and John Wiley and Sons ("John Wiley and Sons") provided by Copyright Clearance Center ("CCC"). The license consists of your order details, the terms and conditions provided by John Wiley and Sons, and the payment terms and conditions.

All payments must be made in full to CCC. For payment instructions, please see information listed at the bottom of this form.

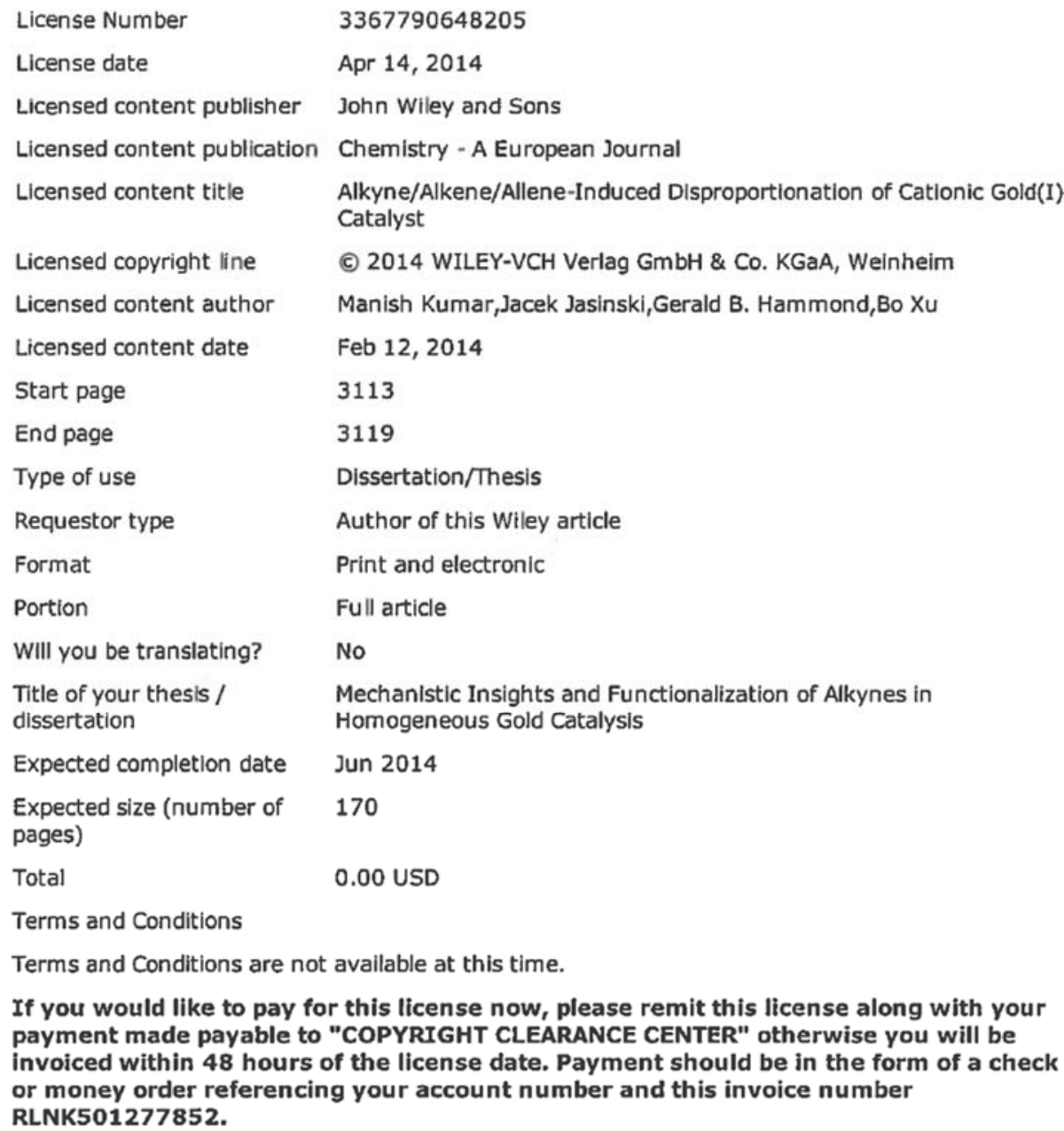

Total

0.00 USD

Terms and Conditions

Terms and Conditions are not available at this time.

If you would like to pay for this license now, please remit this license along with your payment made payable to "COPYRIGHT CLEARANCE CENTER" otherwise you will be invoiced within $\mathbf{4 8}$ hours of the license date. Payment should be in the form of a check or money order referencing your account number and this invoice number

RLNK501277852. 


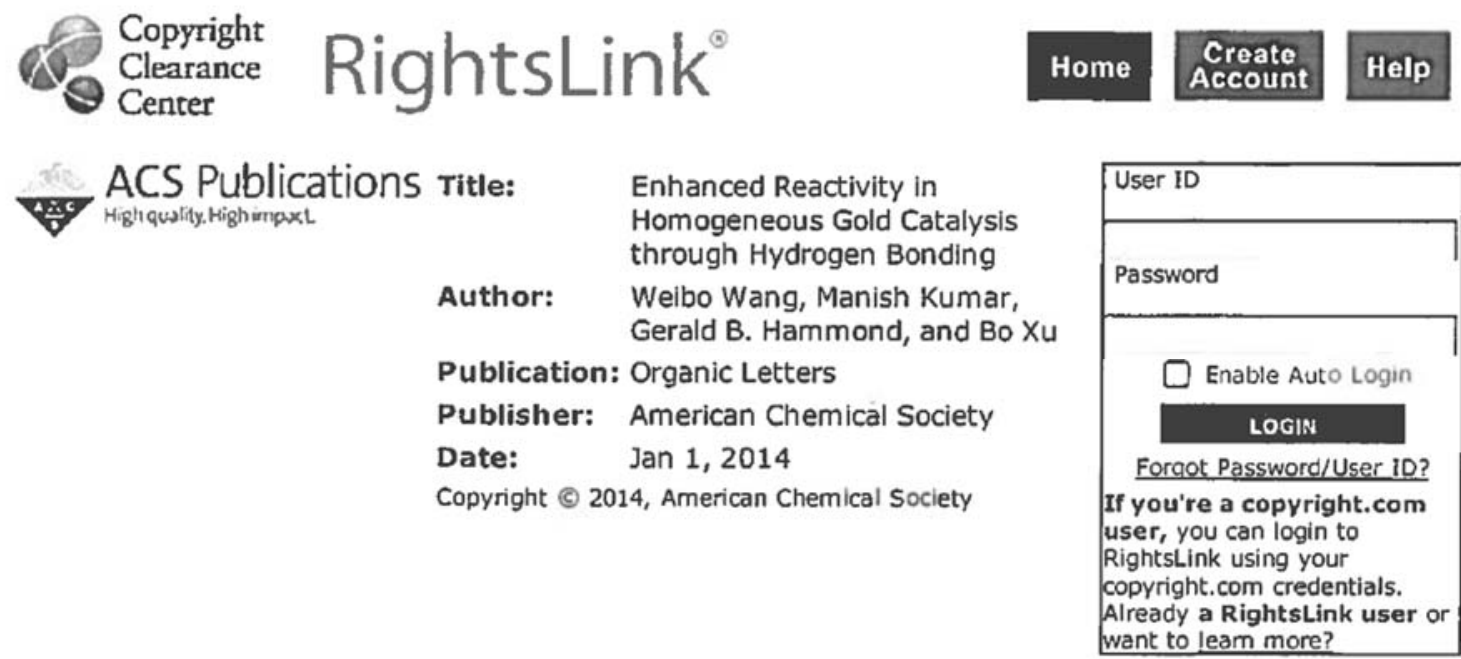

\section{PERMISSION/LICENSE IS GRANTED FOR YOUR ORDER AT NO CHARGE}

This type of permission/license, instead of the standard Terms \& Conditions, is sent to you because no fee is being charged for your order. Please note the following:

- Permission is granted for your request in both print and electronic formats, and translations.

- If figures and/or tables were requested, they may be adapted or used in part.

- Please print this page for your records and send a copy of it to your publisher/graduate school.

- Appropriate credit for the requested material should be given as follows: "Reprinted (adapted) with permission from (COMPLETE REFERENCE CITATION). Copyright (YEAR) American Chemical Society." Insert appropriate information in place of the capitalized words.

- One-time permission is granted only for the use specified in your request. No additional uses are granted (such as derivative works or other editions). For any other uses, please submit a new request.

\section{BACK}

\section{CLOSE WINDOW}

Copyright @ 2014 Copyriaht Clearance Center, Inc. All Rights Reserved. Privacy statement. Comments? We would like to hear from you. E-mail us at customercare@copyriaht.com 


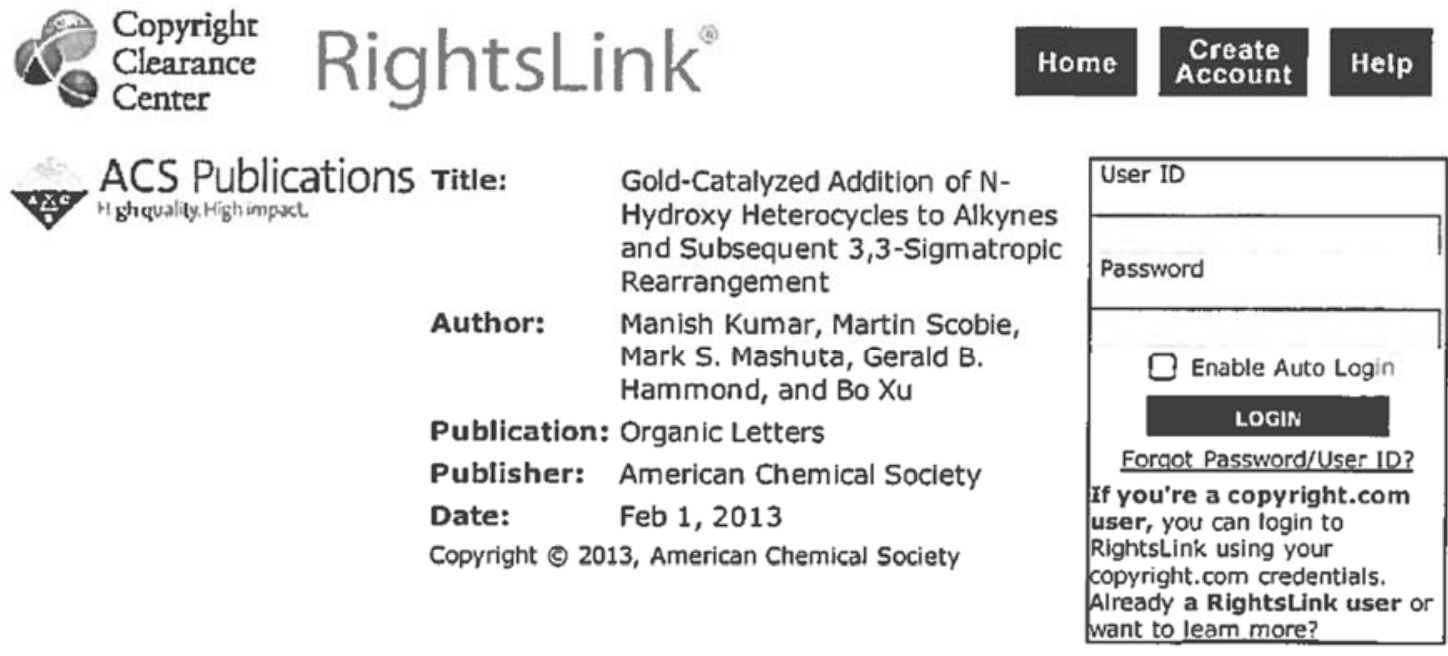

\section{PERMISSION/LICENSE IS GRANTED FOR YOUR ORDER AT NO CHARGE}

This type of permission/license, instead of the standard Terms \& Conditions, is sent to you because no fee is being charged for your order. Please note the following:

- Permission is granted for your request in both print and electronic formats, and translations.

- If figures and/or tables were requested, they may be adapted or used in part.

- Please print this page for your records and send a copy of it to your publisher/graduate school.

- Appropriate credit for the requested material should be given as follows: "Reprinted (adapted) with permission from (COMPLETE REFERENCE CITATION). Copyright (YEAR) American Chemical Society." Insert appropriate information in place of the capitalized words.

- One-time permission is granted only for the use specified in your request. No additional uses are granted (such as derivative works or other editions). For any other uses, please submit a new request.

\section{BACK}

CLOSE WINDOW

Copyright (9) 2014 Copyright Clearance Center, Inc. All Rights Reserved. Privacy statement. Comments? We would like to hear from you. E-mail us at customercare@copyniaht.com 


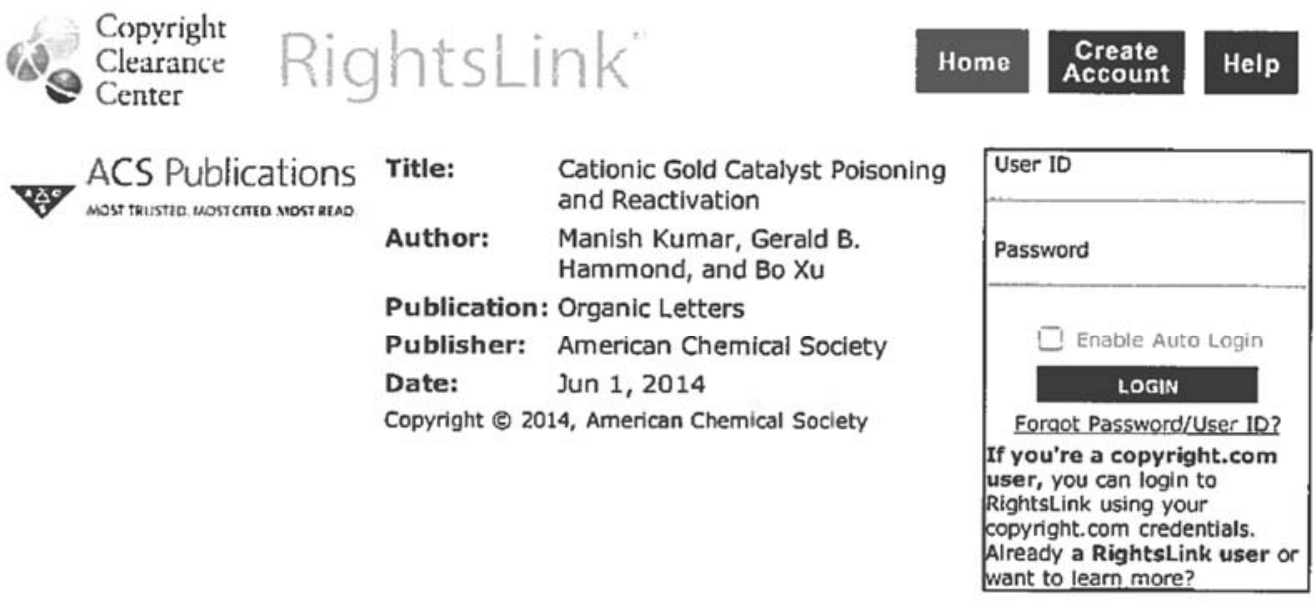

\section{PERMISSION/LICENSE IS GRANTED FOR YOUR ORDER AT NO CHARGE}

This type of permission/license, instead of the standard Terms \& Conditions, is sent to you because no fee is being charged for your order. Please note the following:

- Permission is granted for your request in both print and electronic formats, and translations.

- If figures and/or tables were requested, they may be adapted or used in part.

- Please print this page for your records and send a copy of it to your publisher/graduate school.

- Appropriate credit for the requested material should be given as follows: "Reprinted (adapted) with permission from (COMPLETE REFERENCE CITATION). Copyright (YEAR) American Chemical Society." Insert appropriate information in place of the capitalized words.

- One-time permission is granted only for the use specified in your request. No additional uses are granted (such as derivative works or other editions). For any other uses, please submit a new request.

\section{BACK CLOSEWINDOW}

Copyright (c) 2014 Copyriaht Clearance Center, Inc. All Rights Reserved. Privacy statement. Comments? We would like to hear from you. E-mail us at customercare Qcopuriaht.com 


\title{
CURRICULUM VITAE
}

\author{
Manish Kumar
}

Department of Chemistry

University of Louisville

Louisville, KY- 40292

Mobile: (502)-526-2743

E-mail: manishchem53@gmail.com

\section{EDUCATION}

$\mathrm{PhD}$, Organic Chemistry, University of Louisville, Louisville, KY, USA 2009-2014 Thesis title: "Mechanistic Insights and Functionalization of Alkynes in Homogeneous Gold Catalysis"

MS, Organic Chemistry, Panjab University, Chandigarh, India

2005-2007

Thesis title: "Synthesis of dithiocyanate, Thiocyanatin A, a nematocidal natural product isolated from marine sponge, Oceanapia sp"

BS, Chemistry, Botany \& Zoology, GPG College, Bilaspur, Himachal

2002-2005

Pradesh University, Shimla, India

\section{RESEARCH EXPERIENCE}

Graduate Teaching/Research Assistant, Department of Chemistry, University of Louisville, 08/2009-06/2014

Advisor: Prof. Gerald B. Hammond

- Synthesis of functionalized benzotriazoles using addition of nucleophile to alkyne and subsequently followed by sigmatropic rearrangement.

- Unraveled the intricate details of mechanism of gold catalyst deactivation and to overcome the reactivity-stability dilemma of gold catalysis through additives (neutral organic compounds, counter ions, solvents).

- Understanding of the mechanistic insights of gold catalyzed reactions using kinetics.

Research Project in Organic Chemistry, Department of Chemistry, Institute of Himalayan BioResource Technology (CSIR Lab) Palampur, India. 11/2008$07 / 2009$ 


\section{Advisor: Dr. Pralay Das}

- Development of novel and new organic transformations on transition metal solid support catalyst.

\section{MS Research Project, Panjab University, Chandigarh, India $\quad$ 08/2006-04/2007}

Adviser: Prof. M. L. Sharma

- Synthesis of dithiocyanate, Thiocyanatin A, a nematocidal natural product isolated from marine sponge, Oceanapia sp.

\section{RESEARCH/TECHNICAL SKILLS}

- Handled several organic reagents and catalysts, Familiar with protecting groups, Microwave reactors, Metal catalysts such as Au Pd, Pt, solid supported.

- Experience in air sensitive reagents, Hand over heterocyclic synthesis, Multistep synthesis, Synthesized biologically active compounds, Skill in scale up of reaction.

- Spectroscopic analysis and data interpretation through ${ }^{1} \mathrm{H} \mathrm{NMR},{ }^{13} \mathrm{C} \mathrm{NMR},{ }^{31} \mathrm{P}$, ${ }^{19} \mathrm{~F}$, two dimension NMR, and GCMS.

- Trained in using UV-Vis, FTIR, electrochemistry, NMR, GCMS, LCMS, FTMS, HRMS, and XPS.

- Microsoft office program suite, Endnote program, Gaussian, Molden, Chemdraw and ChemWindow, Fortran 90 language.

- Laboratory equipment maintenance including vacuum pumps, glove box, and schlenk line.

- Impurity profile study on the basis of spectra.

- Experience in the isolation of compounds by MDAP, Flash Master (CombiFlash).

- Familiar with safety assessment of chemicals Material safety database (MSDS) as well as lab safety.

- Proficient in using research database softwares such as SciFinder and Reaxys.

- Trained and mentored undergraduate and new graduate students.

- Presenting theoretical topics and scientific research at group meetings, chemistry department, regional and national meetings.

- Personal skills include collaboration, organization, good verbal and written communication skills.

\section{TEACHING EXPERIENCE}

- $\quad$ Summer-Spring Term, 2013-2014

Teaching Assistant, Chem 344 Organic II Laboratory: Synthesis \& characterization.

- $\quad$ Fall-Spring Term, 2010-2012

Teaching Assistant, Chem 344 Organic II Laboratory: Synthesis \& characterization.

- Summer Term, 2010

Teaching Assistant, Chem 207 Analytical I Laboratory. 
- $\quad$ Spring Term, 2010

Teaching Assistant, Chem 344 Organic II Laboratory: Synthesis \& characterization.

- Fall Term, 2009

Teaching Assistant, Chem 343 Organic I Laboratory: Synthesis \& characterization.

\section{FELLOWSHIPS, HONORS AND AWARDS}

- University of Louisville Graduate Student Council Travel Award for attending $247^{\text {th }}$ ACS National Meeting, Dallas, Texas, $16^{\text {th }}-20^{\text {th }}$ March 2014.

- Received prestigious IMD-3 Travel Award (Institute of Molecular Diversity and Drug Design) for ACS National meeting, Indianapolis, Indiana, $8^{\text {th }}-12^{\text {th }}$ September 2013.

- University of Louisville Graduate Student Council Travel Award for attending 42nd ACS Regional Meeting, Indianapolis, Indiana, $7^{\text {th }}-9^{\text {th }}$ June 2011.

- Selected with scholarship to pursue PhD from University of Louisville, Kentucky (USA) (2009).

- Qualified CSIR-UGC (NET) examination (June 2007) with CSIR ranking (SPM) conducted by University Grant Commission and CSIR for Junior Research Fellowship and Lecturer Ship eligibility.

- Qualified Graduate Aptitude Test in Engineering (GATE) with 409 (94\%) score \& 293 all India ranking (2007).

- Qualified Defence Research and Development Organization (DRDO) Scientist Entry Test (2007).

- Qualified State Level Eligibility Test (SLET), Himachal Pradesh (INDIA) (2006).

- Qualified "Bhabha Atomic Research Center" written test for admission to Ph.D (2007).

- Qualified "Indian Institute of Science, Bangalore" written test for admission to Ph.D (2007).

- First Rank holder in OCET conducted by Panjab University, Chandigarh for admission to MSc. (H.S.) (Chemistry) course (2005).

- Second Rank holder in M.Sc. entrance test conducted by Himachal Pradesh University for admission to M.Sc. (Chemistry) course (2005).

- Qualified College cadre Lecturer test conducted by Himachal Pradesh Public Service Commission (HPPSC) (2008).

- National Merit Scholarship, 1999.

\section{PUBLICATIONS \& PRESENTATIONS}

\section{Manuscripts (Published/ submitting/ in preparation):}

- Cationic Gold Catalyst Poisoning and Re-activation, Kumar, M.; Hammond, G. B.; Xu, Bo. Org. Lett. 2014, 16, 3452-3455. 
- Alkyne/Alkene/Allene Induced Disproportionation of Cationic Gold(I) Catalyst, Kumar, M.; Jacinski, J.; Hammond, G. B.; Xu, Bo. Chem. Eur. J. 2014, 20, 3113-3139.

- Enhanced Reactivity in Homogeneous Gold Catalysis through Hydrogen Bonding, Wang, W.; Kumar, M.; Hammond, G. B.; Xu, B. Org. Lett. 2014, 16, 636-639.

- Gold-catalyzed Addition of $N$-Hydroxy Heterocycles to Alkynes and Subsequent 3,3-Sigmatropic Rearrangement, Kumar, M.; Scobie, M.; Mashuta, M. S.; Hammond, G. B.; Xu, B. Org. Lett. 2013, 15, 724-727.

- Copper Promoted C-N and C-O Type Cross-Coupling Reactions, Das, P.; Sharma, D.; Kumar, M.; Singh, B. Curr. Org. Chem. 2010, 14, 753-783.

\section{Conferences, Workshops:}

- Organic Fluorine Chemistry: Basic Concepts and Application to Materials and Drug Sciences: Professor Kenji Uneyama, Okayama University, Japan: University of Louisville, October 2013.

- Introduction to new ab initio quantum chemistry program: Q-Chem, University of Louisville, March-2010.

- Attended and participated rigorously in the First Chandigarh Science Congress session held at Chandigarh, march, 2007.

- Attended and participated rigorously in the "National Symposium and $3^{\text {rd }}$ R.C.Paul Symposium organized by Chemistry Department, Panjab University, Chandigarh, February, 2007.

\section{Selected Conference Oral \& Poster Presentations:}

- Kumar, M.; Malhotra, D.; Hammond, G. B.; Xu, B. Kinetic Model in Homogeneous Gold Catalysis. $247^{\text {th }}$ ACS National Meeting, Dallas (TX) on $19^{\text {th }}$ March, 2014(Oral). Abstract\#: ORGN-554

- Kumar, M.; Jasinski, J.; Hammond, G. B.; Xu, B. Understanding Gold Decay Mechanism and Improving Efficiency of Gold Catalysis through Rational Choice of Additives. IMD ${ }^{3}$ Fall Fest meeting, Louisville (KY) on $8^{\text {th }}$ November, 2013(Oral). Abstract\#: 5

- Kumar, M.; Jasinski, J.; Hammond, G. B.; Xu, B. Understanding Gold Decay Mechanism and Improving Efficiency of Gold Catalysis through Rational Choice of Additives. $246^{\text {th }}$ ACS National Meeting, Indianapolis (IN) on $9^{\text {th }}$ September, 2013(Oral). Abstract\#: ORGN-183

- Kumar, M.; Xu, B.; Hammond, G. B. An Efficient Synthesis of 5-Substituted Benzotriazole via Gold-catalyzed Intermolecular Alkyne Oxidation.The Fourth Annual Graduate Research Symposium, University of Louisville (KY), March 2012 (Poster). Abstract\#: 21 
- Kumar, M.; Xu, B.; Hammond, G. B. An Efficient Synthesis of 5-Substituted Benzotriazole via Gold-catalyzed Intermolecular Alkyne Oxidation. The $14^{\text {th }}$ Annual IMD3 Symposium, Hank Wagner Conference Center at Jewish Hospital \& St. Mary's Healthcare Louisville (KY), March - 2012 (Poster). Abstract\#: 17

- Kumar, M.; Xu, B.; Vaisberg, A. J.; Hammond, G. B. Synthesis of aromatic derivatives of benzothienopyrimidines showing anti-cancer activity. $42^{\text {nd }}$ ACS Regional Meeting, Indianapolis (IN) on $9^{\text {th }}$ June, 2011(Oral). Abstract\#: CERM171

\section{PROFESSIONAL MEMBERSHIP}

- American Chemical Society, March 2010 - Present.

- ACS Organic Division, May 2013- 2014. 